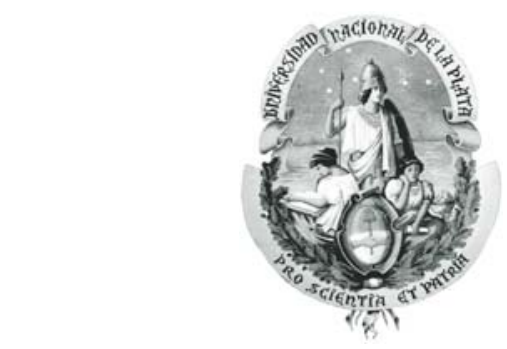

UNIVERSIDAD NACIONAL DE LA PLATA

Facultad de Ciencias Exactas

Departamento de Ciencias Biológicas

\title{
EFECTO DE AGES (PRODUCTOS DE GLICACION AVANZADA) Y DROGAS ANTI-RESORTIVAS SOBRE CELULAS DE HUESO EN CULTIVO
}

\author{
Trabajo de Tesis Doctoral
}

2011

Bqca. María Virginia Gangoiti
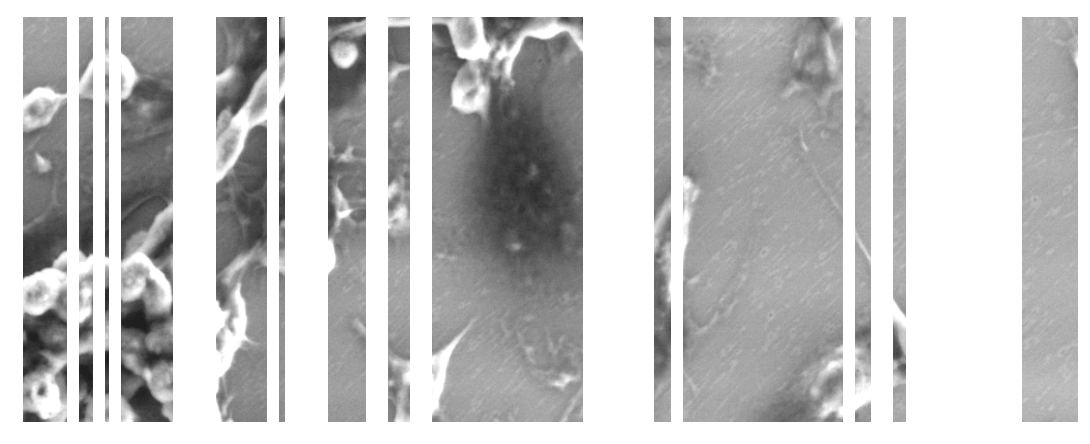

Director: Dra. Ana M. Cortizo

Co-Director: Dr. Antonio D. McCarthy 
Trabajo de Tesis para acceder al grado de Doctor de la Facultad de Ciencias Exactas de la Bioquímica Maria Virginia Gangoiti, realizado bajo la dirección de la Dra. Ana María Cortizo y la codirección del Dr. Antonio McCarthy.

El mismo se realizó en la Catedra de Bioquímica Patológica de la Facultad de Ciencias Exactas de la Universidad Nacional de La Plata, y fue posible gracias a las becas doctorales otorgadas por la Comisión de Investigaciones Cientificas de la Provincia de Buenos Aires (CIC-PBA) 
A mis amores, Pablo y Luciano A mi querida familia 


\section{AGRADECIMIENTOS}

Durante esta estapa son muchas las personas que participaron e hicieron posible de una u otra forma el desarrollo de esta tesis, a quienes quiero expresarles mi más sincero agradecimiento.

A mamá y papá, porque de ellos aprendí el ser responsable y perseverante en mis proyectos; a mis hermanos Jimena, Florencia, Juan Pablo y Marcos por su apoyo y cariño; a Carolina y Milagros, y Pablo M. A todos ellos gracias por el aguante los fines de semana. A mi familia de Gualeguaychú que me acompañana a la distancia en cada etapa.

A mis compañeros del GIOMM: Silvina, Verónica, Juan Ignacio, María José, Malala y Juan Manuel, por estos cinco años compartidos, llenos de discusiones, mates, ensayos pero en especial por su amistad, sus contemplaciones e incondicional apoyo. Por último y en especial quiero agradecerles a mis directores, Ana y Antonio, por abrirme las puertas al mundo científico y confiarme el desarrollo de este tema. Gracias por ser una guía y un ejemplo para todos nosotros. En definitiva, gracias a todos por conformar un ámbito de trabajo agradable en donde siempre hay lugar para compartir un momento "extra-científico".

Al Dr. J. Green-Novartis por proveernos el Zoledronato y Pamidronato y al Dr. Ostrowsky -Laboratorios Elea, Argentina por la donación del Alendronato utilizados en esta tesis

A la Dra. Mónica Mele y su grupo, en especial a Florencia Alvarez, por permitirme obtener las imágenes de microscopía de fluorescencia; al Dr. Caffini y al Bco. Martín Lazza, por permitirme realizar las determinaciones de fluorescencia; al Dr. Amalvy y su grupo, por su colaboración en la adquisición de espectros de fluorescencia bidimensionales, y en especial al Dr. Pablo Peruzzo y al Lic. Sebastián Anbinder por su colaboración en el estudio de los modelos celulares mediante microscopía ESEM; al LIMF por permitirme realizar los ensayos de ESEM; y a Vanina Perez por su colaboración en la adquisición de imágenes mediante microscopía confocal.

A la Agencia Nacional de Promoción Científica y Tecnológica (ANPCyT) y a la Comisión de Investigaciones Científicas de la Provincia de Buenos Aires (CIC-PBA), por el apoyo económico recibido sin el cual no hubiera sido factible el desarrollo de este trabajo.

Por último, quiero agradecerle a Pablo por ser mi compañero, mi pilar y porque juntos hicimos lo mejor que me pasó en la vida: Luciano. A los dos gracias por adaptarse a los tiempos de la tesis y por hacer que el sacrificio sea más ameno. Gracias a todos!!!! 



\section{INDICE}

I- INTRODUCCION 1

INTRODUCCION GENERAL 2

I.1-EL TEJIDO OSEO 5

I.1.1-INTRODUCCIÓN 5

I.1.2-ESTRUCTURA 5

I.1.2.1-Aspecto macroscópico de un hueso largo

I.1.2.2-Hueso Compacto o Cortical

I.1.2.3-Hueso Esponjoso o Trabecular

I.1.3-CONSTITUYENTES DEL TEJIDO OSEO 8

I.1.3.1- La matriz ósea

I.1.3.2- Las células óseas

I.1.4-FORMACION OSEA INTERMEMBRANOSA Y ENDOCONDRAL

I.1.5-MODELADO Y REMODELADO OSEO 16

I.1.5.1-Modelado

I.1.5.2- Remodelado

I.1.5.3- Masa ósea

I.2-OSTEOPOROSIS $\quad 20$

I.2.1-DEFINICION DE LA ENFERMEDAD 20

I.2.2-CAUSAS Y TIPOS DE OSTEOPOROSIS 22

I.2.3-TRATAMIENTO DE LA OSTEOPOROSIS 23

I.2.3.1-Calcio y Vitamina D

I.2.3.2-Calcitonina

I.2.3.3-Estrógenos

I.2.3.4-Raloxifeno

I.2.3.5-Tibolona

I.2.3.6-Hormona paratiroidea

I.2.3.7-Ranelato de estroncio

I.2.3.8-Bisfosfonatos 
I.3-BISFOSFONATOS (BPs) 27

I.3.1-CONSIDERACIONES GENERALES 30

I.3.2-MECANISMO DE ACCION 32

I.3.3- POSIBLES EFECTOS DE LOS BISFOSFONATOS EN OSTEOCITOS 32

I.3.4-POSIBLES EFECTOS DE LOS BISFOSFONATOS EN OSTEOBLASTOS 33

I.3.5- USOS CLÍNICOS Y EFECTOS DE LOS BPs EN HUMANOS 33

I.3.5.1-La enfermedad de Paget

I.3.5.2-Oncología ósea

I.3.5.3-Osteoporosis

I.3.6- BISFOSFONATOS DE USO MAS FRECUENTE 35

I.3.6.1-Alendronato (Ale)

I.3.6.2-Etidronato

I.3.6.3-Risedronato

I.3.6.4-Ibandronato

I.3.6.5-Zolendronato

I.4-DIABETES MELLITUS 37

I.4.1- DEFINICIÓN DE LA ENFERMEDAD 37

I.4.2-CLASIFICACION 38

I.4.2.1- Diabetes tipo 1

I.4.2.2- Diabetes tipo 2

I.4.2.3-Otros tipos específicos de diabetes

I.4.2.4-La diabetes mellitus gestacional (DMG)

\section{I.4.3-FISIOPATOGENESIS DE LA DIABETES MELLITUS 43}

I.4.3.1-El aumento de flujo a través de la vía de los polioles.

I.4.3.2-Producción intracelular de precursores AGE

I.4.3.3-Activación de la PKC

I.4.3.4-Aumento de la actividad en la vía de las hexosaminas

I.4.3.5-El mecanismo unificador

I.4.3.6-La producción de superóxido mitocondrial inducida por la hiperglucemia activa las cuatro vías de daño por la inhibición de GAPDH. 
I.5-PRODUCTOS DE GLICACIÓN AVANZADA (AGES)

51

I.5.1-INTRODUCCION 51

I.5.2-LA FORMACION DE AGEs 51

I.5.3-METABOLISMO DE LOS AGES 54

I.5.4-MECANISMOS DE ACCIÓN LOS AGEs 56

I.5.5-ROL DE LOS AGES EN LAS COMPLICACIONES DE LA DIABETES

59

I.5.5.1 AGE y microangiopatía diabética

I.5.5.1.1 La nefropatía diabética

I.5.5.1.2 La retinopatía diabética

I.5.5.1.3 La neuropatía diabética periférica

I.5.5.2 AGE y macroangiopatía diabética

I.6-HUESO DIABETICO 62

I.7-OBJETIVOS $\quad 66$

II- MATERIALES Y MÉTODOS 67

II.1-MATERIALES 68

II.2-METODOS $\quad 69$

II.2.1-PREPARACION DE AGES PRODUCTOS DE GLICACION AVANZADA

II.2.2-PREPARACIÓN DE SOLUCIONES DE BISFOSFONATOS (BPs) 70

II.2.3-MODELOS CELULARES 71

II.2.3.1-Líneas celulares

II.2.3.1.a-MC3T3-E1

II.2.3.1.b-UMR-106

II.2.3.1.C- $\underline{\text { Raw } 264.7}$

II.2.3.2-Modelo de osteoclastos: Cocultivos de células UMR-106 con Raw 264.7

II.2.4-ENSAYOS BIOQUÍMICOS 74

II.2.4.1-Ensayos de proliferación osteoblástica

II.2.4.2-Ensayos para evaluar la diferenciación a osteoblastos.

II.2.4.2.a-Actividad de fosfatasa alcalina 
II.2.4.2.b-Producción de colágeno tipo I

II.2.4.2.c-Mineralización

II.2.4.3-Evaluación de la muerte celular

II.2.4.4-Determinación de la producción intracelular de especies de oxígeno reactivas (ROS)

II.2.4.5-Ensayo Fluorogénico de Fosfatasas Neutras

II.2.4.6-Reacción citoquímica para fosfatasa ácida tartrato-resistente

II.2.4.7-Determinación de TRAP por colorimetría

II.2.4.8 -Estudios de inmunofluorescencia indirecta

II.2.4.9-Estudios de inmunofluorescencia directa para fibras de actina

II.2.5 Técnicas de microscopía.

II.2.5 1 Microscopía Confocal:

II.2.5 2 Microscopía Electrónica de Barrido Ambiental (E-SEM)

II.2.6-ANALISIS ESTADISTICO 81

III- RESULTADOS $\quad 82$

III.1-RESULTADOS OSTEOBLASTOS 83

III.1.1-EFECTO DE AGES SOBRE LA PROLIFERACIÓN Y LA MORFOLOGIA OSTEOBLASTICA 83

III.1.2-MODULACIÓN DE LA PROLIFERACIÓN DE LOS OSTEOBLASTOS POR AGEs Y BPs $\quad 85$

III.1.3-EFECTO DE AGES Y BPS SOBRE LA APOPTOSIS OSTEOBLASTICA 86 III.1.4-EFECTO DE AGEs y BPS SOBRE LA DIFERENCIACIÓN OSTEOBLASTICA III.1.5- EFECTO DEL AGES Y ALENDRONATO SOBRE LA MORFOLOGÍA DE OSTEOBLASTOS EN CULTIVO 89

III.1.6- EFECTO DE AGES Y BPS SOBRE EL CITOESQUELETO DE OSTEOBLASTOS EN CULTIVO 90

III.1.7-ACCIÓN DE ALTAS DOSIS DE BPs SOBRE LA ACTINA, TUBULINA Y FAK EVALUADA POR INMUNOFLUORESCENCIA 91

III.1.8-MODULACIÓN DE LA PROLIFERACIÓN OSTEOBLASTICA. ROL DEL CALCIO INTRACELULAR 95 
III.1.9-EFECTO DE AGEs y BPs SOBRE LA PRODUCCIÓN DE ESPECIES DE OXIGENO REACTIVAS (ROS) 96

III.1.10-EFECTO DE AGES Y BPs SOBRE LA ACTIVIDAD DE FOSFATASAS NEUTRAS $\quad 97$

III.2-RESULTADOS OSTEOCLASTOS $\quad 100$

III.2.1-COCULTIVOS: MODELO DE OSTEOCLASTOS 100

III.2.2-CINETICA DE EXPRESION DE TRAP EN FUNCION DEL TIEMPO DE COCULTIVO $\quad 100$

III.2.3-ACCION DE LOS AGEs SOBRE LA ACTIVIDAD TRAP 101

III.2.4-ACCION DE AGES $Y$ DISTINTAS CONCENTRACIONES DE ALENDRONATO SOBRE LA ACTIVIDAD TRAP DE LOS OSTEOCLASTOS 102 III.2.5-ACCION DE AGES Y ALENDRONATO $10^{-5} \mathrm{M}$ SOBRE LA ACTIVIDAD TRAP DE OSTEOCLASTOS EN DISTINTOS MOMENTOS DEL COCULTIVO 103 III.2.6-ACCION DE LOS AGES Y ALENDRONATO SOBRE EL NUMERO DE OSTEOCLASTOS 104

III.2.7-EXPRESION DE RAGE EN OSTEOCLASTOS 105

III.2.7.1- Microscopía de Fluorescencia Optica.

III.2.7.2-Microscopía de Fluorescencia Confocal

IV- DISCUSION 110

V-CONCLUSIONES 126

VI- LISTADO DE ESQUEMAS FIGURAS Y TABLAS 128

VI.1- FIGURAS 129

VI.2-TABLAS $\quad 131$

VII- REFERENCIAS 132 
I

INTRODUCCION
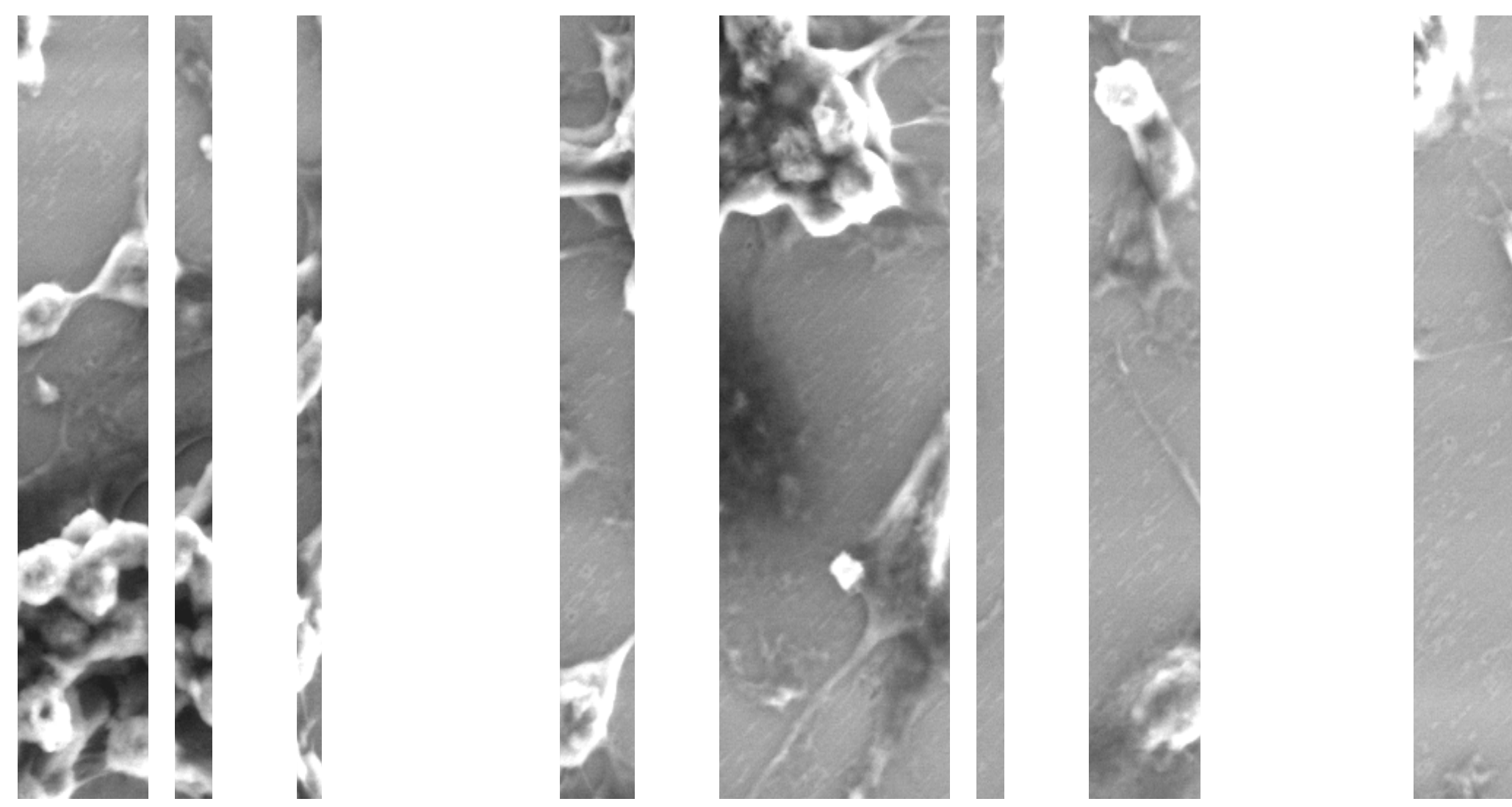


\section{INTRODUCCION GENERAL}

La Diabetes mellitus (DM) es un conjunto de trastornos metabólicos, que afecta a diferentes órganos y tejidos y se caracteriza por un aumento de los niveles de glucosa en la sangre. Es causada por una baja producción de la hormona insulina, o su inadecuado uso por parte del cuerpo, lo cual repercute en el metabolismo de los carbohidratos, lípidos y proteínas.

La DM ya era conocida antes de la era cristiana. La primera referencia de esta enfermedad se atribuye al papiro de Ebers, hallado en el año 1873 en Tebas (Egipto). En dicho papiro, que data del año 1553 a.C, ya se describen síntomas que parecen corresponder a la diabetes y unos remedios a base de decocciones para la "excesiva producción de orina" que actualmente conocemos como poliuria. La antigua literatura hindú describe en los Vedas a la orina pegajosa de los diabéticos, con sabor a miel y que atrae fuertemente a las hormigas. En un tratado chino de medicina interna del siglo III d.C. se mencionan los síntomas de la diabetes aunque no se llega a dar con un tratamiento. Fue Areteo de Capadocia quien, en el siglo II de la era cristiana, le dio a esta afección el nombre de Diabetes, que significa en griego “correr a través de”, refiriéndose así a la eliminación exagerada de agua por el riñón, expresando que el agua entraba y salía del organismo.

Desde el siglo III hasta el siglo XVI no hubo mayores contribuciones de la medicina al campo de la diabetes. Se destaca en el siglo XI el médico árabe Avicenna, quien describió en su famoso Canon de medicina a la diabetes y recomienda un tratamiento a base de semillas de alholva y cedro, ambas con propiedades hipoglucemiantes.

Tras un largo período, en 1679, el anatomista inglés Tomás Willis hizo una descripción magistral de la Diabetes, quedando desde entonces reconocida por su sintomatología como entidad clínica. Refiriéndose al sabor dulce de la orina, Willis le dio a esta enfermedad el nombre de Diabetes mellitus (sabor a miel). Por su parte, el médico inglés Mathew Dobson estudió en forma más profunda la orina de los diabéticos, y en 1775 identificó la presencia de glucosa en la orina, explicando de esta manera su sabor dulce.

Los trabajos clínicos y anatomopatológicos adquirieron gran importancia a fines del siglo XIX y culminaron con las experiencias de pancreatectomía en perros realizadas por Mering y Minkowski en 1889, las cuales demostraron de manera concluyente que al remover el páncreas de los perros resultaba en una diabetes fatal. La búsqueda de la presunta hormona producida por el páncreas se inició de inmediato y, en 1921, fueron los jóvenes canadienses Frederick Grant Banting y Charles H. Best quienes consiguieron aislar la insulina y demostrar su efecto hipoglucemiante. La primera inyección de insulina se aplicó en 1922 en el Hospital 
General de Toronto, inaugurándose así una nueva esperanza para los afectados de diabetes. En 1923, Banting y Best fueron galardonados con el Premio Nobel de Medicina por este descubrimiento que significó una de las más grandes conquistas médicas del siglo XX y con el cual llegó la era de tratamiento actual.

A pesar de los grandes avances que se han realizado desde entonces, los cuales han conseguido mejorar tanto la calidad como la expectativa de vida del paciente diabético, quedan todavía sin resolver muchas cuestiones relacionadas con la fisiopatología de la enfermedad y sus complicaciones.

La DM afecta al 5\% de la población mundial. En el año 2000 se estimaba que alrededor de 171 millones de personas eran diabéticos en el mundo, y se pronostica que llegarán a 370 millones en 2030. Durante el curso de esta enfermedad, los pacientes pueden desarrollar complicaciones crónicas, tales como vasculopatías, nefropatías, retinopatías, neuropatía, y alteraciones óseas. Se han descrito alteraciones en el metabolismo fosfocálcico y del hueso, con reducción en el contenido mineral óseo, osteopenia, mayor cantidad de fracturas y disminución en la cicatrización de las mismas

Los mecanismos que causan la enfermedad ósea aún no han sido identificados. Uno de los factores involucrados en el desarrollo de estas complicaciones es la glicosilación no enzimática (glicación) de proteínas y la formación excesiva de productos avanzados de glicación (AGEs). Los AGEs in vitro, pueden inducir alteraciones estructurales y funcionales sobre diversas células y tejidos. Se ha reportado previamente que la acumulación de AGEs sobre proteínas de matriz extracelular, así como los AGEs solubles inducen efectos deletéreos sobre el crecimiento y diferenciación de osteoblastos en cultivo. Estos efectos podrían ocurrir a través de la interacción de AGEs con receptores de superficie descriptos y caracterizados en osteoblastos. Todos estos efectos podrían contribuir a la patogénesis de la osteopenia diabética

Los bisfosfonatos (BPs) son análogos estables del pirofosfato (PPi) que se acumulan en el hueso debido a su gran afinidad por la hidroxiapatita, donde inhiben la resorción ósea mediada por los osteoclastos. Por esta razón, los BPs se han transformado en los fármacos más importantes para el tratamiento de diversas patologías como la enfermedad de Paget, enfermedades óseas asociadas a tumores y la osteoporosis post-menopáusica. Los estudios realizados sobre osteoclastos demostraron que los BPs pueden inhibir la resorción ósea por varias rutas diferentes, dependiendo de su estructura química y concentración. Existe 
evidencia reciente que sugiere que parte de los efectos de los BPs sobre la resorción ósea podrían ser indirectos, a través de sus efectos sobre los osteoblastos.

Por lo tanto, se consideró de interés abordar el estudio de los efectos de los BPs y sus mecanismos de acción sobre células osteoblásticas, así como estudiar los efectos que ejercen los AGEs y los BPs sobre los osteoclastos y osteoblastos en cultivo, ya que podrían existir interacciones de ambos factores a nivel del hueso.

La primera parte de este trabajo de tesis presenta una introducción a los aspectos generales del tejido óseo. A continuación se describe a la osteoporosis y su tratamiento, dedicando en este último punto una sección especial para los bisfosfonatos. Luego se describe a la Diabetes Mellitus, su patogénesis y complicaciones crónicas, y se dedica una sección a los productos de glicación avanzada (AGEs). Por último, se realiza una descripción del hueso diabético. En base a la información descripta, se plantean los objetivos de esta tesis.

En la siguiente parte se describen los materiales y métodos utilizados en el desarrollo de este trabajo.

Posteriormente se presentan los resultados obtenidos divididos en dos secciones: la primera se ocupa de los resultados más importantes obtenidos sobre las células osteoblásticas, y en la segunda sección se detallan los resultados obtenidos en un modelo de osteoclastos. Luego se realiza la discusión de los mismos.

Por último, se presentan las conclusiones generales de este trabajo de tesis. 


\section{I.1-EL TEJIDO OSEO}

\section{I.1.1-INTRODUCCION}

El tejido óseo forma la mayor parte del esqueleto, es el armazón que soporta nuestro cuerpo y junto con los músculos permite los movimientos. Además por su robustez protege a los órganos vitales de posibles traumatismos. Su dureza y su persistencia a través de millones de años nos dan una falsa impresión de la vida de los huesos. Contrariamente a lo que se pensaría, el sistema óseo es un tejido dinámico, continuamente en fase de remodelación. En él se almacenan una serie de minerales, especialmente calcio y fósforo, necesarios para la contracción muscular y muchas otras funciones. Cuando son necesarios, el hueso libera dichos minerales a la sangre la cual los distribuye a otras zonas del organismo

\section{I.1.2-ESTRUCTURA}

Estructuralmente, el esqueleto humano adulto consiste en 213 huesos formados por tejido óseo, cartílagos, médula ósea y el periostio (membrana que rodea los huesos).

Los huesos se pueden clasificar según su forma. Encontramos huesos planos como el cráneo, mandíbula, escápula, etc, y huesos largos como son el fémur, la tibia y el húmero. [RossPaulina]

Los huesos planos se desarrollan mediante osificación intermembranosa en cambio los huesos largos lo hacen mediante la combinación de la osificación endocondral y la intermembranosa. (Ver apartado I.1.4)

\section{I.1.2.1-Aspecto macroscópico de un hueso largo}

La estructura de un hueso largo se presenta en la Figura I.1.2.1. La misma está consituída por:

- Diáfisis: la parte alargada del hueso

- Epífisis: extremos ensanchados o terminaciones del hueso

- Metáfisis: unión de la diáfisis con las epífisis. En el hueso adulto esta parte es ósea, siendo cartilaginosa en la fase de desarollo del mismo.

- Cartílago articular: es una fina capa de cartílago hialino que recubre la epífisis donde el hueso se articula con otro hueso.

- Periostio: membrana que rodea la superficie del hueso no cubierta por cartílago. Esta compuesta por dos capas: 
1. La capa exterior formada por un tejido conjuntivo denso e irregular que contiene los vasos sanguíneos, vasos linfáticos y nervios que entran al hueso.

2. La capa osteogénica contiene células óseas de varios tipos (osteoblastos, osteoclastos), fibras elásticas y vasos sanguíneos

El periostio es esencial en el crecimiento óseo, en su reparación y en su nutrición.

- Cavidad medular: es un espacio cilíndrico situado en la parte central de la diáfisis que en los adultos contiene la médula ósea amarilla

- Endostio: la cavidad medular está tapizada por el endostio, una membrana que contiene las células osteoprogenitoras, osteoblastos y osteoclastos

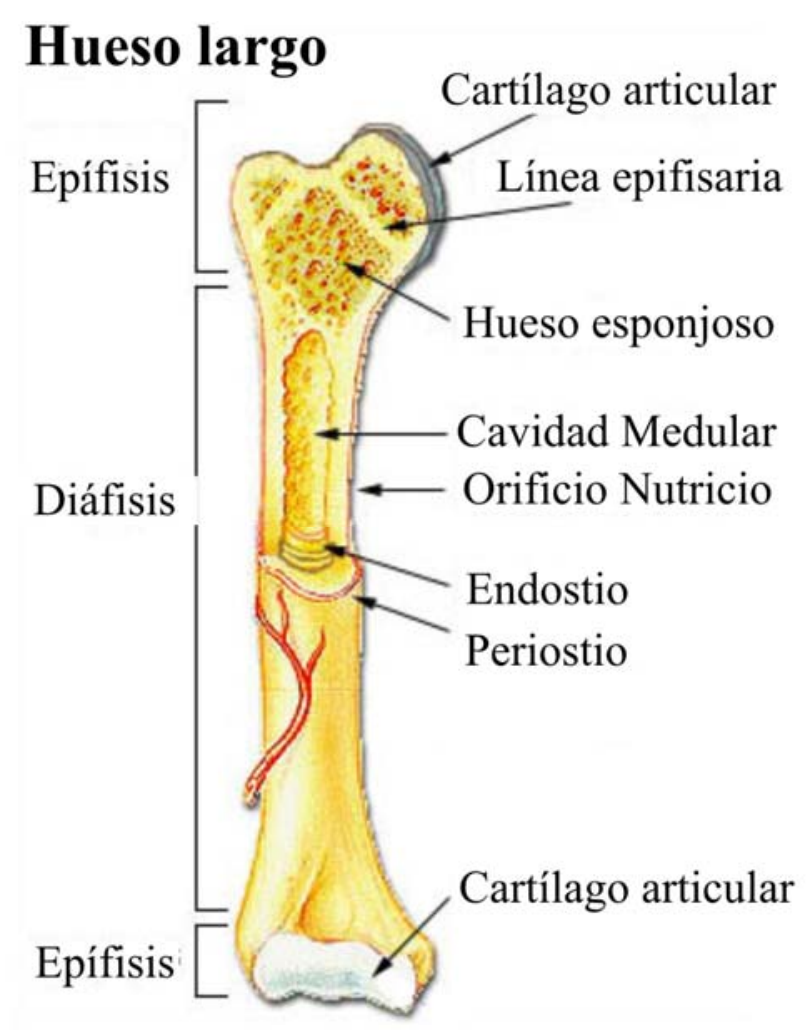

Figura I.1.2.1.1-Esquema de la estructura de un hueso largo en fase de crecimiento.

Otra clasificación que podemos realizar es en hueso cortical y hueso trabecular.

A nivel macroscópico, el hueso cortical aparece denso y sólido mientras que el hueso trabecular se describe como una red de trabéculas (semejan a un panal) que rodean a la médula ósea como se muestra en la Figura I.1.2.1.2. A nivel microscópico ambos huesos, cortical y trabecular, están compuestos por una estructura básica denominada osteona. 


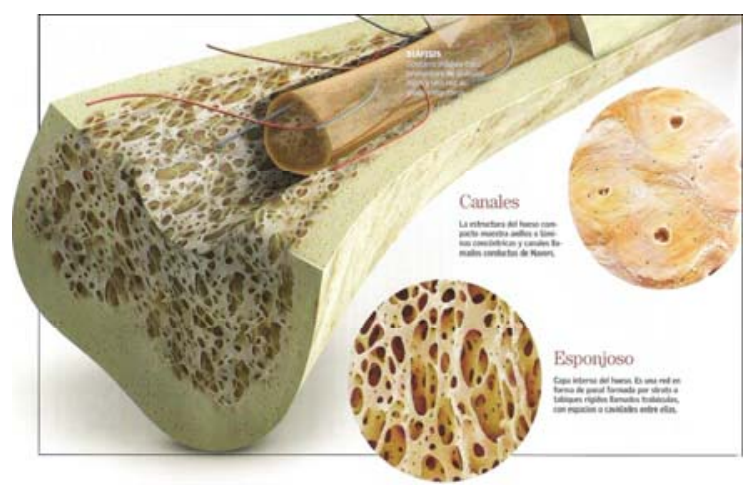

Figura I.1.2.1.2- Disposición de los tejidos óseo cortical y óseo trabecular en un hueso largo.

\section{I.1.2.2-Hueso Compacto o Cortical}

Este constituye la mayor parte de la diáfisis de los huesos largos así como de la parte externa de todos los huesos del cuerpo. El hueso compacto constituye una protección y un soporte. Tiene una estructura de láminas o anillos concéntricos alrededor de canales centrales llamados canales de Havers que se extienden longitudinalmente (Figura I.1.2.2).

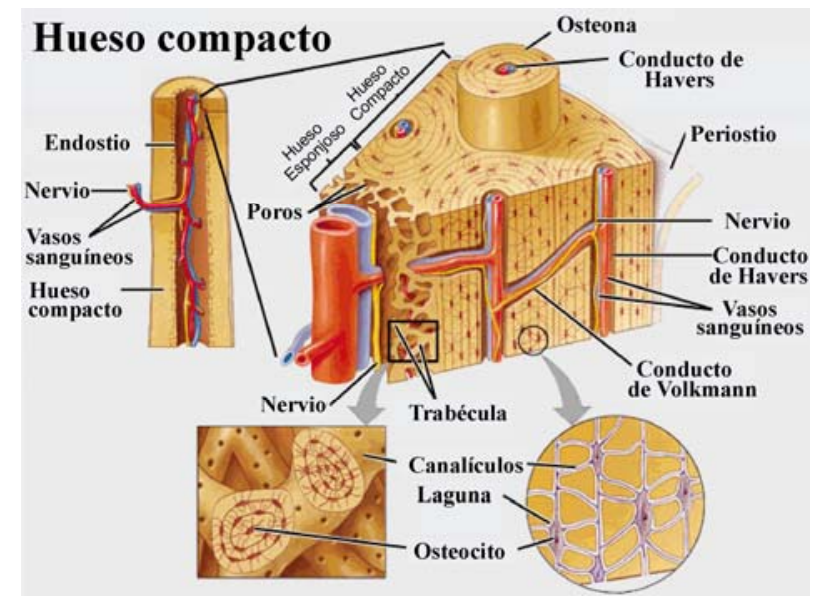

Figura I.1.2.2-Detalle de la de la estructura ósea microscópica de hueso cortical y hueso trabecular.

Los canales de Havers están conectados con otros canales llamados canales de Volkmann que perforan el periostio. Ambos canales son utilizados por los vasos sanguíneos y nervios para extenderse por el hueso. Entre las láminas concéntricas de matriz mineralizada hay pequeños orificios o lagunas donde se encuentran los osteocitos. Para que estas células puedan intercambiar nutrientes con el líquido intersticial, cada laguna dispone de una serie de canalículos por donde se extienden prolongaciones de los osteocitos. Los canalículos están 
conectados entre sí y, eventualmente a los canales de Havers. El conjunto de un canal central, las láminas concéntricas que lo rodean y las lagunas, canalículos y osteocitos en ellas incluídos recibe el nombre de osteona o sistema de Havers. Las restantes láminas entre osteonas se llaman láminas intersticiales.

\section{I.1.2.3-Hueso Esponjoso o Trabecular}

El hueso esponjoso contiene osteonas trabeculares, en las cuales las láminas intersticiales están dispuestas de forma irregular formando unos tabiques o placas llamadas trabéculas. Estos tabiques forman una estructura esponjosa dejando huecos que están llenos de la médula ósea como puede observarse en la Figura I.1.2.2. Dentro de las trabéculas están los osteocitos que yacen en sus lagunas con canalículos que irradian desde las mismas. En este caso, los vasos sanguíneos penetran directamente en el hueso esponjoso y permiten el intercambio de nutrientes con los osteocitos.

El hueso esponjoso es el principal constituyente de las epífisis de los huesos largos y del interior de la mayor parte de los huesos

\section{I.1.3-CONSTITUYENTES DEL TEJIDO OSEO}

El hueso se puede considerar como un composite, es decir una combinación de mineral, colágeno, agua, proteínas no colágenas, lípidos, elementos vasculares y células óseas.

Como otros tejidos conjuntivos, el hueso o tejido óseo está constituido por una matriz extracelular en la que se encuentran las células dispersas, con la particularidad que en este caso la matriz está mineralizada.

\section{I.1.3.1- La matriz ósea}

La matriz extracelular está constituida por: $5-10 \%$ de agua, $20-40 \%$ de proteínas (colágeno y proteínas no colágenas), 50-70\% de sales minerales y menos de 3\% de lípidos.

La matriz mineral está compuesta mayormente por cristales de hidroxiapatita $\left(\mathrm{Ca}_{10}\left(\mathrm{PO}_{4}\right)_{6} \mathrm{OH}_{2}\right)$ deficiente en $\mathrm{OH}$ y análoga al mineral geológico. Estos cristales son extremadamente pequeños $(\sim 200 \AA)$. Además contienen numerosas impurezas tales como carbonato, magnesio y fosfatos ácidos. Estos pequeños e imperfectos cristales son mucho más solubles que la apatita geológica, lo que le permite actuar en el organismo como reservorio de calcio, fosfatos y magnesio. Estas sales minerales se depositan por cristalización en el entramado formado por las fibras de colágeno, durante el proceso de calcificación o mineralización. 
La matriz orgánica está formada predominantemente por colágeno en un $90 \%$ y el resto lo conforman proteínas no colágenas. La presencia de esta matriz le proporciona al hueso elasticidad y flexibilidad. La red de colágeno determina la organización estructural del hueso y provee el sustrato para la adhesión celular. El 95\% del colágeno es de tipo I y el restante colágeno es tipo $\mathrm{V}$. La molécula de colágeno es una triple hélice de cadenas $\alpha$. Cada cadena posee una estructura repetitiva característica que consiste en un triplete Gly-X-Y, donde $\mathrm{X}$ es prolina e $\mathrm{Y}$ es hidroxiprolina. Además estas cadenas sufren modificaciones posttraduccionales, son hidroxiladas en residuos de Lys, glicosiladas en residuos de lisina o hidroxilisina con galactosa, glucosa o ambas y forman puentes covalentes intra e intermoleculares. Estas moléculas de colágeno, por tener una tasa de recambio baja, son los principales objetivos para la formación de productos de glicacion avanzada. La formación de enlaces cruzados intermoleculares e intramoleculares en el colágeno como resultado del proceso de glicación conduce a alteraciones estructurales, dando lugar a una mayor rigidez y resistencia a la digestión proteolítica. Las proteínas no colágenas (PNC) constituyen el 10-15 $\%$ del total de proteínas óseas. Aproximadamente un cuarto de ellas son exógenas como la albúmina y la $\alpha_{2}$ HSglicoproteína (derivadas del suero), los factores de crecimiento y otras tantas moléculas presentes en trazas. Las células óseas sintetizan y secretan las proteínas no colágenas y se pueden dividir en cuatro grupos:

a- Proteoglicanos: versican, hialuronan, decorina, biglicano y en menor cantidad fibromodulina, osteoadherina, lumican y asporina.

b- Proteínas glicosiladas: fosfatasa alcalina, osteonectina (la más abundante de las $\mathrm{PNC}$ ), tetranectina, tenascina-C y tenascina-W.

c- Proteínas glicosiladas con actividad de adhesión celular: Osteopontina, sialoproteina ósea, DMP (proteína de matriz de dentina), MEPE (fosfoglicoproteína de matriz celular), DSPP (dentina sialofosfoproteína). Proteínas N-glicosiladas trombospodinas, fibronectina, vitronectina fibrilina 1 y 2

d- Proteínas $\gamma$-carboxiladas (gla) tienen propiedades de unión al $\mathrm{Ca}^{++}$: Proteínas ácido $\gamma$-carboxílico de matriz (MGP), Osteocalcina (BGP), Proteína S. 


\section{I.1.3.2- Las células óseas}

Se pueden describir cuatro tipos de células:

Células osteoprogenitoras: son células no especializadas derivadas del mesénquima, el tejido del que derivan todos los tejidos conectivos. Se encuentran células osteoprogenitoras en la capa interna del periostio, en el endostio y en los canales del hueso que contienen los vasos sanguíneos. Son capaces de dividirse y proliferar y bajo condiciones apropiadas tiene la capacidad de diferenciarse a osteoblastos y osteocitos, o a adipocitos, condroblastos y mioblastos (Figura I.1.3.2.1). El factor de transcripción Cbfa1/Runx-2 es específico de osteoblastos y es imprescindible en las fases tempranas de diferenciación osteoblástica. Otro factor de transcripción importante implicado en la diferenciación osteoblástica es Osterix, el cual que actúa en la etapa mas tardía de la diferenciación [Yang et al, 2002].

Osteoblastos: son las células del tejido óseo responsables de la síntesis de los componentes de la matriz extracelular. Secretan principalmente colágeno tipo I y otros materiales utilizados para la construcción del hueso. Son células cúbicas que se encuentran en las superficies óseas y se pueden detectar histoquímicamente por la actividad de fosfatasa alcalina (un marcador temprano del fenotipo osteoblástico). El osteoblasto maduro activo posee una ultraestructura típica de células encargadas de la secreción de matriz de tejido conectivo, presentando núcleo grande, aparato de Golgi desarrollado y extenso retículo endoplasmático. La membrana plasmática se caracteriza también por ser rica en fosfatasa alcalina y por poseer receptores para la hormona PTH, estrógenos y 1.25-dihidroxivitamina $\mathrm{D}_{3}$ (vitamina $\mathrm{D}$ ). Los osteoblastos son células especializadas que no están diferenciadas terminalmente (Figura I.1.3.2.2). Durante el proceso de formación ósea los osteoblastos pueden quedar rodeados de la matriz ósea donde se diferencian hacia un estado maduro dando lugar a los osteocitos. Otro posible destino es convertirse en células de revestimiento en la superficie del hueso como una capa simple de osteoblastos planos inactivos. Estos pueden estar en el endostio separados de la médula ósea o subyacer en el periostio directamente en las superficies mineralizadas. La otra posibilidad es que activen su mecanismo apoptótico antes de quedarse embebidos en la matriz ósea. Los osteoblastos regulan la diferenciación y actividad de los osteoclastos. De esta manera, los osteoblastos junto con los osteoclastos, juegan un papel importante en el recambio óseo y en la homeostasis del calcio. 


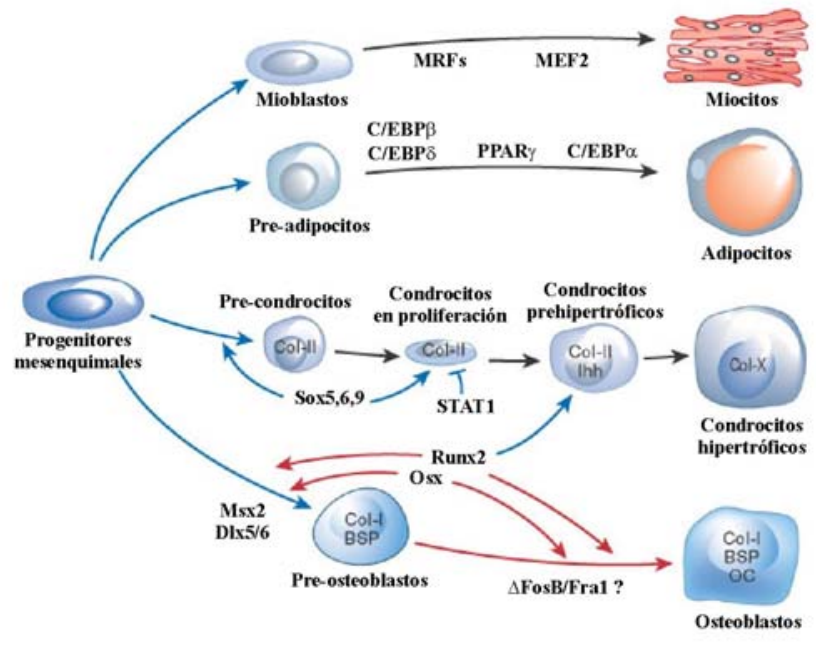

Figura I.1.3.2.1-Esquema de los distintos linajes en que puede diferenciarce una célula mesenquimal.

Los osteoblastos se diferencian a partir de las células progenitoras mesenquimales que también pueden diferenciarse a miocitos (bajo el control de MRFs y MEF2), a adipocitos (bajo el control de C/EBP $\alpha, \beta$ y $\delta$ y PPAR $\gamma$ ), y hacia condrocitos bajo el control de Sox5, -6 y -9 y STAT1. Runx2 es esencial para la diferenciación osteoblastica y también está involucrada en la maduración de los condrocitos. Osterix (Osx) actúa luego de Runx2 induciendo la maduración de osteoblastos que expresan marcadores osteoblásticos incluida la osteocalcina. Abreviaturas: MRFs, myogenic regulatory factors (including MyoD, myogenin, myogenic factor 5 and myogenic regulatory factor 4); MEF2, myocyte-enhancer factor 2; C/EBP, CCAAT-enhancer-binding protein; PPAR $\gamma$ peroxisome proliferator-activated receptor $\gamma$; STAT1, signal transducers and activators of transcription-1; Runx2, runt-related transcription factor 2; Col-I/II/X, type I/II/X collagen; Ihh, Indian hedgehog; BSP, bone sialoprotein; OC, osteocalcin [Harada y Rodan, 2003].

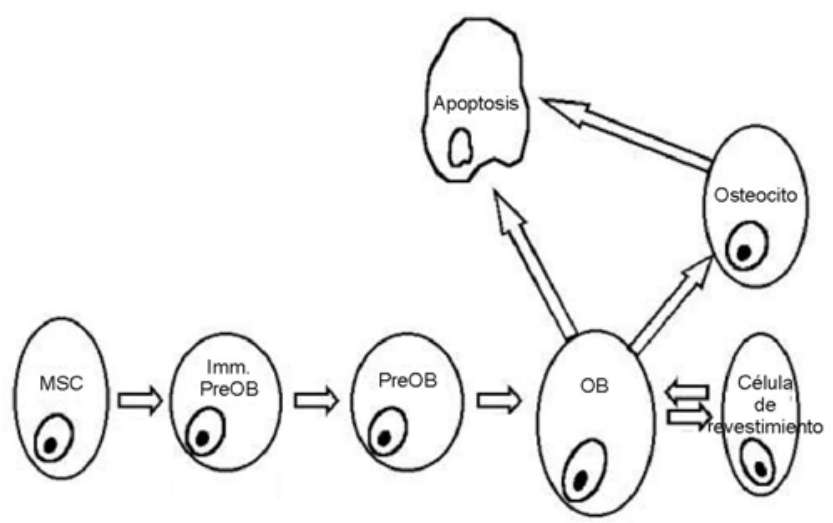

Figura I.1.3.2.2- Detalle de la diferenciación de una célula mesenquimal a osteoblasto y los posibles destinos de esta célula. 
Osteocitos: son células óseas maduras derivadas de los osteoblastos (Figura I.1.3.2.2). Estas células han perdido la capacidad de dividirse y pueden residir por largos períodos, hasta décadas, en el hueso humano. La apoptosis de los osteocitos puede resultar en perdida de masa ósea. Cada osteocito se encuentra en su laguna y se comunica con los otros por medio de procesos celulares que transcurren por los canalículos. En el hueso, aparecen negativos para actividad de fosfatasa alcalina, pero producen altas concentraciones de osteocalcina, galectina 3 y CD44 (Receptor de adhesión celular para hialuronato). Los osteocitos están encargados de mantener las actividades celulares del tejido óseo como el intercambio de nutriente. En estudios recientes se ha descrito la importancia que tienen actuando como mecanosensores y la activación local del remodelado.

Osteoclastos: son las células especializadas en la resorción ósea. Los principales precursores preosteoclástico son los macrófagos de medula ósea (Figura I.1.3.2.3). Los precursores mononucleares circulan por la sangre y en la superficie del hueso proliferan, se fusionan formando células multinucleares, forman el borde en cepillo y realizan la resorción. La osteoclastogenesis necesita dos citoquinas esenciales para producirse (Figura I.1.3.2.4). La primera que actúa es el ligando para el receptor activador del factor nuclear kappa B (RANKL) y su papel es clave, al unirse a su receptor específico, en la iniciación de la señal de diferenciación y activación de los osteoclastos. El RANKL es un miembro de la superfamilia de los factores de necrosis tumoral TNF y se expresa en la superficie de los osteoblastos y actúa al unirse a su receptor (RANK) expresado en la membrana de los precursores osteoclásticos. Existe un inhibidor circulante llamado osteoprotegerina (OPG). La OPG se puede unir a RANK y neutralizar la acción de RANKL, y pueden regular negativamente tanto la osteoclastogénesis como la activación de los osteoclastos maduros. El RANKL también actúa sobre el osteoclasto maduro estimulando la actividad resortiva influyendo sobre la organización del citoesqueleto. El segundo factor requerido es el factor estimulador de colonias macrofágico M-CSF, promueve la proliferación de precursores y la supervivencia de todos los miembros del linaje osteoclástico, ejerciendo ese efecto a través del receptor de tirosin quinasa (c-Fms). El M-CSF es producido por una variedad de células, particularmente las células osteoblásticas. La resorción del hueso se produce debido a que el osteoclasto es capaz de crear un microambiente con la matriz ósea. El compartimiento creado esta aislado del espacio extracelular general y se acidifica aproximadamente a $\mathrm{pH} 4.5$ mediante una bomba de protones $\left(\mathrm{H}^{+}\right.$-ATPasa) y un canal de $\mathrm{Cl}^{-}$(CIC-7) ubicados en la membrana del borde en cepillo (Figura I.1.3.2.5). 


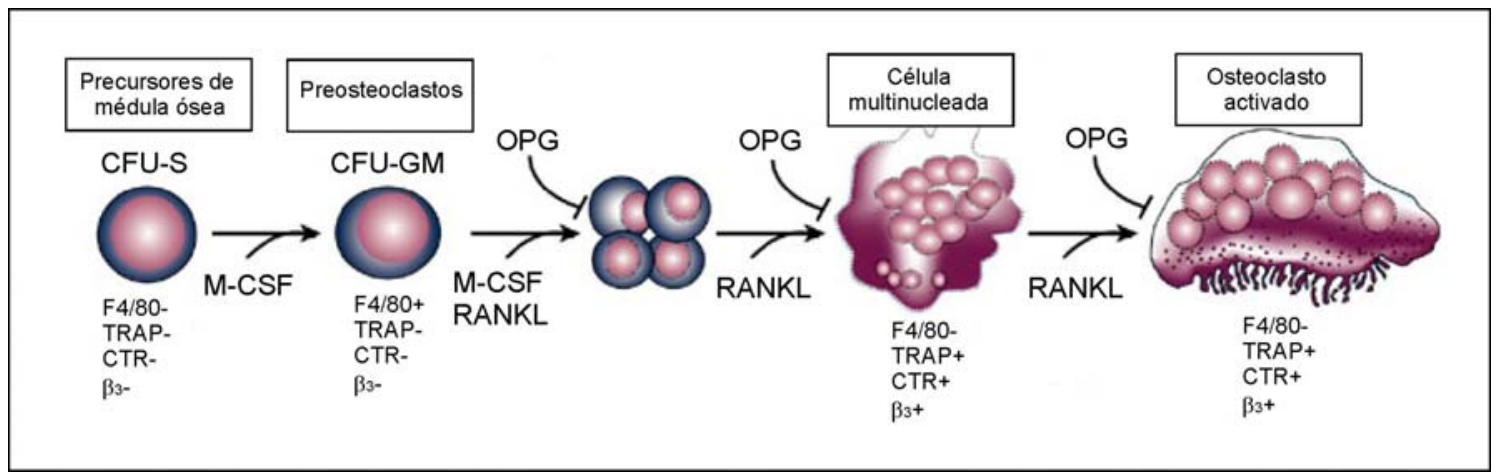

Figura I.1.3.2.3- Esquema del desarrollo de diferenciación de precursores hematopoyéticos en osteoclastos maduros.

La maduración se produce en el hueso de células mononucleares periféricas con los rasgos del linaje macrófago. El M-CSF (CSF-1) y RANKL son esenciales para la osteoclastogénesis, y su acción durante la asignación de linaje y la maduración. La OPG se puede unir a RANK y neutralizar la acción de RANKL, y pueden regular negativamente tanto la osteoclastogénesis y la activación de los osteoclastos maduros [Boyle et al, 2003].
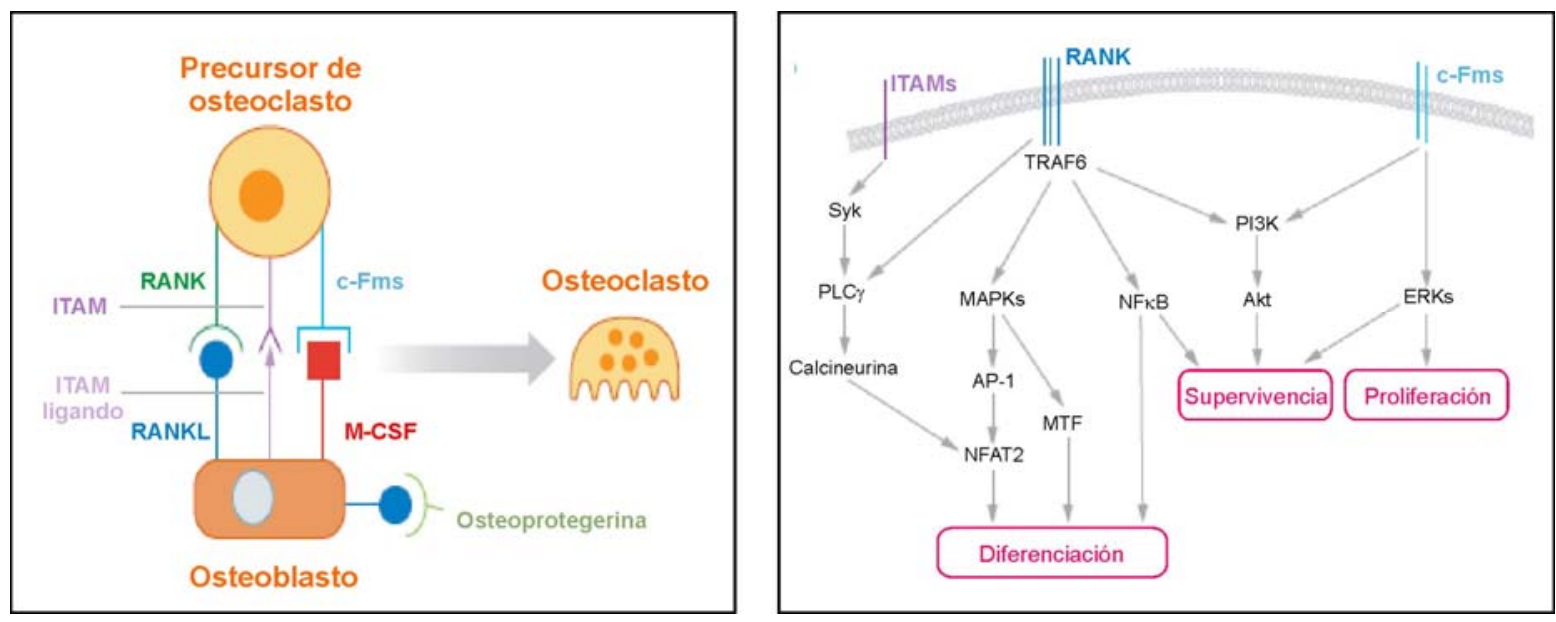

Figura I.1.3.2.4- Mecanismo de diferenciación osteoclástica.

La diferenciación osteoclastica require el contacto directo entre el precursor ostoclastico y el osteoblasto o sus células precursoras estromales (ver figura de la izquierda). Estas células expresan la forma unida a membrana de las dos citoquinas claves en la osteoclastogenesis: RANKL y M-CSF. El precursor osteoclastico expresa en su membrana el receptor RANK y para M-CSF. (c-Fms). La osteoprotegerina es un inhibidor soluble de RANK Derecha: Las principales vias activadas por los tres receptores esenciales en la osteoclastogenesis. RANK, ITAMs (immunoreceptor tyrosine-based activation motifs) y c-Fms [Novack y Teitelbaum1, 2008]. 


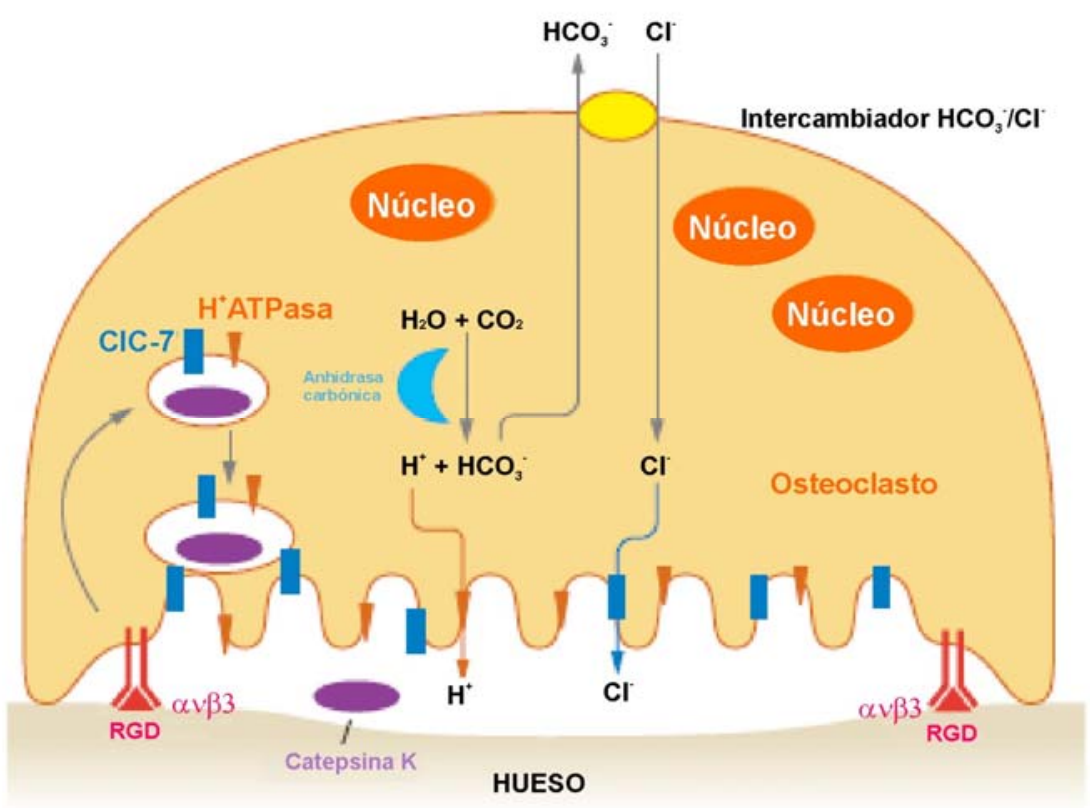

Figura I.1.3.2.5- Mecanismo de resorción ósea del osteoclasto.

El osteoclasto se adhiere al hueso a través de la integrina $\alpha v \beta 3$ creando una "zona sellada". Esto provoca una señal que desencadena la formación de la máquina resortiva. La anhidrasa carbónica inicia la acidificación generando $\mathrm{H}^{+}$y $\mathrm{HCO}_{3}{ }^{-}$. Los protones son transportados fuera de la célula hacia la laguna de resorción por una bomba de protones $\left(\mathrm{H}^{+}\right.$- ATPasa) localizada en el borde en cepillo. Esta organela resortiva se forma a partir de vesículas que se fusionan en la zona de la membrana plasmática que está en contacto con el hueso. El pH intracelular se mantiene por la presencia de un canal de $\mathrm{Cl}^{-}$localizado en el borde en cepillo y transporta $\mathrm{Cl}^{-}$a la laguna. La matriz ósea orgánica compuesta básicamente por colágeno de tipo I, se degrada mediante la acción de la catepsina K, una proteasa ácida secretada al espacio de resorción [Novack y Teitelbaum1, 2008]

En la membrana lateral posee un intercambiador de $\mathrm{Cl}^{-}$y $\mathrm{HCO}_{3}{ }^{-}$. Por este, el $\mathrm{Cl}^{-}$ ingresa a la célula y el bicarbonato formado por la acción de la enzima anhidrasa carbónica a partir de $\mathrm{CO}_{2}$ y $\mathrm{H}_{2} \mathrm{O}$, la abandona (Figura I.1.3.2.5).

El medio ácido disuelve la matriz ósea, dejando expuesta la matriz orgánica de colágeno, la cual es degradada por una enzima proteolítica, la catepsina K. El osteoclasto posee en su membrana basal integrinas que reconocen colágeno, fibronectina y laminina pero la principal integrina es la $\alpha \mathrm{v} \beta 3$ y reconoce al motivo Arg-Gly-Asp (RGD) el cual está presente en la mayoría de las proteínas del hueso como la osteopontina y la sialoproteina. De esta manera se crea un microentorno aislado por una zona sellada formada por la unión de las integrinas $\alpha v \beta 3$ a la matriz. Estas integrinas también están involucradas en señales intracelulares. Junto con la formación del borde en cepillo se produce una reorganización de los filamentos de actina formando una estructura anular llamada "anillo de actina". 


\section{I.1.4-FORMACION OSEA INTERMEMBRANOSA Y ENDOCONDRAL}

La formación de un hueso puede darse mediante dos mecanismos:

a-Formación ósea intermembranosa: en este mecanismo, el tejido conectivo de origen mesenquimatoso se condensa en forma directa para formar hueso primario en la cercanía de los vasos sanguíneos. Este tejido primario rápidamente se reorganiza a hueso lamelar.

b- Formación ósea endocondral: Este mecanismo está involucrado en el crecimiento longitudinal de los huesos largos y de las vértebras (Figura I.1.4). Inicialmente los condrocitos de la placa de crecimiento proliferan y se hipertrofian. Esto es seguido por una degradación parcial de la matriz cartilaginosa, que entonces se mineraliza formando espículas. A continuación, el cartílago es invadido por vasos sanguíneos, los condrocitos mueren por apoptosis y las espículas de cartílago mineralizado se tapizan de osteoblastos que forman una cubierta de hueso primario. Estas estructuras mixtas de cartílago y hueso se resorben y se reemplazan por tejido óseo trabecular de organización lamelar.

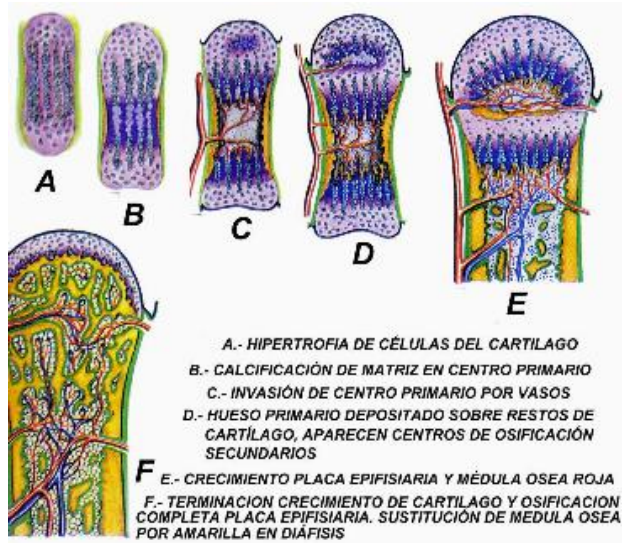

Figura I.1.4- Esquema de la formación ósea endocondral.

Existen dos tipos de hueso, los cuales pueden ser identificados de acuerdo con el patrón de colágeno que forman el osteoide:

- Hueso primario se caracteriza por una organización irregular de fibras de colágeno y es mecánicamente débil.

- Hueso laminar se caracteriza por un alineación regular paralela de colágeno en láminas (lamelas) y es mecánicamente fuerte.

El hueso primario se forma cuando los osteoblastos producen osteoide rápidamente. Este tipo de hueso es el que constituye inicialmente el esqueleto del feto, y es el que se genera en los adultos cuando la formación de hueso nuevo se produce rápidamente como ocurre en la 
reparación de una fractura. Este hueso es remplazado posteriormente por hueso laminar más resistente mediante el mecanismo de remodelación. Prácticamente todos los huesos en el adulto maduro sano son hueso laminar.

\section{I.1.5-MODELADO Y REMODELADO OSEO}

Los huesos son esculpidos por un proceso llamado modelado y a su vez están constantemente renovándose, mediante un proceso denominado remodelado. [Primer in the Metabolic Bone Diseases and Disorders of Mineral Metabolism. Sixth Ed., 2006]

\section{I.1.5.1-Modelado}

El modelado es el mecanismo por cual los huesos son formados o reformados mediante un proceso independiente de los osteoblastos y osteoclastos. Ocurre mayormente durante el crecimiento o en el adulto cuando cambia la forma del hueso en respuesta a la variación en la carga mecánica (por ejemplo, el radio del miembro de un tenista, tiene un diámetro mayor y la corteza es más gruesa en comparación con esas estructuras en el miembro que no utiliza para jugar). El modelado no está acoplado a una resorción previa como en el remodelado. Los agentes anabólicos como la PTH intermitente usados en el tratamiento para la osteoporosis producen un incremento en el modelado óseo.

\section{I.1.5.2- Remodelado}

El remodelado describe el recambio de tejido envejecido por hueso nuevo, e involucra el acoplamiento témporo-espacial entre resorción y formación ósea en las osteonas individuales. El remodelado óseo es tan extenso y activo que se ha estimado que renueva completamente el esqueleto adulto cada 10 años [Manolagas 2000]. En el ciclo de remodelación podemos distinguir básicamente cuatro fases (Figura I.1.5.2.1):

1-Activación: involucra el reclutamiento de los precursores mononucleados de los osteoclastos desde el pool de monocitos- macrófagos circulantes en la sangre, los cuales son estimulados y diferenciados bajo la influencia de ciertas citoquinas y factores de crecimiento a osteoclastos maduros activos.

2-Resorción: implica la digestión del hueso por el osteoclasto. Para ello, éste genera un compartimiento con pH muy ácido (lagunas de Howship), lo cual va acompañado de la secreción de enzimas lisosomales, de esta manera se digieren la fase mineral y la orgánica de la matriz ósea. Esta fase termina con la muerte por apoptosis de las células osteoclásticas. 
3-Fase de reversión: en esta fase la laguna de resorción se puebla de células mononucleadas, tales como monocitos, osteocitos (liberados de la matriz) y de preosteoblastos que son los responsables de la etapa de formación. Es en esta etapa que se produce el acoplamiento entre la resorción y la reposición del hueso removido, mediante la adecuada señalización. Sin un mecanismo eficiente de acoplamiento cada ciclo de remodelación resultaría en una pérdida neta de masa ósea.

4-Formación: este proceso consta de dos pasos: inicialmente los osteoblastos sintetizan la matriz orgánica y posteriormente regulan su mineralización. Una vez que la matriz de colágeno es secretada, comienzan los depósitos de $\mathrm{Ca}$ y fosfatos y la degradación enzimática de inhibidores de la mineralización como el pirofosfato y los proteoglicanos que están presentes en la matriz extracelular. Los osteoblastos se van diferenciando a osteocitos al quedar rodeados de matriz, pero igualmente quedan conectados unos con otros a través de los canalículos formando un sincitio funcional, el cual puede sensar un cambio en las propiedades mecánicas y transmitir esa información a las células de la superficie para que inicien la remodelación cuando sea necesario. Cuando los osteoblastos completaron la formación de matriz pueden tomar distintos caminos. Aproximadamente el 50-70\% muere por apoptosis, algunas quedan incorporadas a la matriz como osteocitos y otras permanecen en la superficie como células óseas de revestimiento.

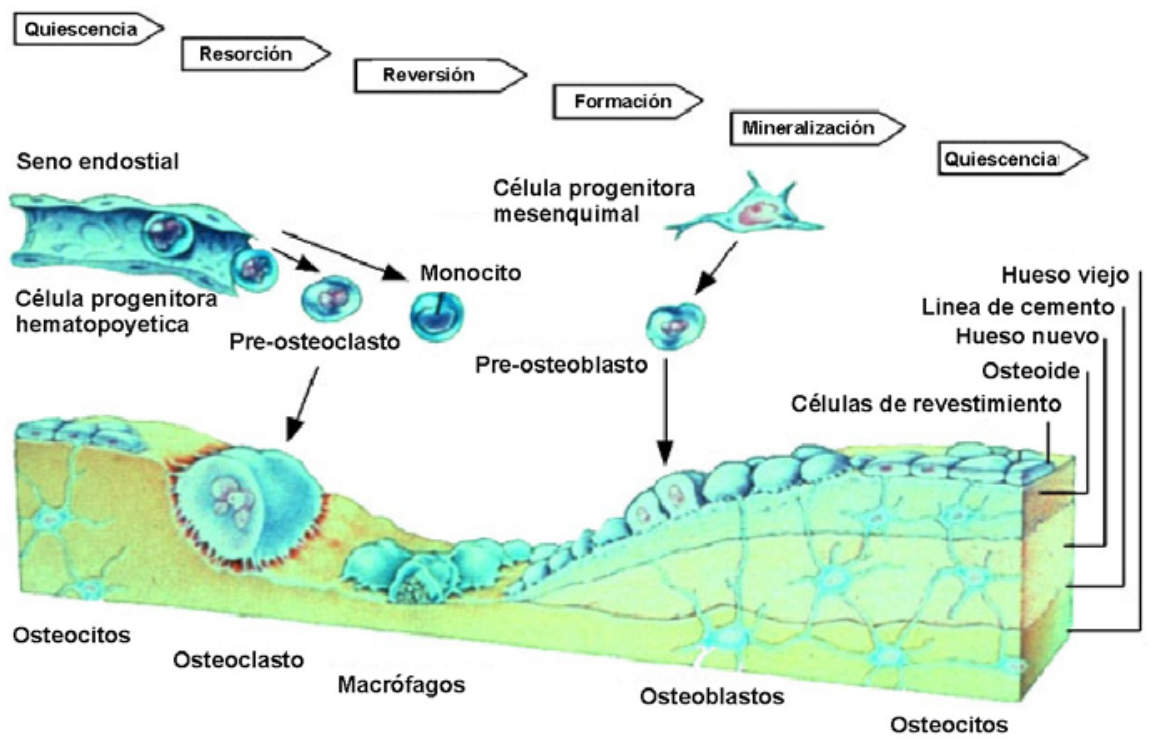

Figura I.1.5.2.1- Esquema de las fases involucradas en el remodelado óseo. 
El resultado neto de un ciclo de remodelación es la producción de una osteona nueva. El proceso es esencialmente similar en hueso cortical como en el trabecular.

En el hueso cortical las BRUs (unidades remodelado oseo) forman un cono llamado "cono de penetración". El ciclo de remodelación dura aproximadamente 120 días mientras que la secuencia de resorción dura 30 días. En el hueso trabecular, en una persona sana, la fase de resorción se produce durante 40-50 días y se forman lagunas de resorción (Figura I.1.5.2.2).
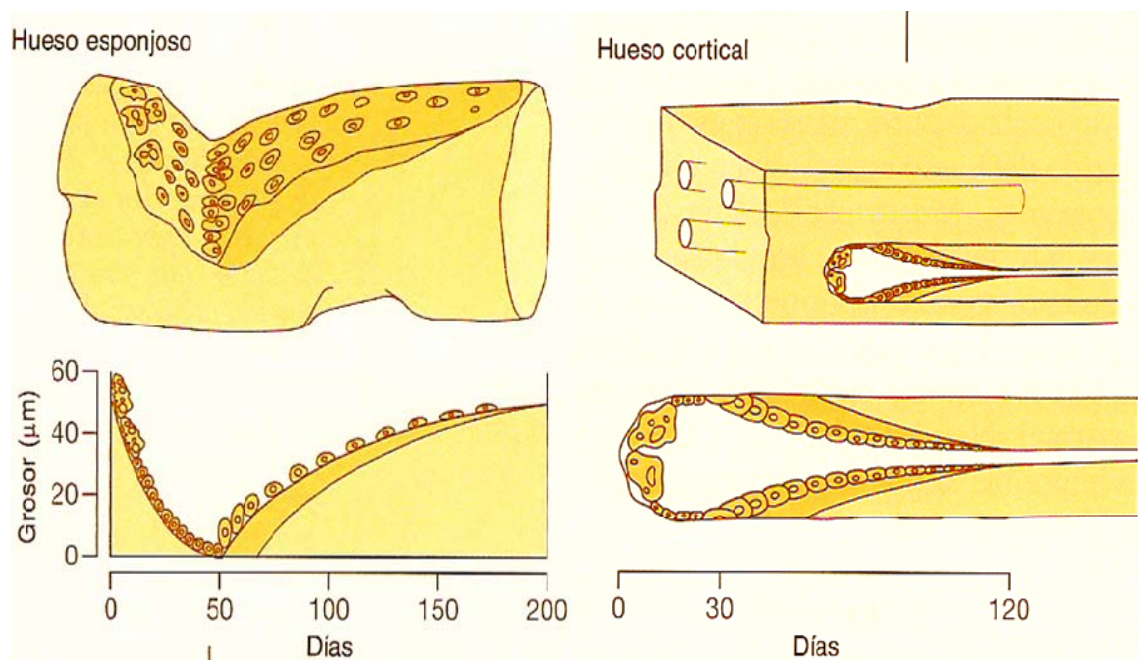

Figura I.1.5.2.2- Esquema del ciclo de remodelación en un hueso esponjoso y un hueso cortical.

El volumen de hueso que se sustituye por hueso nuevo por unidad de tiempo se denomina recambio óseo, y es directamente proporcional al número de BRU activas. La diferencia de volumen entre el hueso formado y el hueso reabsorbido, por unidad de tiempo, se llama balance óseo.

\section{I.1.5.3- Masa ósea}

Mantener la masa ósea implica que los osteoblastos formen tanto hueso como el que han destruido los osteoclastos. Cuando en cada unidad de remodelación se forma menos hueso del que se destruye, la masa ósea disminuye, y se produce un balance óseo negativo.

En condiciones normales la masa ósea de una persona va aumentando desde el nacimiento hasta alcanzar un valor máximo (que llamamos pico de masa ósea) alrededor de los 25 y los 30 años, y se mantiene hasta los 35-40 años, a partir de ese momento se observa 
un balance negativo, que determina la pérdida de masa ósea que se produce con la edad. (Figura I.1.5.3)

El pico de masa ósea esta bajo control genético y se encuentra afectado por el estilo de vida, la nutrición y las enfermedades durante el desarrollo esquelético.

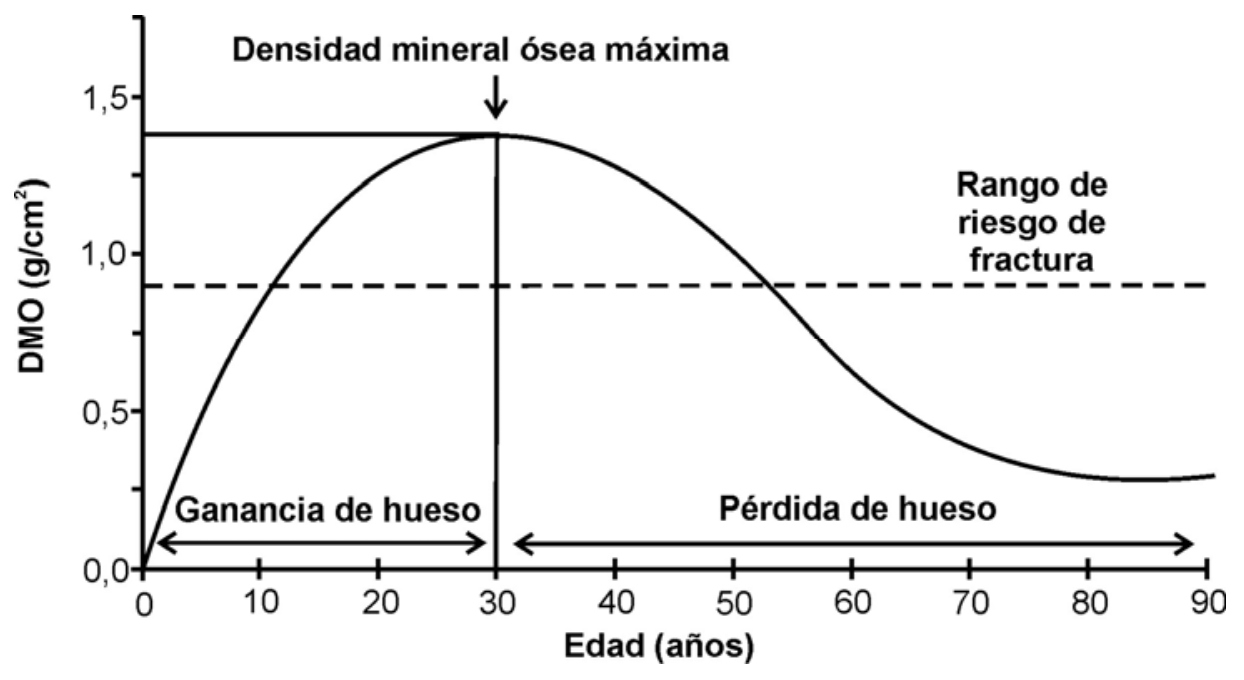

Figura I.1.5.3- Curva de masa ósea en función de la edad.

La causa de pérdida de masa ósea es el aumento del número de unidades de remodelación, que con un balance óseo negativo, dará lugar a un aumento de la cantidad total de hueso perdido. Esta situación se denomina de alto recambio y se observa en el envejecimiento, en la menopausia y acompañando a ciertas situaciones patológicas (hipogonadismo, hipertiroidismo, hiperparatiroidismo, inmovilización).

El resultado de este balance negativo que acompaña al envejecimiento es una pérdida de masa ósea que oscila entre un $0.5 \%$ y un $1 \%$ anual que, al final de la vida, puede suponer un $15 \%$ del pico de masa ósea alcanzado. Las mujeres tienen una aceleración de este proceso durante la menopausia, con pérdidas de $10 \%$ por década. 


\section{I.2-OSTEOPOROSIS}

\section{I.2.1-DEFINICIÓN DE LA ENFERMEDAD}

La osteoporosis es la enfermedad metabólica ósea más frecuente y uno de los mayores problemas de salud pública actualmente en todo el mundo, debido a los enormes costos sociales y económicos que genera.

Desde la celebración del Congreso Mundial de Osteoporosis de 1996 en Ámsterdam, la osteoporosis se define como "una enfermedad sistémica caracterizada por una disminución de la masa ósea, alteración de la microarquitectura ósea, con el consecuente incremento de la fragilidad ósea y susceptibilidad para las fracturas”. Actualmente la osteoporosis se define como una enfermedad esquelética caracterizada por una resistencia ósea disminuida que predispone a una persona a un mayor riesgo de fractura [NIH consensus statement, 2001].

La resistencia ósea depende fundamentalmente de dos factores: densidad mineral (contenido mineral óseo) y la calidad ósea. La densidad mineral ósea (DMO) se expresa en gramos de mineral por área o por volumen, y en un individuo viene determinada por el pico de masa ósea obtenido durante el crecimiento y por la cantidad de pérdida de hueso. La calidad ósea se refiere a la estructura del hueso (microarquitectura), al recambio, al daño acumulado (como las microfracturas) y a la mineralización. La densidad ósea, es decir la cantidad de hueso, se mide por densitometría, y la calidad ósea por histomorfometría.

Kanis y colaboradores en 2001 publicaron el riesgo de fracturas osteoporóticas en hombres y mujeres de acuerdo con su edad y densidad mineral en cuello femoral. Ellos establecieron que el riesgo aumenta con la disminución de la densidad mineral (T-score) y la edad. La probabilidad de fractura de raquis y cadera para cualquier edad, teniendo baja DMO, fue similar para hombres y mujeres.

En 1994, la Organización Mundial de la Salud, la Fundación Europea de Osteoporosis y Enfermedad Ósea y la Fundación Nacional de Osteoporosis de Estados Unidos establecieron cuatro categorías diagnósticas basadas en la medición de la densidad de masa ósea (DMO) (tabla I.2.1) [WHO Study Group, 1994].

Los factores de riesgo de osteoporosis más importantes son los siguientes:

1. Edad (la osteoporosis es más frecuente en el último tercio de la vida).

2. Factores genéticos: sexo (la osteoporosis es más frecuente en la mujer); raza (es más propensa la raza blanca que la negra), carácter familiar (mayor incidencia en 
hijas de madres osteoporóticas), enfermedades hereditarias (osteogénesis imperfecta); constitución (delgadez).

3. Factores hormonales: tiempo de exposición a las hormonas sexuales (la incidencia de osteoporosis es mayor si la menopausia es precoz, la menarca es tardía,), hipertirodismo; hiperparatiroidismo, hipercortisolismo, diabetes tipo 1.

4. Factores higiénico-dietéticos y estilo de vida: aparte de calcio y vitamina D; estado nutritivo (las personas delgadas son más propensas a la osteoporosis, se cree que porque el tejido adiposo es fuente de estrógenos, y porque el peso supone un estímulo mecánico para el esqueleto); ejercicio físico (la sobrecarga mecánica favorece la formación ósea e inhibe la resorción); tabaco y alcohol, (de efectos negativos).

5. Enfermedades no endocrinológicas: malabsorción, hepatopatías, enfermedades inflamatorias (artritis reumatoide), mieloma.

6. Tratamientos: corticoides, citostáticos, anticonvulsivantes, heparina.

Tabla I.2.1-Clasificación de la densidad de masa ósea según la OMS (1994)

\begin{tabular}{|c|c|}
\hline Densidad de masa ósea & Criterio de clasificación \\
\hline Normal & $\begin{array}{l}\text { Valor de DMO }<1 \text { DE por debajo del promedio para adultos } \\
\text { jóvenes. }\end{array}$ \\
\hline Osteopenia & $\begin{array}{l}\text { Valor de DMO }>1 \text { DE por debajo del promedio para adultos } \\
\text { jóvenes. }\end{array}$ \\
\hline Osteoporosis & $\begin{array}{l}\text { Valor de DMO }>2,5 \text { DE por debajo del promedio para adultos } \\
\text { jóvenes. }\end{array}$ \\
\hline Osteoporosis establecida & $\begin{array}{l}\text { Valor de DMO }>2,5 \text { DE por debajo del promedio para adultos } \\
\text { jóvenes y la presencia de una o más fracturas por fragilidad. }\end{array}$ \\
\hline
\end{tabular}

La masa ósea que posee una persona en un momento concreto depende de la que llegó a tener al completar su desarrollo y de las pérdidas sufridas posteriormente. Ambos hechos están determinados por los factores comentados. Se considera que en la producción del valor máximo de masa ósea los factores implicados más importantes son los genéticos. En cambio, en la velocidad de pérdida de masa ósea los factores genéticos parecen tener menor importancia que los adquiridos.

Riggs y Melton (1983) han propuesto la siguiente fórmula para resumir los factores responsables de la masa ósea de un individuo en un momento de su vida:

$$
\mathrm{Q}=\mathrm{I}-(\text { envejecimiento }+ \text { menopausia }+ \text { factores esporádicos })
$$


donde $\mathrm{Q}=$ masa ósea actual e $\mathrm{I}=$ valor máximo de masa ósea. La fórmula subraya la importancia del envejecimiento y de la menopausia frente a los demás factores, que los autores califican de "esporádicos" u ocasionales. Además, proporciona una idea clara de que la osteoporosis es el resultado de la actuación conjunta de diversos factores.

Pese a ser la osteoporosis consecuencia de la interacción de múltiples factores, está muy extendida la costumbre de clasificarla etiológicamente en ciertos tipos, como si cada uno de ellos respondiera a un factor causal único. Aunque ello es incorrecto, dicha clasificación se acepta por resultar útil desde el punto de vista práctico.

\section{I.2.2-CAUSAS Y TIPOS DE OSTEOPOROSIS}

La osteoporosis tiene un origen multifactorial (Tabla I.2.2). Normalmente se diferencia entre dos tipos: la osteoporosis primaria, la cual no tiene factores causales; y la osteoporosis secundaria, en la cual existe un factor causal identificable (excluyendo la menopausia y el envejecimiento).

La osteoporosis primaria es la forma más frecuente de esta enfermedad, la cual obedece a procesos fisiológicos normales que producen una condición de fragilidad ósea con el consiguiente riesgo de fractura. Dentro de esta, existen dos tipos de osteoporosis que afectan a la población joven: la osteoporosis idiopática juvenil y la osteoporosis idiopática en adultos jóvenes. Ambas son infrecuentes. La primera afecta a niños prepuberales, de entre 8 y 14 años, en los que sin factores de riesgo previos comienzan a producirse múltiples fracturas de diferentes localizaciones e incluso una detención del crecimiento. No presentan ninguna anormalidad en los parámetros bioquímicos de remodelado óseo. La osteoporosis idiopática en adultos jóvenes es algo más frecuente que la anterior. Tampoco presenta alteraciones de laboratorio, pero su origen parece relacionarse con la osteogénesis imperfecta, la osteoporosis del embarazo y de la lactancia o de un defecto en la regulación de los osteoblastos.

Por otra parte, la osteoporosis primaria involutiva se clasifica en osteoporosis primaria postmenopaúsica o tipo I, que afecta a mujeres con pérdida acelerada de masa trabecular desde el inicio del climaterio, adquiriendo alto riesgo de fractura por aplastamiento de cuerpos vertebrales o fractura distal de radio, y en osteoporosis primaria senil o tipo II que afecta a ancianos que pierden lentamente tanto masa cortical como trabecular con elevado riesgo de fracturas de cadera [Riggs y Melton, 1983]. La osteoporosis tipo I afecta a mujeres con una proporción de 6:1 respecto al varón, y se presenta entre los 51 y los 75 años de edad. En su fisiopatología encontramos una disminución de la función paratiroidea, de la absorción 
intestinal del calcio y, secundariamente, de la hidroxilación renal de la vitamina D. La osteoporosis tipo II afecta a mujeres principalmente pero con una relación respecto al varón inferior a la tipo I, de 2:1 y se presenta a partir de los 70 años de edad. A diferencia de la osteoporosis primaria I, la función paratiroidea se encuentra aumentada, la absorción intestinal de calcio está disminuida y la hidroxilación renal de vitamina D disminuye primariamente.

Tabla I.2.2-Clasificación etiológica de osteoporosis

\begin{tabular}{cl}
\hline Tipo de osteosporosis & \\
\hline PRIMARIA & Osteoporosis juvenil idiopática \\
& Osteoporosis idiopática en adultos jóvenes \\
& Osteoporosis involutiva (tipo I o posmenopáusica y tipo II o senil) \\
\hline & Anorexia o malnutrición \\
& Depresión \\
& Diabetes mellitus \\
& Enfermedades reumáticas \\
& Fármacos corticoides \\
& Hiperparatiroidismo \\
& Hipertiroidismo \\
& Hipogonadismo \\
& Inmovilización \\
& Insuficiencia renal crónica \\
& Trastornos digestivos y malabsorción \\
\hline
\end{tabular}

En el caso de la osteoporosis secundaria, la lista de factores involucrados es muy extensa e incluye variadas enfermedades. Puede presentarse en pacientes con antecedentes de alcoholismo crónico, hipercortisolismo, hiperparatiroidismo, hipertiroidismo, diabetes mellitus tipo I, artritis reumatoide, inmovilización, síndromes de malabsorción, uso crónico de anticonvulsionantes, anticoagulantes, corticoides, o litio, quimioterapia, hipogonadismo, o enfermedades renales crónicas.

\section{I.2.3-TRATAMIENTO DE LA OSTEOPOROSIS}

El objetivo principal del tratamiento de la osteoporosis es la prevención. El tratamiento en niños, adolescentes y adultos jóvenes está encaminado a alcanzar una masa ósea máxima entre los 20 y 30 años de edad. Para alcanzar esta masa ósea máxima son importantes la nutrición adecuada, el ejercicio físico, la ingestión adecuada de vitamina D y calcio, y la normalidad en los ciclos menstruales. Para pacientes con osteoporosis establecida existe un amplio arsenal de tratamientos médicos que se describen brevemente a continuación. 


\section{I.2.3.1-Calcio y Vitamina D}

El calcio y la vitamina D seguramente guardan con la masa ósea una relación de tipo “umbral”. Ello significa que, por debajo de un determinado aporte de ambas, la masa ósea se resiente. Sin embargo, por encima de él, la adición de ulteriores cantidades de los mismos no tiene como resultado nuevos aumentos de masa ósea.

La recomendación de administrar calcio y vitamina $\mathrm{D}$ junto a los fármacos antirresortivos $\mathrm{u}$ osteoformadores en el tratamiento de la osteoporosis es universal. La vitamina D juega un papel clave para la absorción del calcio. El metabolito activo, la 1,25dihidroxivitamina D tiene una vida media muy corta (4 horas) y tiene mayor costo, por lo que se puede administrar 25-hidroxivitamina D de mayor vida media y más económica. [DawsonHughes, 2005].

\section{I.2.3.2-Calcitonina}

La calcitonina actúa sobre los osteoclastos a través de receptores específicos, conduciendo a la retracción del aparato citoesquelético del osteoclasto, con pérdida del borde rugoso y de su capacidad resortiva. Este fármaco administrado en forma diaria ha demostrado ser eficaz para la estabilización de la masa ósea vertebral tras fracturas vertebrales y disminuye las fracturas vertebrales en pacientes con fracturas prevalentes. No influye en el hueso cortical y también produce un efecto analgésico en las fracturas vertebrales [Silverman, 2003].

\section{I.2.3.3-Estrógenos}

Los estrógenos en parte actúan a través de los osteoblastos, los cuales presentan receptores para ellos. La estimulación osteoblástica se traduciría en una disminución del cociente RANKL/OPG, y por tanto en una inhibición de la actividad osteoclástica. Por otra parte, al efecto antirresortivo de los estrógenos contribuyen probablemente mecanismos indirectos, como la disminución de la producción de citocinas destructoras de hueso. Salvo que la paciente a la que se administran los estrógenos haya sufrido una histerectomía, deben asociarse a ellos gestágenos (terapia hormonal sustitutiva [THS]), para evitar el cáncer de endometrio que pueden inducir. El estudio Women's Health Initiative (WHI) [Cauley, 2003] ha dejado sentada la eficacia de la THS en la disminución de las fracturas osteoporóticas en general, en las vertebrales y en la de cadera.

\section{I.2.3.4-Raloxifeno}

El mayor conocimiento de los receptores estrogénicos han permitido diferenciar dos tipos de éstos, por lo que se han desarrollado fármacos que pueden estimular selectivamente 
unos receptores e inhibir otros; estos fármacos se denominan genéricamente moduladores selectivos de los receptores estrogénicos (SERM) y actúan como antagonistas estrogénicos en el tejido mamario y como agonistas estrogénicos en el hueso [Delmas, 2003]. Se sintetizaron con la idea de mantener los efectos favorables de los estrógenos (inhibición de la resorción ósea) y evitar los desfavorables (cáncer de mama). El raloxifeno es un ejemplo de ello, actúa selectivamente en el hueso y no estimula tejido endometrial. Los resultados de su acción sobre el hueso son inferiores a la de los estrógenos por carecer de la estructura esteroidea de estos. $\mathrm{Su}$ eficacia en la prevención de fracturas vertebrales quedó probada en el estudio MORE [Ettinger, 1999] Sin embargo, no se ha podido demostrar su eficacia sobre las fracturas no vertebrales.

\section{I.2.3.5-Tibolona}

La tibolona es un esteroide sintético que tiene propiedades estrogénicas, androgénicas y progestágenas, y que se utiliza como una forma de THS. No tiene actividad por sí misma, sino que la adquiere cuando se transforma en los tejidos en diversos metabolitos. El ensayo LIFT ha demostrado su capacidad para disminuir las fracturas vertebrales y no vertebrales [Cummings, 2007]. El mismo ensayo LIFT ha mostrado también una disminución del cáncer de mama invasivo. Sin embargo, se observó un aumento notable del porcentaje de accidente cerebrovascular, lo que hace dudosa la conveniencia de su uso.

\section{I.2.3.6-Hormona paratiroidea}

La hormona paratiroidea (PTH) se incluye dentro de los fármacos anabólicos. La PTH al actuar de forma sostenida sobre el hueso, provoca un aumento de la resorción ósea. Este efecto no lo desarrolla actuando directamente sobre los osteoclastos, sino a través de los osteoblastos, que poseen receptores para PTH. Cuando la hormona se une a estos receptores, altera la relación RANKL/OPG a favor del RANKL, lo que finalmente da lugar a la estimulación de los osteoclastos. A diferencia de lo que ocurre cuando la PTH actúa de forma sostenida, cuando lo hace de forma intermitente (por ejemplo, una inyección diaria), estimula la formación ósea. La razón de esta diferencia no se conoce bien, pero se atribuye a que la señalización intraceluar para la estimulación de los osteoclastos se desarrolla más lentamente que la responsable del efecto osteoformador. De esta manera, cuando la administración es intermitente sólo llega a desarrollarse el segundo efecto, mientras que cuando es continuo lo hacen los dos, siendo el primero predominante. Se han comercializado dos formas de PTH: una correspondiente al fragmento aminoterminal 1-34 (teriparatida) y otro correspondiente a la molécula completa (1-84). Un ensayo clínico (Fracture Prevention Trial) [Neer, 2001] ha 
demostrado la eficacia de la PTH 1-34 en la reducción de fracturas vertebrales y no vertebrales. El ensayo TOP [Greenspan, 2007] ha demostrado la eficacia de la PTH 1-84 en la fractura vertebral pero no en la no vertebral ni en la de cadera.

\section{I.2.3.7-Ranelato de estroncio}

Fármaco de propuesta acción dual que actúa mediante la incorporación del estroncio a los cristales de hidroxiapatita inhibiendo la resorción osteoclástica. Puede promover la proliferación osteoblástica y la expresión de osteoprotegerina (OPG) en estas células. Los estudios SOTI [Meunier, 2004] y TROPOS [Reginster, 2005] han demostrado la eficacia del ranelato de estroncio en la prevención de la fractura vertebral y también en la fractura no vertebral. Un análisis post hoc ha concluido la eficacia del fármaco en la prevención de la fractura de cadera en un subgrupo de mujeres de alto riesgo (74 años o más y DMO en cuello femoral de $\mathrm{T}$ inferior o igual a - 3) [Reginster, 2005].

\section{I.2.3.8-Bisfosfonatos}

Los bisfosfonatos constituyen una de las alternativas terapéuticas más eficaces para la prevención de fracturas en las mujeres con osteoporosis. Sus acciones sobre la masa ósea e incidencia de fracturas han quedado plenamente demostradas. Los conocimientos sobre la farmacocinética de los bisfosfonatos provienen de estudios realizados en animales de experimentación y en humanos [Sansom et al, 1995; Porras et al, 1999; Ylitalo et al; 1999] (Ver capítulo I.3 de Bisfosfonatos). 


\section{I.3-BISFOSFONATOS (BPs)}

\section{I.3.1-CONSIDERACIONES GENERALES}

Los bisfosfonatos (BPs) son las drogas más utilizadas para el tratamiento de la osteoporosis y otras enfermedades que se caracterizan por un incremento en la resorción ósea [Russell et al, 2008]. Esto se debe a la capacidad de los BPs de inhibir la disolución de los cristales de hidroxiapatita. [Fleisch et al, 1969]. Durante la década de 1970, los BPs comenzaron a utilizarse como agentes terapéuticos en oncología y actualmente han llegado a ser ampliamente establecidos para el tratamiento y la prevención de complicaciones óseas asociadas con mieloma múltiple o metástasis óseas derivadas de cáncer de mama, próstata y otros órganos. En la osteoporosis posmenopáusica, los BPs reducen los marcadores de recambio óseos, y en los huesos aumentan la densidad mineral ósea (DMO) en columna lumbar y cadera, y reducen el riesgo de fracturas vertebrales y no vertebrales [Reginster et al, 2000; Harris et al, 1999; Black et al, 1996; Boonen et al, 2005]. Los BPs también se utilizan para el tratamiento de la osteoporosis inducida por glucocorticoides y osteoporosis en el varón, y en niños con osteogénesis imperfecta.

Los bisfosfonatos son análogos estables del pirofosfato (PPi), que es un subproducto del metabolismo celular. El PPi se libera en las células en la hidrólisis de ATP a AMP $(\mathrm{ATP} \longrightarrow \mathrm{AMP}+\mathrm{PPi})$. Así el pirofosfato es un inhibidor natural de la mineralización ósea. La fosfatasa alcalina presente en la membrana de los osteoblastos hidroliza el PPi a fósforo inorgánico brindando sustrato para la formación de la hidroxiapatita [Orimo, 2010]. Las personas con alteraciones en el gen de la fosfatasa alcalina presentan una enfermedad llamada hipofosfatasia, en la cual los niveles séricos y urinarios de PPi se encuentran elevados. Estos pacientes presentan una mineralización del esqueleto defectuosa debido a que el exceso de pirofosfato impide la adecuada mineralización del osteoide [Whyte, 2010].

Un BP se forma al reemplazar el enlace P-O-P por un enlace P-C-P, el cual no es hidrolizable químicamente, ni enzimáticamente por las fosfatasas. Como consecuencia de ésto los BPs se excretan inalterados, sin ser metabolizados en el organismo [Russell et al, 2008].

La estructura tridimensional de todos los bisfosfonatos permite la quelación de iones metálicos divalentes como el $\mathrm{Ca}^{++}$[Jung et al, 1973]. Por lo tanto, los BPs se eliminan rápidamente de la circulación [Chen et al, 2002] e in vivo tienen como blanco a la hidroxiapatita de la superficies mineral ósea en los sitios de remodelación activa, en particular las zonas en la resorción [Masarachia et al, 1996]. Los BPs se unen al mineral óseo y puede 
ser liberado de la superficie del hueso en el ambiente ácido de la laguna durante la resorción osteoclástica, debido a que la capacidad de quelación del $\mathrm{Ca}^{++}$se reduce en medio ácido [Ebetino et al, 1998]. La captación celular de los BPs (que están cargados negativamente), en los osteoclastos probablemente se produce por endocitosis, pero no en otros tipos de células in vivo después de su administración [Masarachia et al, 1996; Sato et al, 1991].

Los efectos farmacológicos clásicos de los BPs parecen ser el resultado de dos propiedades fundamentales: su afinidad por el mineral de los huesos y sus efectos inhibitorios sobre los osteoclastos. Las distintas afinidades de unión entre los diferentes BPs de uso clínico, puede influir en la distribución diferencial dentro del hueso, la potencia biológica y la duración de acción. Los efectos inhibitorios de los BPs que contienen nitrógeno (incluyendo Alendronato, Risedronato, Ibandronato y Zoledronato) sobre los osteoclastos parecen ser el resultado de la inhibición de la farnesil pirofosfato sintetasa (FPPS), una enzima clave en un punto de ramificación en la vía del mevalonato. La FPPS genera lípidos isoprenoides utilizados para la modificación postraduccional de las proteínas pequeñas de unión a GTP, esenciales para la función de los osteoclastos. Ciertos efectos sobre otras vías celulares, tales como la prevención de la apoptosis en osteocitos y osteoblastos, son otros mecanismos potencialmente importantes de la acción de estas drogas [Bellido y Plotkin, 2006].

Como clase, los BPs comparten varias propiedades comunes. Sin embargo, como ocurre con otras clases de fármacos, hay diferencias químicas, bioquímicas y farmacológicas entre los distintos BP individuales. Cada uno tiene un perfil único que puede ayudar a explicar las posibles diferencias clínicas importantes entre los BP, en términos de velocidad de inicio de la reducción de la fractura, la eficacia antifractura en diferentes sitios del esqueleto, y el grado y la duración de la supresión del recambio óseo [Russell et al, 2007].

Las diferentes potencias de acción antirresortiva de los distintos BPs dependen de las variaciones en las cadenas laterales (ver Fig I.3.1 y tabla I.3.1). Los principales BPs aprobados para uso clínico son: El Etidronato de sodio (BP de primera generación), Risedronato y Alendronato de sodio (BP de segunda generación).

Tabla I.3.1- Bisfosfonatos y su potencia de acción antirresortiva.

\begin{tabular}{cccc}
\hline Bisfosfonato & Potencia & $\mathbf{R 1}$ & $\mathbf{R} 2$ \\
\hline Etidronato & 1 & $-\mathrm{OH}$ & $-\mathrm{CH}_{3}$ \\
\hline Clodronato & 10 & $-\mathrm{Cl}$ & $-\mathrm{Cl}$ \\
\hline Pamidronato & 100 & $-\mathrm{OH}$ & $-\left(\mathrm{CH}_{2}\right)_{2} \mathrm{NH}_{2}$ \\
\hline Alendronato & 1000 & $-\mathrm{OH}$ & $-\left(\mathrm{CH}_{2}\right)_{3} \mathrm{NH}_{2}$ \\
\hline Risedronato & 5000 & $-\mathrm{OH}$ & $-\mathrm{CH}_{2}-3-$ piridina \\
\hline Ibandronato & 10000 & $-\mathrm{OH}$ & $-\left(\mathrm{CH}_{2}\right)_{2} \mathrm{~N}\left(\mathrm{CH}_{3}\right)\left(\mathrm{CH}_{2}\right)_{4} \mathrm{CH}_{3}$ \\
\hline Zolendronato & $>10000$ & $-\mathrm{OH}$ & $-\mathrm{CH} 2$-imidazol
\end{tabular}




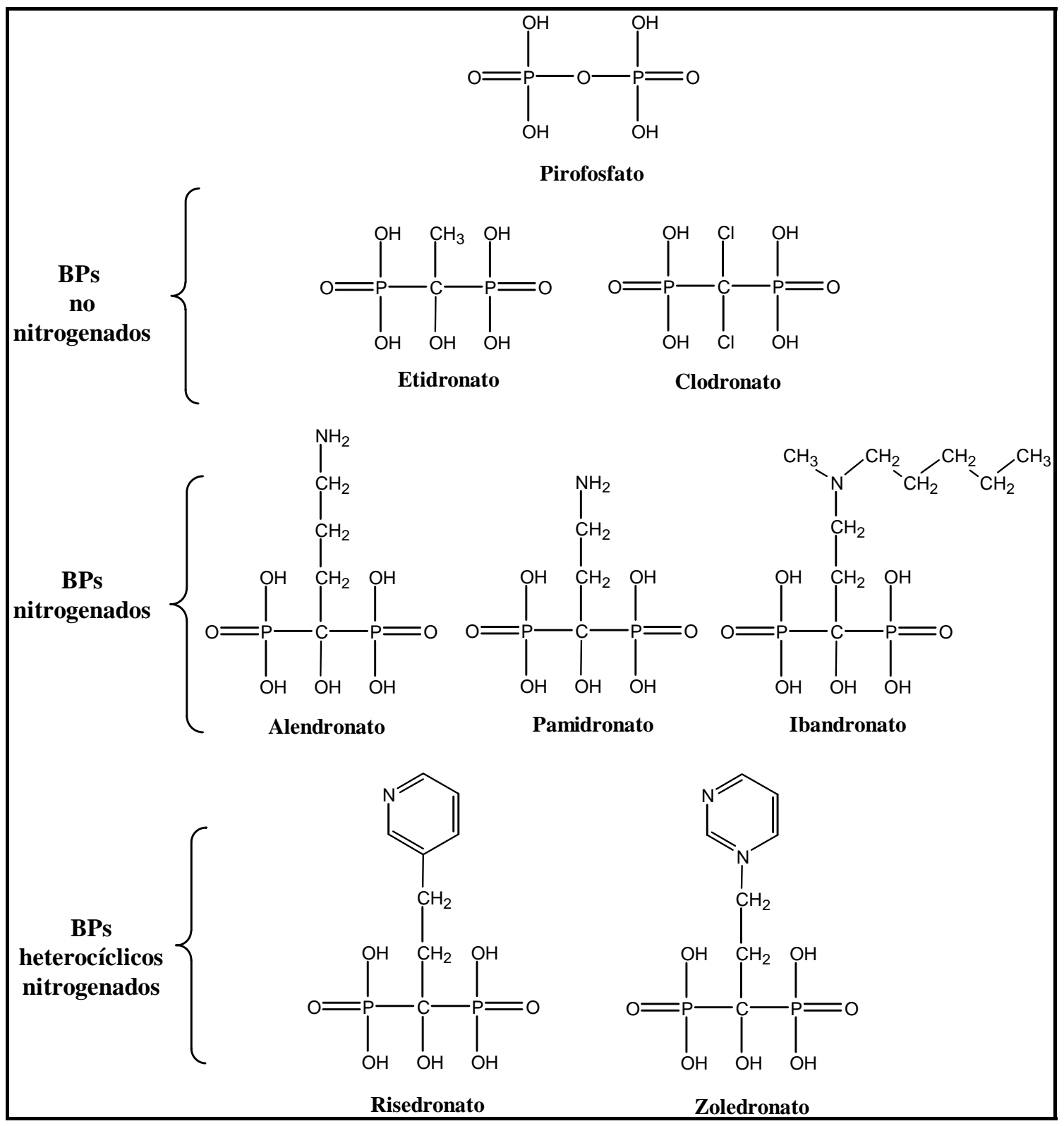

Figura I.3.1- Estructura química de los principales bisfosfonatos.

El Risedronato y Zoledronato son dos de los BPs con más potencia antirresortiva en varios modelos animales [Davis, 1998] debido al átomo de nitrógeno dentro del anillo heterocíclico, mientras que el Ibandronato con su grupo amino mas sustituido es más potente que el Pamidronato y el Alendronato, dos compuestos que tienen un grupo amino primario en una cadena de alquilo. El aumento observado en la potencia antirresortiva con los diferentes grupos R2 está ligado a la capacidad de afectar la actividad bioquímica, por ejemplo, la 
inhibición de la enzima farnesil pirofosfato sintetasa (FPPS), y también a la capacidad de unirse a hidroxiapatita [Nancollas et al, 2006].

\section{I.3.2-MECANISMO DE ACCIÓN}

Podemos encontrar dos vías principales que podrían explicar cómo actúan los BPs sobre los osteoclastos [Rogers, 2003].

Aunque inicialmente se penso que los BPs no se metabolizaban, se encontró que los bisfosfonatos simples o de primera generación como el Clodronato y el Etidronato, que no contienen N, [Rogers, 2004], que las células de mamíferos pueden convertir algunos bisfosfonatos a compuestos tipo AppCp análogos al ATP [Frith et al, 1997].

Estos metabolitos de tipo AppCp se acumulan en altas concentraciones en el citosol de los osteoclastos y otros tipos de células que efectivamente puede internalizar los bisfosfonatos [Mönkkönen, 2001]. La acumulación del metabolito $\mathrm{AppCCl}_{2} \mathrm{p}$ del clodronato en osteoclastos in vitro inhibe la resorción ósea mediante la inducción de la apoptosis de los osteoclastos [Frith, 2001], probablemente mediante la inhibición de enzimas dependientes de ATP, como la adenina nucleótido translocasa, un componente de la membrana mitocondria interna [Lehenkari, 2002].

La inducción de la apoptosis de los osteoclastos parece ser el principal mecanismo por el cual los bisfosfonatos simples inhiben la resorción ósea ya que la capacidad del Clodronato y Etidronato para inhibir la resorción in vitro puede ser superada cuando se utiliza un inhibidor de caspasas [Halasy-Nagy, 2001]

Los bisfosfonatos que contienen nitrógeno (N-BPs), son varios órdenes de magnitud más potentes en la inhibición de la resorción ósea in vivo que los bisfosfonatos simples, [Rogers, 2003; Green y Rogers, 2002], y no se metabolizan a análogos tóxicos del ATP [Benford, 1999]. En cambio, actúan por inhibición de la farnesil difosfato (FPP) sintasa, una enzima clave de la vía del mevalonato (Figura I.3.2). Esta enzima es inhibida por concentraciones nanomolares de los N-PBs [van Beek et al, 1999a; Bergstrom et al, 2000; Dunford et al, 2001]. El ácido Zoledrónico y el Minodronato, similares estructuralmente, son inhibidores muy potentes de la FPP sintasa [Dunford et al, 2001] y son capaces de inhibir la enzima, incluso en concentraciones picomolar. Es importante destacar que los estudios con FPPsintasa recombinante humana reveló que pequeñas modificaciones en la estructura y conformación de la cadena lateral $\mathrm{R}_{2}$ que se sabe que afecta a la potencia antirresortiva [Dunford et al, 2001] también afectan la capacidad de inhibir la FPPsintasa [Rogers, 2003]. 
Estos estudios sugieren que FPPsintasa es el objetivo farmacológico principal de los N-BPs en los osteoclastos in vivo y ayudan a explicar la relación entre la estructura de estos medicamentos y su potencia antirresortiva. La inhibición de la enzima FPPsintasa bloquea la síntesis de farnesil pirofosfato (FPP). Esto conduce a una reducción en las concentraciones del sustrato FPP necesario para la producción de geranilgeranil difosfato (GGPP) a través de la siguiente enzima en la vía, es decir, GGPP sintasa. Ambos FPP y GGPP son metabolitos isoprenoides necesarios para la modificación lípídica (prenilación) de las GTPasas. La prenilación es necesaria para la localización subcelular correcta en la membrana y por lo tanto la función de estas proteínas de señalización [Rogers, 2003]. Mediante la inhibición de FPP, N-BPs evitan la prenilación de las GTPasas pequeñas recién sintetizadas (la mayoría de las cuales se modifican usando GGPP), de modo que las proteínas se acumulan en su forma no prenilada. Las GTPasas pequeñas no pueden ser reemplazadas en los osteoclastos siguiendo el recambio normal de la proteína.

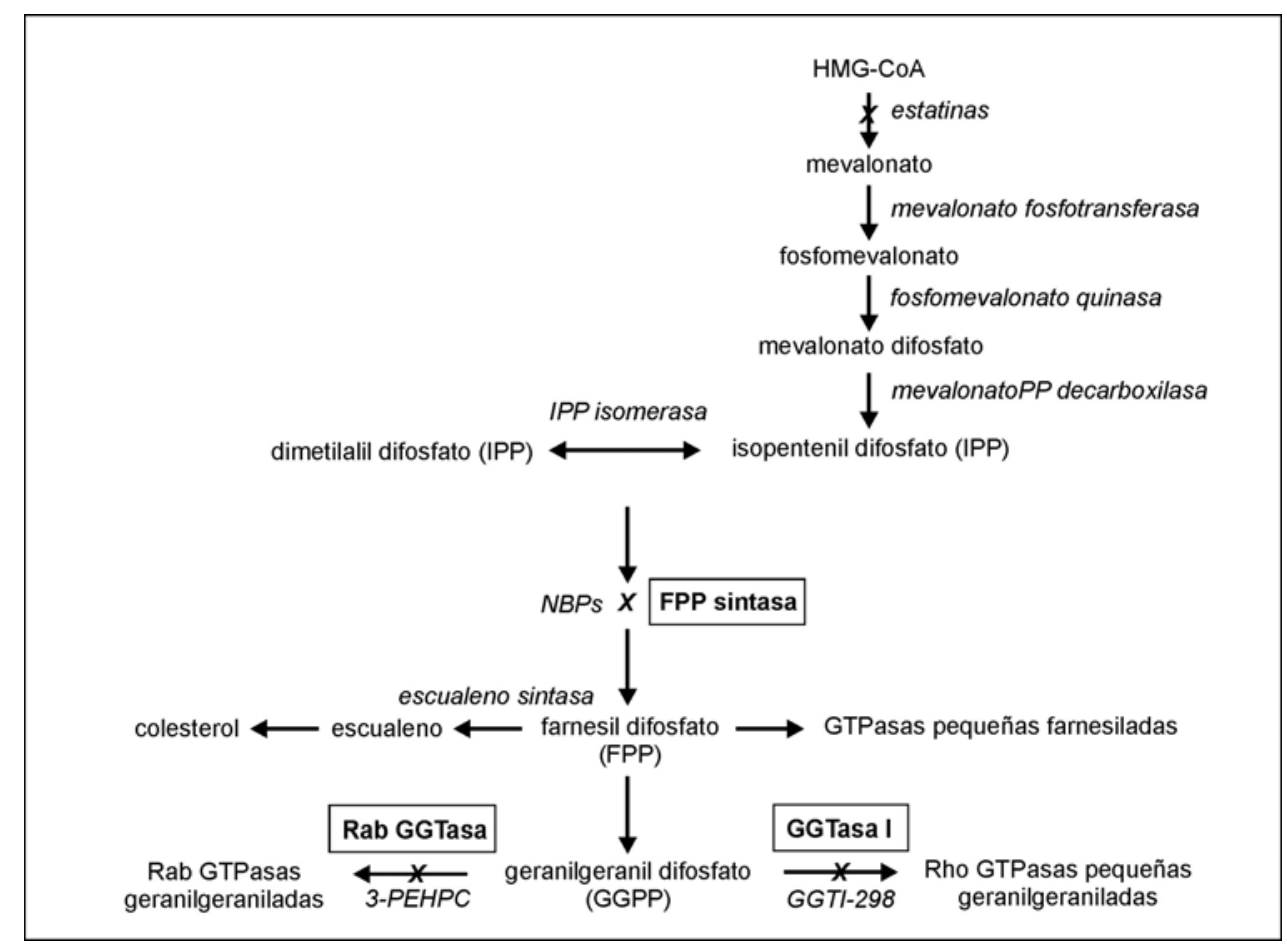

Figura I.3.2-Esquema de la vía del mevalonato.

N-BPs inhibe la enzima FPP sintasa, por lo tanto previene la síntesis del farnesil difosfato (FPP) y geranilgeranil difosfato (GGPP) necesarios para la prenilacion de proteínas. Las Statinas, GGTI-298, y 3-PEHPC también previenen la prenilacion de proteínas en osteoclastos in vitro [inhibiendo la 3-hidroxi-3-metilglutaril CoA reductasa (HMG-CoA reductasa), geranylgeranyltransferasa I (GGTasa I), o Rab geranylgeranyltransferasa (Rab GGTasa), respectivamente] y de esa forma imitan el efecto de los N-BPs sobre los osteoclastos, los cuales dependen de las proteínas geraniladas (Roelofs, 2006). 
Las GTPasas pequeñas, como las del Ras, Rho, Rab y sus familias, son importantes proteínas de señalización que regulan una variedad de procesos celulares importantes para la función de los osteoclastos [Reszka, 1999]. La inhibición de la vía del mevalonato y la pérdida de proteínas preniladas, en particular las geranilgeraniladas GTPasas pequeñas, parecen ser el principal mecanismo de acción de la N-BPs. Además, otros inhibidores de la geranilgeranilación de proteínas, como las estatinas o GGTI-298 (Fig I.3.2), imitan los efectos de los N-BPs. Sin embargo, estudios recientes realizados por van Beek et al, 2003 sugieren que el Pamidronato puede tener una via adicional, aún no identificada, blanco molecular en los osteoclastos, porque (a diferencia de otros N-BPs) el efecto antirresortivo de pamidronato no se podía superar con eficacia con un sustrato de la prenilación de proteínas.

Un informe reciente sugiere otro mecanismo por el cual los N-BPs podrían interrumpir la función de los osteoclastos a través de efectos sobre la vía del mevalonato. La inhibición de la sintasa FPP causa la acumulación aguas arriba del sustrato IPP, el mismo parece ser conjugado con AMP para formar un análogo nuevo del ATP (ApppI) [Mönkkönen et al, 2006]. Este metabolito, como sucede con el tipo AppCp de los BPs simples [Lehenkari, 2002], puede inhibir la adenina nucleótido translocasa mitocondrial e inducir la apoptosis de los osteoclastos. Además, a diferencia de los bisfosfonatos simples que funcionan mediante la inducción de la apoptosis de osteoclastos, el efecto antirresortivo de los N-BP no depende de la apoptosis al menos in vitro [Rogers et al, 2000] por lo tanto, la inhibición de la prenilación de proteínas sigue siendo la explicación más probable para los efectos antirresortivo de los $\mathrm{N}$ BPs.

\section{I.3.3- POSIBLES EFECTOS DE LOS BISFOSFONATOS EN OSTEOCITOS}

Estudios recientes sugieren que los osteocitos pueden ser células diana para los BPs en el hueso. Las concentraciones muy bajas de muchos BPs parecen proteger a los osteocitos (y los osteoblastos) de la apoptosis inducida por glucocorticoides in vitro [Plotkin et al, 1999]. En las líneas celulares y también en animales de experimentación, los osteocitos sufren apoptosis en respuesta a diversos estímulos, incluyendo la exposición a los glucocorticoides, la carga mecánica, microdaño, o ingravidez [Aguirre et al, 2006; Bonewald LF, 2007]. La capacidad de los BPs para inhibir la apoptosis en los osteocitos contrasta con su capacidad de inducir la apoptosis en los osteoclastos. La inhibición de la apoptosis en los osteocitos por los BPs parece estar mediada a través de la apertura de los hemicanales conexina 43 y 
subsiguiente activación de quinasas reguladas por señales extracelulares (ERKs) [Plotkin et al, 2006]. Experimentalmente, la potencia de los BPs individuales en osteocitos es independiente de su clasificación como inhibidores de la actividad osteoclástica. Los efectos de los BPs en osteocitos estarían mediadas por una vía diferente, ya que los que tienen actividades antirresortivas pequeñas son también capaces de aumentar la supervivencia de los osteocitos [Plotkin et al, 2006; Kogianni et al, 2004]. El 1-Aminodimetilaminopamidronato (un análogo Olpadronato) es un claro ejemplo de un bisfosfonato con poca actividad antirresortiva que puede permitir una reducción de la apoptosis y aumento de la fuerza en osteocitos en los animales tratados con glucocorticoides [Plotkin et al, 2007]. En un estudio farmacológico hecho por Follet et al 2007, se puede ver que los BPs en bajas concentraciones tienen la capacidad de prevenir la apoptosis de los osteocitos en animales de experimentación, por efecto de los glucocorticoides o la carga mecánica cíclica. Las interacciones potenciales de los BPs con osteocitos in vivo deben ser estudiardas más a fondo ya que esto puede ayudar a explicar la eficacia antifractura independientemente de lo conocido en los osteoclastos.

\section{I.3.4-POSIBLES EFECTOS DE LOS BISFOSFONATOS EN OSTEOBLASTOS}

A pesar de muchos estudios, los efectos directos de los BPs sobre los osteoblastos in vivo han sido difíciles de apreciar en concentraciones clínicamente relevantes. Aunque se ha demostrado que muy bajas concentraciones de los BPs estimulan la proliferación y maduración de los osteoblastos in vitro [Rogers, 2003; Im et al, 2004], la mayoría de los efectos clínicos sobre la función osteoblástica (por ejemplo, la supresión de los marcadores bioquímicos osteoblásticos) puede atribuirse a los efectos indirectos sobre el ciclo de remodelación mediada por la reducción de la resorción ósea. Los BPs ejercen fuertes efectos inhibitorios sobre las células del linaje osteoblástico a concentraciones altas similares a las que causan la inhibición de los osteoclastos [Idris et al, 2008]

\section{I.3.5- USOS CLÍNICOS Y EFECTOS DE LOS BPs EN HUMANOS}

Los BPs han sido ampliamente utilizados para el tratamiento de la enfermedad de Paget y en oncología, así como para el tratamiento y la prevención de la osteoporosis. Su uso en estas diversas condiciones clínicas en las que aumenta la resorción ósea por diversos procesos patológicos proporciona una base para la comprensión de su farmacología clínica general. 


\section{I.3.5.1-La enfermedad de Paget}

Varios de los BPs se han utilizado para el tratamiento de la enfermedad de Paget. El orden de potencia basado en la dosis de los BPs utilizados para suprimir el recambio óseo excesivo en la enfermedad de Paget parece ser similar a su orden de potencia antirresortivo observado en animales: etidronato $<<$ clodronato, pamidronato $<$ alendronato $<<$ risedronato zoledronato [Fleisch H, 2000; Green y Rogers, 2002].

\section{I.3.5.2-Oncología ósea}

Los bisfosfonatos son muy eficaces en el tratamiento de problemas óseos asociados con malignidad, incluyendo la hipercalcemia y/o aumento de la destrucción del hueso, y acctualmente son los fármacos de elección [Ross et al, 2004]. Se utilizan varios BPs para reducir la incidencia de eventos relacionados con el esqueleto, en mieloma [Sirohi y Powles, 2004], metástasis del cáncer de mama [Coleman, 2005], el cáncer de próstata metastásico [Parker, 2005], cáncer de pulmón, el carcinoma de células renales y otros tumores sólidos. El Zoledronato, el Clodronato, el Ibandronato y el Pamidronato son las drogas aprobadas para uso clínico. El orden de las potencias relativas de los BPs utilizados en oncología, en general es consistente con las potencias antirresortivas observadas en estudios experimentales y otras enfermedades.

\section{I.3.5.3-Osteoporosis}

La osteoporosis es la más reciente de las indicaciones clínicas para el uso de los BPs, y el principal uso oral de los BPs es el tratamiento de esta enfermedad. El Etidronato fue el primer BP aprobado para el tratamiento de la osteoporosis [Watts et al, 1990; Storm et al, 1990], seguido del Alendronato [Liberman et al, 1995; Black et al, 1996; Bone et al, 2004],

Risedronato [McClung et al, 2001], y el Ibandronato [Chesnut et al, 2004], y más recientemente Zoledronato [Black et al, 2007]. Éstos BPs aumentan la masa ósea y reducen el riesgo de fractura en la espina dorsal por un 30-70\%, y también en diversos grados en otras zonas esqueléticas en las mujeres postmenopáusicas [Boonen et al, 2005]. También hay estudios de eficacia para el Clodronato [McCloskey et al, 2004; McCloskey et al, 2007] y Pamidronato [Brumsen et al, 2002] en pacientes con osteoporosis, que son dos BPs adicionales aprobados para el tratamiento de la osteoporosis en algunos países. 


\section{I.3.6- BISFOSFONATOS DE USO MÁS FRECUENTE}

\section{I.3.6.1-Alendronato (Ale)}

El Ale es un aminobisfosfonato cuyo principio activo es el 4-amino-1hidroxibutilideno-1,1-bisfosfonato. El Ale se localiza preferentemente en las zonas de resorción ósea activa mediada por osteoclastos, denominadas "lagunas de resorción".

El Ale no se metaboliza en los animales ni en el hombre. Tanto en uno como en otro, la eliminación tiene lugar por excreción renal. La vida media de eliminación terminal es de aproximadamente un año en la rata, de tres año en el perro y más de 10 años en la mujer osteoporótica. Los estudios in vitro sobre la unión del Ale indican que aproximadamente un $78 \%$ se une a las proteínas plasmáticas en el hombre, a concentraciones clínicamente importantes, sobre todo a la albúmina. Puesto que la capacidad de unión es muy grande y la saturación porcentual por Ale, muy baja, Ale no debe producir desplazamientos detectables de otros fármacos que se unan a los mismos lugares.

A los 3-6 meses del inicio del tratamiento con Ale a $10 \mathrm{mg} /$ día los marcadores bioquímicos de la remodelación ósea disminuyen a valores próximos a la media para las mujeres postmenopaúsicas [Bone et al, 2000]. En diversos estudios se ha encontrado incrementos de la densidad ósea en columna vertebral del 8\% y en cadera del 7\% en un plazo de 3 años y aumentos algo menores con $5 \mathrm{mg} /$ día [Liberman et al, 1995]. El seguimiento a largo plazo demuestra que los valores de la DMO de la columna vertebral siguen aumentando durante al menos 7 años y que la DMO de otras localizaciones se mantiene así como los valores bioquímicos de recambio óseo dentro del rango normal para las mujeres premenopaúsicas [Tonino et al, 2000].

\section{I.3.6.2-Etidronato}

El etidronato es un bisfosfonato no nitrogenado. Los estudios de que disponemos sobre él han incluido un número pequeño de mujeres, por lo que no se pueden extraer de ellos conclusiones claras. Un metaanálisis ha señalado que es eficaz en la reducción de las fracturas vertebrales pero no en las no vertebrales [Cranney et al, 2001].

\section{I.3.6.3-Risedronato}

El risedronato es también un aminobisfosfonato ampliamente estudiado. Su eficacia en las fracturas vertebrales se comprobó en los ensayos VERT norteamericano [Harris et al, 1999] y VERT multinacional [Reginster et al, 2000], y la eficacia en la fractura no vertebral, en el VERT norteamericano. La eficacia sobre la fractura de cadera se comprobó en el estudio HIPSG [McClung et al, 2001]. 


\section{I.3.6.4-Ibandronato}

Es un aminobisfosfonato del cual se dispone de un único estudio de eficacia frente a fracturas (BONE) [Chesnut III et al, 2004]. Ha quedado demostrada su eficacia frente a la fractura vertebral, pero no frente a la no vertebral. Un análisis post hoc en mujeres con DMO en cadera inferior a $-3 \mathrm{~T}$ mostró una reducción en la incidencia de fracturas no vertebrales del $69 \%$.

\section{I.3.6.5-Zolendronato}

Este bisfosfonato de reciente introducción se administra en una dosis única anual [Black et al, 2007]. Así se asegura la adherencia al tratamiento, pero se plantea el interrogante de cuánto va a poder usarse ya que se administra vía intravenosa y puede producir un síndrome pseudogripal y presenta mayor riesgo de fibrilación auricular. Ha demostrado su eficacia en fracturas vertebrales y en fracturas de cadera. 


\section{I.4-DIABETES MELLITUS}

\section{I.4.1- DEFINICIÓN DE LA ENFERMEDAD}

La Diabetes mellitus es un grupo de enfermedades metabólicas caracterizada por la hiperglicemia resultante de defectos en la secreción de la insulina, de la acción de la insulina o de ambos. [Report of the Expert Committee, 2003]

La hiperglicemia crónica de la diabetes esta asociada con el deterioro de varios organos y daño a largo plazo, especialmente de ojos, riñones, nervios, corazón y vasos sanguíneos

Diversos procesos patogénicos están involucrados en el desarrollo de la diabetes, éstos abarcan desde la destrucción autoinmune de células $\beta$ del páncreas (con la consecuente deficiencia de insulina) hasta anormalidades en el metabolismos de azúcares, grasas y proteínas, resultantes de la resistencia a la acción de la insulina en sus órganos blanco. Los síntomas de una marcada hiperglicemia incluyen poliuria, polidipsia, alteraciones del peso corporal, y a veces polifagia y visión borrosa. Las complicaciones a largo plazo de la diabetes incluyen la retinopatía con pérdida potencial de la visión, nefropatía que conduce a la insuficiencia renal, neuropatía periférica con riesgo de úlceras en los pies, amputaciones, etc. La glicación de las proteínas y otras macromoléculas tisulares y el exceso de producción de compuestos de poliol a partir de la glucosa, se encuentran entre los posibles mecanismos por los cuales la hiperglucemia crónica produce daño en los tejidos. Los pacientes con diabetes tienen una mayor incidencia de aterosclerosis arterial cardiovascular, periférica y enfermedad cerebrovascular. Otras afecciones que se encuentran en pacientes con diabetes son hipertensión arterial y alteraciones del metabolismo de las lipoproteínas.

La gran mayoría de los casos de diabetes caen en dos grandes categorías etiopatogénicas (discutido en mayor detalle más abajo). En la primera categoría, la diabetes tipo 1, la causa es una deficiencia absoluta de secreción de insulina. Los individuos con mayor riesgo de desarrollar este tipo de diabetes a menudo pueden ser identificados mediante evidencia serológica de un proceso patológico autoinmune que ocurre en los islotes pancreáticos, y por marcadores genéticos. En la otra categoría, mucho más frecuente, la diabetes tipo 2, la causa es una combinación de resistencia a la acción de la insulina y una respuesta compensatoria inadecuada en la secreción de insulina. En esta última categoría, un grado de hiperglucemia suficiente para causar cambios patológicos y funcionales en los distintos tejidos diana, pero sin síntomas clínicos, puede estar presente durante un largo 
período de tiempo antes de que se detecte la diabetes. Durante este período asintomático, es posible demostrar una alteración en el metabolismo de carbohidratos por determinación de la glucosa plasmática en ayunas o después de un desafío con una carga oral de glucosa.

El grado de hiperglucemia puede cambiar con el tiempo, dependiendo de la extensión de la enfermedad subyacente. En algunas personas con diabetes, el control glucémico adecuado se puede lograr con la reducción de peso, el ejercicio y / o antidiabéticos orales. Estas personas por lo tanto no requieren insulina. Otros individuos que tienen alguna secreción de insulina residual, no requieren de insulina exógena para el control glucémico adecuado. Las personas con amplia destrucción $\beta$-celular y por lo tanto sin la secreción de insulina residual, requieren insulina para sobrevivir. Así, el grado de hiperglucemia refleja la severidad del proceso metabólico subyacente y su tratamiento, más que la naturaleza del propio proceso.

\section{I.4.2-CLASIFICACIÓN}

La Asociación Americana de Diabetes (ADA: American Diabetes Association) clasificó a la Diabetes Mellitus en cuatro tipos: I-Diabetes Tipo 1; II-Diabetes Tipo 2; IIIOtros Tipos; y IV-Diabetes gestacional. Dicha clasificación se presenta esquematizada en la Tabla I.4.2. [Diagnosis and Classification of Diabetes Mellitus, 2008].

\section{I.4.2.1- Diabetes tipo 1}

Se manifiesta como consecuencia de la destrucción de las células $\beta$. Por lo general conduce a la deficiencia absoluta de insulina. Dentro de esta se incluyen:

a-Diabetes inmunomediada. Ésta forma de diabetes, anteriormente comprendida en los términos de diabetes insulino-dependiente, diabetes tipo 1 o diabetes juvenil, resulta de una destrucción celular autoinmune de las células $\beta$ del páncreas. Los marcadores de la destrucción inmune de las células $\beta$ son: los autoanticuerpos para células de los islotes (ICAs), los autoanticuerpos para insulina (IAAs), los autoanticuerpos para la ácido glutámico decarboxilasa $\left(\mathrm{GAD}_{65}\right)$, y los autoanticuerpos para la tirosina fosfatasa IA-2 y IA-2 $\beta$. Por lo menos uno de estos anticuerpos están presentes en el 85 a 90\% de los individuos cuando se les detecta hiperglucemia en ayunas. Además, la enfermedad esta fuertemente asociada a HLA, con vinculación a los genes DQA y DQB, y está influenciado por los genes DRB. Estos alelos HLA-DR/DQ pueden ser predisponentes o de protección. La destrucción 
Tabla I.4.2-Clasificación etiológica de la Diabetes Mellitus.

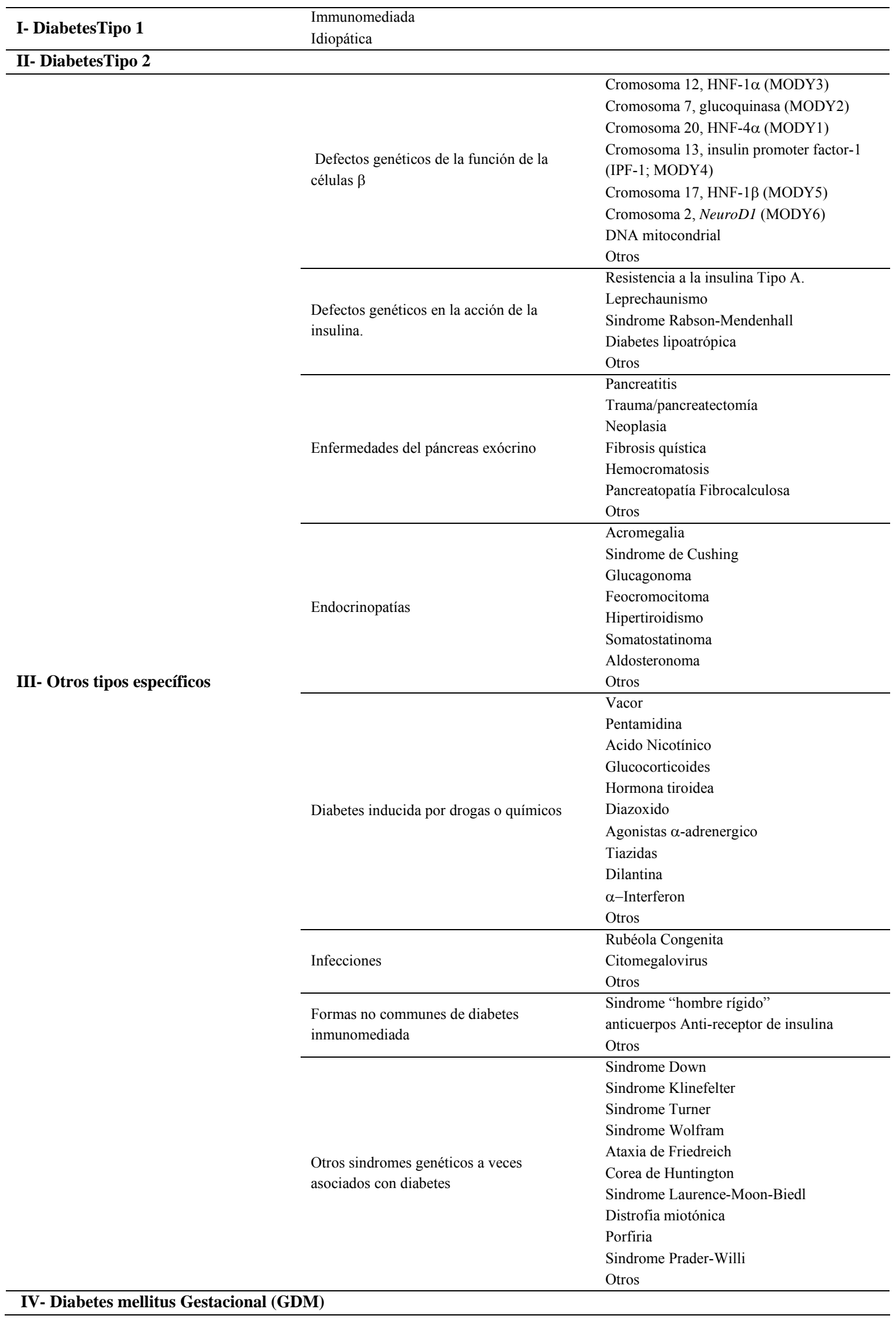


autoinmune de las células $\beta$ tiene múltiples predisponentes genéticas y también está relacionada con factores ambientales que aún están mal definidos. Estos pacientes también son propensos a otros trastornos autoinmunes como la enfermedad de Graves, tiroiditis de Hashimoto, la enfermedad de Addison, vitíligo y. anemia perniciosa.

b-Diabetes idiopática. Algunas formas de diabetes tipo 1 no tienen etiología conocida. Algunos de estos pacientes tienen insulinopenia permanente y son propensos a la cetoacidosis, pero no poseen evidencia de autoinmunidad. Aunque sólo una minoría de los pacientes con diabetes tipo 1 entran en esta categoría, la mayoría de estos son de origen africano o asiático. Esta forma de diabetes es fuertemente heredada, carece de pruebas inmunológicas de autoinmunidad para células $\beta$ y no esta asociada al HLA.

\section{I.4.2.2- Diabetes tipo 2}

Este tipo de diabetes abarca desde una resistencia a la insulina (mayormente) con deficiencia relativa de insulina, a un defecto de secreción de insulina con resistencia a la insulina.

Esta forma de diabetes, que representa el 90-95\% de las personas con diabetes, anteriormente conocida como diabetes insulino-independiente, diabetes tipo II, o diabetes del adulto, comprende los individuos que tienen resistencia a la insulina y por lo general tienen relativa (no absoluta) deficiencia de insulina. Al menos inicialmente, y con frecuencia durante toda su vida, estas personas no necesitan tratamiento con insulina para regular la hiperglucemia. Hay probablemente muchas causas diferentes de esta forma de diabetes. La mayoría de los pacientes con esta forma de diabetes son obesos y la obesidad en sí causa un cierto grado de resistencia a la insulina. Los pacientes que no son obesos, según los criterios de peso tradicionales, pueden tener un mayor porcentaje de grasa corporal distribuidos principalmente en la región abdominal. Esta forma de diabetes no se diagnostica a menudo durante muchos años porque la hiperglucemia se desarrolla gradualmente y a menudo en su fase inicial, no es lo suficientemente grave como para que el paciente note cualquiera de los síntomas clásicos de la diabetes. Sin embargo, estos pacientes tienen un mayor riesgo de desarrollar complicaciones macrovasculares y microvasculares. Por lo tanto, en estos pacientes la secreción de insulina es defectuosa e insuficiente para compensar la resistencia a la insulina. La resistencia a la insulina puede mejorar con la reducción de peso y / o el tratamiento farmacológico de la hiperglucemia. El riesgo de desarrollar esta forma de diabetes aumenta con la edad, la obesidad y la falta de actividad física. Ocurre más frecuentemente en 
mujeres con DM Gestacional previa y en individuos con hipertensión o dislipemia, y su frecuencia varía en diferentes subgrupos étnicos / raciales. A menudo se asocia con una fuerte predisposición genética, más que la forma autoinmune de la diabetes tipo 1. Sin embargo, la genética de esta forma de diabetes es compleja y aun no está claramente definida.

\section{I.4.2.3-Otros tipos específicos de diabetes}

Dentro de este grupo se encuentran inlcuidas las siguientes:

a-Defectos genéticos de las células $\beta$. Varias formas de diabetes se asocian con defectos monogenéticos en la función de las células beta. Se conocen como la diabetes tipo juvenil de desarrollo en la madurez (MODY) y se caracterizan por la alteración de la secreción de insulina, sin defecto o con mínima modificación de la acción de la insulina. La más común es la mutación en el factor de transcripción hepático denominado factor nuclear de hepatocitos HNF-1 $\alpha$. Las menos frecuentes son las mutaciones en HNF-4 $\alpha$, HNF-1 $\beta$, factor promotor de la insulina (IPF)-1, y el Neuro D1. También se han encontrado asociadas con la diabetes mellitus mutaciones puntuales en el ADN mitocondrial.

b-Los defectos genéticos en la acción de la insulina. Las anormalidades metabólicas asociadas con mutaciones del receptor de la insulina pueden variar desde la hiperinsulinemia y la hiperglucemia modesta a la diabetes grave. En el pasado, este síndrome se denominó tipo A resistencia a la insulina. El Leprechaunismo y el Síndrome de Rabson Mendenhall son dos síndromes pediátricos que tienen mutaciones en el gen receptor de la insulina.

c-Enfermedades del páncreas exócrino. Cualquier proceso que dañe de forma difusa el páncreas puede causar diabetes. Los procesos adquiridos incluyen pancreatitis, trauma, infección, pancreatectomía y carcinoma pancreático

d-Endocrinopatías. Varias hormonas (por ejemplo, hormona de crecimiento, el cortisol, el glucagón, la epinefrina) antagonizan la acción de la insulina. Cantidades excesivas de estas hormonas (por ejemplo, la acromegalia, síndrome de Cushing, glucagonoma, feocromocitoma, respectivamente) puede causar diabetes.

e-Diabetes inducida por drogas o químicos. Existen algunos medicamentos que no causan la diabetes por sí mismos, pero pueden desencadenar la diabetes en los individuos con resistencia a la insulina. Determinadas toxinas, como Vacor (un veneno para ratas) y la pentamidina intravenosa pueden destruir las células beta del páncreas. 
También hay muchos fármacos (el ácido nicotínico) y hormonas (los glucocorticoides) que pueden alterar la acción de la insulina.

f-Infecciones. Ciertos virus se han asociado con la destrucción de las células $\beta$. La diabetes ocurre en pacientes con rubéola congénita, aunque la mayoría de estos pacientes tienen HLA y marcadores inmunes característicos de la diabetes tipo 1 . Además, el virus Coxsackie B, citomegalovirus, adenovirus, y la parotiditis han sido implicados en la inducción de ciertos casos de la enfermedad.

g-Formas poco frecuentes de la diabetes mediada por inmunidad. El síndrome del hombre rigido es una enfermedad autoinmune del sistema nervioso central. Los pacientes suelen tener altos títulos de los autoanticuerpos GAD y aproximadamente un tercio desarrollará diabetes. Los anticuerpos anti-receptor de la insulina puede causar diabetes mediante la unión al receptor de la insulina, bloqueando así la unión de la insulina a su receptor en los tejidos diana. Sin embargo, en algunos casos, estos anticuerpos pueden actuar como un agonista de la insulina después de la unión al receptor y por ello puede causar hipoglucemia. En el pasado, este síndrome se habia denominado resistencia a la insulina tipo B.

h-Otros síndromes genéticos a veces asociados con la diabetes. Muchos síndromes genéticos van acompañados de un aumento en la incidencia de la diabetes mellitus. La lista de síndromes aparece en la tabla I.4.2.

\section{I.4.2.4-La diabetes mellitus gestacional (DMG)}

DMG se define como cualquier grado de intolerancia a la glucosa con inicio o primer reconocimiento durante el embarazo (en particular en el 3er trimestre del embarazo). La definición se aplica independientemente de si se utiliza insulina o solo modificación de la dieta como tratamiento o si la condición persiste después del embarazo. Luego de seis semanas o más de terminado el embarazo, la mujer debe ser reclasificada, en una de las siguientes categorías: 1) diabetes, 2) IFG (glucosa alterada en ayunas), 3) IGT (prueba de tolerancia a la glucosa alterada) o 4) normoglucemia. En la mayoría de los casos de GDM, la regulación de la glucosa volverá a la normalidad después del parto. 


\section{I.4.3-FISIOPATOGÉNESIS DE LA DIABETES MELLITUS}

En los '90 se realizaron dos estudios que mostraron la importancia del control de la hiperglucemia en la diabetes melitus tipo 1 y tipo 2. En el DCCT (Estudio de Control y Complicaciones de la Diabetes) [DCCT, 1993] se estudiaron pacientes diabéticos de tipo 1 y se observó que el grupo que llevaban un control intensivo de la glucemia presentó una reducción tanto en la aparición de microangiopatías como en la progresión de las mismas, una vez establecidas. En el UKPDS (Estudio Prospectivo de Diabetes en Reino Unido) [1998] se estudiaron a personas con diabetes tipo 2 con un control intensivo de la hiperglucemia contra un control convencional. Además en este estudio se estudió diferenciadamente a las personas que presentaban hipertensión arterial. Se observó que el tratamiento intensivo de la hipertensión se asoció a una reducción en la presencia de microangiopatías y de macroangiopatías relacionadas a la diabetes. Por lo tanto, este estudio demostró la importancia del control de la hiperglucemia, asícomo de los factores de riesgo cardiovascular, para prevenir las complicaciones micro y macrovasculares.

Como vimos la hiperglucemia es la causa del daño tisular que presentan las personas diabéticas. El daño es sobre un grupo de células, las células endoteliales capilares de la retina, las células mesangiales en el glomérulo renal, las neuronas y células de Schwann en los nervios periféricos [Brownlee, 2001]. En la diabetes, la hiperglucemia baña a todas las células de cada tejido, pero afecta solo a un grupo. Esto responde a que la mayoría de las células son capaces de reducir el transporte de glucosa dentro de la célula cuando se exponen a la hiperglucemia, por lo que su concentración de glucosa interna se mantiene constante. Por el contrario, las células dañadas por la hiperglucemia son aquellas que no pueden hacer esto de manera eficiente. Los mecanismos responsables de los efectos nocivos de la hiperglucemia en el tejido son los siguientes: [Brownlee, 2005].

El primer mecanismo que se descubrió fue el aumento de flujo de la vía de los polioles descrito en los nervios periféricos en 1966. Luego a finales de 1970 surgieron los productos finales de glicación avanzada (AGEs). A finales de 1980 y principios de 1990, se descubrió la activación de la isoformas de la proteína quinasa $\mathrm{C}(\mathrm{PKC})$ inducida por la hiperglucemia. $\mathrm{Y}$ a finales de 1990 se descubrió un flujo aumentado de la vía de las hexosaminas y la consiguiente modificación de proteínas por la $\mathrm{N}$-acetilglucosamina. 


\section{I.4.3.1-El aumento de flujo a través de la vía de los polioles.}

La vía de los polioles, se centra en la enzima aldosa reductasa, la cual normalmente tiene la función de la reducción de aldehídos tóxicos a alcoholes inactivos, pero cuando la concentración de glucosa en la célula se vuelve demasiado alta, la aldosa reductasa también reduce la glucosa a sorbitol, que posteriormente se oxida a fructosa. En el proceso de reducción intracelular de glucosa en sorbitol, la aldosa reductasa consume el cofactor NADPH.

Sin embargo, como se muestra en la Figura. I.4.3.1, el NADPH también es el cofactor esencial para la regeneración de un antioxidante intracelular crítico, el glutatión reducido. Así la vía del poliol, al disminuir la cantidad de glutatión reducido, aumenta la susceptibilidad al estrés oxidativo intracelular [Brownlee, 2001].

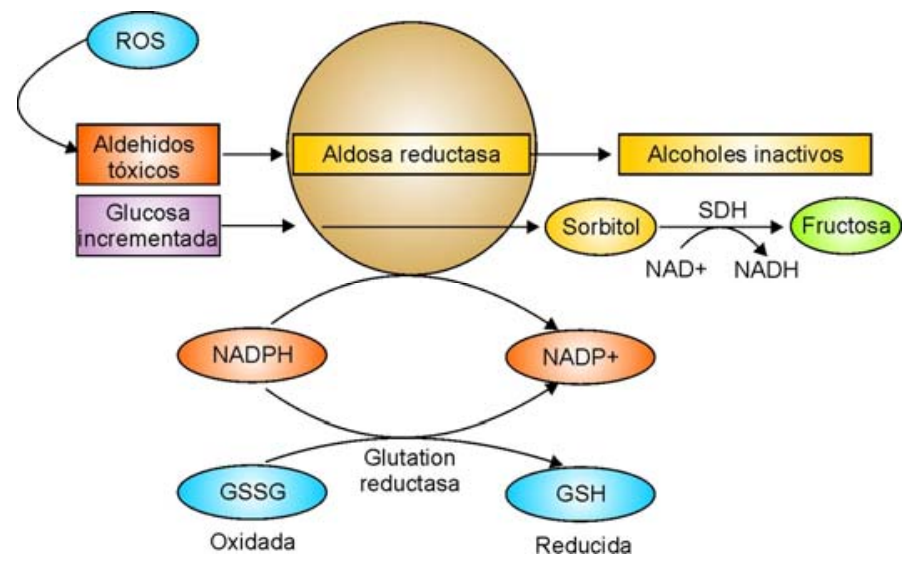

Figura I.4.3.1- Esquema del aumento de flujo a través de la vía de los polioles. [Brownlee, 2001].

\section{I.4.3.2-Producción intracelular de precursores AGE}

La producción intracelular de los precursores de AGEs (Advanced Glycation End Products) parece dañar las células mediante tres mecanismos (Figura I.4.3.2). El primer mecanismo es la modificación de las proteínas intracelulares, en particular, de las proteínas implicadas en la regulación de la transcripción génica. En el segundo mecanismo, los precursores AGE pueden difundir fuera de la célula y modificar moléculas de la matriz extracelular, cambiando de esta manera la señalización entre la matriz y la célula provocando una disfunción celular. El tercer mecanismo involucra la modificación de las proteínas circulantes en la sangre, tales como la albúmina, por acción de precursores AGE que difunden fuera de la célula. Estas proteínas circulantes modificadas pueden unirse a los receptores de 
AGE y activarlos, lo que ocasiona la producción de citoquinas inflamatorias y factores de crecimiento, que a su vez originan la patología vascular [Brownlee, 2001].

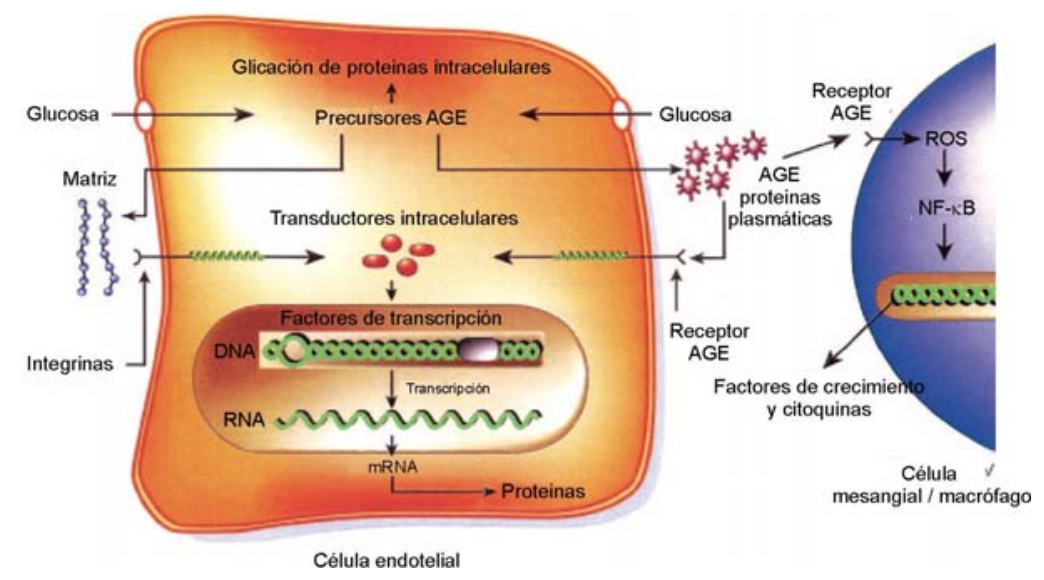

Figura I.4.3.2- Esquema del incremento intracelular de precursores AGE y sus consecuencias. [Brownlee, 2001]

\section{I.4.3.3-Activación de la PKC}

En esta vía, la hiperglicemia dentro de la célula aumenta la síntesis de una molécula llamada diacilglicerol, que es un cofactor esencial para la activación de las isoformas clásicas de la proteína quinasa $-\mathrm{C},-\beta,-\delta \mathrm{y}-\alpha$. Cuando se activa la $\mathrm{PKC}$ por la hiperglucemia intracelular, existe una variedad de efectos sobre la expresión genética (Figura I.4.3.3). Por ejemplo, disminuye la producción de la sintasa de óxido nítrico endotelial (eNOS) y por lo tanto de NO (vasodilatador), mientras que se incrementa la endotelina-1 (vasoconstrictor). También se incrementan el factor de crecimiento transformante- $\beta$ (TGF- $\beta$ ) y el inhibidor del activador del plasminógeno-1 (PAI-1) que contribuyen también a la oclusión vascular.

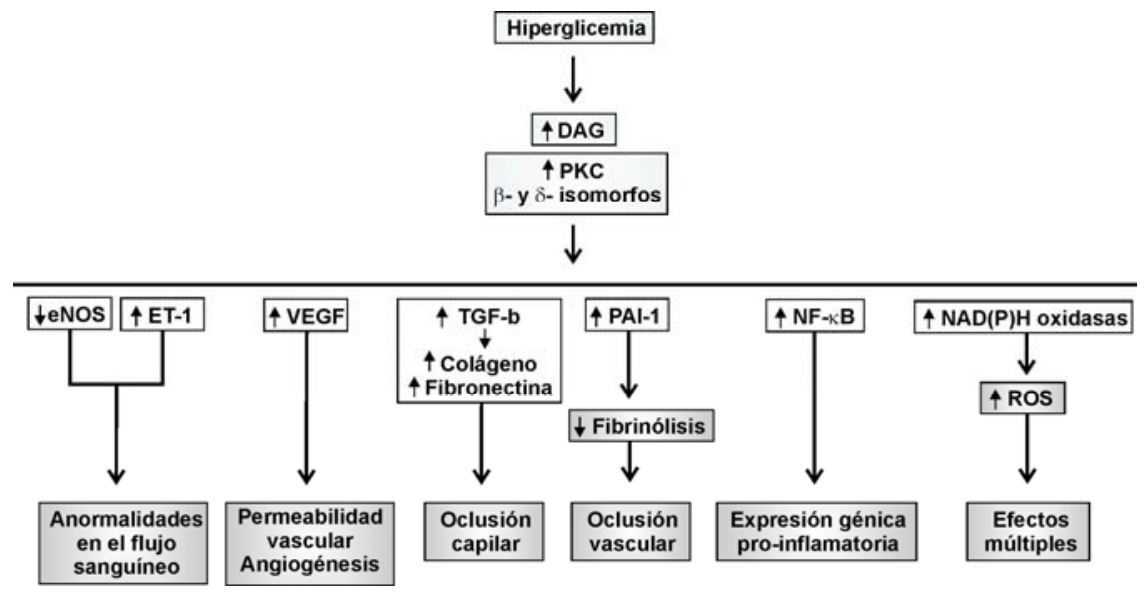

Figura I.4.3.3- Consecuencias de la activación de la PKC inducida por la hiperglucemia [Brownlee, 2001]. 


\section{I.4.3.4-Aumento de la actividad en la vía de las hexosaminas}

Cuando la concentración de glucosa es alta dentro de una celula, la mayor parte de la glucosa se metaboliza a través de la glucólisis, pasa a glucosa- 6 fosfato, a continuación a fructosa-6-fosfato, y luego por el resto de la vía glucolítica. Sin embargo, algunas moléculas de fructosa-6-fosfato se desvían hacia una vía de señalización en la que una enzima llamada GFAT (glutamina: fructosa-6-fosfato amidotransferasa) convierte la fructosa-6-fosfato a glucosamina-6-fosfato y finalmente a UDP (uridina difosfato) N-acetil glucosamina. Luego estos compuestos se adicionan a los residuos de serina y treonina de algunos factores de transcripción (de la misma forma que el proceso de fosforilación). Esta modificación con glucosamina, a menudo da lugar a cambios patológicos en la expresión génica. Por ejemplo, en la Figura I.4.3.4, el aumento de la modificación del factor de transcripción Sp1 resulta en incremento en la expresión del factor de crecimiento transformante- $\beta_{1}$ y del activador del inhibidor de plasminógeno 1 , los cuales son perjudiciales para los vasos sanguíneos diabéticos

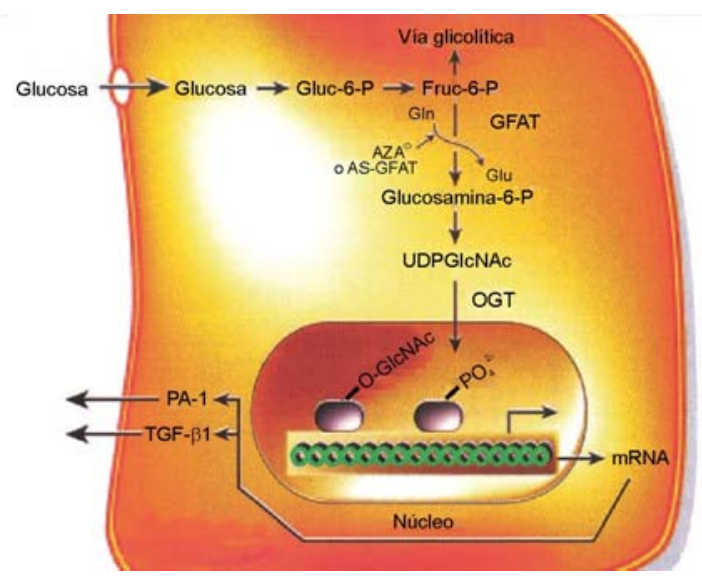

Figura I.4.3.4- Hiperglicemia incrementa el flujo a través de la vía de la hexosamina. [Brownlee, 2001]

\section{I.4.3.5-El mecanismo unificador}

Buscando un mecanismo unificador que explique la patogénesis de la enfermedad microvascular diabética se encontro un denominador común entre todos los tipos de células que son dañadas por la hiperglucemia: un aumento de la producción de especies reactivas del oxígeno (ROS) [Brownlee, 2005]. 


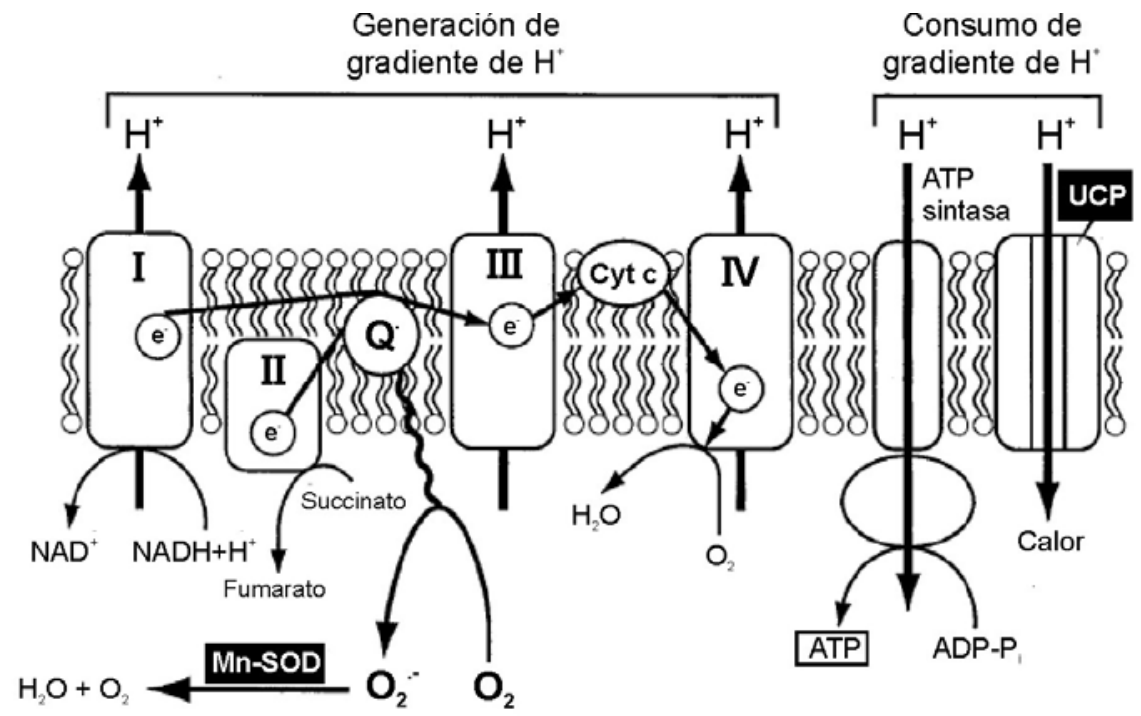

Figura I.4.3.5- Producción de superóxido inducida por hiperglicemia mediante la cadena de transporte electrónico mitocondrial [Brownlee, 2001].

Hay cuatro complejos I, II, III y IV en la cadena de transporte electrónico mitocondrial. Cuando la glucosa se metaboliza a través del ciclo del ácido tricarboxílico (TCA), genera donadores de e-, el NADH (que dona los e- al complejo I) y el $\mathrm{FADH}_{2}$, formado por la succinato deshidrogenasa,(que dona e- al complejo II). Los electrones (e $\mathrm{e}^{-}$) de estos dos complejos se pasan a la coenzima Q, y luego se transfieren al complejo III, citocromo-C, el complejo IV, y finalmente al $\mathrm{O}_{2}$, que se reduce a $\mathrm{H}_{2} \mathrm{O}$. Parte de la energía de los electrones se utiliza para bombear $\mathrm{H}^{+}$a través de la membrana en los complejos I, III y IV.La energía de este gradiente de potencial a traves de la mb mitocondrial impulsa la síntesis de ATP por la ATP sintasa. Por otra parte, las proteínas desacoplantes (UCPs) pueden disminuir gradiente de potencial para generar calor como una forma de mantener la tasa de generación de ATP constante.

En las células diabéticas con alto nivel de glucosa en su interior, hay más glucosa que se oxida en el ciclo del ATC, que en realidad empuja a más donantes de electrones (NADH y FADH2) en la cadena de transporte electrónico. Como resultado, el gradiente de potencial a través de la membrana mitocondrial aumenta hasta llegar hasta un umbral. En este punto, la transferencia de electrones en el interior del complejo III está bloqueada, haciendo que los electrones se acumulen en la coenzima $\mathrm{Q}$, que dona los electrones uno a la vez al oxígeno molecular, lo que genera superóxido (Figura I.4.3.5). La isoforma mitocondrial de la enzima superóxido dismutasa degrada este radical libre del oxígeno a peróxido de hidrógeno, que luego se convierte en $\mathrm{H}_{2} \mathrm{O}$ y $\mathrm{O}_{2}$ por otras enzimas.

\section{I.4.3.6-La producción de superóxido mitocondrial inducida por la hiperglucemia} activa las cuatro vías de daño por la inhibición de GAPDH.

La figura I.4.3.6.1 muestra el esquema que se propuso para unir todas las vias. Este modelo se basa en el hecho de que la diabetes en animales y pacientes, y la hiperglucemia en 
las células, todas disminuyen la actividad de una enzima glucolítica clave: la gliceraldehído 3fosfato deshidrogenasa (GAPDH). Cuando se inhibe la actividad de GAPDH, se incrementa el nivel de todos los intermediarios glucolíticos que se encuentran en fases previas. Los niveles crecientes del metabolito glucolítico gliceraldehído-3-fosfato activan aguas arriba dos de las cuatro vías. Se activa la vía de los AGEs, dado que el metilglioxal uno de los principales precursores AGE intracelular, que se forma a partir del gliceraldehído 3-fosfato. También activa la ruta PKC, ya que el activador de la PKC, el diacilglicerol, también se forma a partir de gliceraldehído-3 fosfato.

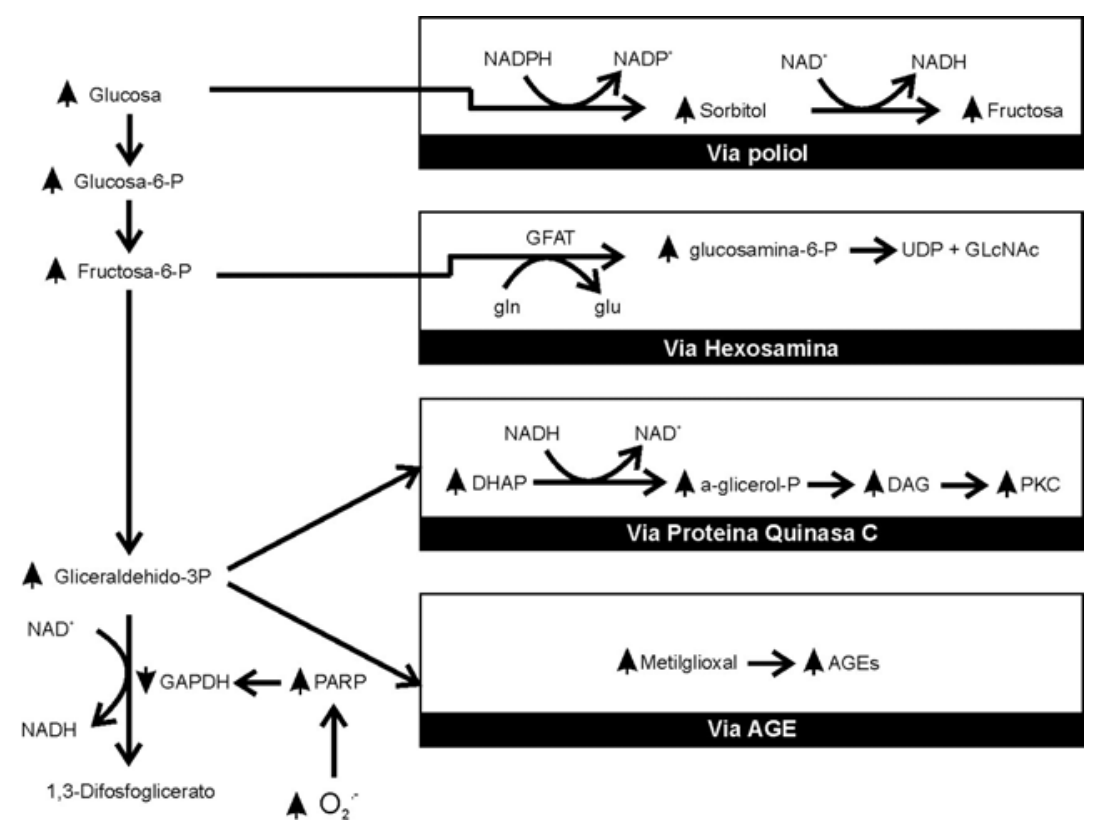

Figura I.4.3.6.1- La producción de superóxido mitocondrial inducida por la hiperglucemia activa las cuatro vías de daño por la inhibición de GAPDH [Brownlee, 2001].

Más arriba, los niveles fructosa-6-fosfato aumentan, lo que aumenta el flujo a través de la vía de las hexosamina, donde fructosa 6-fosfato se transforma en UDP-N acetilglucosamina (UDP-GlcNAc) por la enzima GFAT. Por último, la inhibición de GAPDH aumenta los niveles intracelulares de glucosa. Esto aumenta el flujo a través de la vía de los polioles, donde la enzima aldosa reductasa consume NADPH en el proceso.

La producción de superóxido mitocondrial inducida por la hiperglucemia inhibe la GAPDH in vivo, mediante la activación de poli-ADP ribosa polimerasa. (PARP).

La PARP, es una enzima reparadora de ADN que se encuentra exclusivamente en el núcleo, y GAPDH, una enzima glicolítica que residen en el citosol. Normalmente, PARP 
reside en el núcleo en forma inactiva, a la espera de daño en el ADN para activarse (Fig. I.4.3.6.2). Cuando el aumento de la glucosa intracelular genera aumento de ROS en la mitocondria, encontramos que estos radicales libres inducen roturas en las hebras de ADN, activando a la PARP. Una vez activada, PARP divide a la molécula de NAD en sus dos componentes: el ácido nicotínico y ADP-ribosa. PARP luego procede a hacer polímeros de ADP-ribosa, que se acumulan en GAPDH y otras proteínas nucleares. Aunque se suele pensar que la GAPDH reside exclusivamente en el citosol, normalmente se encuentra dentro y fuera del núcleo, donde desempeña un papel crítico en la reparación del ADN.

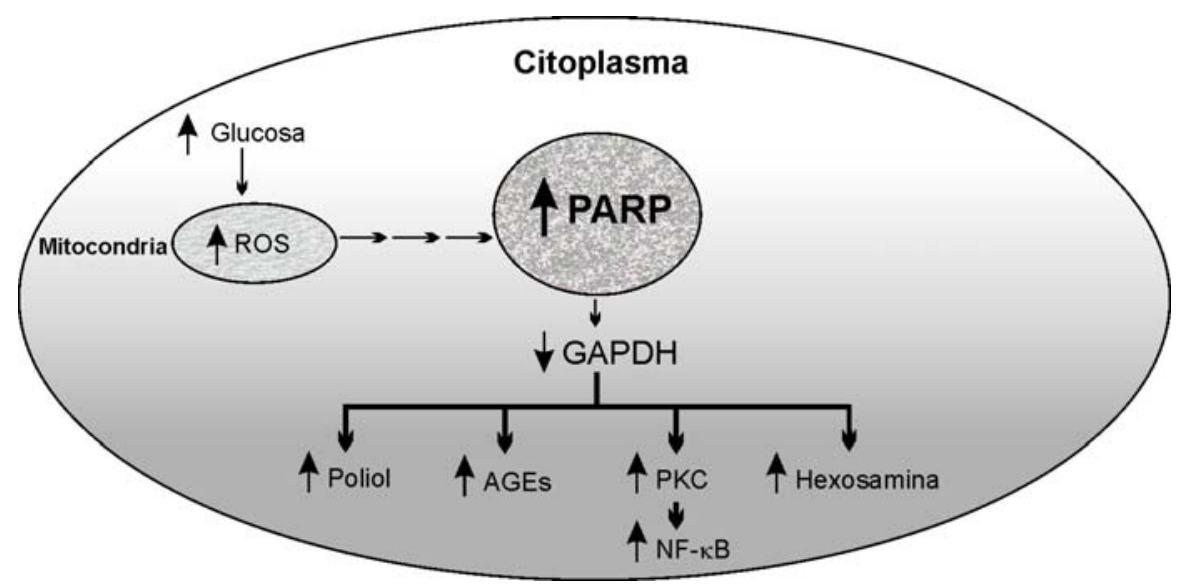

Figura I.4.3.6.2- Mecanismo unificador del daño celular causado por la hiperglicemia. La hiperglucemia intracelular en las células blanco de las complicaciones diabéticas, provoca aumento de la producción mitocondrial de ROS, lo que causa ruptura en las cadenas de ADN nuclear, que activan la PARP. La PARP a continuación, modifica GAPDH, lo que reduce su actividad. Por último, la disminución de la actividad GAPDH activa la vía de los polioles, aumenta la formación de AGE intracelular, activa la PKC y, posteriormente, $\mathrm{NF} \kappa \mathrm{B}$, y aumenta el flujo de la via de las hexosaminas [Brownlee, 2001].

\section{I.4.4-COMPLICACIONES CRONICAS DE LA DIABETES MELLITUS}

Las complicaciones vasculares de la diabetes mellitus son la principal causa de morbilidad y mortalidad en los países desarrollados y constituyen una creciente preocupación para las autoridades sanitarias de todo el mundo [Zimmet et al, 2001].

Las complicaciones crónicas más comunes en los pacientes con Diabetes mellitus son la enfermedad renal terminal (nefropatía diabética) y la enfermedad cardiovascular. Así, estas complicaciones son responsables del 50-80\% del total de los fallecimientos.

Tradicionalmente, la retinopatía, nefropatía y la neuropatía han sido denominadas complicaciones microvasculares o microangiopatías. Por otro lado, la aterosclerosis y sus secuelas: el infarto agudo de miocardio, el accidente cerebrovascular y el accidente vascular 
Introducción: Diabetes Mellitus

periférico con gangrena se conocen como complicaciones macrovasculares o macroangiopatías.

Existen también complicaciones mixtas, como el pie diabético y las alteraciones óseas y articulares, en las cuales se interrelacionan las disfunciones micro y macrovasculares, dando como resultado una patología de origen complejo. 


\section{I.5-PRODUCTOS DE GLICACIÓN AVANZADA (AGEs)}

\section{I.5.1-INTRODUCCIÓN}

Los productos finales de glicacion avanzada (AGEs) son una clase heterogénea de moléculas formadas a partir de reacciones aminocarbonilo de naturaleza no enzimática, que se producen a lo largo de la vida pero se incrementan en el estado de hiperglucemia de la diabetes. Considerados importantes mediadores patógenicos de las complicaciones diabéticas, los AGEs son capaces de modificar de manera irreversible las propiedades químicas y funcionales de las diversas estructuras biológicas. A través de la generación de radicales libres, la formación de enlaces cruzados con proteínas o interacciones con receptores celulares, los AGEs promueven, respectivamente, el estrés oxidativo, cambios morfofuncionales y aumento de la expresión de mediadores inflamatorios. La contribución de AGEs para el desarrollo y progresión de complicaciones de la diabetes está bien demostrado en la literatura [Barbosa et al, 2008; Jakus y Rietbrock, 2004; Ahmed, 2005].

\section{I.5.2-LA FORMACIÓN DE AGEs}

Los productos finales de glicación avanzada (AGEs) son una gran variedad de sustancias que se forman a partir de reacciones amino carbonilo de naturaleza no enzimática entre azúcares reductores (o lípidos oxidados) y proteínas, ácidos nucleicos o aminofosfolipidos [Barbosa et al, 2008]. Aunque algunos de los mecanismos que conducen a la formación de AGEs permanecen aún desconocidos, la química de estas complejas reacciones puede esquematizarse como se muestra en la Fig. I.5.2.1

La reacción de Maillard comienza con la reacción de un carbonilo (aldehído o cetona) de un azúcar reductor para formar una base de Schiff reversible con un grupo amino de una biomolécula, por ejemplo, el aminoácido lisina. La base de Schiff puede sufrir rearreglos intramoleculares para formar un producto de Amadori, el cual luego sufre una serie de rearreglos, deshidratación, y condensación para formar un producto final irreversible el cual puede ser fluorescente y de color marrón amarillento, algunos pueden formar entrecruzamientos estables inter e intramoleculares [Ulrich y Cerami, 2001]. Algunos ejemplos de los distintos tipos de AGEs lo podemos apreciar en la Fig. I.5.2.2. 


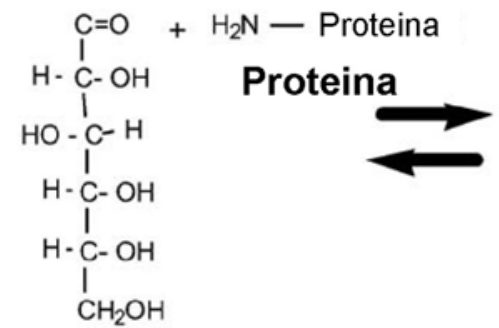

Glucosa

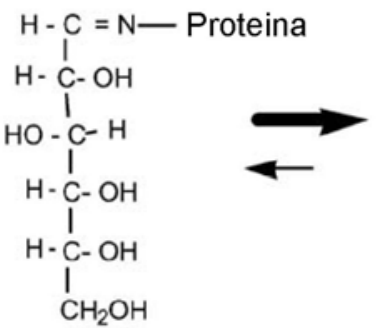

Base de Shiff

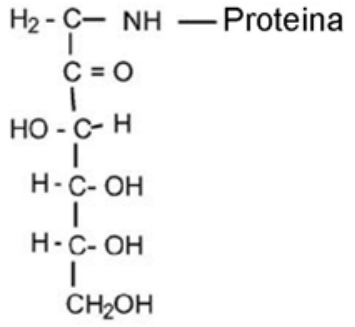

Producto de Amadori

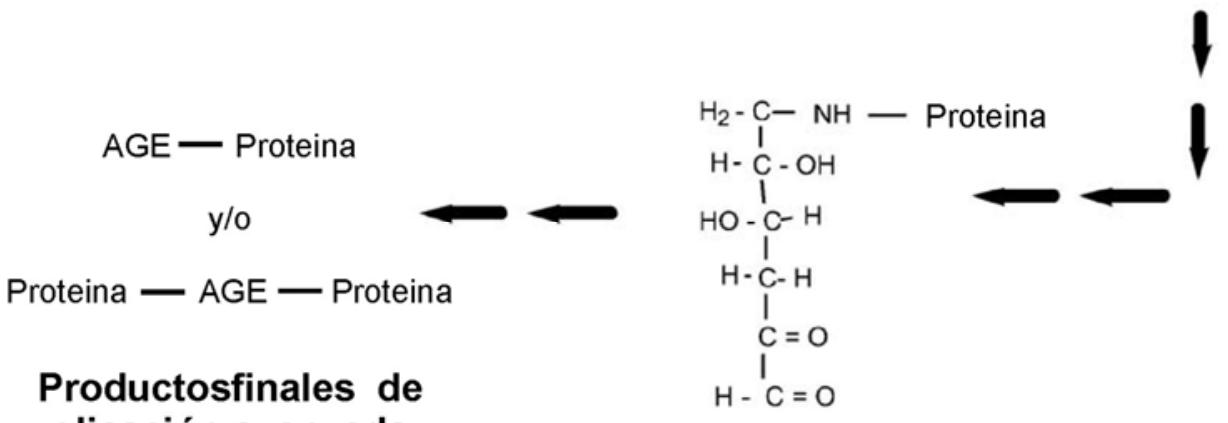
glicación avanzada (AGE)

\section{Intermediario dicarbonílico}

Fig. I.5.2.1 Ejemplo de la vía clásica de la glicosilación de proteínas por la glucosa que lleva a la formación de AGE a través de productos de Amadori.

La primera reacción entre la glucosa y grupo amino de una proteína forma una base de Schiff reversible la cual puede reorganizarse y dar un grupo fructosamina o producto de Amadori. Con el tiempo los productos de Amadori pueden formar AGE a través de intermediarios dicarbonilos, tales como la 1,4 deoxiglucosona unida a proteínas plasmáticas. [Peyroux y Sternberg, 2006]

Los mecanismos alternativos para la formación de AGEs incluyen la llamada via de estrés carbonilico, en la que la oxidación de los lípidos o azúcares genera a compuestos dicarbonílicos intermediarios altamente reactivos [Huebschmann et al, 2006]. La glucólisis y autooxidación de la glucosa, por ejemplo, producen metilglioxal y glioxal, que interactúan con los aminoácidos para formar AGEs. Estos compuestos dicarbonílicos llegan a ser 20.000 veces más reactivos que la glucosa y son los principales intermediarios de la formación de AGEs [Meade et al, 2003]. Los AGEs formados a partir de la oxidación de los azúcares o lípidos también se pueden llamar, respectivamente, productos de glicoxidación o lipoxidación avanzada. Debido a la complejidad y heterogeneidad de las reacciones que pueden ocurrir, pocos AGEs han sido claramente identificados, bien caracterizados y ampliamente estudiados, por ejemplo la carboximetilisina (CML), y los AGEs pirralina y pentosidina [Barbosa et al, 2008]. 
(A) AGEs entrecruzados fluorescentes:

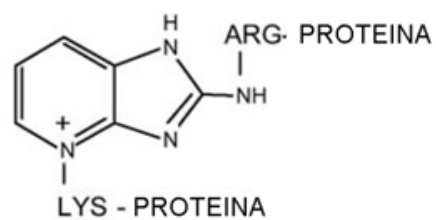

Pentosidina

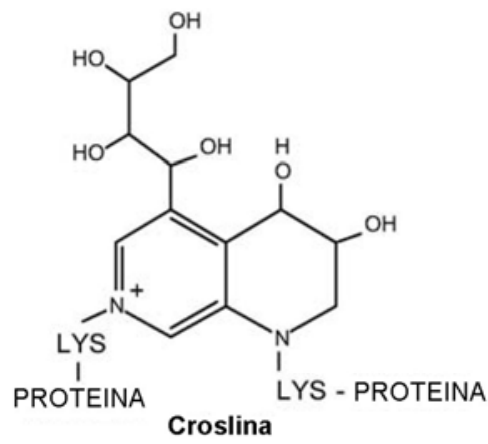

(B) AGEs entrecruzados no fluorescentes:

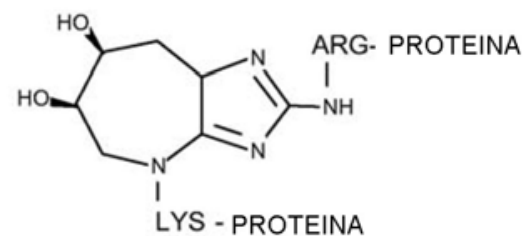

Glucosepan

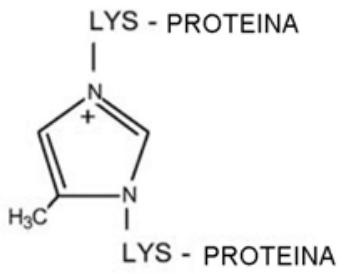

MOLD (dimero de metilglioxal lisina)

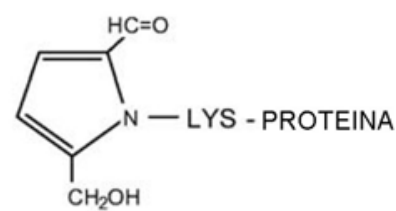

Pirralina

Fig. Fig. I.5.2.2 Estructuras químicas de los tres tipos de AGE:

(A) AGE entrecruzados fluorescentes como la pentosidina y crosslina, (B) AGE entrecruzados no fluorescentes como glucosepan y el MOLD, (metilglioxal lysine dimer) (C) AGE no entrecruzados como la CML y pirralina. [Peyroux y Sternberg, 2006]

In vivo, la cantidad de AGEs que se encuentran sobre una proteina depende de la reactividad inherente de sus grupos aminos y esta determinada por el microambiente, la concentración de glucosa, y la vida media de las proteínas [Wautier y Schmidt, 2004].

Inicialmente se creía que los AGEs se formaban principalmente a partir de las reacciones no enzimáticas entre la glucosa y las proteínas extracelulares. Sin embargo, debido a la mayor reactividad de los precursores dicarbonílicos derivados de la glucosa generados intracelularmente (glioxal, metilglyoxal y 3 deoxiglicosona), en la actualidad se considera que la alta concentración de glucosa dentro de la célula es el evento principal de iniciación en la formación de AGEs tanto intra como extracelulares [Brownlee, 2005; Brownlee, 2001]. 


\section{I.5.3-METABOLISMO DE LOS AGES}

El pool endógeno de AGEs refleja principalmente el equilibrio cinético de dos procesos opuestos: la formación endógena y la captación de AGEs exógeno, por una parte, y por otro lado la degradación y la eliminación de AGEs por los sistemas especializados [Jakus y Rietbrock, 2004].

La formación de AGEs se produce lentamente, en condiciones fisiológicas, y afecta principalmente a moléculas de larga vida media, como el colágeno, que ejercen una función importante en el proceso de envejecimiento [Forbes et al, 2005]. Otras proteínas de larga duración también pueden sufrir glicación avanzada, incluyendo la mielina, tubulina, activador del plasminógeno 1 y el fibrinógeno [Vlassara, 1996].

Sin embargo, en condiciones de hiperglucemia o estrés oxidativo, la formación de AGEs aumenta considerablemente [Jay et al, 2006; Lapolla et al, 2005]. Las personas con diabetes tienen concentraciones séricas de AGEs significativamente más alto que los sujetos no-diabéticos [Sharp et al, 2003]. La evaluación de la hemoglobina glucosilada (HbA1C), variante de la hemoglobina que transporta un producto de Amadori en su cadena $\beta$, refleja la aparición de hiperglucemia en los últimos tres meses e, indirectamente, la glicación avanzada [Rahbar, 2005; Forbes et al, 2005].

La formación de AGEs es predominantemente endógena, pero estos productos pueden ser introducidos en el cuerpo por fuentes exógenas, como el tabaquismo y la dieta [Peppa et al, 2003].

La dieta es considerada la principal fuente exógena de AGEs y puede ejercer una influencia importante en el desarrollo de diversas patologías, especialmente la diabetes [Vlassara, 2005]. Se sabe que aproximadamente el 10\% de los AGEs ingeridos con la dieta son absorbidos, aunque los mecanismos relativos a la absorción de tales, no son totalmente comprendidos. De la fracción absorbida, aproximadamente dos tercios son retenidos en el cuerpo y sólo un tercio se excreta en la orina dentro de 48 horas para los sujetos con función renal normal [Koschinsky et al, 1997].

La formación de AGEs en los alimentos se ve reforzada por métodos de elaboración que utilizan altas temperaturas y baja humedad (coccion al horno o a la parrilla), y alimentos ricos en contenido de materia grasa [Goldberg et al, 2004]. Hay evidencias de que los AGEs dietéticos se añaden al pool de AGEs endógeno, lo que favorece la aparición y progresión de las complicaciones de la diabetes [Peppa et al, 2003; Vlassara H, 2005]. 
El humo es también una importante fuente exógena de AGEs. Durante la combustión de tabaco, las especies reactivas de AGEs se volatilizan, son absorbidos por los pulmones y pueden interactuar con las proteínas del suero [Vlassara y Palace, 2002]. Esto se refleja en el hecho de que las concentraciones séricas de AGE y apoproteína B-AGE en los individuos fumadores son significativamente mayores que en las personas no fumadoras [Cerami et al, 1997].

El cuerpo tiene mecanismos de defensa contra la acumulación de AGEs. Los sistemas de enzimas como la oxaldehído reductasa y la aldosa reductasa son capaces de influir en el pool endógeno de los AGEs y en la desintoxicación eficiente de los intermedios dicarbonílicos reactivos. Los sistemas enzimáticos glioxilasa I y II, fructosamina-3-quinasa y oxidasa fructosamina (amadoriasa) también son responsables de la interrupción de las reacciones de glicación en diferentes etapas. Sin embargo, en condiciones de exceso de AGEs, como la diabetes, hiperlipidemia, insuficiencia renal y en los individuos que consumen una dieta con alto contenido de AGEs, estos sistemas pueden no ser suficientes [Barbosa et al, 2008].

La eliminación de los AGEs formados sobre los distintos componentes tisulares, se lleva a cabo por proteólisis extracelular o por células scavenger como los macrófagos, que endocitan AGEs a través de receptores y realizan una proteólisis intracelular [Bierhaus et al, 1998]. La proteólisis intracelular de AGEs produce AGE-péptidos (también llamados "segunda generación de AGEs") y "aductos AGE libres " (aductos AGE unidos a un solo aminoácido) que, tras ser liberados en el plasma, pueden ser excretadas en la orina [Gugliucci, 2007]. La resistencia de las proteínas de matriz extracelular a la proteolisis, hace que la eliminación de los AGEs unidos a estas sea menos favorables [Gugliucci, 2007]. Mientras que los aductos AGEs libres se vierten directamente en la orina, los AGE-péptidos son endocitados por las células epiteliales del túbulo proximal y posteriormente degradados por el sistema endolisosomal a AGEs-aminoácidos. Existe la hipótesis de que los AGE-aminoácidos se exportan de nuevo a la luz de la nefrona para una posterior excreción [Gugliucci y Bendayan, 1996]. Los aductos AGEs libres son la principal forma de excreción de los AGEs por orina, mientras que la excreción como AGEs-péptidos ocurre en menor medida [Gugliucci y Bendayan, 1996].

Por lo tanto, la eficiencia de remoción de AGEs depende, en última instancia, de la eficacia de la depuración renal. La disfunción renal que se presenta en pacientes con nefropatía, por ejemplo, resulta en la ineficiente remoción de AGEs circulantes y contribuye 
considerablemente a las altas concentraciones de AGEs sérico y tisular encontrados en estos indiduos [Gugliucci, 2007; Nakamura et al, 2003].

\section{I.5.4-MECANISMOS DE ACCIÓN LOS AGEs}

Los AGEs pueden dañar las células por tres mecanismos básicos: El primero es la modificación de las estructuras intracelulares, incluyendo aquellas que participan en la transcripción génica. El segundo mecanismo es mediante la modificación de la señalización de las moléculas de la matriz extracelular (glicadas) y la célula, causando disfunción. El tercer mecanismo se refiere a la modificación de proteínas o lípidos en la sangre. Las proteínas y los lípidos circulantes modificados por los AGEs a continuación, pueden unirse a receptores específicos, causando la producción de citoquinas inflamatorias y factores de crecimiento, que a su vez, contribuyen a la patología vascular de la diabetes [Bierhaus et al, 1998; Brownlee, 2005].

Hoy en día, sabemos de la existencia de un complejo sistema de reconocimiento de los AGEs, que tienen un papel importante en la patología asociada con la diabetes [Vlassara y Palace, 2002].

Entre una variedad de receptores para AGEs que se han descrito en la literatura, la molécula del receptor RAGE es probablemente el mejor caracterizado [Lin, 2006; Yonekura et al, 2005].

El RAGE pertenece a la superfamilia de las inmunoglobulinas de superficie de la célula, con su gen localizado en el cromosoma 6 en el complejo mayor de histocompatibilidad entre los genes de clase II y III. Las regiones para el factor nuclear-kB (NF-kB) y la interleucina-6 (IL-6) se encuentran en el gen promotor de RAGE, controlando la expresión de este receptor RAGE y asociando al RAGE las respuestas inflamatorias.

El RAGE es mínimamente expresado en tejidos y vasos en condiciones fisiológicas. Sin embargo, su expresión está aumentada en los macrófagos, monocitos, células musculares lisas, células endoteliales, astrocitos y osteoblastos en condiciones de exceso de AGE, un ejemplo de retroalimentación positiva [Lin, 2006; Goldin et al, 2006; Cortizo et al, 2003; Mercer et al, 2007].

Estudios in vitro han demostrado que la unión RAGE /AGEs lleva a la producción de estrés oxidativo debido a la estimulación de $\mathrm{NAD}(\mathrm{P}) \mathrm{H}$ oxidasa que produce un aumento de ROS [Goldin et al, 2006]. La generación de ROS incrementa los niveles de p21 ${ }^{\text {ras }}$ unidos a 
GTP activando así a las ERK 1 y 2. De ese modo las ERKs producen la activación del factor de transcripción NF-kB [Schmidt et al, 1999].

La interacción entre AGE y RAGE, en las células endoteliales, activa la transcripción NF-kB, lo que aumenta la expresión posterior de sus genes diana, como la endotelina-1, molécula de adhesión celular vascular-1 (VCAM-1), selectina E, el factor tisular, trombomodulina, el VEGF (factor de crecimiento endotelial vascular) y citoquinas proinflamatorias como las interleuquinas-1 $\alpha$ (IL-1 $\alpha$ ), IL-6 y el factor de necrosis tumoral- $\alpha$ (TNF- $\alpha$ ), además regula positivamente al mismo RAGE (Fig I.5.4.1). El bloqueo de RAGE, a su vez, inhibe la activación de NF-kB [Yonekura et al, 2005; Goldin et al, 2006].

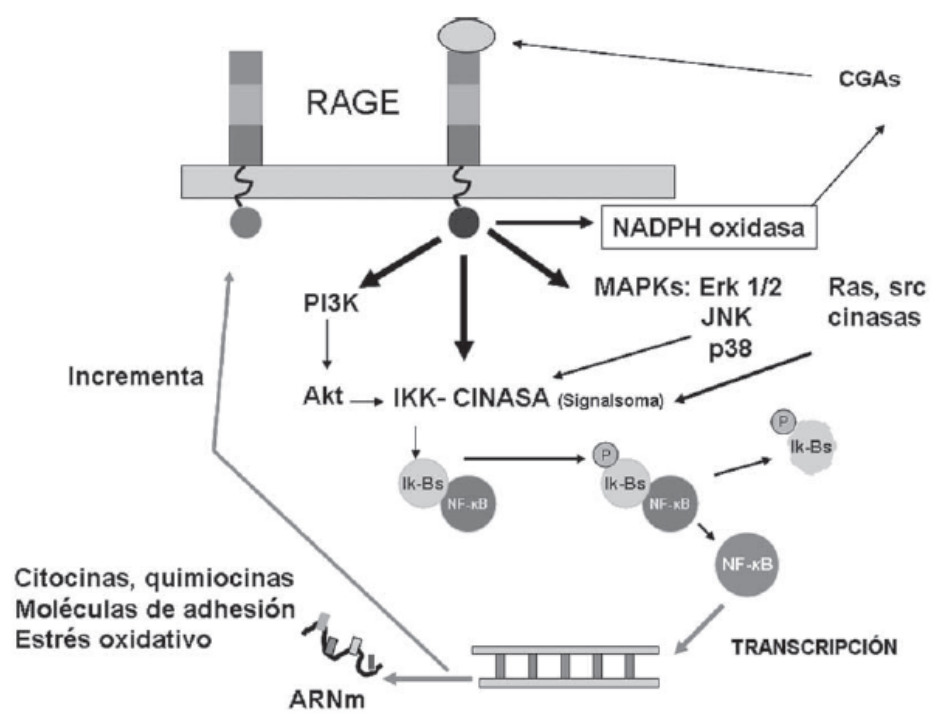

Fig I.5.4.1. Esquema de señalización de la activación del receptor para los compuestos de glicosilaciónavanzada (RAGE) [Mosquera, 2010].

Luego de la activación de RAGE por alguno de sus ligandos (CGAs o AGEs), el componente citosólico de la molécula activa una red de sistemas de señalización compuesta principalmente por las cinasas del fosfoinositide 3 o protein cinasa-B (PI3K), la protein cinasas activadas por mitógenos (MAPK s compuesta por: la cinasa terminal Jun-N (JNK), p38 y las cinasas reguladas por signos extracelulares: ERK) y el Ras. Estas señalizaciones convergen en el complejo de cinasas llamadas IKK signalsoma que fosforilan al inhibidor del factor de transcripción NF-kB en el citoplasma (IK-Bs); este deja libre al NF-kB y posteriormente es degradado.

El NF-kB se transloca al nucleo induciendo al ADN a codificar para varios factores proinflamatorios como la expresión de moléculas de adhesión, citocinas, quimiocinas y el estrés oxidativo. A su vez el ADN codifica para la neoexpresión de RAGE, actuando como un mecanismo de retroalimentación y aumentando el proceso inflamatorio. Per se, la activación de RAGE puede directamemente influir en el estrés oxidativo al aumentar la expresión de la oxidasa del NAD(P)H y originar aumento del contenido de anión superóxido.

Por otra parte, se ha demostrado que RAGE se une a una serie de otros péptidos y proteínas que no son AGE, incluyendo algunas isoformas de S100 [Stern et al, 2002] y 
anfoterina (HMGB-1 high mobility group box 1) [Yan et al, 2004], ligandos que también están implicados en la lesión vascular progresiva.

El RAGE endógenos solubles (sRAGE) es una variante del receptor de membrana y se ha detectado en el plasma. Este RAGE soluble carece de los dominios transmembrana $\mathrm{COOH}$ terminal y pueden unir a ligandos extracelulares. El exceso de sRAGE puede unir competititivamente a ligandos del RAGE, evitando su interacción con el receptor RAGE transmembrana y, por tanto, impidiendo la señalización celular. El papel como potencial terapéutico de sRAGE se ha descripto en modelos experimentales de nefropatía diabética y aterosclerosis [Goh y Cooper, 2008].

Otros receptores, como los llamados AGE-R1, AGE-R2 y AGE-R3/galectina-3, y el Ezrin, radixin y moesina (familia de ERM) [McRobert et al, 2003] y receptores scavenger de macrófagos clase A tipos I y II, también son capaces de reconocer y unirse a AGEs [Goldin et al, 2006].

AGE-R1 (oligosacariltransferasa 48) facilita el aclaramiento de AGE, y parece estar implicado en la unión específica y la degradación del ligando AGE.

AGE-R3 (galectina-3) pertenece a la familia de las lectinas, proteínas de unión a hidratos de carbono. AGE-R3 está regulado positivamente en la hiperglucemia y después de la exposición a AGE, por ejemplo en osteoblastos en cultivo [Mercer et al, 2004].

La familia de las proteínas ERM (ezrin, radixin y moesina) se ha visto que se unen a AGE, con una afinidad similar a otros receptores tales como RAGE. Las ERM están presentes en todos los órganos donde se presentan complicaciones en la diabetes y la interacción de AGEs con el sitio de unión localizado en el extremo N-terminal de las ERM podría inhibir sus funciones [McRobert et al, 2003]. Estas funciones incluyen enlaces cruzados entre las proteínas de la membrana plasmática y el citoesqueleto de actina, por lo tanto, la presencia de AGEs alteraría la interacción célula-célula, la adhesión célula-matriz extracelular y produciría una forma irregular de la célula.

El llamado CD36, receptor scavenger clase B, de manera similar reconoce AGEs y participa en la eliminacion de estos compuestos de la circulación y tiene un importante papel en la inducción de estrés oxidativo en la célula.

Los AGEs son también reconocidos por el receptor scavenger clase E, receptor lectinalike de LDL oxidada-1 (LOX-1), y la presencia de AGEs aumenta la expresión de LOX-1 en ratas diabeticas. Otros receptores scavenger que unen AGEs son Fasciclina, factor de crecimiento epidérmico-like (EGF), el factor de crecimiento epidérmico tipo laminina-like 
(LE), dominio de enlace que contienen los receptores scavenger-1 y -2 (FEEL-1, y FEEL-2) [Goldin et al, 2006].

\section{I.5.5-ROL DE LOS AGES EN LAS COMPLICACIONES DE LA DIABETES}

Los AGEs se consideran importantes mediadores patogénicos de las complicaciones de la diabetes, convencionalmente clasificadas en micro y macroangiopatías.

La microangiopatía diabética es un término general usado para describir los cambios funcionales de lechos microvasculares en los que las células del endotelio son progresivamente dañadas por la hiperglucemia, lo que resulta en la oclusión capilar, isquemia e insuficiencia orgánica

El término macroangiopatía diabética se refiere a complicaciones cardiovasculares, enfermedades que constituyen la principal causa de morbimortalidad en pacientes con diabetes mellitus tipo 2

Ambos tipos de diabetes 1 y 2 representan un factor de riesgo independiente y de gran alcance para la enfermedad arterial coronaria, accidente cerebrovascular y enfermedad arterial periférica [Basta et al, 2004; Vlassara y Palace, 2003].

\section{I.5.5.1 AGE y microangiopatía diabética.}

Las células que se ven particularmente afectadas por la hiperglucemia son: las células endoteliales de los capilares de la retina, las células mesangiales de los glomérulos renales, las neuronas y las células de Schwann en los nervios periféricos. Esto se debe a la incapacidad de estas células de regular el transporte de glucosa al medio interno, siendo susceptibles a las altas concentraciones de glucosa durante los estados de hiperglucemia. Estas altas concentraciones intracelulares de glucosa, a su vez, estimular las vías bioquímicas responsables de los cambios fisiopatológicos de la diabetes, es decir, la vía de los polioles, la vía de la hexosamina, la vía de los AGEs y la vía de la proteína quinasa $\mathrm{C}$, entre las cuales se destaca la vía de formación de AGEs [Brownlee, 2005; Brownlee, 2001].

\section{I.5.5.1.1 La nefropatía diabética}

La nefropatía diabética es la causa principal de la enfermedad renal en los países desarrollados [Yamamoto et al, 2001a]. Aunque los eventos moleculares precisos que llevan a la nefropatía diabética están siendo todavía investigados, se sabe que se acumulan altos niveles de AGE en la membrana basal glomerular, las células mesangiales, los podocitos y células tubulares renales [Soulis-Liparota et al, 1995]. Los AGE (a través del RAGE) aumentan la liberación del factor de crecimiento tumoral- $\beta$ (TGF- $\beta$ ), que estimula la síntesis 
de componentes de la matriz de colágeno, un fenómeno que debe contribuir, al menos parcialmente, al engrosamiento de la membrana basal característico de la nefropatía diabética [Oldfield et al, 2001]. La acumulación de AGEs en el colágeno de la membrana basal, junto con la capacidad de estos compuestos para unirse a las proteínas plasmáticas, también pueden contribuir al engrosamiento la membrana basal, cambios en la filtración y finalmente a la pérdida de la función glomerular. La reducción de la filtración es, en parte, debido a la compresión de los capilares y a una disminución de la superficie donde se produce la filtración a causa de la expansión del lecho mesangial [Barbosa et al, 2008]. Las células mesangiales en cultivo expresan receptores para los AGEs y responden a los AGEs mediante el aumento de la síntesis de proteínas de la matriz y el colágeno tipo IV [Vlassara y Palace, 2002].

\section{I.5.5.1.2 La retinopatía diabética}

La CML (entre otros AGEs) se ha localizado en los vasos sanguíneos de la retina en pacientes con diabetes tipo 2 y este hallazgo se correlaciona con el grado de retinopatía [Murata et el, 1997; Stitt, 2001]. Cuando los animales no diabéticos se infunden con albúmina-AGE preformados, los aductos se acumulan alrededor y dentro de los pericitos, colocalizados con RAGE, inducen engrosamiento de la membrana basal, y contribuyen a la ruptura de la barrera hemato-retiniana interna [Stitt et al, 1997; Stitt et al, 2000].

Los pericitos expresan receptores RAGE que cuando interactuan con sus ligandos AGE, desencadenan el aumento de la transducción de señales celulares y causan de los fenómenos característicos de la retinopatía diabética: la pérdida de pericitos. En las células endoteliales, RAGE-AGE causa sobreproducción del factor de crecimiento de las células del endotelio vascular (VEGF), que a su vez, estimula la angiogénesis y la neovascularización, ambos también implicados en la patogénesis de la retinopatía [Ahmed, 2005].

\section{I.5.5.1.3 La neuropatía diabética periférica}

Se han documentado elevados niveles de AGEs en los nervios periféricos de los sujetos con diabetes. La via AGE- RAGE es un mecanismo probable que vincula la microangiopatía y la neuropatía, y es apoyado por la colocalización de la CML, RAGE, el NF- $\mathrm{B}$ e IL-6 en los vasos epineurales, perineurales y endoneurales. Se ha demostrado en modelos murinos [Chen et al, 2004] que los AGE empeoran la neuropatía diabética mediante la reducción de la velocidad de conducción sensomotora y la disminución de flujo sanguíneo a los nervios periféricos [Ahmed, 2005]. 


\section{I.5.5.2 AGE y macroangiopatía diabética.}

En contraste con las células implicadas en la enfermedad microvascular de la diabetes, en las células endoteliales arteriales, capaces de regular la concentración interna de la glucosa, hay un aumento en el flujo de ácidos grasos libres desde los adipocitos debido a la resistencia a la acción de insulina o a la falta de esta hormona. El consiguiente aumento de la oxidación de los ácidos grasos por las mitocondrias conduce a una superproducción de especies reactivas del oxígeno (ROS) por la cadena de transporte de electrones mitocondriales, que activa las vías bioquímicas mismo responsable de los cambios fisiopatológicos en la diabetes: la vía de los polioles, a través de la hexosamina, a través de la proteína quinasa $\mathrm{C}$ y la vía de la formación de AGEs [Brownlee, 2005; Brownlee, 2001].

Las AGEs pueden ser altamente perjudiciales para la integridad y la función de los vasos sanguíneos de varias maneras. En la pared de los vasos los AGEs forman enlaces cruzados intra e intermolecular dentro de proteínas de la matriz, "atrapan" las proteínas plasmáticas, provocan la rigidez de la vasculatura, e inhiben la actividad del óxido nítrico (NO) y prostaciclina (PGI2), además de interactuar con los receptores para modular un gran numero de propiedades celulares. Los AGEs no sólo disminuyen los niveles de estos dos factores relajantes, sino que también induce la producción de endotelina-1 (un potente vasoconstrictor) por las células endoteliales mediante la activación de NF-kB.

En las lipoproteínas plasmáticas de baja densidad (LDL), los AGE inician reacciones oxidativas que promueven la formación de LDL oxidada. La interacción de los AGEs con las células que se acumulan en las placas ateroscleróticas, como los fagocitos mononucleares y células musculares lisas, generar estímulos que intensifican la respuesta inflamatoria.

Además, la interacción de los AGEs con los componentes de la pared del vaso aumenta la permeabilidad vascular, la expresión de la actividad procoagulante y la generación de ROS, dando lugar a una mayor expresión de moléculas de adhesión endotelial de leucocitos. Los AGEs modulan las fases iniciales de aterogenesis, provocando un proceso inflamatorio-proliferativo y contribuyendo a la propagación de la inflamación y alteración vascular en la enfermedad establecida [Barbosa et al, 2008; Basta et al, 2004; Goldin et al, 2006]. 


\section{I.6-HUESO DIABÉTICO}

La relación entre diabetes y osteopenia ha recibido considerable atención en los últimos 60 años, iniciada con los hallazgos de Albright y Reifenstein, quienes demostraron, mediante la evaluación con rayos $\mathrm{X}$, la pérdida de masa mineral ósea de pacientes diabéticos [Albright y Reifenstein, 1948]. Desde entonces, la relación entre la osteopenia y la diabetes está bien establecida.

La diabetes mellitus se ha asociado con la aparición de una serie de complicaciones que afectan el sistema esquelético, de manera colectiva conocido como "enfermedad diabética ósea" u "osteopatía diabética" [Bouillon, 1991].

El fenotipo esquelético diabéticos presenta las siguientes características: [Retzepi y

Donos, 2010]

-disminución del crecimiento óseo lineal durante de crecimiento puberal en adolescentes con diabetes [Salerno et al.1997];

-reducción de la DMO y mayor riesgo de aparición de osteopenia y osteoporosis [Vestergaard 2007];

-aumento del riesgo de fractura [Janghorbani et al, 2007];

-alteración de la cicatrización ósea y alteración potencial de regeneración ósea [Cozen, 1972].

El hallazgo de osteopenia y osteoporosis en pacientes jóvenes con diabetes mellitus tipo 1, incluso poco después de la aparición de la diabetes mellitus, ha llevado a la hipótesis de que la insulina actúa como un factor anabólico óseo [Thrailkill et al, 2005]. Debido a que la diabetes mellitus tipo 1 se produce normalmente en niños, adolescentes y jóvenes, la deficiencia de insulina coincide con una relativa inmadurez esquelética, por lo tanto podría afectar la acumulación ósea y el pico máximo de masa ósea [Hofbauer et al, 2007].

Un mayor pico de masa ósea, se prevé para los pacientes con diabetes tipo 2, cuya enfermedad generalmente comienza más tarde en la vida y además tienden a tener sobrepeso.

Se encuentra una disminución en la DMO en pacientes con diabetes tipo 1 pero una DMO normal o incrementada para los de tipo 2. [Räkel et al, 2008]. En ambos tipos de diabetes, la formación de hueso, la microarquitectura y por lo tanto la calidad ósea están alteradas. Muchos estudios muestran que en la diabetes hay una disminución en la formación ósea mientras que la resorción y la mineralización se presentan normales. Este estado de bajo recambio óseo se corresponde con la observación de una disminución en el tiempo de reparación de fracturas óseas en la diabetes. En los pacientes con diabetes tipo 2 la disminución en el recambio óseo explicaría el aumento en la DMO observada, mientras que 
otros postulan que esto aumenta la fragilidad del hueso, independientemente de la DMO, a través de la acumulación de microfracturas. [Räkel et al, 2008].

Un estudio del 2001 de Nicodemus y Folson demostró que el riesgo de fracturas de cadera es 12 veces mayor en mujeres con diabetes tipo 1 en comparación con la población general. Por su parte, las mujeres con diabetes tipo 2 tenían un aumento significativo de 1,7 veces en el riesgo. Estos hallazgos coinciden con los descriptos en el estudio sistemático que realizó Janghorbani et al [2007] de todas las publicaciones que presentaban la relación entre la diabetes de tipo 1 y diabetes de tipo 2 y el riesgo de fracturas. Se encontró que la asociación entre el tipo de diabetes y la incidencia en la fractura de cadera fue mayor en la diabetes tipo 1 (Riesgo Relativo: 6) que para la diabetes tipo 2 (Riesgo Relativo: 2).

La interpretación de los datos de fracturas como una medida del metabolismo óseo es particularmente difícil en los pacientes con diabetes de larga data [Ivers et al, 2001], porque las complicaciones visuales y neurológicas pueden predisponerlos a accidentes, de modo que un mayor riesgo de fracturas no solamente depende de la densidad ósea. Otros factores que hacen que los estudios sean difíciles de interpretar es la presencia de la enfermedad renal diabética y la neuropatía periférica que podrían contribuir a una pérdida de mineral. En la DM tipo 1 la neuropatía periférica constituye un factor de riesgo independiente para reducir la densidad mineral ósea (BMD) en el esqueleto en general [Rix et al, 1999; Räkel et al, 2008].

Si bien existen pruebas tanto para una mayor tasa de fracturas y la densidad ósea anormal en ambas formas de diabetes, la magnitud del riesgo es claramente mayor en los pacientes con diabetes mellitus tipo 1.

Uno de los posibles factores que altera la calidad ósea en la diabetes es la presencia de AGEs en el hueso.

En un estudio se mostró que los niveles séricos de CML y pentosidina se encuentran aumentados en pacientes osteoporóticos cuando se los compara con los pacientes sanos [Hein, 2003].

Los AGEs se acumulan con la edad, pero se ven incrementados en la diabetes. El proceso de formación ósea puede ser influenciado y alterado por la modificación de las proteínas del hueso por AGEs.

La FAL ósea es una proteína que está involucrada en la formación de hueso y en el proceso de mineralización, se ensayó in vitro y se observó que se inactiva mediante la reacción de Maillard [Koyama et al, 1998]. Por otro lado, McCarthy et al [1998] encontró que la glicación in vitro de la FAL induce inhibición de la actividad y cambios en su estructura. 
También se encontró que la osteocalcina, que es la segunda proteína en importancia luego del colágeno, se glica, lo cual podría contribuir a la osteopenia diabética [Gundberg et al, 1986]

Una posible explicación para la disminución en la resistencia ósea en la diabetes, es la acumulación de AGEs en las moléculas de colágeno del hueso. Las proteínas entrecruzadas por AGEs disminuyen su solubilidad y poseen una alta resistencia a la digestión proteolítica, con la consecuente alteración de las propiedades físicoquímicas y mecánicas de los componentes del tejido, dando una mayor rigidez al colágeno [Hein, 2006].

Además de los cambios en la funcionalidad, la glicación del colágeno altera las interacciones celulares con la matriz extracelular mediada por integrinas [McCarthy et al, 2004].

Los estudios sobre las líneas celulares indican que los AGEs también afectan el metabolismo de las células óseas. Los AGEs en el colágeno inhiben la expresión fenotípica de los osteoblastos y estimulan la interleuquina-6 en las células derivadas de hueso [Schwartz, 2003].

Nuestro grupo demostró que el colágeno modificado por AGEs es capaz de regular la proliferación y diferenciación de las células osteoblásticas inhibiendo la actividad de fosfatasa alcalina y la formación de nódulos de mineralización. La acumulación de AGEs sobre la matriz extracelular puede regular la proliferación y diferenciación de las células osteoblásticas. Esos efectos parecen depender del estadío de desarrollo osteoblástico y posiblemente involucra la expresión de NO sintasa y la producción de ROS intracelular [McCarthy et al, 2001a].

También se estudió el efecto de la adición de AGE-BSA a cultivos de células osteoblásticas, y resultó en una significativa inhibición en la proliferación y diferenciación (expresión de FAL y secreción de colágeno tipo 1) de manera dosis y tiempo dependiente [McCarthy et al, 1997]. Luego se encontró que la modulación que ejercen los AGEs-BSA sobre el crecimiento y desarrollo pueden ser el resultado de un mecanismo autocrinoparacrino que involucra el sistema IGF- IGFBP (proteína de unión a IGF) [McCarthy et al, 2001b].

Ya en el año 1999, nuestro grupo estudió la posible presencia de proteínas de unión a los AGEs en las células osteoblásticas, demostrando que ambas líneas celulares (UMR-106 y MC3T3-E1) expresaron sitios específicos de unión y que los mismos dependen de la fase de desarrollo osteoblástico [McCarthy et al, 1999]. Luego se caracterizaron mejor y se vio que 
estas células osteoblásticas expresaban RAGE [Cortizo et al, 2003] y galectina 3 [Mercer et al, 2004]. La presencia de AGEs en los cultivos de osteoblastos modula la expresión y secreción de galectina 3, lo que podría tener consecuencias significativas en el metabolismo osteoblástico y el recambio óseo [Mercer et al, 2004].

Se observó también que los efectos biológicos inducidos por AGEs descriptos previamente en los osteoblastos, pueden estar mediados por RAGE y que la expresión de este receptor es modulada por la presencia de AGEs [Cortizo et al, 2003].

Al mismo tiempo, a través de la interacción con receptores de membrana celular, los AGEs podrían modular no sólo la diferenciación osteoblástica y la función, sino también la osteoclastogénesis, y en consecuencia disminuir la remodelación ósea y el recambio de colágeno, facilitando la acumulación de más AGEs en la matriz ósea [Valcourt et al, 2007].

En conjunto estos resultados indican que los AGEs pueden contribuir a algunos de los mecanismos fisiopatológicos de la remodelación ósea alterada que se observa en el envejecimiento y la diabetes.

Con respecto al tratamiento de la osteopenia/osteoporosis diabética, no se sabe si las terapias utilizadas actualmente para la osteoporosis, las cuales muestran una reducción en el riesgo de fractura en las poblaciones de edad avanzada con DMO baja, podrán ser igualmente eficaces en la reducción de las fracturas en los diabéticos tipo 2, con DMO normal o aumentada. Sin embargo, hay pruebas iniciales de que los tratamientos antirresortivos en pacientes con diabetes tienen resultados similares a los observados en sujetos no diabéticos [Jude et al, 2001, Keegan et al, 2004]. Tampoco se conoce si el tratamiento intensivo para la diabetes y la reducción de las complicaciones diabéticas pueden tener efectos sobre el hueso [Dominguez et al, 2004]

En la actualidad, se recomienda que los pacientes con diabetes tipo 1 sean vigilados con más cuidado que las personas no diabéticas o aquellos con diabetes tipo 2, y deben ser alentados a consumir una dieta rica en calcio y vitamina D. Parece que el tratamiento intensivo con insulina y un peso corporal estable en pacientes con diabetes tipo 1 es importante para prevenir la pérdida ósea [Campos Pastor et al, 2000]. Para los pacientes con diabetes tipo 2 que están en buen control metabólico, la prevención y el tratamiento de la osteoporosis puede ser abordado de una manera similar a los pacientes sin diabetes como se indica en la nueva guía médica de la Fundación Nacional de Osteoporosis [Lewiecki y Watts, 2009]. 


\section{I.7-OBJETIVOS}

Los objetivos del presente trabajo de tesis fueron:

\section{$\underline{\text { Objetivo General }}$}

Investigar los mecanismos patogénicos de los AGEs en modelos de células óseas en cultivo, así como el rol de agentes anti-resortivos como los bisfosfonatos (BPs) sobre dichos efectos.

\section{Objetivos Específicos}

1. Analizar el efecto de los AGEs y de diversos BPs sobre el crecimiento y diferenciación de osteoblastos y osteoclastos en cultivo.

2. Estudiar el efecto de los AGEs y BPs sobre la actividad de diversas fosfatasas óseas.

3. Investigar los efectos pro-apoptóticos y anti-apoptóticos de los AGEs y BPs en osteoblastos en cultivo.

4. Determinar los mecanismos de transducción de señales involucrados en la acción de AGEs y BPs en osteoblastos y osteoclastos en cultivo. 


\section{II}

\section{MATERIALES Y MÉTODOS}
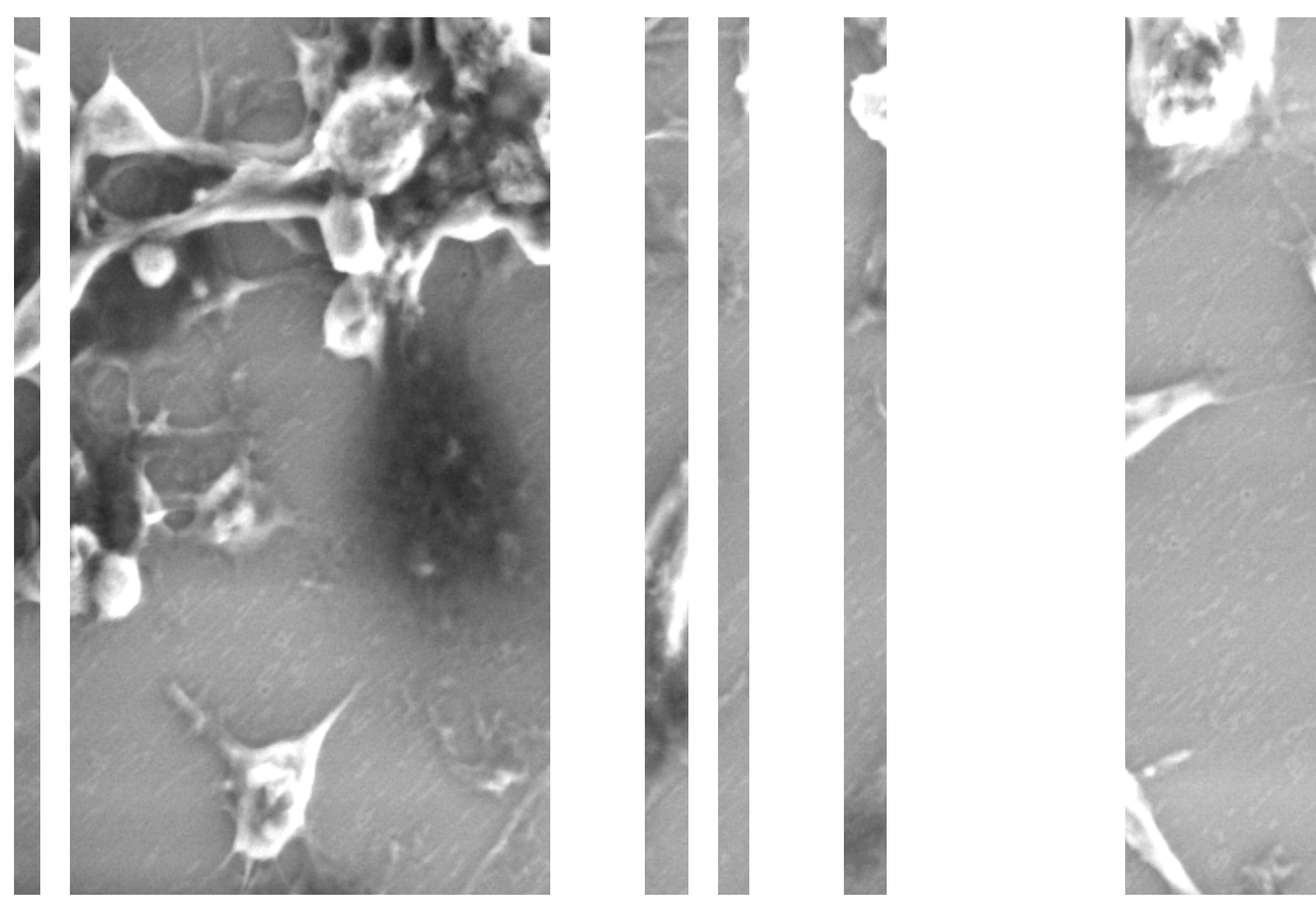


\section{II.1-MATERIALES}

$\checkmark$ Alendronato, trihidrato de la sal monosódica del ácido 4-amino-1-hidroxibutiliden1,1-bisfosfónico provisto por Laboratorios Elea (Argentina)

$\checkmark$ Pamidronato, sal disódica del ácido 3-amino 1-hidroxi propiliden-1,1-bisfosfónico provisto por Novartis (Basel, Suiza)

$\checkmark$ Zoledronato, sal disódica ácido 1-hidroxi-2-(1H-imidazol-1-il)-etilideno-1,1bisfosfónico provisto por Novartis (Basel, Suiza)

$\checkmark$ Medio Eagle modificado por Dulbecco (DMEM), Microvet (Laboratorio Microvet S.A., Buenos Aires, Argentina)

$\checkmark$ Tripsina-EDTA, Gibco (Invitrogen, Buenos Aires, Argentina)

$\checkmark$ Suero fetal bovino, GBO (GBO Argentina S.A., Buenos Aires, Argentina).

$\checkmark$ Material para el cultivo de tejidos, Nunc (Tecnolab, Buenos Aires, Argentina).

$\checkmark$ Filtros Centricon cut off $=10 \mathrm{kDa}$, Amicon Inc. (Beverly, Mass., USA).

$\checkmark$ Albúmina sérica bovina (BSA), Sigma-Aldrich (Buenos Aires, Argentina).

$\checkmark$ D-glicolaldehído, Sigma-Aldrich (Buenos Aires, Argentina).

$\checkmark$ Tritón X-100, Sigma-Aldrich (Buenos Aires, Argentina).

$\checkmark$ p-Nitrofenilfosfato, Sigma-Aldrich (Buenos Aires, Argentina)

$\checkmark$ Colorante Sirius Red, Sigma-Aldrich (Buenos Aires, Argentina).

$\checkmark$ Colorante Alizarin S red (ICN)

$\checkmark$ Dihidro-rhodamina 123 (DHR), Molecular Probes (Buenos Aires, ARG)

$\checkmark$ Anexina V-FITC, Molecular Probes (Buenos Aires, ARG)

$\checkmark$ Ioduro de propidio, (PI) Molecular Probes (Buenos Aires, ARG)

$\checkmark$ 6,8-difluoro-4-metilumbeliferil fosfato (DiFMUP) sustrato fluorogénico, Molecular Probes (Buenos Aires, ARG).

$\checkmark$ Anticuerpos Anti RAGE policlonal en conejo(Sta Cruz Biotechnology Inc. (CS, USA)

$\checkmark$ Anticuerpos Anti tubulina policlonal en conejo (Sta Cruz Biotechnology Inc. (CS, USA)

$\checkmark$ Anticuerpos Anti FAK policlonal en conejo (Sta Cruz Biotechnology Inc. (CS, USA)

$\checkmark$ Segundo anticuerpo anti-conejo polyclonal en cabra IgG-FITC (Sta Cruz Biotechnology Inc. (CS, USA)

$\checkmark$ paloidina-FITC Molecular Probes (Buenos Aires, ARG)

Todos los otros productos químicos y reactivos se adquirieron de fuentes comerciales y son de grado analítico 


\section{II.2-MÉTODOS}

\section{II.2.1-PREPARACIÓN DE AGES (PRODUCTOS DE GLICACIÓN AVANZADA, PGA).}

Los productos de glicación avanzada fueron preparados mediante la incubación de 10 $\mathrm{mg} / \mathrm{ml}$ de albúmina sérica bovina con $33 \mathrm{mM}$ de D-glicolaldehído en $150 \mathrm{mM}$ de PBS (buffer fosfato salino) $\mathrm{pH}=7.4$ a $37^{\circ} \mathrm{C}$ por 3 días bajo condiciones de esterilidad [Unno et al., 2004]. El D-glicolaldehído se utilizó como agente glicante en lugar de la glucosa, por su mayor reactividad en la glicosilación no-enzimática. Se incubó un control de albúmina sérica bovina en las mismas condiciones pero en ausencia del azúcar. Las moléculas de azúcar que no reaccionaron fueron removidas mediante centrifugación/filtración por medio de filtros Centricon con un punto de corte de $10 \mathrm{kDa}$. La concentración de proteínas se determinó por el método de Bradford usando BSA como estándar. La formación de los productos de glicación avanzada (AGEs) se evaluó con un espectrofluorómetro FLUORAT®-02-PANORAMA de LUMEX, utilizando la fluorescencia característica de los AGEs. Se midió el espectro de emisión excitando a $\lambda: 370 \mathrm{~nm}$ (que es el máximo que presenta en el espectro de excitación) y se obtuvo el máximo a $\lambda: 450 \mathrm{~nm}$ (Fig. II.2.1.1). Los valores de fluorescencia de AGE-BSA se midieron a una concentración de $1 \mathrm{mg} / \mathrm{ml}$ de proteína y se expresan en unidades arbitrarias. [Rubio-Ruiz, 2008]

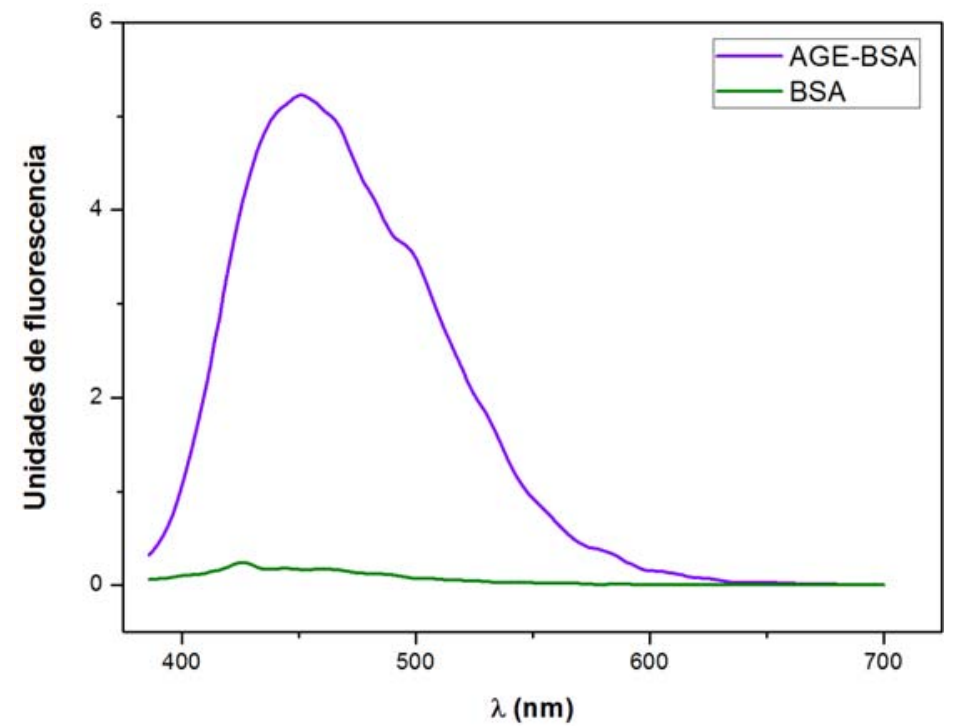

Fig. II.2.1.1. Espectro de emisión de fluorescencia de AGE-BSA y BSA no glicada.

Ambas soluciones se evaluaron a una concentración de $1 \mathrm{mg} / \mathrm{mL}$ de proteína. Podemos apreciar que en el espectro de emisión obtenido excitando con $\lambda: 370 \mathrm{~nm}$, el máximo de fluorescencia que encontramos para AGEBSA $(\lambda: 450 \mathrm{~nm})$ no está presente en la curva de BSA no glicada 
Los datos correspondientes a las longitudes de onda máximas: $\lambda$ emisión:450 nm y $\lambda$ excitación:370 $\mathrm{nm}$ se obtuvieron a partir de los espectros bidimensionales de las dos soluciones como se puede ver en la Fig II.2.1.2.

(A)

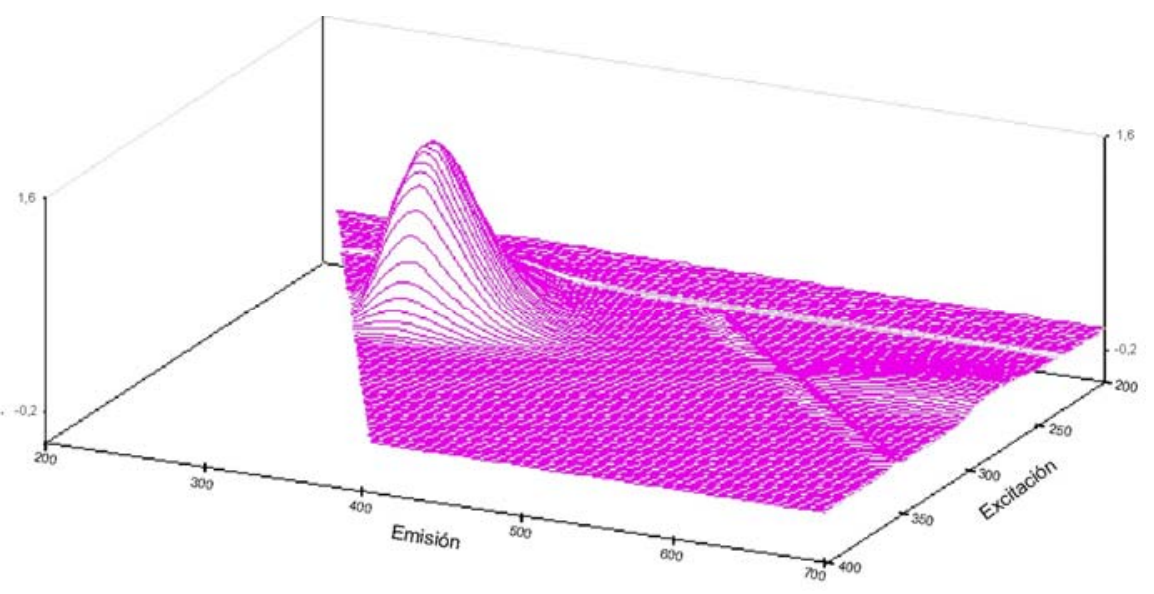

(B)

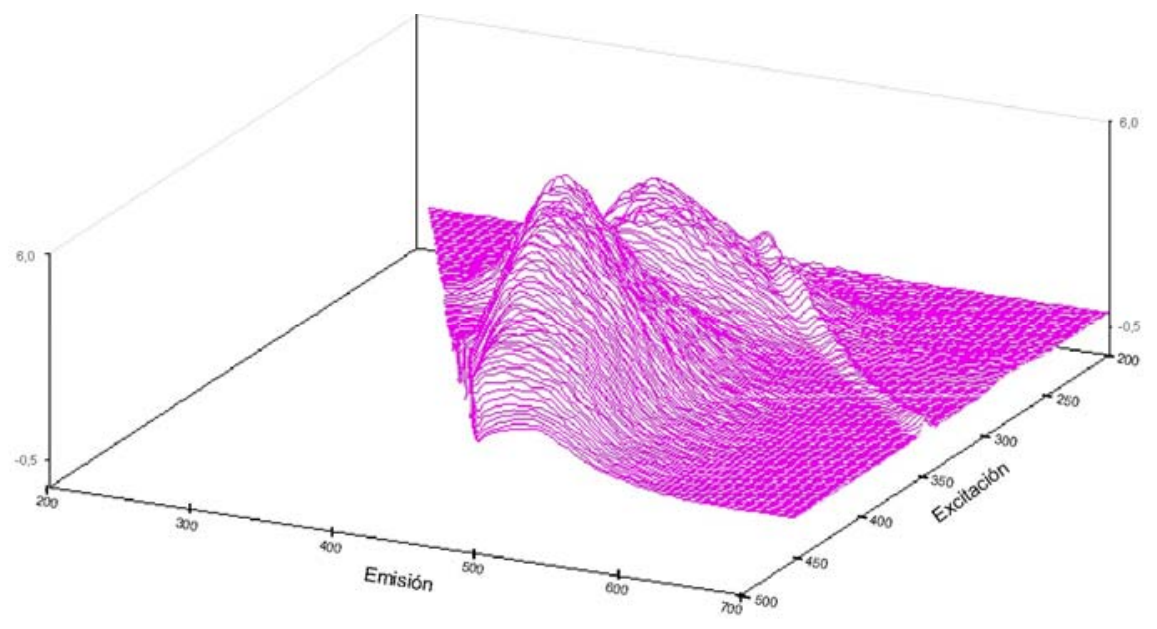

Fig. II.2.1.2.Espectros de fluorescencia bidimensionales.

En la figura (A) se muestra el espectro de BSA en PBS $(1 \mathrm{mg} / \mathrm{ml})$ y en la figura (B) el espectro de AGE-BSA en PBS: $(1 \mathrm{mg} / \mathrm{ml})$.

\section{II.2.2-PREPARACIÓN DE SOLUCIONES DE BISFOSFONATOS (BPs)}

Los Bisfosfonatos que se utilizaron en este trabajo de tesis fueron Alendronato, Pamidronato y Zoledronato. Los mismos entran en la clasificación de bisfosfonatos nitrogenados. Las drogas sólidas de éstos, se pesaron en balanza analítica y se disolvieron en agua destilada estéril para preparar soluciones stock de concentración $10^{-2} \mathrm{M}$, las cuales fueron fraccionadas y congeladas a $-20{ }^{\circ} \mathrm{C}$. Al momento de iniciar los experimentos se realizaron las 
diluciones seriadas correspondientes $\left(10^{-3} \mathrm{M}-10^{-7} \mathrm{M}\right)$ para obtener las concentraciones finales deseadas en cada pocillo de cultivo celular.

\section{II.2.3-MODELOS CELULARES}

\section{II.2.3.1-Líneas celulares}

\section{II.2.3.1.a-MC3T3-E1}

Es una línea clonada preosteoblástica, obtenida de calvaria de ratón (Mus musculus). Son células que tienen morfología fibroblástica y crecen en forma adherente. Se cultivan con DMEM (Dulbecco's Modified Eagle's Medium) al cual se le adiciona suero fetal bovino (SFB) al $10 \%$, estreptomicina $100 \mu \mathrm{g} / \mathrm{ml}$ y penicilina $100 \mathrm{U} / \mathrm{ml}$ y se incuban en atmósfera humidificada con $5 \%$ de $\mathrm{CO}_{2}$ a $37^{\circ} \mathrm{C}$.

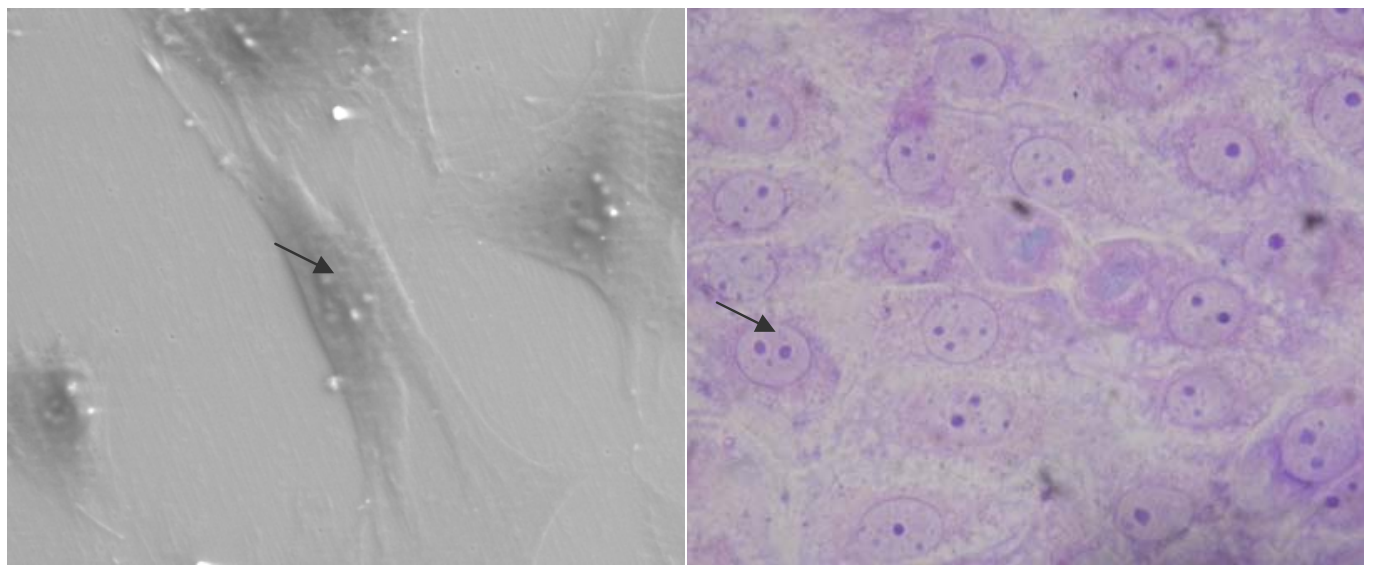

Fig.II.2.3.1.a Imágenes de las células MC3T3-E1 en cultivo.

Derecha: Foto de las células MC3T3-E1 teñidas con Giemsa, microscopio óptico Nykon, 400x. Izquierda: Imagen tomada por E-SEM (2500x) en la cual se aprecia la forma fibroblástica de las células MC3T3-E1. Nótese el núcleo celular redondo y la presencia de nucleolos (flecha).

Cuando estas células crecen con medio osteogénico, es decir suplementado con ácido ascórbico $25 \mathrm{mg} / \mathrm{ml}$ y una fuente de fosfato inorgánico $5 \mathrm{mM}$ (beta-glicerofosfato) durante 7 días, expresan altos niveles de fosfatasa alcalina y colágeno tipo 1, los cuales son marcadores de diferenciación osteoblástica. Si estas condiciones se mantienen por 21 días, se observa la mineralización de la matriz extracelular. [Quarles et al, 1992], [Wang et al, 1999]. De esta manera, en las células MC3T3-E1, se puede determinar la actividad de fosfatasa alcalina, la 
producción de colágeno tipo 1 y la formación de nódulos de mineralización como indicadores de diferenciación a osteoblastos.

Estas células son buenos modelos para el estudio in vitro de la diferenciación osteoblástica, ya que poseen un comportamiento similar a los cultivos primarios de osteoblastos de calvaria.

Para realizar los subcultivos se lava la monocapa con PBS-EDTA $1 \mathrm{mM} \mathrm{pH}=7.4 \mathrm{y}$ luego se coloca $1 \mathrm{ml}$ de $0.25 \%$ de Tripsina-PBS EDTA, se aspira y se coloca medio de cultivo, se homogeneiza bien, se deja una alícuota y luego se resuspende en DMEM-10\%SFB.

\section{II.2.3.1.b-UMR-106}

Es una línea clonada obtenida de un osteosarcoma transplantable de rata (Rattus norvegicus) inducido a través de una inyección con radiofósforo $\left({ }^{32} \mathrm{P}\right)$. Poseen un modo de crecimiento adherente y su morfología es epitelial.
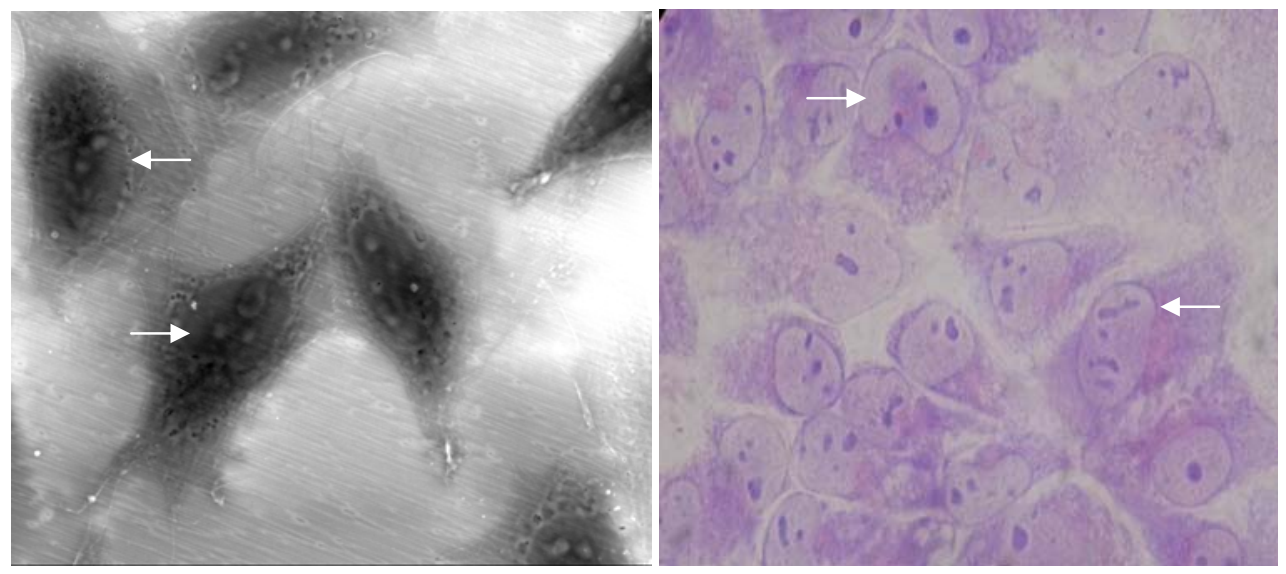

Fig.II.2.3.1.b Imágenes del cultivo de células UMR-106.

Derecha: Imagen de las células UMR-106 teñidas con Giemsa (400x). Izquierda: Fotos obtenidas por E-SEM (2800x) en la cual se aprecia la forma epitelial de las células. Las flechas blancas señalan distintas células, mostrando la heterogeneidad que encontramos en la relación núcleo/citoplasma en las células de esta línea.

Expresan marcadores osteoblásticos tempranos como son la producción de colágeno tipo 1 y altos niveles de la actividad de la enzima fosfatasa alcalina, además responden a la PTH aumentando los niveles intracelulares de cAMP. [Partridge et al, 1983]. Sin embargo, esta línea no expresa marcadores de diferenciación tardíos (osteocalcina, osteonectina) ni mineralizan el cultivo.

Las células se cultivan en DMEM con suero fetal bovino al 10\%, estreptomicina 100 $\mu \mathrm{g} / \mathrm{ml}$ y penicilina $100 \mathrm{U} / \mathrm{ml}$ en atmósfera humidificada con $5 \%$ de $\mathrm{CO}_{2}$ a $37^{\circ} \mathrm{C}$. Estas células 
conservan las propiedades de diferenciación de un osteoblasto maduro siendo de esta manera un modelo apropiado para el estudio de los efectos hormonales sobre tumores, así como para el estudio de la regulación hormonal de los osteoblastos.

Los subcultivos de UMR-106 se realizan de la misma forma que se describió para las MC3T3-E1. En estas células se hicieron ensayos de actividad de fosfatasa alcalina y se determinó la producción de colágeno tipo 1 .

\section{II.2.3.1.c- $\underline{\text { Raw } 264.7}$}

Es una línea celular clonal derivada de un tumor inducido mediante la inyección intraperitoneal del virus murino de leucemia Abelson en ratones machos adultos (Mus musculus). Son células que poseen morfología de macrófago/monocito y crecimiento adherente. Estas características se puede observar en la Fig.II.2.3.2.

Las células Raw 264.7 crecen en medio DMEM con SFB al 5\%, en atmósfera humidificada con $5 \%$ de $\mathrm{CO}_{2}$ a $37^{\circ} \mathrm{C}$. Los subcultivos se realizan mediante scrapping. Se lava una vez la monocapa con PBS-EDTA $1 \mathrm{mM} \mathrm{pH}=7.4$ y luego se coloca $1 \mathrm{ml}$ de PBS-EDTA unos minutos, se aspira y se pasa el scrapper para remover la monocapa. Se resuspenden en DMEM-5\% SFB.

\section{II.2.3.2-Modelo de osteoclastos: Cocultivos de células UMR-106 con Raw 264.7}

Para la obtención de células similares a osteoclastos se utilizó el método de cocultivo de líneas celulares. [Nicolin et al, 2006]. En este caso se utilizaron las líneas celulares UMR106 (osteoblastos) y las Raw 264.7 (macrófagos).

Las células se subcultivaron en platos multipocillo en una relación Macrófago/Osteoblasto $=2 / 1$. Se incubaron durante aproximadamente 4 días, cambiando el medio día por medio, hasta observar el desarrollo de células gigantes multinucleadas (Fig.II.2.3.2. derecha). En ese momento se colocaron las diferentes condiciones (BSA o AGEs y/o Bisfosfonatos) y se prosiguió la incubación por 4 días más. Al final del período de incubación, los cocultivos se observaron con el microscopio óptico para corroborar la obtención de células multinucleadas gigantes con gránulos birrefringentes en el citoplasma (simil osteoclastos). 

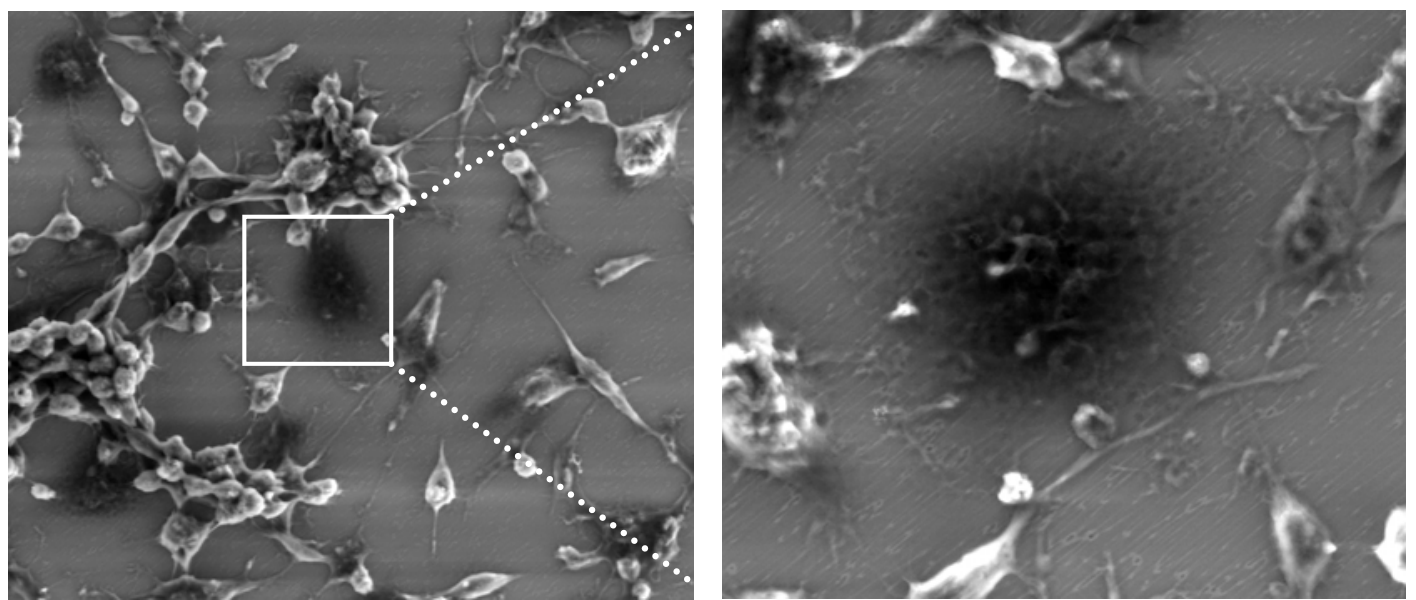

Fig.II.2.3.2. Imágenes de E-SEM de los cocultivos de Raw 264.7 y UMR-106.

Izquierda: Se aprecian las células macrofágicas Raw 264.7 redondas, pequeñas y con alto contraste. Por otro lado, las células más grandes y oscuras corresponden a los osteoclastos (1400x). Derecha: Ampliación del recuadro de la imagen de la izquierda que contiene a un osteoclasto (3000x).

Luego se determinó la presencia de células con actividad de fosfatasa ácida tartratoresistente $($ TRAP $(+))$ utilizando una reacción citoquímica, ya que esta enzima es altamente expresada en los osteoclastos maduros. Así mismo, se determinó la actividad TRAP por un ensayo colorimétrico en extractos celulares de los cocultivos. Para ello, las células fueron lavadas con PBS y solubilizadas en Tritón X-100 al 0.1\%. Una alícuota del extracto celular fue usada para determinar proteínas por el método de Bradford [Bradford, 1976].

\section{II.2.4-ENSAYOS BIOQUÍMICOS}

\section{II.2.4.1-Ensayos de proliferación osteoblástica}

La proliferación celular se determino usando el bioensayo mitogénico de cristal violeta según lo descripto por Okajima et al., 1992, con algunas modificaciones. Las células UMR106 y las MC3T3-E1 se plaquearon en platos de 48 pocillos e incubaron por $24 \mathrm{~h}$ con diferentes condiciones experimentales en DMEM libre de suero. Posteriormente la monocapa se lavó con buffer salino fosfato y se fijo con 5\% glutaraldehído/PBS a temperatura ambiente por $10 \mathrm{~min}$. Luego, las células se tiñeron con Cristal Violeta al $0.5 \%$ en $25 \%$ de metanol durante $10 \mathrm{~min}$. Al final de ese período de tiempo, la monocapa se lavó exhaustivamente. El colorante captado por las células se extrajo usando $0.5 \mathrm{ml} /$ pocillo de buffer $0.1 \mathrm{M}$ glicina/ $\mathrm{HCl}$, $\mathrm{pH}=3.0$ (30\% metanol) y luego se transfirió a tubos de kahn. La Absorbancia se leyó a 540 nm luego de realizar la dilución conveniente para cada muestra. Nuestro grupo demostró 
previamente [Cortizo y Etcheverry, 1995] que, bajo estas condiciones, este bioensayo colorimétrico muestra una fuerte correlación con la proliferación celular determinada mediante el recuento en cámara de Neubauer. Con el objetivo de evaluar el posible rol del calcio en la modulación de la proliferación osteoblástica por los productos de glicación avanzada y/o bisfosfonatos, en ciertos experimentos también se incluyó $10 \mu \mathrm{M}$ de Nifedipina, un bloqueante de canales L de Calcio, en el medio de incubación.

\section{II.2.4.2-Ensayos para evaluar la diferenciación a osteoblastos.}

La diferenciación osteoblástica se evaluó en las líneas celulares MC3T3-E1 y UMR106 mediante la determinación de la actividad enzimática de la fosfatasa alcalina, la producción de colágeno tipo 1 y la formación de nódulos de mineralización (solo en la línea MC3T3E1).

\section{II.2.4.2.a-Actividad de fosfatasa alcalina}

La actividad de fosfatasa alcalina se ensayó como lo describieron Cortizo y Etcheverry [1995]. La monocapa de células se lavó con PBS y se solubilizó en Tritón X-100 al 0.1\%. Una alícuota del extracto celular se usó para determinar proteínas por el método de Bradford [Bradford, 1976]. La actividad de fosfatasa alcalina se midió espectrofotométricamente utilizando para-nitrofenilfosfato (p-NPP) como sustrato. El p-nitrofenol (producto coloreado de la hidrólisis) se determinó por Absorbancia a $405 \mathrm{~nm}$ luego de incubar la mezcla de reacción a $37^{\circ} \mathrm{C}$ en buffer $\mathrm{pH} 10.4$, durante un período de tiempo predeterminado según el tipo celular. Los resultados se expresaron como nmol p-NP/mg proteína*min.

\section{II.2.4.2.b-Producción de colágeno tipo I}

La producción de colágeno tipo I se evaluó utilizando un microensayo colorimétrico mediante la técnica de Sirius Red [Tullberg-Reinert y Jundt, 1999]: las células se fijaron con mezcla de Bouin (Ac. pícrico: formaldehído 35\%: Ac. acético glacial - $15: 5: 1$ ) durante 1h. Se lavó la monocapa celular con agua y se tiño con una solución de Sirius Red (Rojo serio) por $1 \mathrm{~h}$. El material teñido se disolvió en $1 \mathrm{ml}$ de hidróxido de sodio $0.1 \mathrm{~N}$ y se midió la Absorbancia a $550 \mathrm{~nm}$.. La curva de calibración que se utilizó fue $\mu \mathrm{g}$ col $=41.88^{*} \mathrm{DO}_{500 \mathrm{~nm}^{-}}$ 3.89 y se realizó de la siguiente manera: se depositaron de 2 a $40 \mu \mathrm{g}$ de colágeno disuelto en $0.02 \mathrm{~N}$ acido acético en los pocillos plásticos, se incubó a $37^{\circ} \mathrm{C}$ para la formación del film por evaporación del solvente [McCarthy et al, 2001a]. Los film obtenidos fueron lavados y sometidos al mismo procedimiento que las muestras. 


\section{II.2.4.2.c-Mineralización}

Los depósitos de calcio extracelulares (nódulos de mineralización) se evaluaron luego de 21 días de diferenciación usando la tinción de Rojo de Alizarina S [Ueno et al, 2001]. Los depósitos de calcio teñidos se extrajeron con $1 \mathrm{ml}$ de solución de hidróxido de sodio $0.1 \mathrm{~N}$ y la densidad óptica se midió a $548 \mathrm{~nm}$.

\section{II.2.4.3-Evaluación de la muerte celular}

La apoptosis se evaluó usando el ensayo de Anexina V/Ioduro de propidio como se describe en el trabajo de Molinuevo et al [2004]. La fase temprana de la apoptosis se caracteriza por la externalización de la fosfatidilserina desde la capa interna a la capa externa de la bicapa lipídica que forma la membrana plasmática. De esa manera puede unirse a la Anexina $\mathrm{V}$ marcada con fluoresceína (una proteína que naturalmente tiene afinidad por la fosfatidilserina) y ser evidenciada por microscopía de fluorescencia [Varga et al, 1999]. Las células cultivadas sobre cubreobjetos e incubadas $24 \mathrm{~h}$ con BSA o AGE y/o Alendronato 10

${ }^{8} \mathrm{M}$, se lavaron e incubaron con Anexina V-FITC $(1 \mu \mathrm{g} / \mathrm{ml})$ y Ioduro de propidio $(2.5 \mu \mathrm{g} / \mathrm{ml})$ en buffer de unión (10mM Hepes / $140 \mathrm{mM} \mathrm{NaCl} / 2.5 \mathrm{mM} \mathrm{CaCl}_{2}, \mathrm{pH}$ 7.4). Luego de lavar exhaustivamente con PBS, las células se fijaron con paraformaldehído 4\% en PBS durante 10 minutos y se montaron en portaobjetos. Se observó usando un microscopio de fluorescencia (Nikon 5000). El porcentaje de células apoptóticas y necróticas se determinó contando las células marcadas por campo utilizando un aumento de 400X en un total de 30 campos para cada condición experimental.

Los estadíos tempranos de la apoptosis se evidencian como Anexina V-FITC (+)/PI (-) mientras que estadíos apoptóticos /necróticos fueron caracterizados como Anexina $\mathrm{V}(+) / \mathrm{PI}(+)$

\section{II.2.4.4-Determinación de la producción intracelular de especies de oxígeno reactivas (ROS)}

La generación intracelular de radicales libres en osteoblastos se evaluó mediante la oxidación de dihidrorodamina 123 (DHR 123) a rodamina según la técnica previamente descripta por McCarthy et al [2001]. La técnica se basa en que las especies altamente oxidantes como el $\mathrm{OH}^{*}$ y $\mathrm{ONOO}^{*} / \mathrm{ONOOH}$, son capaces de oxidar la DHR a rodamina, un compuesto fluorescente, de manera que puede ser detectada la $\lambda$ emisión $=532 \mathrm{~nm}$ utilizando una $\lambda$ excitación $=495 \mathrm{~nm}$ [Kooy et al, 1994]. Las monocapas de células osteoblásticas se cultivaron en platos de 24 pocillos bajo diferentes condiciones experimentales durante $24 \mathrm{~h}$. Al final de este período de incubación, el medio fue reemplazado por DMEM libre de suero 
con DHR $10 \mu \mathrm{M}$ y las células se incubaron por $4 \mathrm{~h}$. más. Las células se lavaron con PBS varias veces y luego la monocapa se lisó en $1 \mathrm{ml}$ de $0.1 \%$ Tritón X-100. La concentración de producto oxidado (Rodamina) presente en el extracto celular fue determinada midiendo la intensidad de fluorescencia relativa con respecto a un estándar $0.5 \mu \mathrm{M}$ de Rodamina. [Cortizo et al, 2000] Una alícuota del extracto se usó para determinar proteínas totales por el método de Bradford [Bradford, 1976].

\section{II.2.4.5-Ensayo Fluorogénico de Fosfatasas Neutras}

Para evaluar el efecto de los AGEs y bisfosfonatos sobre la actividad de fosfatasas neutras osteoblásticas de utilizó un ensayo fluorogénico. El mismo se llevó a cabo incubando la monocapa de células con $200 \mu \mathrm{g} / \mathrm{ml}$ de BSA o AGEs más diferentes concentraciones de bisfosfonatos $\left(10^{-4}, 10^{-5}\right.$ o $\left.10^{-6} \mathrm{M}\right)$ por $24 \mathrm{~h}$. Luego se realizó un lisado celular con Tritón $\mathrm{X} 100$ al $0.1 \%$ y se incubó una alícuota conteniendo $50 \mu \mathrm{g}$ de proteínas con el sustrato fluorogénico DiFMUP (6,8-difluoro-4-metilumbeliferil 86 fosfato) por 10 minutos como lo describió Molinuevo et al., 2007. El producto fluorescente se midió a intervalos de un minuto durante 10 minutos a una $\lambda$ excitación: $360 \mathrm{~nm}$ y $\lambda$ emisión: $450 \mathrm{~nm}$ utilizando un espectrofluorómetro Shimadzu RF-1500.

\section{II.2.4.6-Reacción citoquímica para fosfatasa ácida tartrato-resistente}

En los modelos de cocultivo de células UMR-106/ Raw264.7 se determinó la presencia de células gigantes multinucleadas con actividad fosfatasa ácida tartrato-resistente (TRAP $(+)$ ) utilizando un kit para una reacción citoquímica (Sigma-Aldrich), con el objetivo de evaluar la formación y maduración de los osteoclastos. Dicha reacción involucra una diazotación en la cual se forma un precipitado violáceo en las células que presentan actividad TRAP. Para ello las células se lavaron con PBS y se fijaron 30 segundos con una solución que contiene citrato, acetona y formaldehído37\%. Luego se lavó con abundante agua destilada y se incuba una hora a $37^{\circ} \mathrm{C}$ al resguardo de la luz con una solución que contiene naftol AS-Bi fosfato y sal de Fast Garnet GBC (como agente copulador). Este compuesto de diazonio se acopla rápidamente a $\mathrm{pH}$ ácido, formando depósitos altamente insolubles. El ácido tartárico se utiliza para demostrar la presencia de fosfatasa ácida tartratorresistente. El naftol AS-BI, liberado por la hidrólisis enzimática, se acopla inmediatamente con la sal de Fast Garnet GBC, formando depósitos de color castaño insolubles en los puntos de actividad. Las células con fosfatasa ácida sensible al ácido tartárico están desprovistas de actividad, mientras que las células osteoclasto simil con fosfatasa resistente al ácido tartárico no están afectadas por dicho tratamiento. 


\section{II.2.4.7-Determinación de TRAP por colorimetría}

Los cocultivos se lavaron con PBS y se solubilizaron en $250 \mu 1$ de Tritón X-100 0.1\% y se reservaron en tubos eppendorf [Valcourt et al, 2007]. Una alícuota del extracto celular se incubó con el buffer de reacción (412 mM acido acético, 0.209\% Triton X-100, $412 \mathrm{mM}$ $\mathrm{NaCl}, 4.12 \mathrm{mM}$ EDTA, 10.6mM acido ascórbico, $10.1 \mathrm{mM}$ p-nitrofenilfosfato, $41.6 \mathrm{mM}$ tartrato de sodio a $\mathrm{pH}=5.5$ ) durante $1 \mathrm{~h}$ a $37^{\circ} \mathrm{C}$ en oscuridad. (Vol. final: $1 \mathrm{ml}$ ). Luego se detuvo la reacción agregando $200 \mu \mathrm{l}$ de $\mathrm{NaOH} 300 \mathrm{mM}$. Los cambios colorimétrico se midieron por Absorbancia a $405 \mathrm{~nm}$. Con otra alícuota del extracto se determinó la concentración de proteínas por el método de Bradford. Se expresaron los resultados como Actividad TRAP específica $=$ nmol de $\mathrm{p}-\mathrm{NP} / \mathrm{mg}$ de Prot.* min.

\section{II.2.4.8 -Estudios de inmunofluorescencia indirecta}

Las células subconfluentes crecidas sobre cubreobjetos de vidrio se lavaron 2 veces en PBS frío y se fijaron con paraformaldehído 4\% en PBS durante 20minutos a temperatura ambiente. Luego se permeabilizaron con metanol $100 \%$ durante 4 minutos a $-20{ }^{\circ} \mathrm{C}$ y se lavaron con PBS. Con el fin de evitar las uniones inespecíficas, se realizó un bloqueo con 1\% BSA en PBS ( $\mathrm{pH}=7.4)$ durante 30 minutos. Se incubó con el primer anticuerpo (anti RAGE, anti tubulina o anti FAK, en los ensayos correspondientes) 1:200 con PBS ( $\mathrm{pH}=7.4$ ) 1\% BSA durante 1 hora a temperatura ambiente y se lavó con PBS tres veces durante 10 minutos. Posteriormente, se realizó una incubación con el segundo anticuerpo adecuado marcado con fluoresceína en PBS pH=7.4, durante 60 minutos a temperatura ambiente (1:200). Se lavó con PBS tres veces durante 10 minutos y se montó con glicerol $80 \%$. En algunos ensayos los núcleos se tiñeron con Ioduro de Propidio (rojo). Se observaron los preparados con un microscopio de fluorescencia Nikon 5000 y se tomaron fotografías usando una cámara Nikon coolpix. En el caso del ensayo para determinar RAGE en los osteoclastos también se observaron por microscopia confocal (Microscopio Confocal Leica TSC SP5 AOBS)

\section{II.2.4.9-Estudios de inmunofluorescencia directa para fibras de actina}

Las células se plaquearon sobre cubreobjetos de vidrio en DMEM 10\% FBS, luego se lavó con PBS, se fijó con paraformaldehído 4\% por 10 minutos. Se permeabilizaron las células con metanol frío por 4 minutos y se bloqueó por dos horas con BSA al 3\% en PBS. Luego se las incubó con paloidina-FITC (1:100) por 2 horas a temperatura ambiente. Luego se lavó con PBS tres veces durante 10 minutos y se montó con glicerol 80 \% PBS. En el segundo lavado se agregó Ioduro de propidio para teñir los núcleos celulares. Se observaron 
los preparados con un microscopio de fluorescencia Nikon 5000 y se tomaron imágenes para su análisis [Cortizo y Kreda, 2000].

\section{II.2.5 Técnicas de microscopía.}

\section{II.2.5 1 Microscopía Confocal:}

El equipo utilizado es un Microscopio Confocal Leica TSC SP5 AOBS perteneciente al consorcio conformado en la Fac de Cs Exactas de la UNLP.

El principio en el que se basa fue postulado por Minsk en 1955, se basa en eliminar la luz procedente de los planos fuera del foco. Un diafragma o pinhole colocado delante del detector permite eliminar la luz procedente de los planos fuera de la zona de plano focal. (Fig. II.2.5 1)

El microscopio trabaja en epiluminación, es decir con muestras que reflejan la luz o emiten fluorescencia. La fluorescencia es una propiedad que poseen ciertas moléculas que consiste en emitir luz de una longitud de onda mayor al ser excitadas con luz de una determinada longitud de onda. Las sustancias que tienen fluorescencia se denominan fluorocromos y tienen espectros de emisión y excitación característicos. Por ejemplo los usados en este trabajo son el ioduro de propidio (rojo) $\lambda$ exc/ $\lambda$ emisión: $536 / 617 \mathrm{~nm}$ y FITC (isotiocianato de fluoresceína) (verde) anclado a algún anticuerpo $\lambda$ exc/ $\lambda$ emisión: 494/520nm

La luz procedente del plano focal es recogida en un fotomultiplicador donde se transforma en una señal eléctrica que se digitaliza y almacena en un ordenador visualizándose a través del monitor. Cada número de la matriz (píxel) es visualizado en el monitor del ordenador con una intensidad de color o nivel de gris en función de una determinada paleta de colores, formándose de este modo la imagen que ve el observador.

Aplicaciones del microscopio confocal:

-Observación de imágenes teñidas con un marcaje simple: lo cual permite obtener imágenes de mejor calidad que con el microscopio óptico de fluorescencia al eliminar la luz procedente de los planos fuera del foco.

-Observación de imágenes teñidas con marcaje múltiple: permite estudiar muestras marcadas con más de un fluorocromo recogiendo las señales en imágenes distintas o combinándolas en la misma imagen.

-Observación tridimensional de la muestra (xyz) Variando la posición del plano focal es posible obtener imágenes a diferentes profundidades obteniéndose un 
conjunto de secciones ópticas que nos dan información sobre la estructura tridimensional de la muestra. Esta opción permite determinar, por ejemplo en que región celular se encuentra la marca.

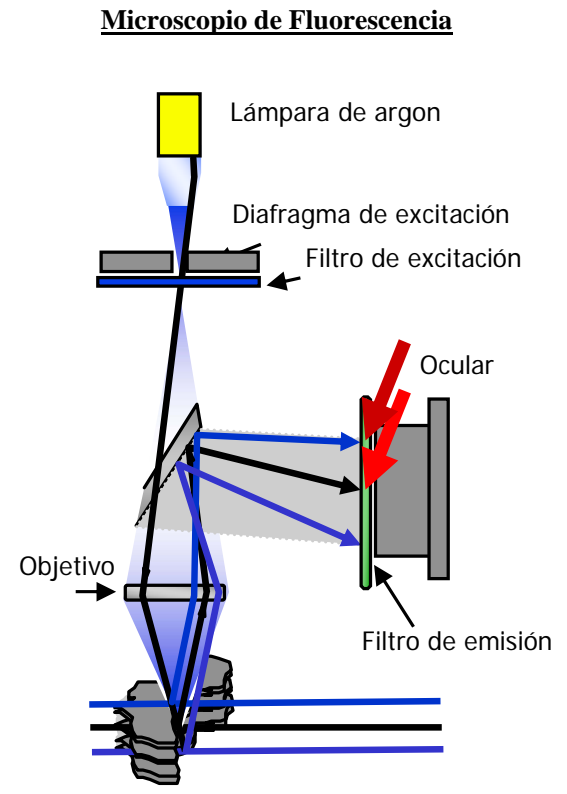

Microscopio Confocal de Fluorescencia

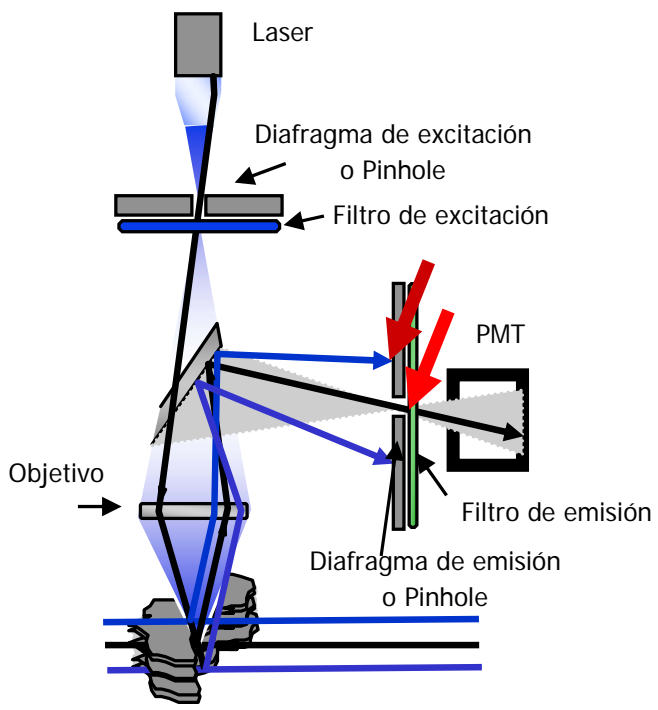

Fig. II.2.5 1 Esquemas comparativos de un microscocopio de fluorescencia óptico y un microscopio confocal.

\section{II.2.5 2 Microscopía Electrónica de Barrido Ambiental (E-SEM)}

Se utilizó esta técnica para observar la morfología de los cultivos y las células en particular. Para ello, las células se cultivaron sobre cubreobjetos, luego se lavaron con PBS, se fijaron por 10 minutos con glutaraldehído 5\%, se lavaron con agua destilada y se observaron con E-SEM. La ventaja que presenta el modo ambiental de observación con respecto al SEM, entre otras, es que las muestras no tienen un tratamiento previo ni deben ser recubiertas con metales para transformarlas en superficies conductoras [Muscariello et al, 2005]. Permite observar a las células en su condición natural.

El equipo que se empleó es FEI- Quanta 200 (Holanda) y se utilizó en Modo Ambiental (E-SEM, environmental scanning electron microscopy). Las condiciones que se fijaron para obtener las imágenes fueron $3{ }^{\circ} \mathrm{C}$ en la celda y 5 torr, con $75 \%$ de humedad relativa. Previamente se realizó una purga de 4 ciclos yendo de 10 a 8 torr, para que no se dañen las células. El detector que posee el equipo es un detector gaseoso de electrones secundarios GSED (gaseous secondary electron detector) [Stokes, 2003, Stokes et al, 2003]. 


\section{II.2.6-ANÁLISIS ESTADÍSTICO}

Los resultados se expresaron como la media \pm SEM y fueron obtenidos a partir de tres experimentos independientes realizados por triplicado. Las diferencias entre grupos se establecieron mediante Oneway ANOVA con test Tukey post-hoc. Para datos con distribución no normal se utilizo no-parametrical Kruskal Wallis con test Dunn post-hoc usando el programa estadistico GraphPad In Stat version 3.00 (Graph Pad Software, San Diego, California, USA). Un valor $\mathrm{p}<0.05$ se consideró significativo para todos los análisis estadísticos. 


\section{III}

\section{RESULTADOS}
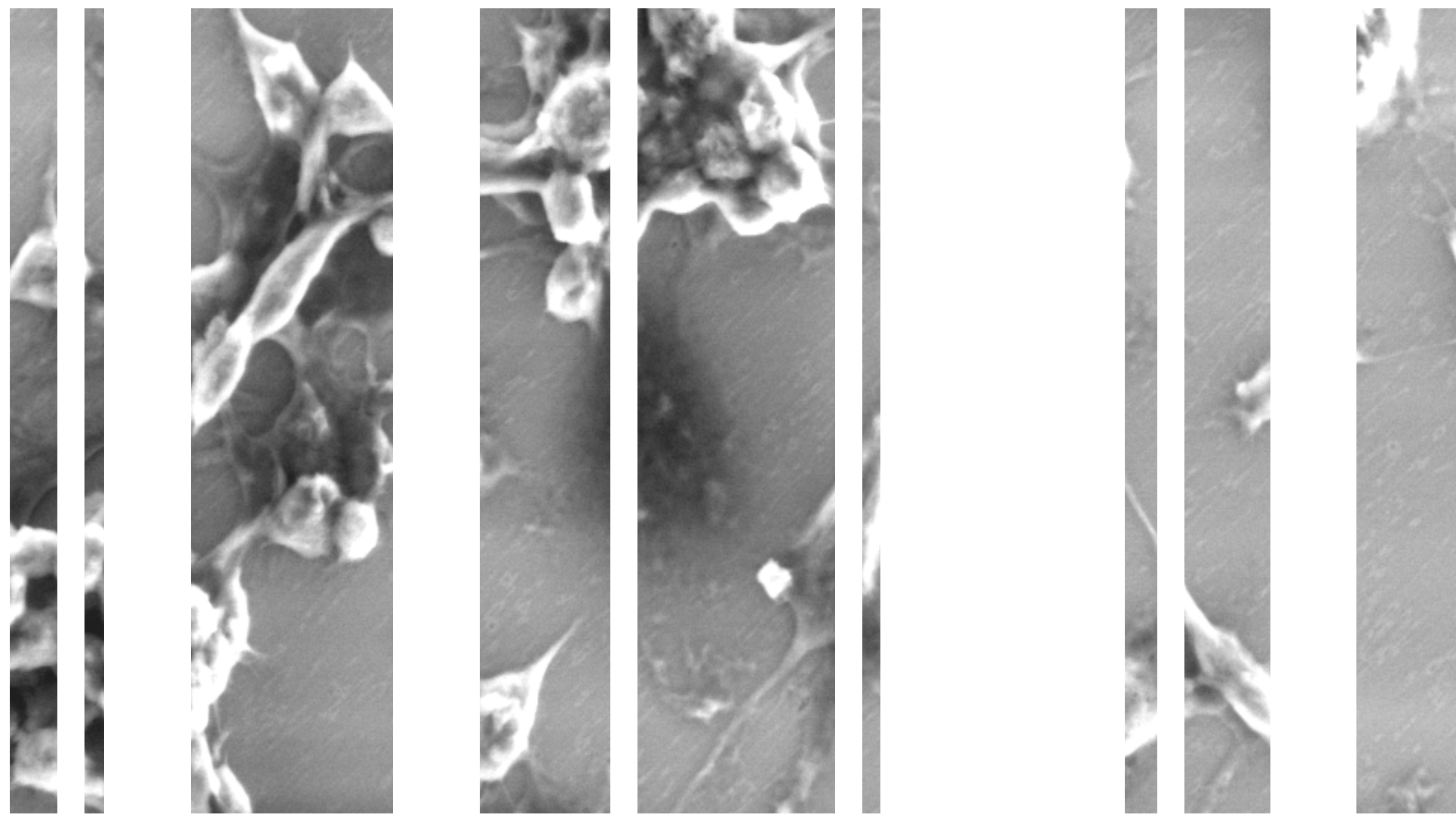


\section{III.1-RESULTADOS OSTEOBLASTOS}

\section{III.1.1-EFECTO DE AGES SOBRE LA PROLIFERACIÓN Y LA MORFOLOGIA OSTEOBLASTICA.}

Con el objeto de corroborar resultados previos de nuestro grupo [McCarthy et al, 1997], en una serie de estudios se investigó el efecto de los AGEs sobre la proliferación en las dos líneas de osteoblastos en cultivo.

Las células MC3T3-E1 y UMR-106 se incubaron por $24 \mathrm{~h}$ con concentraciones crecientes de BSA o AGEs-BSA (50, 100 y $200 \mu \mathrm{g} / \mathrm{ml})$. Luego de este período de incubación, se evaluó la proliferación celular mediante el bioensayo de Cristal Violeta.

Como podemos ver en la Figura III.1.1.1 la incubación con AGEs a la concentración de $50 \mu \mathrm{g} / \mathrm{ml}$ no produce una inhibición significativa de la proliferación en ninguna de las dos líneas celulares. Por su parte, las concentraciones de 100 y $200 \mu \mathrm{g} / \mathrm{ml}$ de AGEs, producen una inhibición que es dependiente de la dosis y es más marcada en la línea MC3T3-E1 que en las células UMR-106.

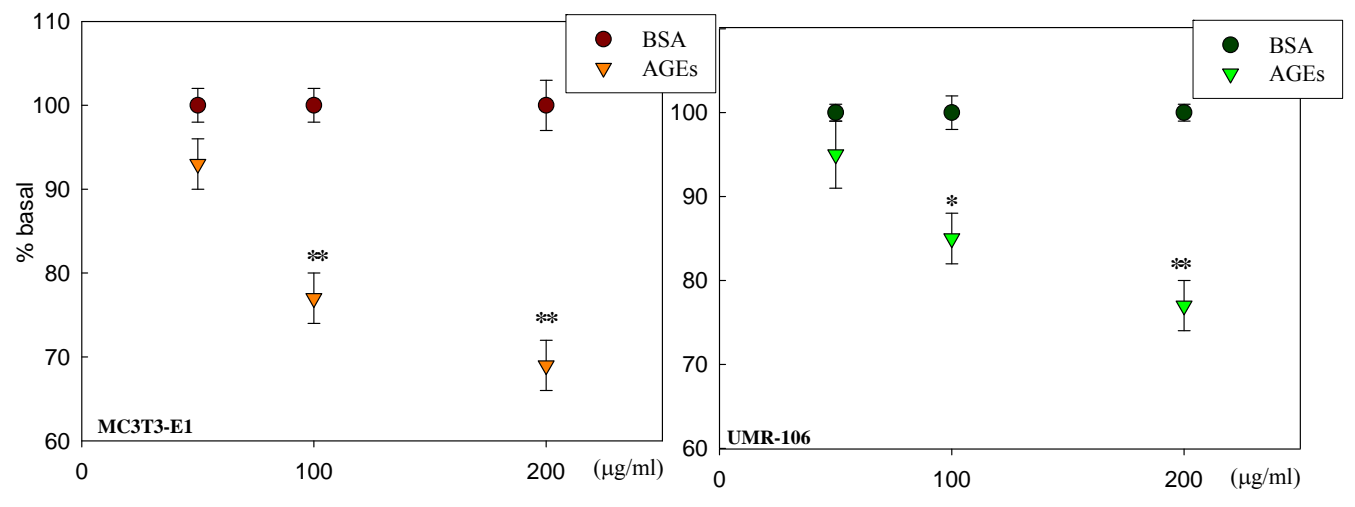

Figura III.1.1.1- Efecto de los AGEs sobre la proliferación los osteoblastos. Las células MC3T3-E1 (izquierda) y UMR-106 (derecha) se incubaron con BSA o AGEs durante 24 h. Se determinó la proliferación por Cristal Violeta y se graficó como $\%$ basal vs concentración $(*$ p $<0.01, * *$ $\mathrm{p}<0.001$ respecto de BSA)

A continuación se investigó si los AGEs producen algún cambio sobre la morfología celular. Para ello, los osteoblastos de las dos líneas celulares (MC3T3-E1 y UMR-106) cultivados sobre cubreobjetos se incubaron con AGEs y BSA (como control) $100 \mu \mathrm{g} / \mathrm{ml}$ por 24 horas. Luego las muestras se observaron por E-SEM. (Figura III.1.1.2). 


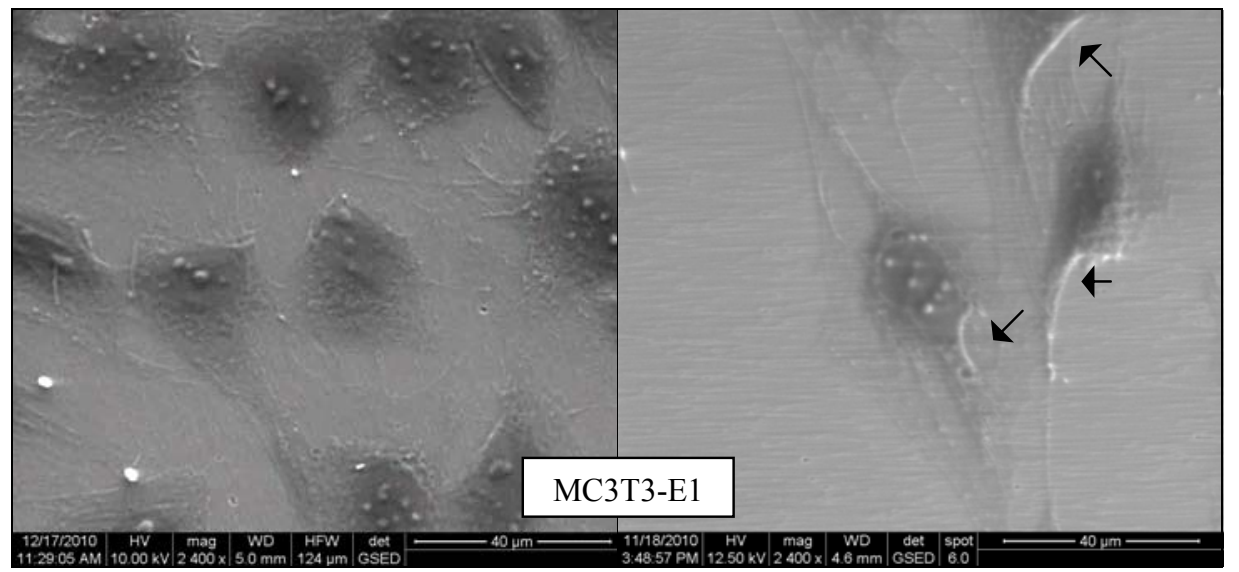

BSA AGEs

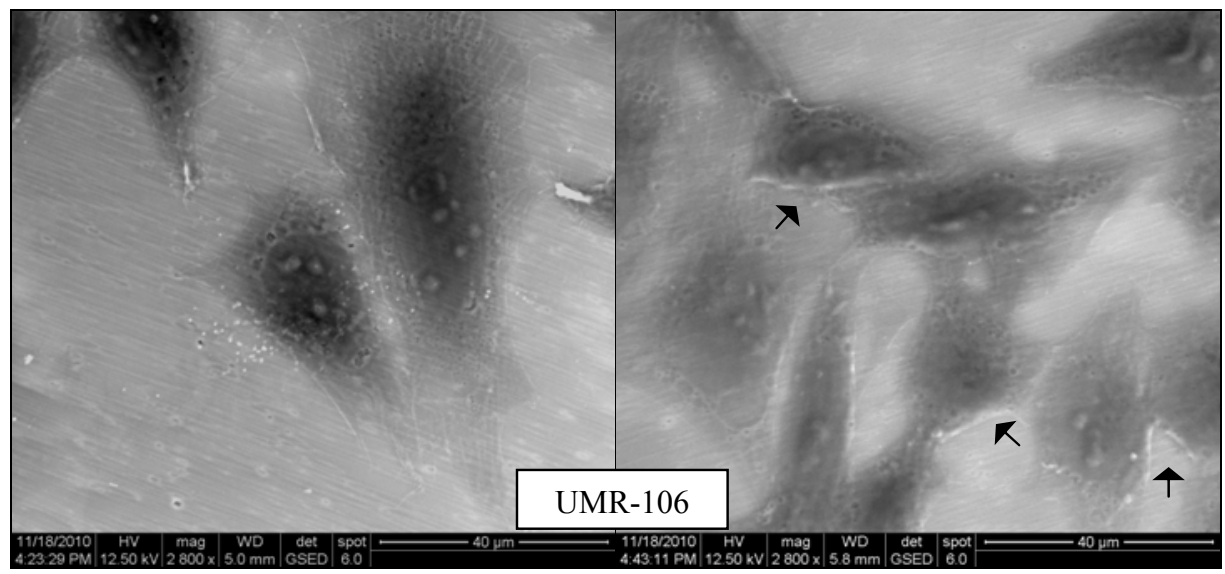

Figura III.1.1.2- Imágenes de E-SEM del efecto de los AGEs sobre los osteoblastos. Las células MC3T3-E1 y UMR-106 se incubaron durante $24 \mathrm{~h}$ en presencia de BSA (izquierda) o AGEs $100 \mathrm{ug} / \mathrm{ml}$ (derecha). Las flechas señalan las zonas birrefringentes que corresponden a porciones despegadas de las células. (aumento: 2400x para las células MC3T3-E1 y 2800x para las células UMR-106)

Al observar las fotos podemos ver que en ambas líneas, las células incubadas con BSA, presentan el citoplasma extendido y bordes regulares, hecho que se traduce en las imágenes de E-SEM como estructuras opacas. Mientras que los osteoblastos expuestos a los AGEs, muestran menos superficie adherida a la matriz. Con BSA las células presentan una forma aplanada, mientras que en presencia de AGEs se observan mas globosas y en relieve. 
Resultados: Osteoblastos

\section{III.1.2-MODULACIÓN DE LA PROLIFERACIÓN DE LOS OSTEOBLASTOS POR}

\section{AGEs Y BPs}

Las células MC3T3-E1 y UMR-106 se incubaron por $24 \mathrm{~h}$ con $100 \mu \mathrm{g} / \mathrm{ml}$ de BSA o AGEs-BSA, con o sin diferentes concentraciones de Alendronato, Pamidronato o Zoledronato $\left(10^{-8} \mathrm{M}, 10^{-6} \mathrm{M}\right.$ o $\left.10^{-4} \mathrm{M}\right)$. Estas concentraciones se eligieron dado que en pacientes osteoporóticos bajo tratamiento con bisfosfonatos (BPs), se postula que los osteoblastos se encuentran expuestos a niveles menores a $10^{-5} \mathrm{M}$ [Spreafico et al., 2006] que es la dosis terapéutica. Luego de este período de incubación, se evaluó la proliferación celular mediante el método de Cristal Violeta.
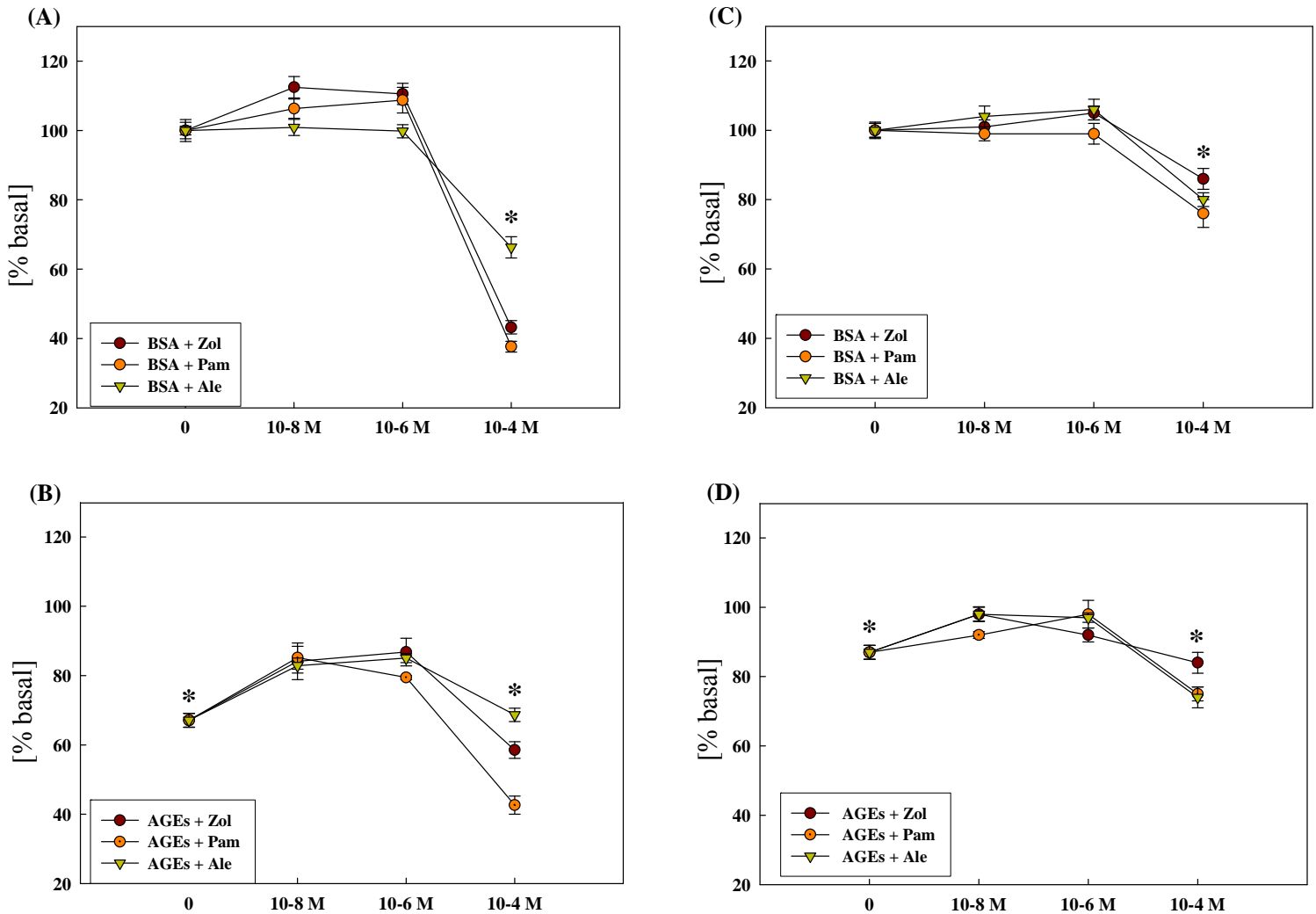

Figura III.1.2-Efecto de los AGEs y BPs sobre la proliferación celular. Las células MC3T3-E1 fueron incubadas por $24 \mathrm{~h}$ con $100 \mu \mathrm{g} / \mathrm{ml}$ BSA (A) o AGEs-BSA (B), con o sin diferentes concentraciones $\left(10^{-8} \mathrm{M}, 10^{-6} \mathrm{M}\right.$ o $\left.10^{-4} \mathrm{M}\right)$ de Alendronato, Pamidronato o Zoledronato. Las células UMR-106 se incubaron con $100 \mu \mathrm{g} / \mathrm{ml}$ BSA (C) o AGEs-BSA (D), en presencia o ausencia de diferentes concentraciones de Alendronato, Pamidronato o Zoledronato $\left(10^{-4} \mathrm{M}, 10^{-6} \mathrm{M}\right.$ o $\left.10^{-8} \mathrm{M}\right)$ durante $24 \mathrm{~h}$. Los resultados están expresados como \% del basal (BSA solo) y se muestran como la Media \pm SEM. (* $<<0.01$ respecto de BSA) 
Como se puede apreciar en la Figura III.1.2, la presencia de AGEs disminuyó significativamente la proliferación osteoblástica y ese efecto fue revertido por la coincubación con Alendronato, Pamidronato o Zoledronato en concentración $10^{-8} \mathrm{M}$ o $10^{-6} \mathrm{M}$, particularmente en la línea MC3T3-E1. Sin embargo, la co-incubación con altas concentraciones $\left(10^{-4} \mathrm{M}\right)$ de los tres BPs resultó tóxica para los osteoblastos y ese efecto fue independiente de la presencia o no de AGEs.

\section{III.1.3-EFECTO DE LOS AGES Y BPs SOBRE LA APOPTOSIS OSTEOBLASTICA}

Una posible explicación para la modulación diferencial de la proliferación osteoblástica que muestran los AGEs y BPs, podría ser que indujeran efectos opuestos sobre la apoptosis de los osteoblastos.

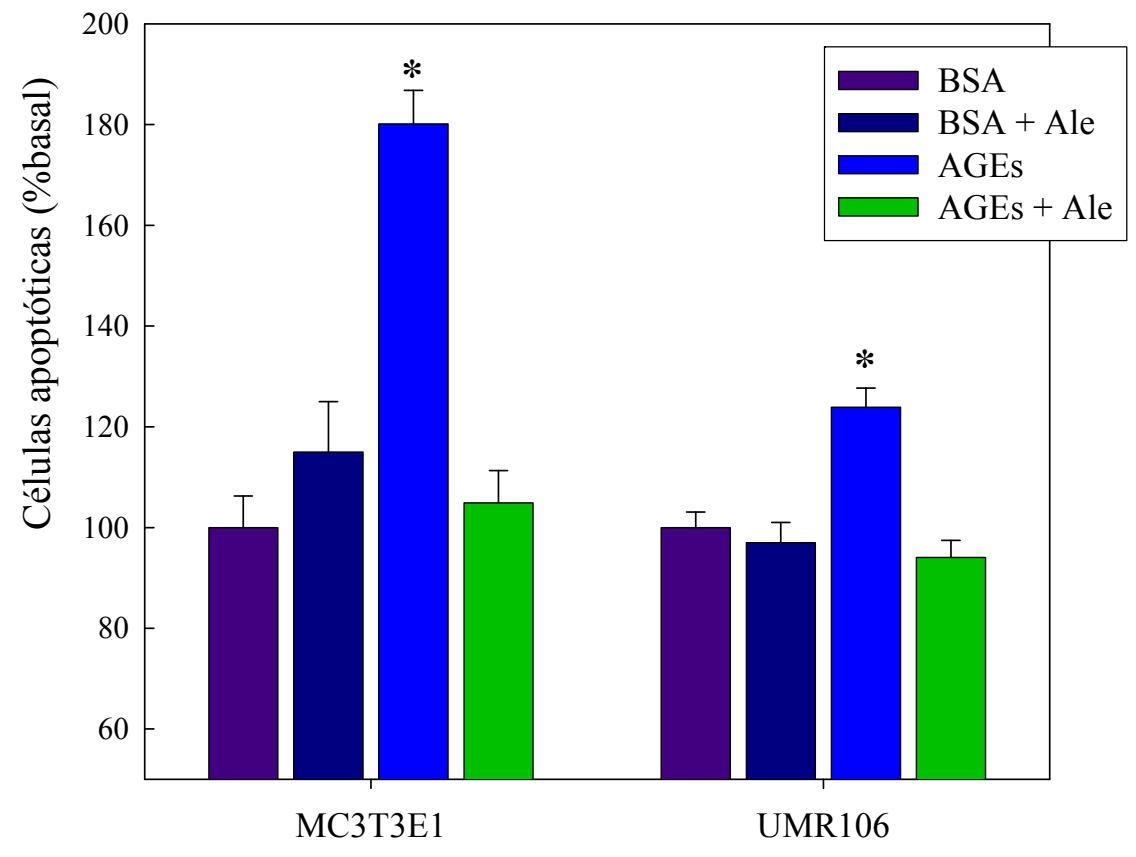

Figura III.1.3- Efecto de AGEs y Alendronato sobre la inducción de apoptosis en células osteoblásticas UMR106 o MC3T3E1.

Las células fueron incubadas durante $24 \mathrm{~h}$ con $100 \mu \mathrm{g} / \mathrm{ml}$ de BSA o AGEs-BSA, con o sin $10^{-8} \mathrm{M}$ de Alendronato. La apoptosis fue evaluada mediante tinción con Anexina V/Ioduro de Propidio. El \% de apoptosis fue determinado contando el número de células por campo en 30 campos. Los resultados están expresados como $\%$ del basal (BSA solo), y se muestran como la Media \pm SEM. (* $\mathrm{p}<0.01$ con respecto a BSA)

Con el objeto de probar esta hipótesis, las células MC3T3-E1 y UMR106 se incubaron durante $24 \mathrm{~h}$ con $100 \mu \mathrm{g} / \mathrm{ml}$ de BSA o AGEs-BSA, con o $\sin 10^{-8} \mathrm{M}$ Alendronato, luego de lo 
cual se evaluó la inducción a apoptosis mediante el método de Anexina V / PI como se describe en Materiales y Métodos.

La Figura III.1.3 muestra que en ambas líneas celulares, los AGEs indujeron un significativo aumento en la apoptosis, el cual fue completamente revertido por dosis bajas de Alendronato. Además, no se encontró un efecto directo del Alendronato solo (Ale + BSA) sobre la apoptosis de ambas líneas celulares, a la dosis estudiada.

\section{III.1.4-EFECTO DE AGEs y BPs SOBRE LA DIFERENCIACIÓN OSTEOBLASTICA}

En otros experimentos, se evaluó el efecto de AGEs y BPs sobre la maduración de células osteoblásticas Para ello, los pre-osteoblastos MC3T3-E1 fueron inducidos a diferenciarse en presencia de un medio osteogénico ( $\beta$-glicerol-fosfato y ácido ascórbico) durante dos semanas. Al final de este período se los incubó por $72 \mathrm{~h}$ con $100 \mu \mathrm{g} / \mathrm{ml}$ de BSA o AGEs con o sin Alendronato $10^{-8} \mathrm{M}$. Por otro lado, cultivos confluentes de células de osteosarcoma UMR106 (48 h), se incubaron en presencia de $100 \mu \mathrm{g} / \mathrm{ml} \mathrm{BSA} \mathrm{o} \mathrm{AGEs} \mathrm{con} \mathrm{o}$ sin Alendronato $10^{-8} \mathrm{M}$ durante $72 \mathrm{~h}$. Luego de esta incubación, se evaluó en ambas líneas celulares la expresión de fosfatasa alcalina (FAL) y la producción de colágeno tipo 1, como se describe en Materiales y Métodos.

Como se muestra en la Figura III.1.4.1 y Figura III.1.4.2, en ambas líneas celulares la incubación con bajas dosis de Alendronato no afectó la diferenciación celular en condiciones basales, es decir en presencia de BSA no modificado. Por otro lado, los AGEs disminuyeron significativamente la expresión de FAL (Figura III.1.4.1(A)) y la producción de colágeno tipo 1 (Figura III.1.4.1 (B)). Sin embargo, en ambos casos la co-incubación con Alendronato a bajas dosis inhibió completamente el efecto deletéreo inducido por AGEs.

Finalmente, se investigó el efecto de AGEs y Ale sobre la mineralización en células MC3T3-E1 inducidas a diferenciación en un medio osteogénico durante 21 días. En los últimos 5 días de esta diferenciación se adicionó $100 \mu \mathrm{g} / \mathrm{ml}$ de BSA o AGEs-BSA, en presencia o ausencia de Alendronato $10^{-8} \mathrm{M}$, luego de lo cual se midió la formación de nódulos de mineralización. Se encontró que en presencia de AGEs la mineralización de la matriz se vio inhibida respecto al control de BSA (Figura III.1.4.2). El Alendronato no afectó la formación de nódulos de mineralización bajo condiciones basales (BSA), pero fue capaz de prevenir completamente el efecto inhibitorio inducido por los AGEs. 

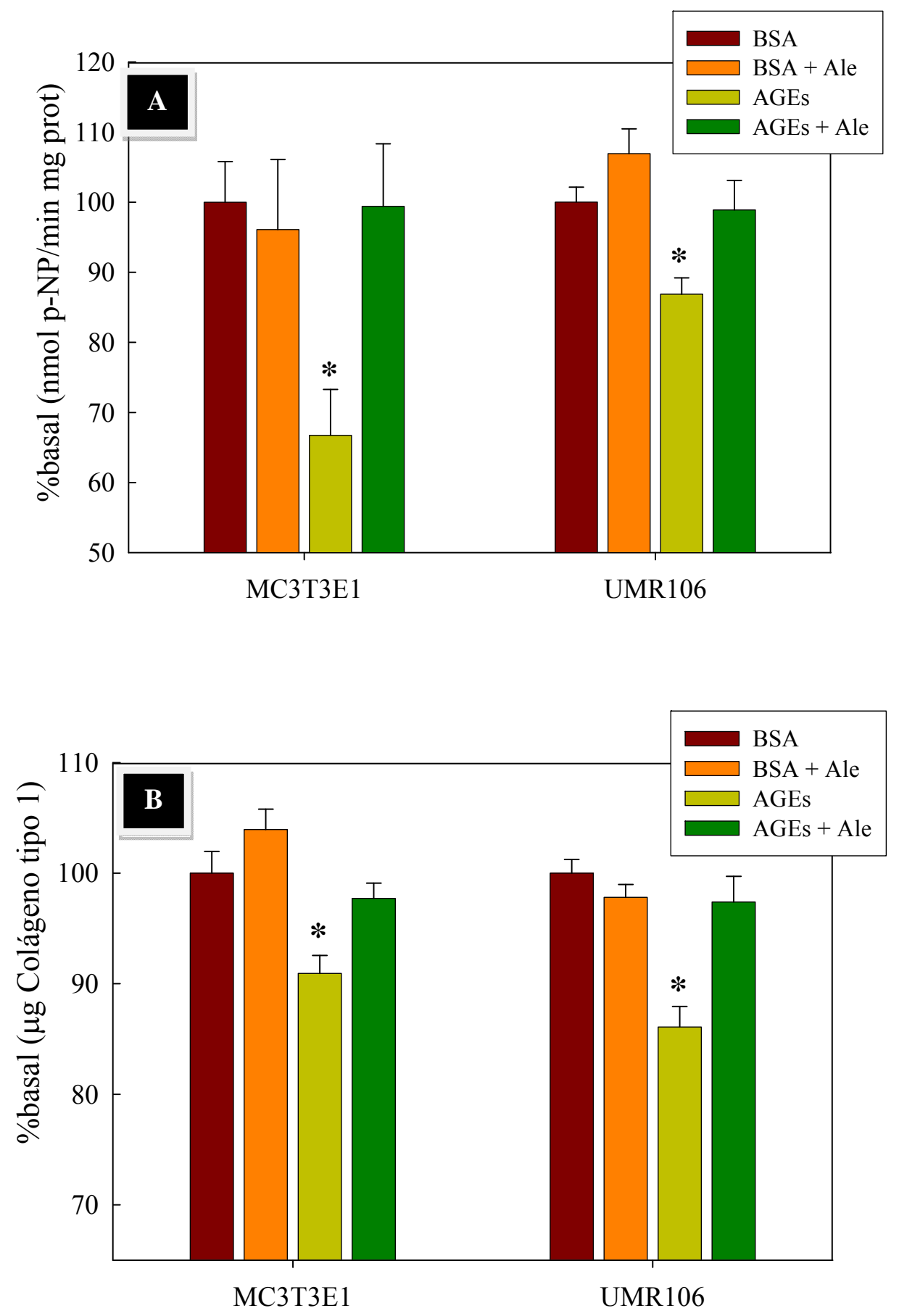

Figura III.1.4.1- Efecto de AGEs y BPs sobre la diferenciación osteoblástica.

Los osteoblastos MC3T3E1 (pre-tratados con $\beta$-glicerol-fosfato y ácido ascórbico durante dos semanas) o las células UMR106 plaqueadas e incubadas hasta confluencia fueron expuestas durante $72 \mathrm{~h}$ a $100 \mu \mathrm{g} / \mathrm{ml} \mathrm{de} \mathrm{BSA} \mathrm{o}$ AGEs-BSA, con o sin Alendronato $10^{-8} \mathrm{M}$. En ambas líneas celulares se evaluó la expresión de fosfatasa alcalina (A), y la producción de colágeno tipo 1 (B) $(* \mathrm{p}<0.01$ con respecto a BSA) 


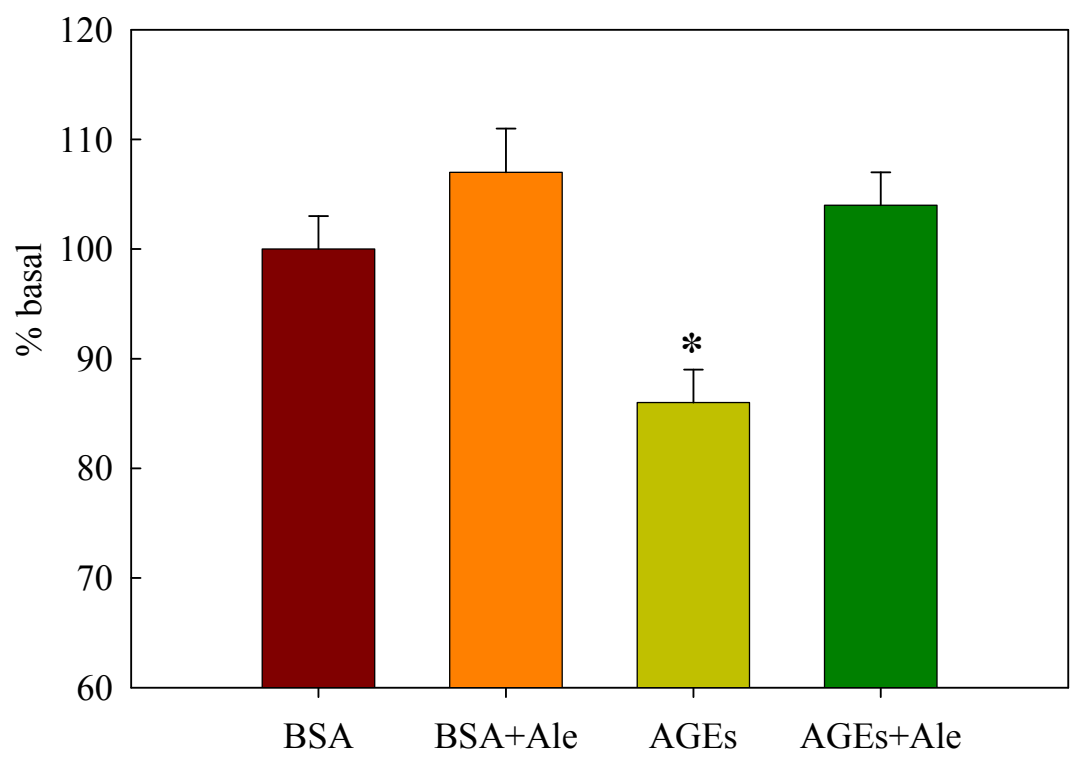

Figura III.1.4.2- Efecto de AGEs y BPs sobre la diferenciación osteoblástica.

En las células MC3T3E1 diferenciadas durante 21 días se determinó la formación de nódulos de mineralización bajo diferentes condiciones: con $100 \mu \mathrm{g} / \mathrm{ml}$ de BSA o AGEs-BSA, en presencia o ausencia de Alendronato 10${ }^{8} \mathrm{M}$ durante los últimos 5 días de diferenciación. Los resultados están expresados como \% del basal (BSA solo) y se muestran como la Media $\pm \operatorname{SEM}(* \mathrm{p}<0.01$ con respecto a BSA)

\section{III.1.5- EFECTO DEL AGES Y ALENDRONATO SOBRE LA MORFOLOGÍA DE OSTEOBLASTOS EN CULTIVO.}

A las células UMR-106 se las plaqueó sobre cubreobjetos y se ensayaron 6 condiciones: a-BSA $100 \mu \mathrm{g} / \mathrm{ml}$
c-BSA $100 \mu \mathrm{g} / \mathrm{ml}$ - Alendronato $10^{-8} \mathrm{M}$
e-BSA $100 \mu \mathrm{g} / \mathrm{ml}$ - Alendronato $10^{-5} \mathrm{M}$ b-AGEs $100 \mu \mathrm{g} / \mathrm{ml}$ d-AGEs $100 \mu \mathrm{g} / \mathrm{ml}$ - Alendronato $10^{-8} \mathrm{M}$ f-AGEs $100 \mu \mathrm{g} / \mathrm{ml}$ - Alendronato $10^{-5} \mathrm{M}$

Se incubaron 24 horas, se fijaron las células rápidamente con glutaraldehido $5 \%$ y se lavaron con agua destilada. Las condiciones de observación fueron $3^{\circ} \mathrm{C}, 5$ torr y $75 \%$ de humedad relativa.

En las imágenes de la Figura III.1.5 podemos observar que las células incubadas con BSA (condición (a): control) poseen el citoplasma extendido y los bordes regulares y bien adheridos al vidrio, se observan planas y se evidencian los núcleos con los nucleolos. Las células que fueron incubadas además con Alendronato $10^{-8} \mathrm{M}$ (condición $(c)$ ) conservan estas características, no así las que se expusieron a Alendronato $10^{-5} \mathrm{M}$, las cuales tienen un menor cantidad de conexiones intercelulares, con procesos celulares muy finitos y en relieve entre las células vecinas (observar en la figura la condición (e)). 
Por otra parte en las células expuestas a AGEs (condición (b)) se aprecian modificaciones en la morfología respecto a la condición control. Tal como describimos en la sección III.1.2, podemos ver que el citoplasma en algunas zonas se contrae y se vuelve más voluminoso dando regiones de alto contraste al observar por E-SEM. Lo mismo podemos observar en la condición $(d)$ en la cual las células se incubaron también con Alendronato 10

${ }^{8} \mathrm{M}$. En la última condición $(f)$ podemos ver que algunas células están mucho más afectadas por el tratamiento conjunto de AGEs y Alendronato a alta concentración. Se observa el citoplasma muy contraído con numerosos procesos celulares finos entre las células y mucho más evidentes que cuando se incubó con Alendronato $10^{-5} \mathrm{M}$ solamente.

\section{III.1.6- EFECTO DE AGEs Y BPs SOBRE EL CITOESQUELETO DE OSTEOBLASTOS EN CULTIVO.}

El ensayo se realizó por inmunofluorescencia directa incubando las células UMR-106 con paloidina-FITC. Se utilizaron las seis condiciones que se ensayaron en la sección III.1.5 y las imágenes obtenidas se presentan en la Figura III.1.6.

Los osteoblastos en las diferentes condiciones presentan las mismas características morfológicas que describimos en la sección anterior. Pero en este caso podemos incluir la descripción de lo que sucede con las fibras de estrés de actina en cada condición

Los osteoblastos incubados con BSA (condición control (a)) presentan una alta densidad de fibras de estrés de actina, las cuales se distribuyen en forma longitudinal en la célula, de borde a borde y se observan múltiples procesos interconectando células vecinas. En los osteoblastos que se incubaron con AGEs (b) podemos ver una desorganización de los filamentos de actina, los cuales se hacen más cortos e irregulares y no se distribuyen de borde a borde celular. También se observa la pérdida de procesos intercelulares y por lo tanto una disminución en el área de contacto entre ellas.

La incubación con Alendronato $10^{-8} \mathrm{M}(c)$ induce un incremento en la densidad de fibras de actina en el citoesqueleto de las células que de otra manera mantienen su forma habitual. En las células incubadas con Alendronato $10^{-5} \mathrm{M}$ (e) se observan importantes alteraciones, con fibras de actina más cortas, más gruesas y desorganizadas mostrando un recorrido en zigzag. Además las células perdieron el contacto entre ellas o lo hacen a través de procesos intercelulares muy finos. 
Las células incubadas con AGEs y Alendronato $10^{-8} \mathrm{M}(d)$, presentan características de las dos condiciones $(b)$ y $(c)$. Es decir, encontramos un aumento en la densidad de fibras de actina pero la presencia de AGEs produce una pérdida de procesos intercelulares.

Finalmente la coincubación de AGEs con Alendronato $10^{-5} \mathrm{M}(f)$ provoca una desorganización mayor del citoesqueleto de actina, con fibras muy cortas y al azar, lo que afecta notablemente la forma de las células con bordes muy irregulares. El contacto entre células vecinas también se ve afectado y caracterizado por escasos procesos intercelulares muy delgados (se vuelven a observar claramente entre las células como en la sección III.1.5)

\section{III.1.7-ACCIÓN DE ALTAS DOSIS DE BPs SOBRE LA ACTINA, TUBULINA Y FAK EVALUADA POR INMUNOFLUORESCENCIA}

Para profundizar el estudio del efecto tóxico de altas dosis de BPs sobre los osteoblastos, las células UMR-106 se incubaron con o sin BP (Zolendronato y Alendronato) $10^{-4} \mathrm{M}$ durante $24 \mathrm{~h}$. Posteriormente se realizó el ensayo de inmunofluorescencia para actina, tubulina y quinasas de adhesión focal (FAK).

Como se puede apreciar en la Figura III.1.7, las células no tratadas con los BPs presentan una forma poligonal y una cierta cantidad de procesos intercelulares. Bajo estas condiciones, también se observa una distribución regular de las fibras de estrés de actina y tubulina en el citoplasma, mientras que la fluorescencia asociada con FAK está uniformemente concentrada en los núcleos. Al incubar las células en presencia de BPs $10^{-4} \mathrm{M}$ se inducen cambios en la morfología celular y en la reorganización del citoesqueleto de actina, teniendo el Zoledronato una acción más potente que el Alendronato. De esta manera, las células tratadas con BPs se observan menos planas, con una disminución en el número y longitud de los procesos intercelulares, mientras que los núcleos y el citoplasma aparecen más pequeños y condensados. Además, las células expuestas a $10^{-4} \mathrm{M}$ de BP muestran una redistribución de la actina del citoplasma a la membrana plasmática, una red de tubulina citoplasmática más difusa y una distribución relativamente desigual de FAK en los núcleos. 


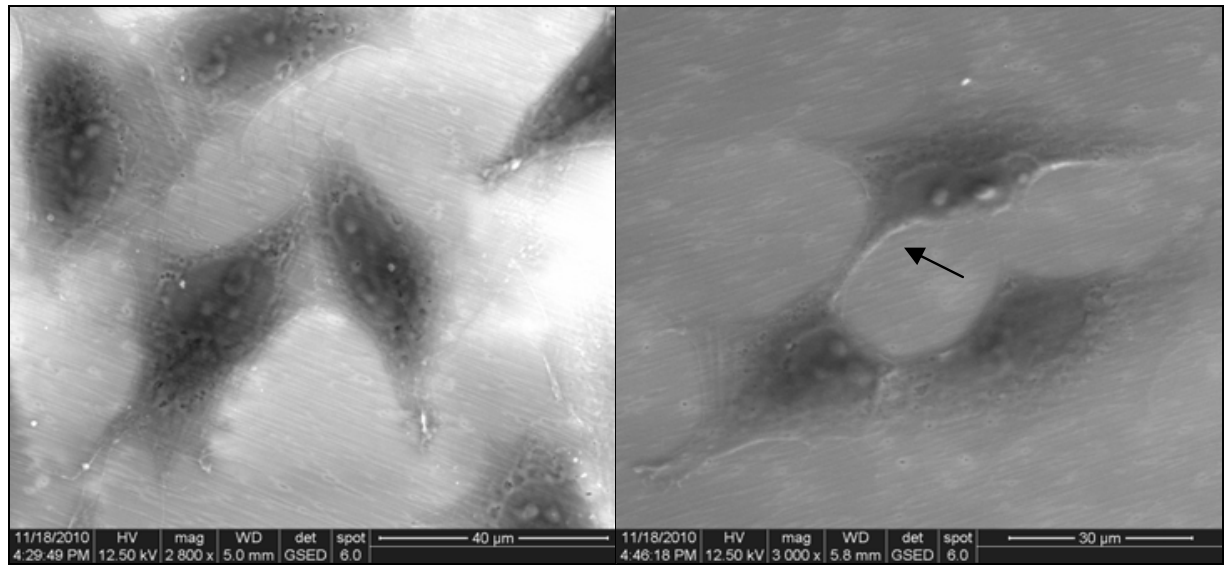

(a) BSA

(b) AGEs

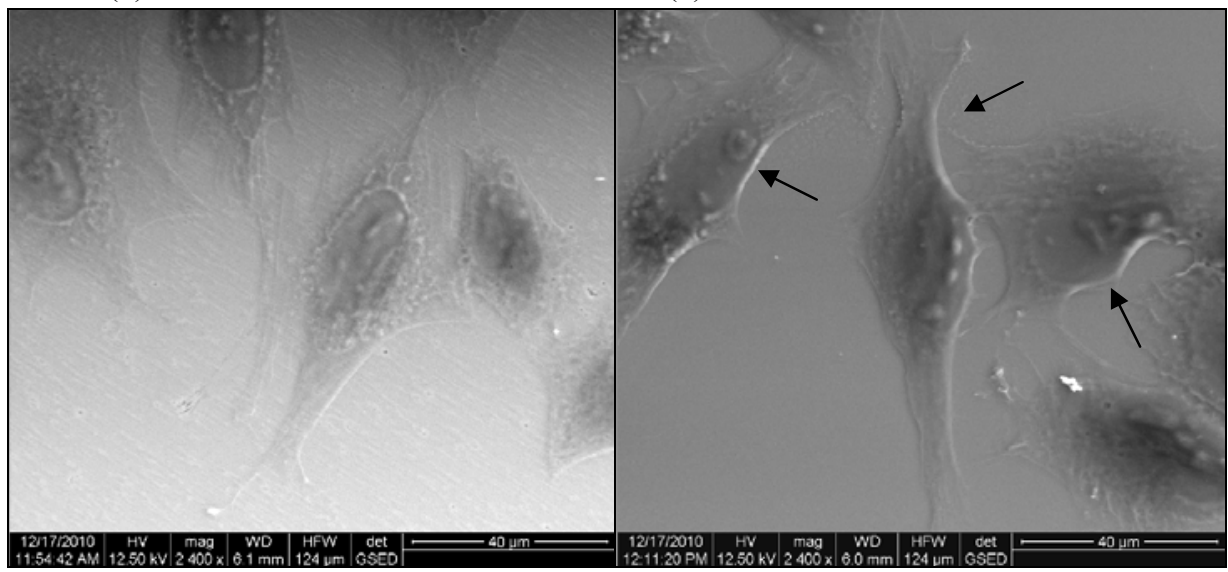

(c) BSA + Alendronato $10^{-8} \mathrm{M}$

(d) AGEs + Alendronato $10^{-8} \mathbf{M}$

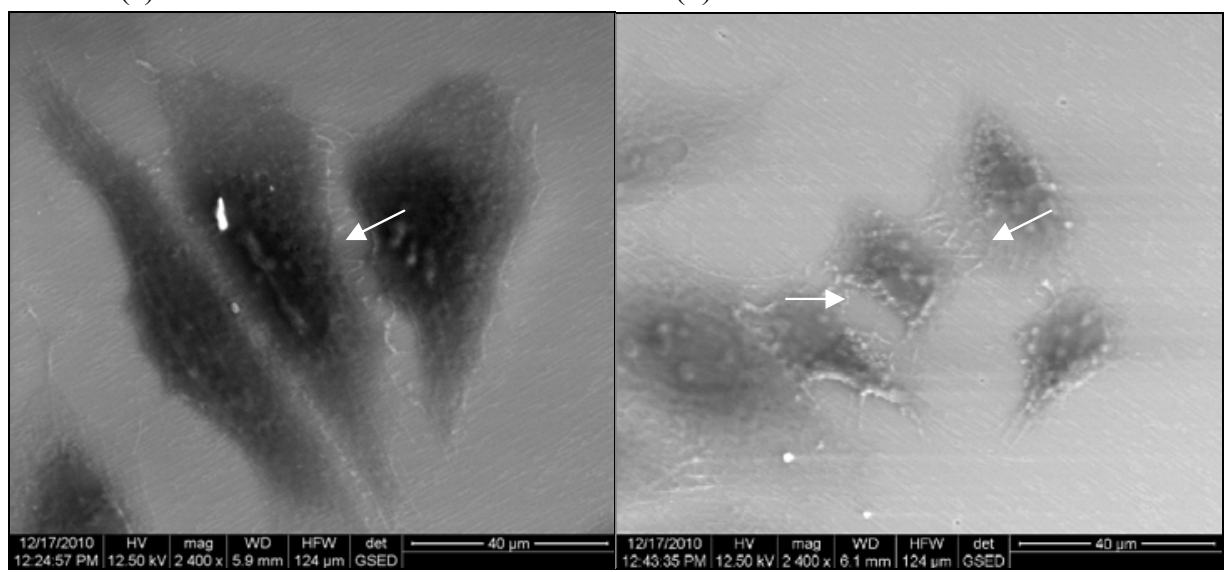

(e) BSA + Alendronato $10^{-5} \mathbf{M}$

(f) AGEs+ Alendronato $10^{-5} \mathbf{M}$

Figura III.1.5- Efecto del AGEs y Alendronato sobre la morfología de osteoblastos en cultivo: Imágenes de E-SEM.

Las células UMR106 se incubaron durante $24 \mathrm{~h}$ en presencia de BSA (a) o AGEs $100 \mathrm{ug} / \mathrm{ml}$, (b) con o $\sin$ Alendronato $10^{-8} \mathrm{M}(\mathrm{c})$ y $(\mathrm{d})$ o $10^{-5} \mathrm{M}(e)$ y $(f)$. Las imágenes se realizaron a $2500 \mathrm{x}$. 


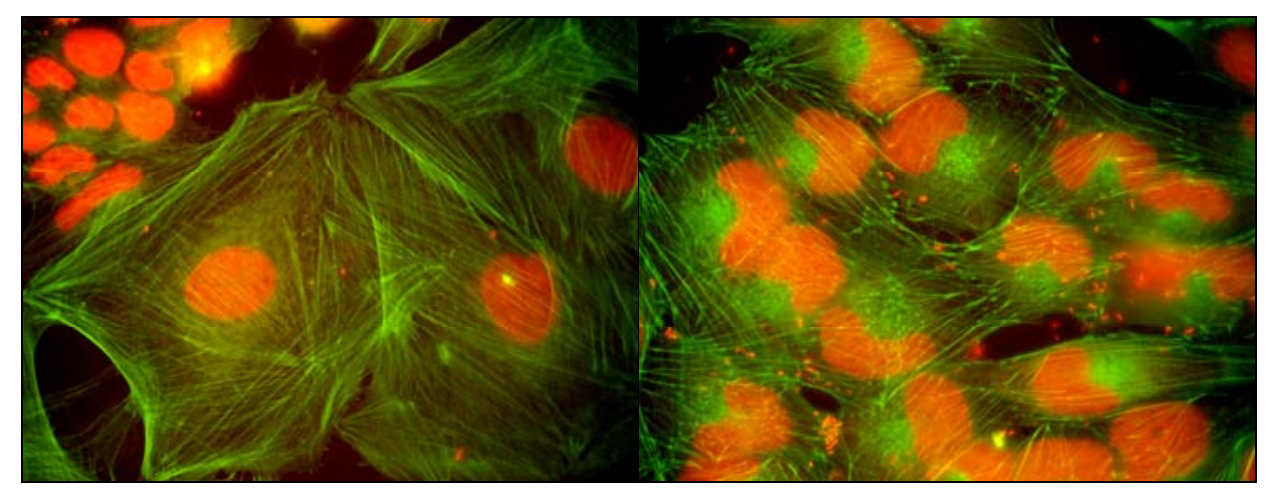

(a) BSA

(b) AGEs

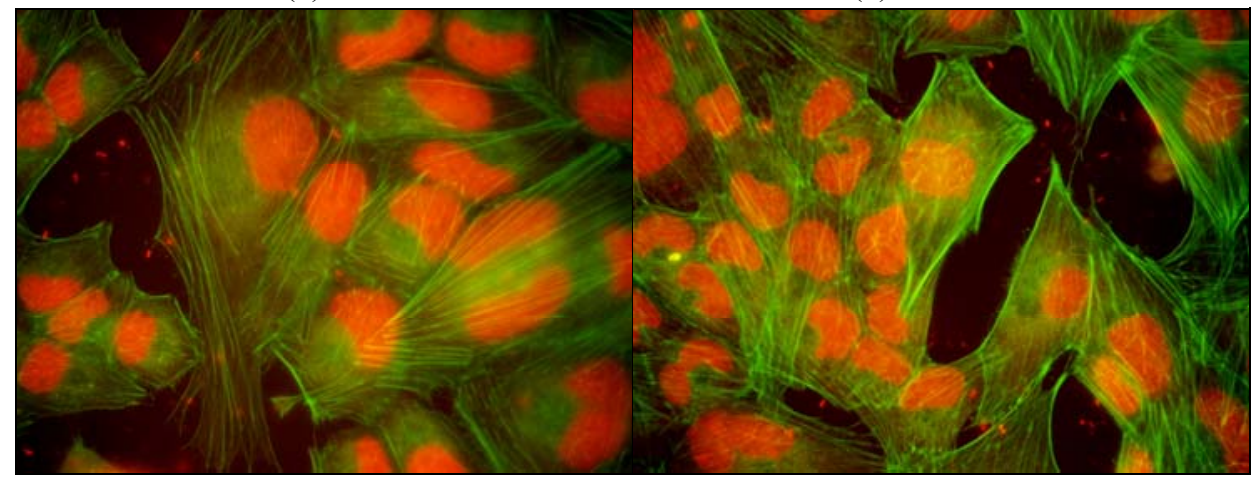

(c) BSA + Alendronato $10^{-8} \mathbf{M}$

(d) AGEs + Alendronato $10^{-8} \mathbf{M}$

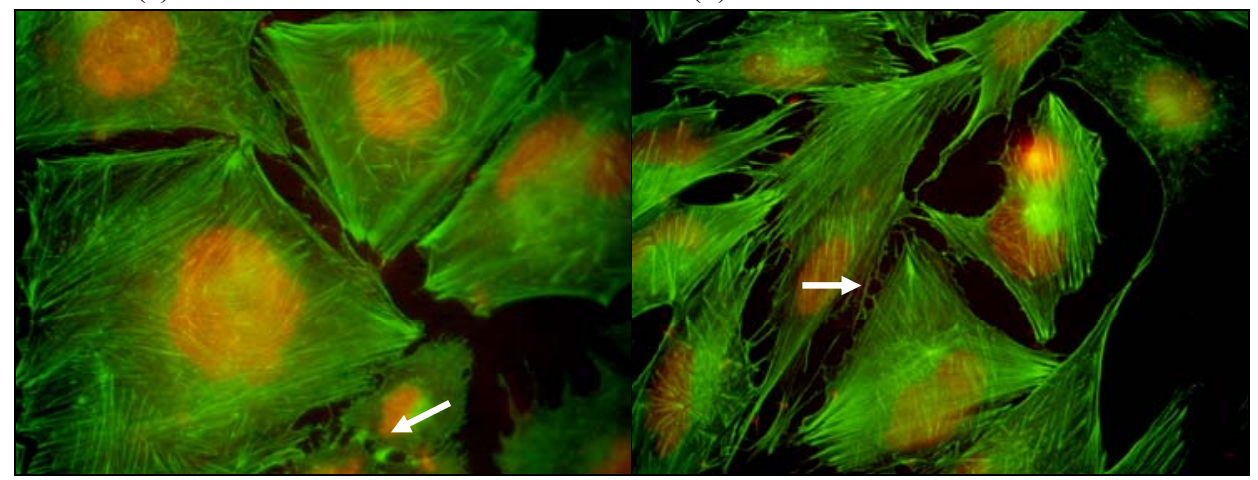

(e) BSA + Alendronato $10^{-5} \mathbf{M}$

(f) AGEs + Alendronato $10^{-5} \mathbf{M}$

Figura III.1.6- Efecto del AGEs y Alendronato sobre las fibras de actina. Las células UMR106 se incubaron durante $24 \mathrm{~h}$ en presencia de BSA (a) o AGEs $100 \mathrm{ug} / \mathrm{ml},(b)$ con o $\sin$ Alendronato $10^{-8} \mathrm{M}(c)$ y $(d)$ o $10^{-5} \mathrm{M}(e)$ y $(f)$. Luego se incubaron con paloidina-FITC para determinar por inmunofluorescencia directa los filamentos de actina (en verde). Los núcleos celulares se tiñeron con Ioduro de propidio (en rojo). Las imágenes están tomadas a 1000x. 

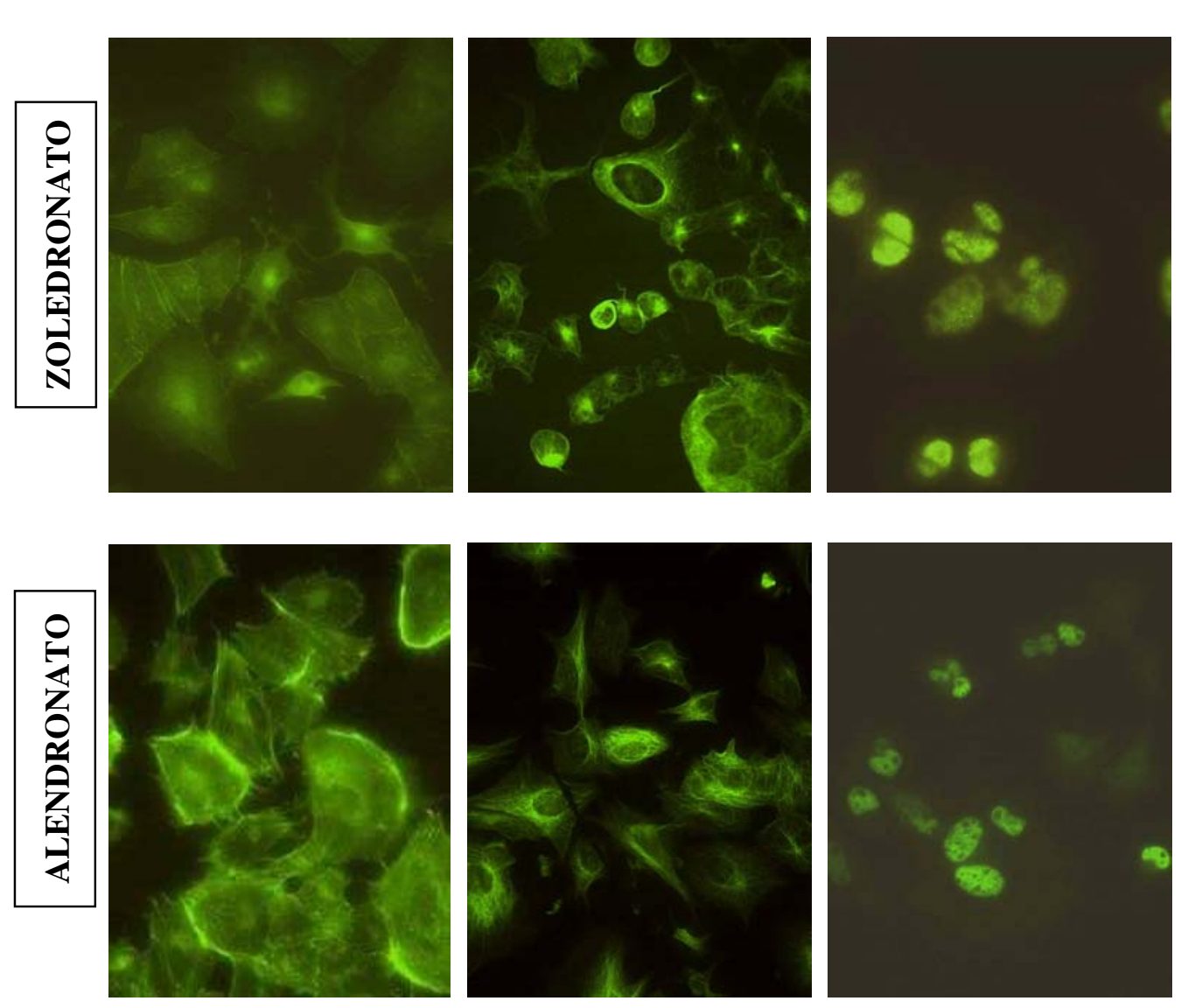

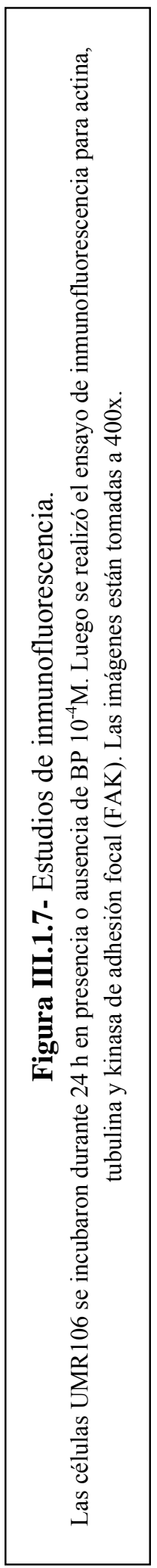


Resultados: Osteoblastos

III.1.8-MODULACIÓN DE LA PROLIFERACIÓN OSTEOBLASTICA. ROL DEL

\section{CALCIO INTRACELULAR}

En una serie de experimentos, se evaluó la posible participación del calcio intracelular sobre los efectos deletéreos de los AGEs así como sobre el efecto de bajas dosis de BP. Para ello, en algunos experimentos se preincubaron las células durante $10 \mathrm{~h}$ con $10 \mu \mathrm{M}$ de Nifedipina (un inhibidor de canales de calcio sensibles al voltaje de tipo L) con o $\sin 10^{-8} \mathrm{M}$ Alendronato.
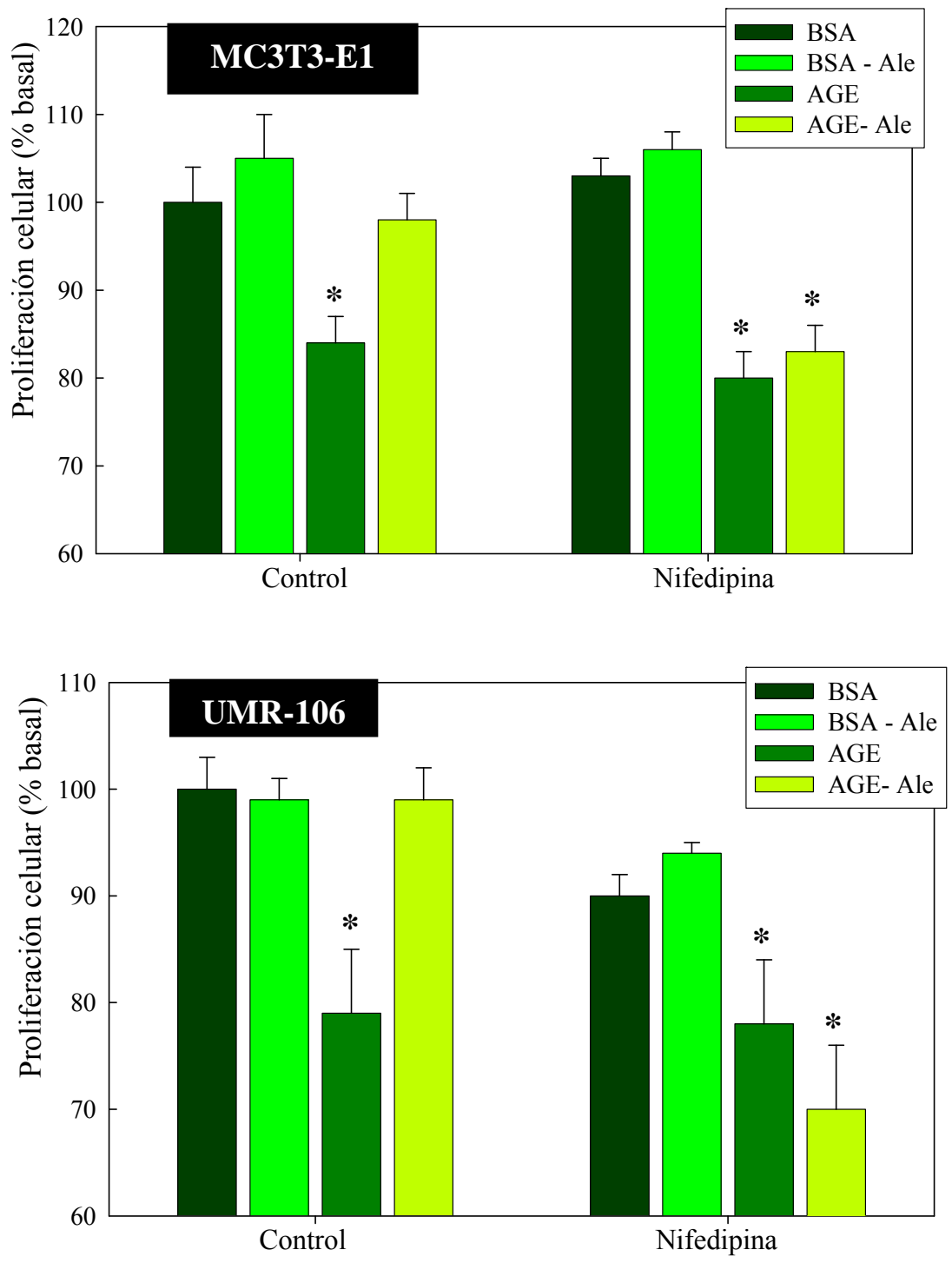

Figura III.1.8- Rol del calcio intracelular en el efecto de AGEs y BPs sobre la proliferación osteoblástica

Las células MC3T3-E1 y UMR-106 se incubaron 24hs con BSA o AGEs-BSA $100 \mu \mathrm{g} / \mathrm{ml}$, en presencia o ausencia de Alendronato $10^{-8} \mathrm{M}$ y preincubados por $10 \mathrm{~h}$ con Nifedipina $10 \mu \mathrm{M}$. Se determinó la proliferación celular por el método de Cristal Violeta. Los resultados están expresados como \% del basal (BSA solo), y se muestran como la Media \pm SEM. $(* \mathrm{p}<0.01$ con respecto a BSA) 
Luego se adicionaron $100 \mu \mathrm{g} / \mathrm{ml}$ de BSA o AGEs-BSA al medio de cultivo y la incubación se siguió hasta completar las 24h. Aunque la Nifedipina no influyó sobre la disminución en la proliferación celular provocada por los AGEs, sí anuló completamente la reversión producida por el Alendronato sobre el efecto de los AGEs mencionado anteriormente (Figura III.1.8) en ambas líneas celulares.

\section{III.1.9-EFECTO DE AGEs y BPs SOBRE LA PRODUCCIÓN DE ESPECIES DE OXIGENO REACTIVAS (ROS)}

Se ha demostrado previamente que ciertos efectos de los AGEs son mediados por la generación intracelular de ROS como segundos mensajeros, en particular aquellos efectos que dependen de la interacción de los AGEs con su receptor RAGE [Ding et al, 2006]. De esta manera, quisimos evaluar si esta vía de traducción de señales estaba involucrada en los efectos de los AGEs y BPs sobre los osteoblastos.

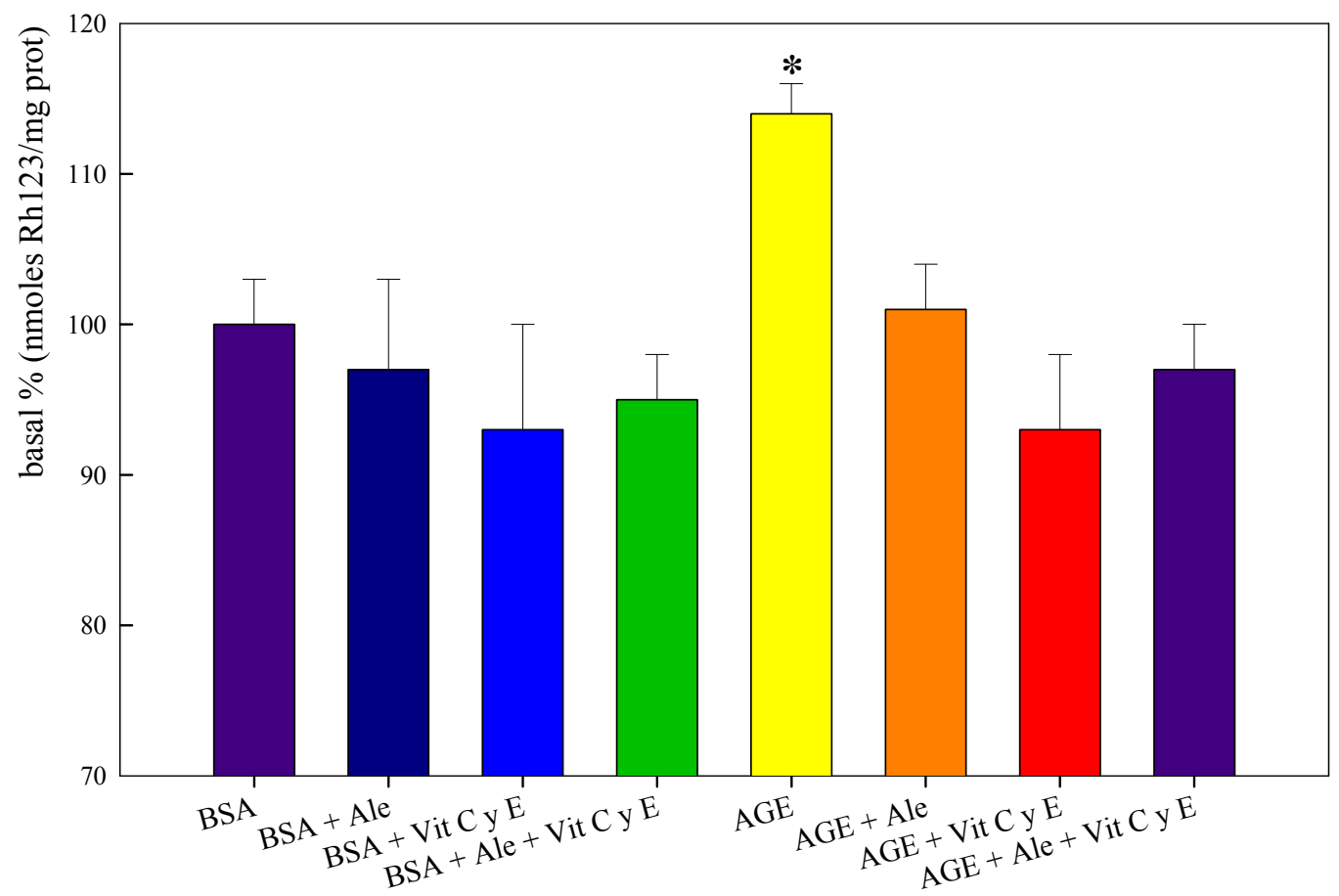

Figura III.1.9- Producción intracelular de ROS: efecto de AGEs y BPs

Los osteoblastos MC3T3E1 fueron incubadas por $24 \mathrm{~h}$ con $100 \mu \mathrm{g} / \mathrm{ml}$ de BSA o AGEs-BSA, con o sin $10^{-8} \mathrm{M}$ de Alendronato (Ale) y en presencia o ausencia de $50 \mu \mathrm{M}$ de vitaminas $\mathrm{C}$ y E (como agentes antioxidantes). Los resultados fueron referidos a la condición basal en la cual se incubaron con BSA solamente y de muestran como la Media \pm S.E.M $(* \mathrm{p}<0.01$ con respecto a BSA) 
Para ello, se incubaron las células osteoblásticas con $100 \mu \mathrm{g} / \mathrm{ml}$ de BSA o AGEs-BSA, con o sin Alendronato $10^{-8} \mathrm{M}$ y en presencia o ausencia de $50 \mu \mathrm{M}$ de vitaminas $\mathrm{C}$ y $\mathrm{E}$ (como antioxidantes), luego de lo cual se evaluó la producción intacelular de ROS mediante el método de DHR, como se describe en Materiales y Métodos

En la Figura III.1.9 se puede observar que las células osteoblásticas expuestas a los AGEs mostraron un incremento significativo de la producción intracelular de ROS. En presencia de Alendronato a bajas dosis y/o antioxidantes ese aumento se vio completamente bloqueado.

\section{III.1.10-EFECTO DE AGEs Y BPS SOBRE LA ACTIVIDAD DE FOSFATASAS NEUTRAS}

En otros estudios se evaluó la acción de los BPs sobre la actividad de fosfatasas neutras intracelulares, como otro posible mecanismo para la regulación del desarrollo osteoblástico. Para ello, la monocapa confluente de células osteoblásticas se incubó durante $24 \mathrm{~h}$ con BSA o AGEs, y en presencia o ausencia de diferentes concentraciones de Alendronato. Los lisados celulares obtenidos se incubaron por 10 minutos con el sustrato fluorogénico DiFMUP: la actividad de las fosfatasas neutras se determinó mediante la velocidad de aparición del producto fluorescente (DiFMU).

Tabla III.1.10-Efecto de BSA, AGEs y diferentes dosis de Alendronato sobre la actividad de las fosfatasas neutras totales en las células osteoblásticas UMR106.

\begin{tabular}{|l|c|c|}
\hline \multicolumn{1}{|c|}{ Condiciones } & $\begin{array}{c}\text { Actividad } \\
\text { [\% de BSA 200] }\end{array}$ & $\begin{array}{c}\text { Actividad } \\
\text { [\% de AGEs 200] }\end{array}$ \\
\hline BSA $200 \mu \mathrm{g} / \mathrm{ml}$ & 100 & - \\
\hline BSA $200+10^{-6} \mathrm{M}$ Ale & 57 & - \\
\hline BSA $200+10^{-5} \mathrm{M}$ Ale & 41 & 100 \\
\hline BSA $200+10^{-4} \mathrm{M}$ Ale & 32 & 103 \\
\hline AGEs $200 \mu \mathrm{g} / \mathrm{ml}$ & 43 & 83 \\
\hline AGEs $200+10^{-6} \mathrm{M}$ Ale & 45 & 63 \\
\hline AGEs $200+10^{-5} \mathrm{M}$ Ale & 36 & 27 \\
\hline AGEs $200+10^{-4} \mathrm{M}$ Ale & & \\
\hline
\end{tabular}



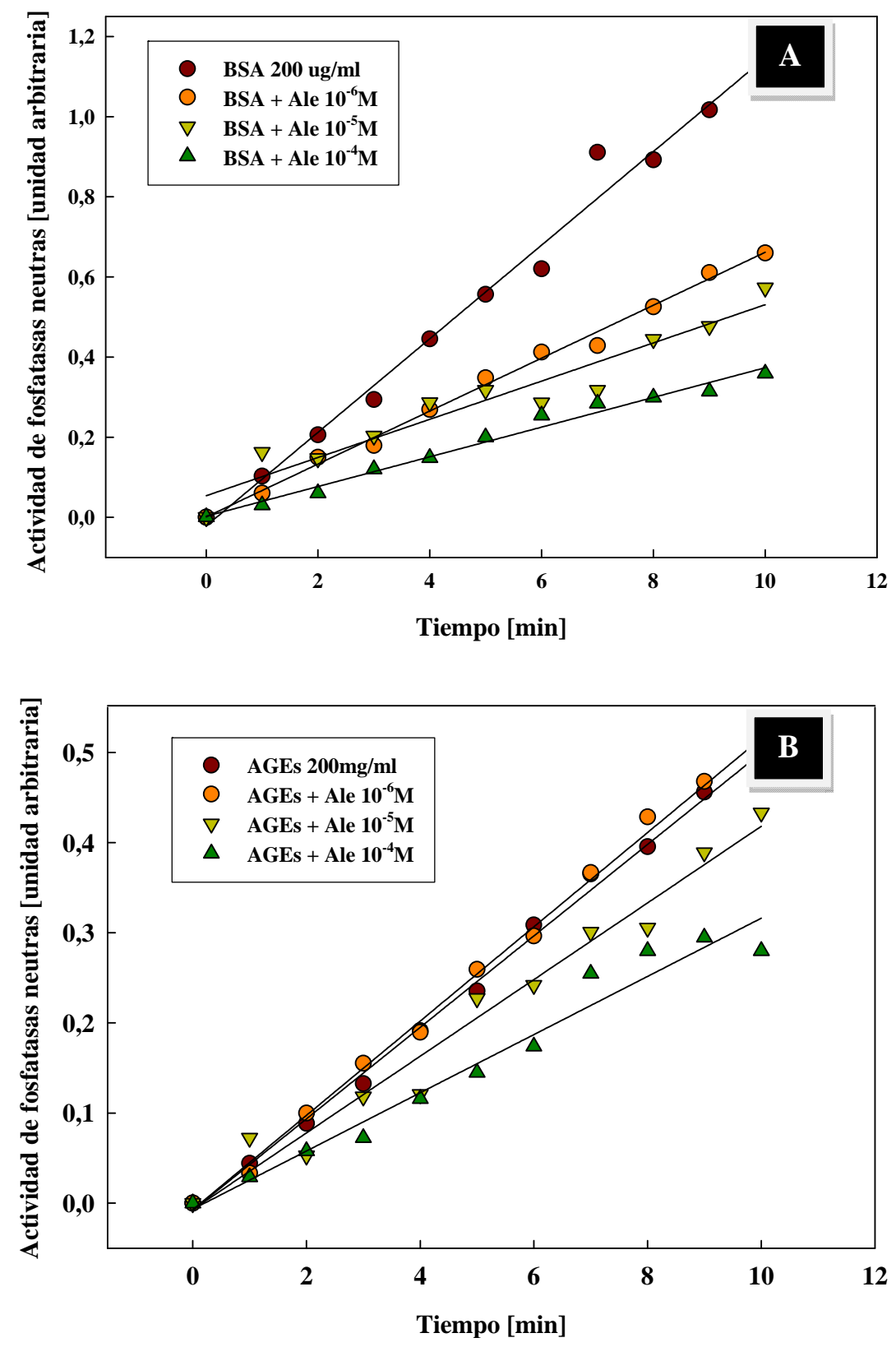

Figura III.1.10- Efecto de AGEs y BPs sobre la actividad de Fosfatasas Neutras en osteoblastos.

La monocapa confluente de células osteoblásticas UMR106 fue incubada por $24 \mathrm{~h}$ con $200 \mu \mathrm{g} / \mathrm{ml}$ de BSA o AGEs-BSA, en presencia o ausencia de diferentes concentraciones $\left(10^{-4}, 10^{-5}\right.$ o $\left.10^{-6} \mathrm{M}\right)$ de Alendronato (Ale). Luego, alícuotas del lisado celular $(50 \mu \mathrm{g}$ de proteínas) fueron incubadas durante 10 minutos con el sustrato fluorogénico DiFMUP. El producto fluorescente resultante fue medido cada minuto como se describe en Materiales y Métodos. Para cada condición experimental, las pendientes fueron calculadas mediante regresión lineal con el objeto de cuantificar la actividad de fosfatasas neutras totales, lo cual se muestra en la Tabla III.1.10 
Como puede observarse en la Fig. III.1.10 y en la Tabla III.1.10, encontramos que los AGEs inhibieron un 50\% de la actividad de las fosfatasas neutras, en comparación con la actividad obtenida en presencia de BSA (note las diferentes escalas utilizadas en las Figura III.1.10 A y B).

Por otro lado en presencia BSA, el Alendronato $10^{-6} \mathrm{M}$ indujo un efecto similar al AGEs, es decir, un 50\% de inhibición en la actividad de fosfatasas neutras (Figura III.1.10.A).

El efecto de AGEs y Alendronato no fue aditivo, dado que no se encontró diferencia en la actividad de fosfatasas neutras en presencia de AGEs solo y AGEs más Alendronato $10^{-6} \mathrm{M}$ (Figura III.1.10.B).

Finalmente observamos que la actividad de fosfatasas neutras fue inhibida en forma dosis-dependiente por concentraciones crecientes de Alendronato $\left(10^{-5} \mathrm{M}\right.$ y $\left.10^{-4} \mathrm{M}\right)$, tanto con BSA como con AGEs-BSA. Estos niveles de Alendronato son compatibles con una significante quelación de cationes divalentes por parte del bisfosfonato. 


\section{III.2-RESULTADOS OSTEOCLASTOS}

\section{III.2.1-COCULTIVOS: MODELO DE OSTEOCLASTOS}

Para la obtención de este modelo de osteoclastos se utilizó el método de cocultivo de osteoblastos y macrófagos. Se cocultivaron células UMR-106 (línea osteoblásticas) con células Raw 264.7 (línea monocito-macrofágica) durante aproximadamente 4 días, cambiando el medio cada dos días, hasta observar la formación de células gigantes multinucleadas al microscopio óptico. Con el objetivo de evaluar la formación y maduración de los osteoclastos, se determinó la presencia de células con actividad de fosfatasa ácida tartrato-resistente (TRAP (+)) utilizando un kit para dicha reacción citoquímica. (Figura III.2.1).

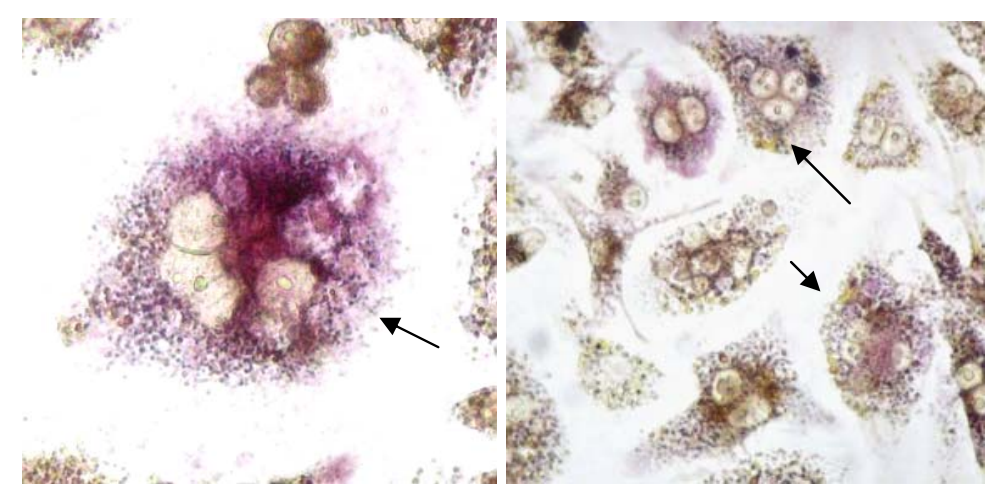

Figura III.2.1-.Cocultivo de ocho días en los que podemos observar células multinucleadas TRAP $(+)$ (flechas). Obj 40x

\section{III.2.2-CINÉTICA DE EXPRESIÓN DE TRAP EN FUNCIÓN DEL TIEMPO DE COCULTIVO}

Para evaluar la evolución de la expresión de la TRAP en los cocultivos UMR106-Raw 264.7, éstos se cocultivaron durante diferentes tiempos, luego de lo cual se realizó la determinación de la actividad enzimática en un lisado celular total. Los niveles basales de TRAP, correspondientes a las células Raw264.7 fueron de 42 nmol de p-NP/min*mg de proteína, mientras que en las células UMR106 esta actividad fue de $6 \mathrm{nmol}$ de p-NP/min*mg de proteína, Los cambios de actividad TRAP con el tiempo se pueden apreciar en la Figura III.2.2. Al observar la curva obtenida, vemos que a la semana de iniciado el cocultivo, la actividad TRAP se duplica con respecto a la condición basal de los macrófagos Raw 264.7 Asimismo, al cuarto día ya se puede ver un aumento significativo en dicha actividad. 


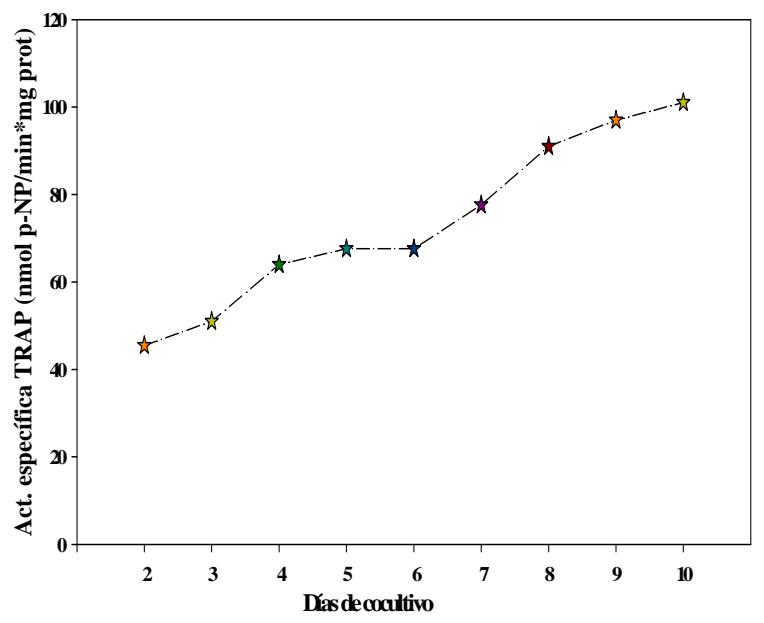

Figura III.2.2-Cinética de expresión de TRAP

Los cocultivos de UMR-106/Raw264.7 se mantuvieron por diferentes períodos de cultivo, luego de lo cual se determinó la actividad TRAP con un ensayo colorimétrico. Se expresaron los resultados en actividad TRAP específica $=$ nmol de $\mathrm{p}-\mathrm{NP} / \mathrm{mg}$ de Prot* min.

\section{III.2.3-ACCIÓN DE LOS AGEs SOBRE LA ACTIVIDAD TRAP}

En otra serie de estudios quisimos evaluar el efecto de los AGEs sobre el desarrollo y actividad de los osteoclastos. Para ello, a cocultivos de 4 días le agregamos distintas concentraciones de BSA o AGE-BSA $(50 \mu \mathrm{g} / \mathrm{ml}, 100 \mu \mathrm{g} / \mathrm{ml}, 200 \mu \mathrm{g} / \mathrm{ml})$ y se mantuvieron en esas condiciones hasta completar los 8 días de cultivo. Como muestra la Figura III.2.3, los AGEs inhibieron en forma dosis dependiente, la actividad TRAP entre 10 y $30 \%$ del basal (incubado en presencia de BSA).

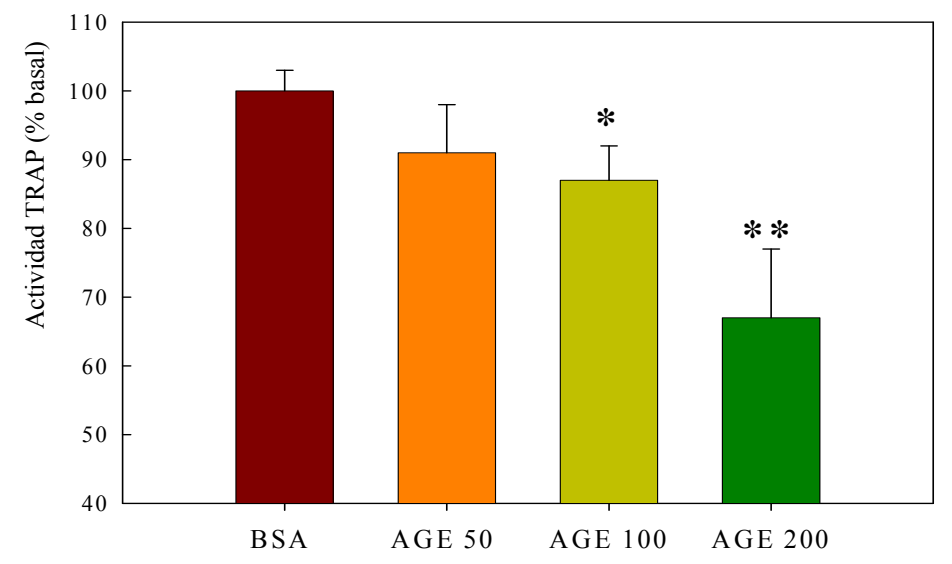

Figura III.2.3-Efecto de los AGEs sobre la actividad TRAP.

Las células UMR106 y Raw264.7 se cocultivaron durante 4 días hasta la aparición de células multinucleadas, y luego se incubaron con diferentes concentraciones de BSA o AGEs-BSA (50 $\mu \mathrm{g} / \mathrm{ml}, 100 \mu \mathrm{g} / \mathrm{ml}$ y $200 \mu \mathrm{g} / \mathrm{ml})$ por 4 días más. La actividad TRAP se determinó determinó colorimétricamente en los lisados celulares. Los resultados se expresan como \%basal y se presentan como la media +/-SEM. Se grafica una sola barra para BSA, pero que en realidad cada condición de AGE se comparó con su propio control de BSA. $(* \mathrm{p}<0.05$, ** $\mathrm{p}<0.01)$ 


\section{III.2.4-ACCIÓN DE LOS AGES Y DISTINTAS CONCENTRACIONES DE}

\section{ALENDRONATO SOBRE LA ACTIVIDAD TRAP DE LOS OSTEOCLASTOS}

Una vez evaluado el efecto de los AGEs, investigamos el posible efecto del agregado de diferentes dosis de Alendronato en coincubación con los AGEs. Para ello elegimos la concentración de $100 \mu \mathrm{g} / \mathrm{ml}$ de AGE, la cual inhibe aproximadamente un 13\% la actividad TRAP respecto al control con BSA (Figura III.2.4). Como resultado de estos experimentos, encontramos que bajas dosis de Alendronato $\left(10^{-8} \mathrm{M}-10^{-6} \mathrm{M}\right)$ indujeron una inhibición significativa, y similar al AGE, sobre la actividad de TRAP de cocultivos desarrollados en presencia de BSA. Por el contrario, en presencia de AGE no se observó una inhibición adicional de las bajas dosis de Alendronato, a la ya producida por el AGE. Por otro lado, altos niveles de Alendronato $\left(10^{-5} \mathrm{M}-10^{-4} \mathrm{M}\right)$ inhibieron la actividad TRAP en forma significativa, observando un $20-25 \%$ de inhibición respecto al cultivo con BSA y un 17\% inhibición respecto al cultivo en presencia de AGEs. Así, parecería haber un pequeño efecto aditivo de los dos agentes sobre la actividad de TRAP observada en presencia de AGE y altas dosis de Alendronato (aproximadamente $30 \%$ de inhibición respecto al cultivo en presencia de BSA basal).

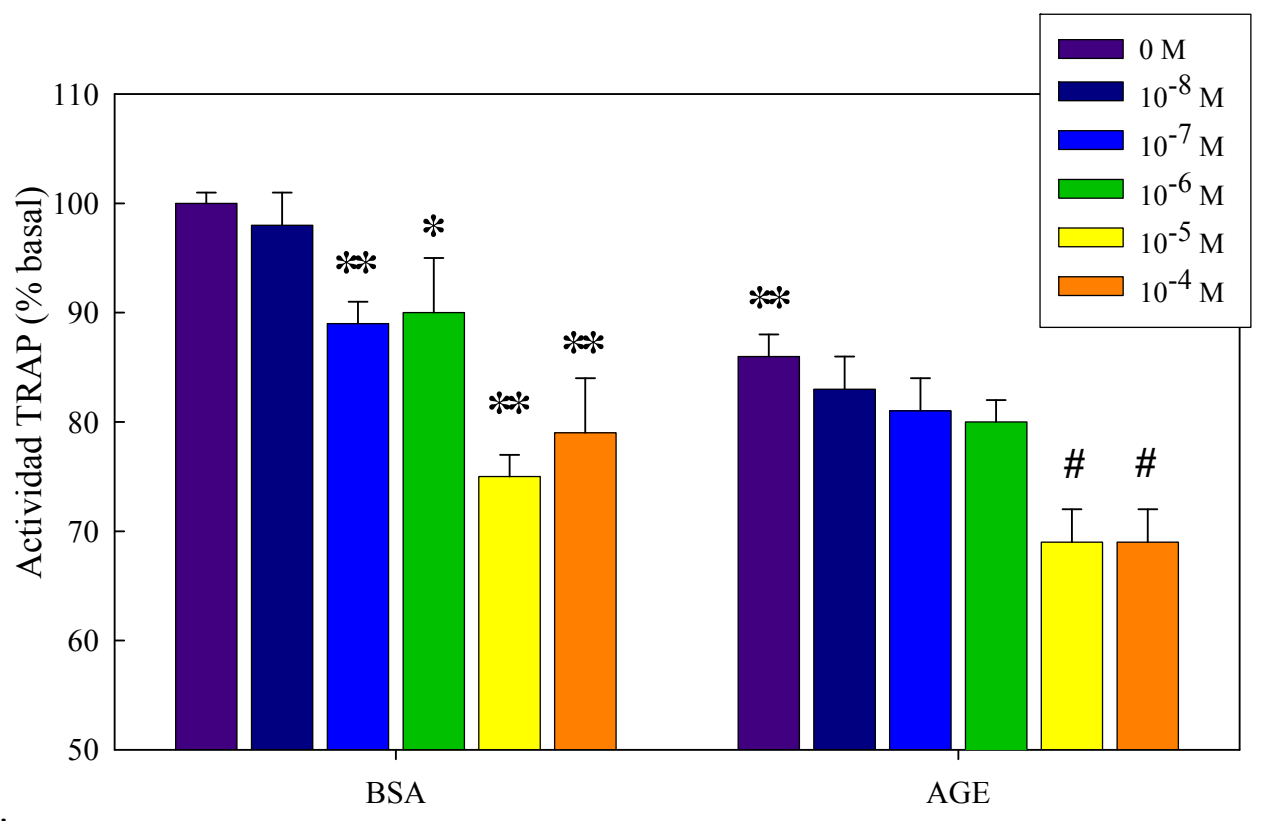

Figura III.2.4-Efecto de los AGEs y distintas concentraciones de Alendronato sobre la actividad TRAP.

Las células UMR106 se cocultivaron con los macrófagos Raw264.7 durante 8 días. Al cumplirse 4 días de cultivo se les agregó BSA o AGEs-BSA en presencia o ausencia de Alendronato en concentraciones crecientes $\left(10^{-8} \mathrm{M}-10^{-4} \mathrm{M}\right)$ y se incubó hasta completar los 8 días de cultivo. Finalmente se evaluó la actividad TRAP por el método ya descripto. Los resultados se expresan como \% basal y se presentan como la media $+/$-SEM $(* \mathrm{p}<0.05$, ** $\mathrm{p}<0.001$ respecto de BSA) (\# $\mathrm{p}<0.001$ respecto de AGEs) 


\section{III.2.5-ACCIÓN DE LOS AGEs Y ALENDRONATO $10^{-5} \mathrm{M}$ SOBRE LA ACTIVIDAD TRAP DE OSTEOCLASTOS EN DISTINTOS MOMENTOS DEL COCULTIVO}

Para evaluar en qué fase del cocultivo actúa cada uno de estos agentes (AGEs y Alendronato) se realizó una serie de ensayos para abarcar las distintas etapas:

1- Un cocultivo de 8 días con las diferentes condiciones desde el inicio (desde la formación de los osteoclastos)

2- Un cocultivo corto de 4 días incubado con las condiciones.

3- Un cocultivo de 8 días en el cual se colocaron las condiciones desde el cuarto día hasta el final.

Las incubaciones se realizaron con Alendronato $10^{-5} \mathrm{M}$ coincubado con BSA o AGEsBSA $100 \mu \mathrm{g} / \mathrm{ml}$. Luego se lisaron las células y en los lisados se determinó la actividad TRAP por ensayo colorimétrico midiendo la Absorbancia a $405 \mathrm{~nm}$. Los resultados se expresan como \% basal y se presentan como la media +/-SEM.

En la Tabla III.2.5 se puede ver que el AGE inhibe significativamente la actividad TRAP bajo todas las condiciones experimentales probadas.

El Alendronato $10^{-5} \mathrm{M}$ comienza a actuar en la segunda fase, dado que la incubación con Alendronato en el cocultivo corto no produce una inhibición significativa en la actividad TRAP. En la última columna puede observarse que la coincubación con ambos compuestos induce un efecto aditivo, tanto si se agregan en la segunda fase como durante todo el periodo de cultivo de 8 días.

Tabla III.2.5-Acción de los AGEs y Ale $10^{-5} \mathrm{M}$ sobre la actividad TRAP de osteoclastos (* $\mathrm{p}<0.05)$

\begin{tabular}{|c|c|c|c|c|}
\hline & $\begin{array}{c}\text { BSA 100 } \\
\mathbf{\mu g} / \mathbf{m l}\end{array}$ & $\begin{array}{c}\text { BSA Ale 10 } \\
{ }^{5} \mathbf{M}\end{array}$ & $\begin{array}{c}\text { AGEs 100 } \\
\mathbf{\mu g} / \mathbf{m l}\end{array}$ & AGE Ale 10 ${ }^{-5} \mathbf{M}$ \\
\hline $\begin{array}{c}\mathbf{8} \text { días c/ } \\
\text { condiciones }\end{array}$ & $\mathbf{1 0 0 + / - 2}$ & $86+/-5 *$ & $86+/-3 *$ & $69+/-2 *$ \\
\hline $\begin{array}{c}\mathbf{4} \text { días iniciales c/ } \\
\text { condiciones }\end{array}$ & $\mathbf{1 0 0 + / - 2}$ & $\mathbf{9 8 + / - 6}$ & $75+/-3 *$ & $73+/-5 *$ \\
\hline $\begin{array}{c}\mathbf{8 d i a s ,} \mathbf{4} \text { días } \\
\text { finales } \\
\text { condiciones }\end{array}$ & $\mathbf{1 0 0 + / - 1}$ & $75+/-6 *$ & $86+/-2 *$ & $69+/-3 *$ \\
\hline
\end{tabular}




\section{III.2.6-ACCIÓN DE LOS AGES Y ALENDRONATO SOBRE EL NÚMERO DE OSTEOCLASTOS.}

A cocultivos de 4 días, incubados sobre cubreobjetos colocados en platos de 6 pocillos, se les agregó BSA o AGEs $100 \mu \mathrm{g} / \mathrm{ml}$, con Alendronato $10^{-8} \mathrm{M}$ o con Alendronato $10^{-}$ ${ }^{5} \mathrm{M}$. Se incubaron por 4 días, luego de los cuales se fijaron, se tiñeron con Giemsa, se montaron sobre portaobjetos y se contaron las células con 3 o más núcleos en 50 campos a $400 x$.

En la Fig. III.2.6 puede observarse el número promedio de osteoclastos por campo en las distintas condiciones. Como podemos apreciar, la presencia de AGEs en el cocultivo, produjo una inhibición significativa del número de osteoclastos (55\% del BSA), mientras que el Alendronato indujo una disminución significativa y dosis dependiente en el número de osteoclastos. Así, el agregado de bajas dosis de Alendronato en presencia de AGE, no indujo un efecto adicional sobre la inhibición producida por el AGE sobre el número de osteoclastos. Por el contrario, altas concentraciones de Alendronato $\left(10^{-5} \mathrm{M}\right)$ indujeron una inhibición significativa sobre el número de osteoclastos desarrollados en presencia de AGE (16\% con respecto a AGEs).

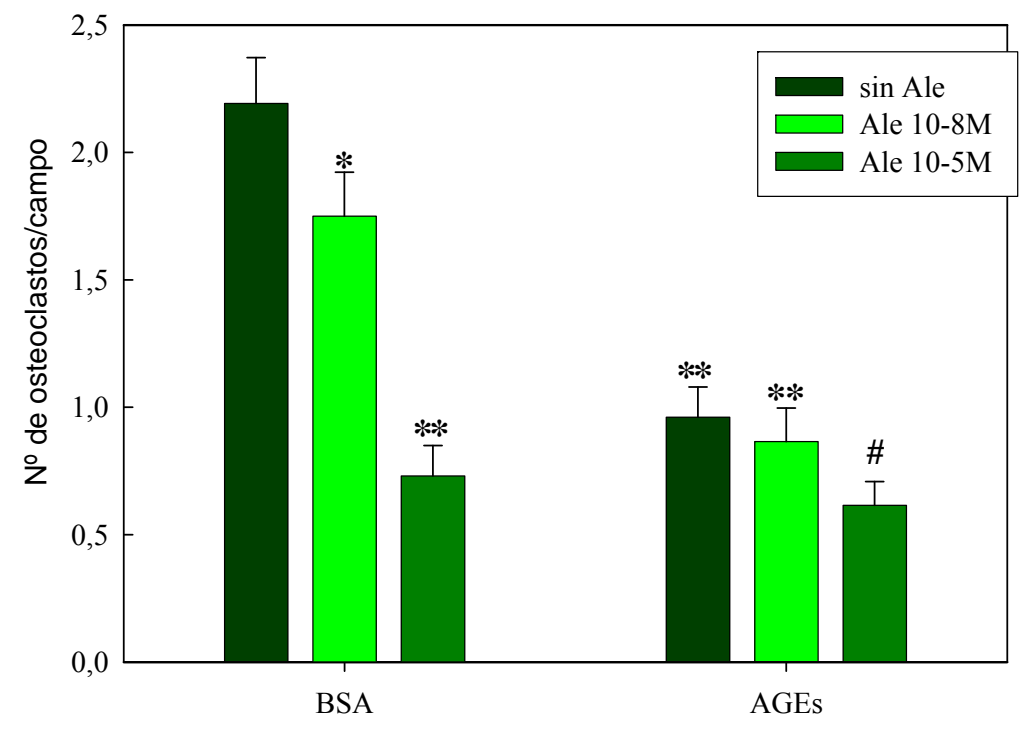

Figura III.2.6- Efecto de los AGEs y Alendronato sobre el número de osteoclastos. Se graficó el número promedio de osteoclastos por campo en las diferentes condiciones. Para ello se contaron las células con 3 o más núcleos en 50 campos a $400 \mathrm{x}$. Los resultados se expresaron como la Media +/- SEM $(* \mathrm{p}<0.05, * * \mathrm{p}<0.001$ respecto de BSA) (\# $\mathrm{p}<0.01$ respecto de AGEs) 


\section{III.2.7-EXPRESION DE RAGE EN OSTEOCLASTOS.}

En vista de los efectos inhibitorios del AGE sobre el desarrollo de osteoclastos y la expresión de TRAP, decidimos investigar si esos efectos podrían involucrar una modulación en la expresión de RAGE, uno de los receptores previamente descriptos en osteoclastos para los AGEs [Valcourt et al, 2007]. Para este fin realizamos un ensayo de inmunofluorescencia indirecta para RAGE, utilizando cocultivos incubados sobre cubreobjetos en condiciones basales durante 4 días, y sometidos luego, durante 4 días adicionales, a las siguientes condiciones experimentales:

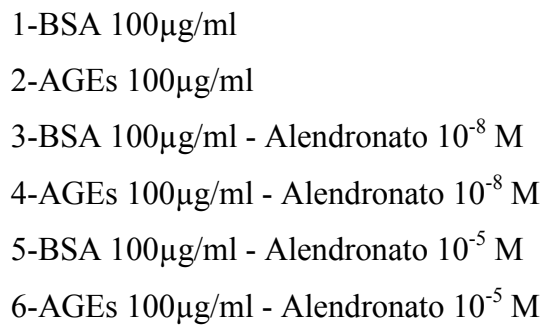

Se utilizó un anticuerpo anti-RAGE conjugado con FITC (fluorocromo verde), mientras que los núcleos se tiñeron con Ioduro de propidio (fluorocromo rojo). Las muestras se montaron en portaobjetos, se sellaron y se observaron por dos medios distintos:

\section{III.2.7.1- Microscopía de Fluorescencia Óptica.}

Por medio del microscopio de fluorescencia se obtuvieron imágenes de las muestras (Fig III.2.7.1 (A)), que luego se analizaron con el programa Image $\mathrm{J}$ para cuantificar la fluorescencia asociada a RAGE. Los resultados de la cuantificación se graficaron en la Fig III.2.7.1 (B). En el gráfico podemos ver que los osteoclastos incubados con AGEs presentan un incremento del $52 \%$ en la fluorescencia asociada a RAGE comparado con los controles de BSA. Por otro lado, el agregado de Alendronato $10^{-8} \mathrm{M}$ en presencia de BSA indujo también un incremento significativo en la fluorescencia asociada al RAGE (aproximadamente 30\% del respecto de BSA solo). Por el contrario, altas dosis de Alendronato no modificaron la expresión del RAGE en los cocultivos incubados con BSA. Finalmente, pudimos observar que bajas dosis de Alendronato en presencia de AGEs no alteraron la "up-regulation" del RAGE inducida por los AGEs. Sin embargo, cuando los osteoclastos se incubaron con AGEs y Alendronato $10^{-5} \mathrm{M}$, este bisfosfonato bloqueó el efecto estimulante de los AGEs sobre la expresión de su receptor RAGE.

\section{III.2.7.2-Microscopía de Fluorescencia Confocal}

Con las observaciones hechas con el microscopio confocal, se pudieron obtener imágenes de mayor resolución y sobre todo, determinar la localización sub-celular de la 
marca fluorescente asociada al RAGE. Las imágenes capturadas con el microscopio confocal se presentan en las Figuras III.2.7.2.1 y III.2.7.2.2.

Para determinar la localización de la marca se hizo un barrido en el eje z, del campo que incluía a la célula multinucleada y se obtuvieron 10 planos focales por muestra. Las imágenes seleccionadas corresponden a planos que incluyen a varios núcleos.

En la Figura III.2.7.2.1 se muestra la serie de imágenes obtenidas de los osteoclastos incubados con BSA solo y con Alendronato $10^{-8} \mathrm{M}$ o $10^{-5} \mathrm{M}$ (condiciones 1,3 y 5 respectivamente), mientras que en la Figura III.2.7.2.2 se muestra la serie análoga para osteoclastos incubados con AGEs y Alendronato (condiciones 2, 4 y 6 respectivamente).

Las imágenes de la primera columna de ambas figuras corresponden al canal verde donde se observa la fluorescencia asociada al RAGE. El análisis de la intensidad de fluorescencia de estas imágenes tiene la misma tendencia que el realizado a partir del microscopio de fluorescencia óptico (datos no presentados).

En el panel de BSA (Figura III.2.7.2.1) vemos que la presencia de Alendronato $10^{-8} \mathrm{M}$ produce un aumento de la fluorescencia asociada al RAGE tanto en el citoplasma como en el núcleo de los osteoclastos. En cambio los osteoclastos incubados con Alendronato $10^{-5} \mathrm{M}$ presentan una intensidad de fluorescencia similar al control de BSA.

En las imágenes de la Figura III.2.7.2.2 puede observarse nuevamente que las muestras que se incubaron con AGEs expresan una mayor intensidad de fluorescencia que en el control con BSA, tanto en el citoplasma como en el núcleo, especialmente en los nucleolos y en la membrana nuclear (observar las flechas en las fotos de la sección III.2.7.2). El agregado de Alendronato $10^{-8} \mathrm{M}$ en presencia de AGEs no modificó este patrón de marcación. Sin embargo, la coincubación con AGEs y Alendronato $10^{-5} \mathrm{M}$ indujo una disminución en la fluorescencia asociada al RAGE en el citoplasma, pero no así en el núcleo, los nucleolos o la membrana nuclear 
(A)
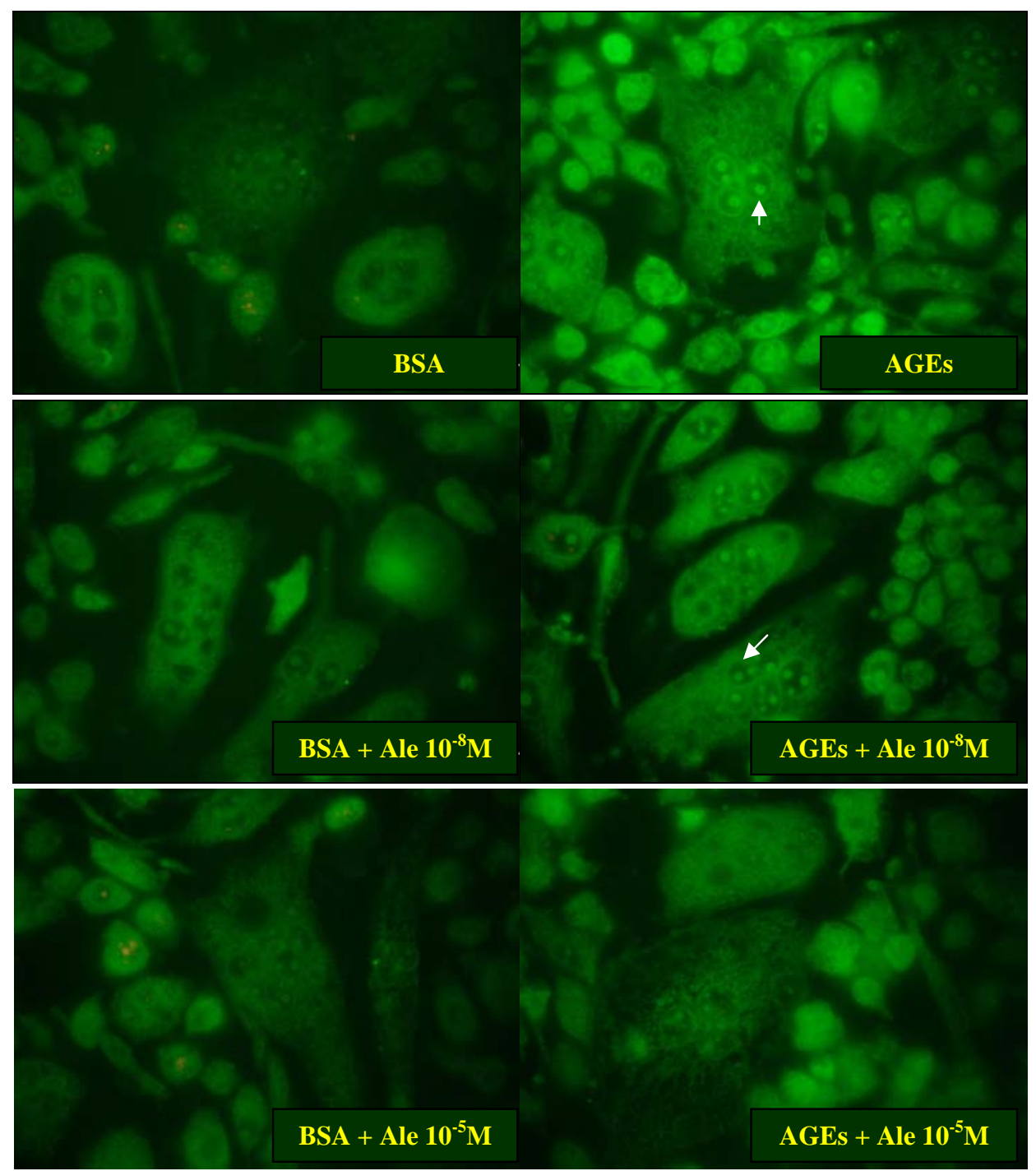

(B)

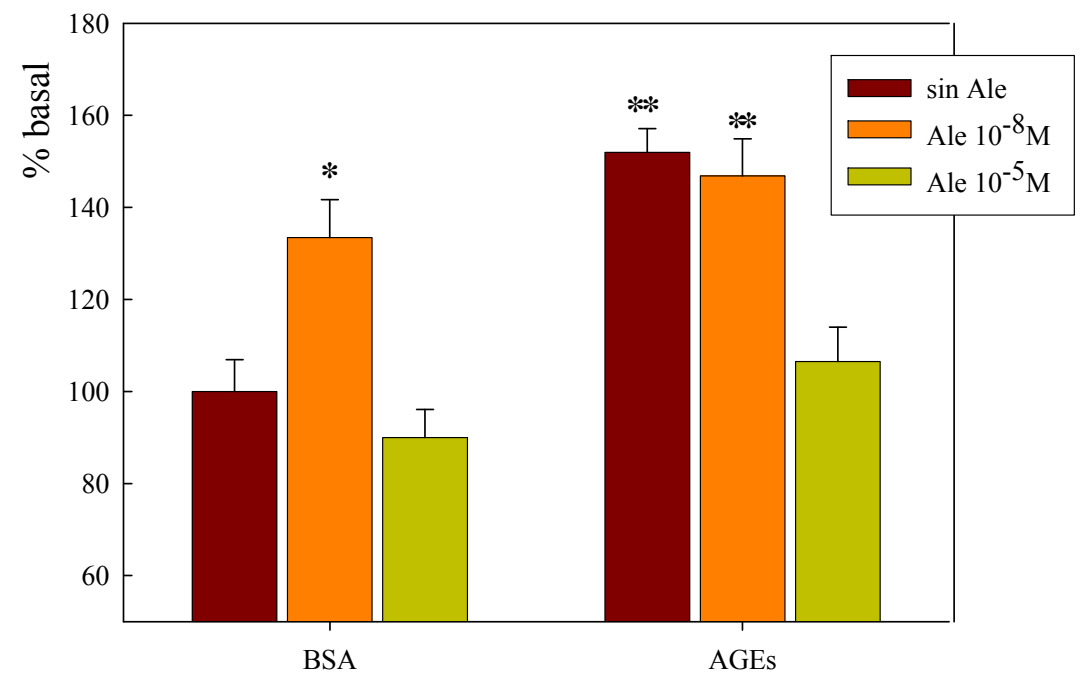

Figura III.2.7.1-Determinación de RAGE en osteoclastos por IFI

Los cocultivos se incubaron con BSA o AGEs $(100 \mathrm{ug} / \mathrm{ml})$ en presencia o ausencia de Ale $10^{-8} \mathrm{M}$ o $10^{-}$ ${ }^{5} \mathrm{M}$. Luego se realizó el ensayo de inmunofluorescencia para RAGE. (A) Las imágenes están tomadas a 1000x, se cuantificó la fluorescencia de las mismas y se graficó como \% del basal (BSA) (B) 

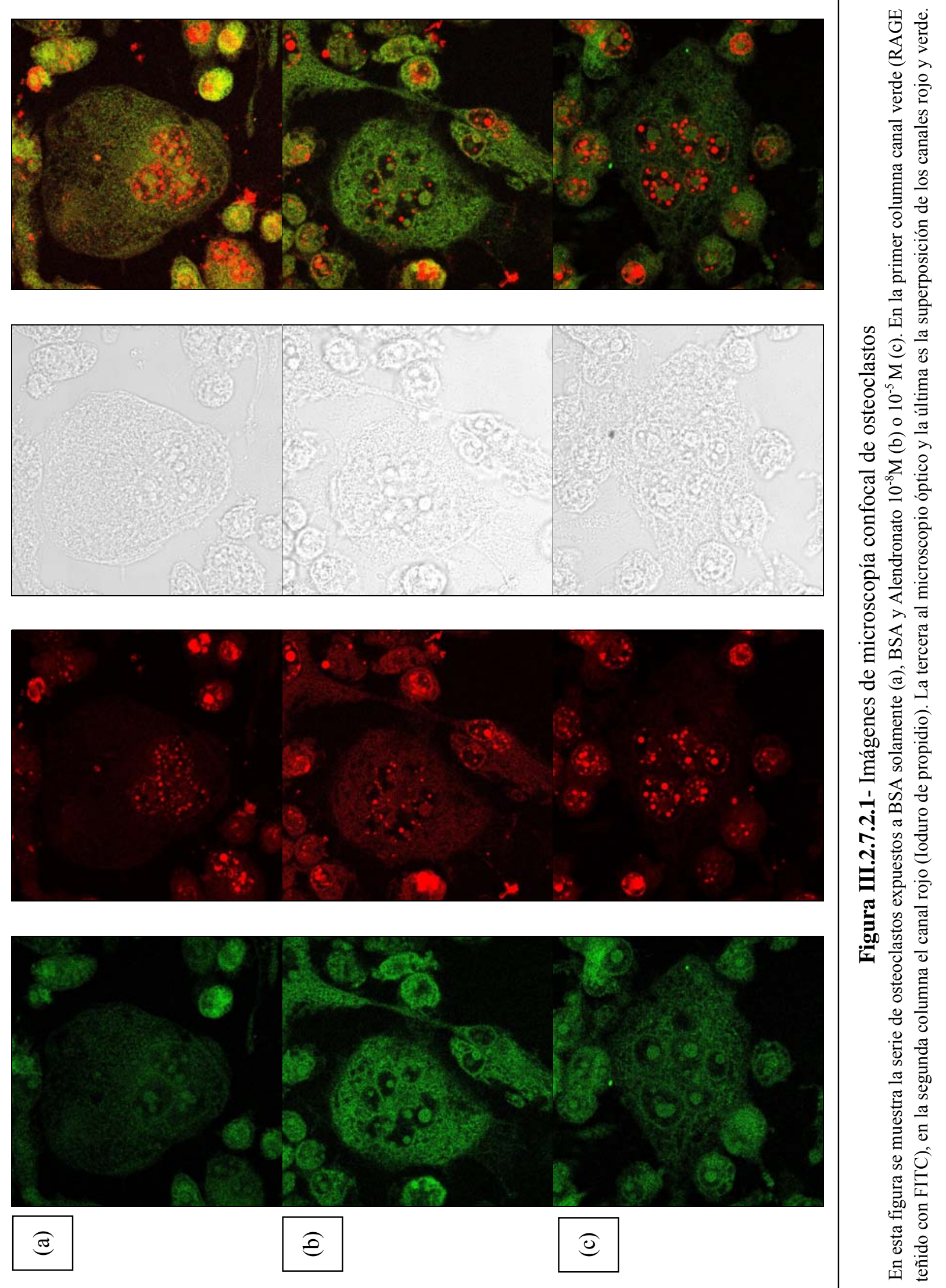

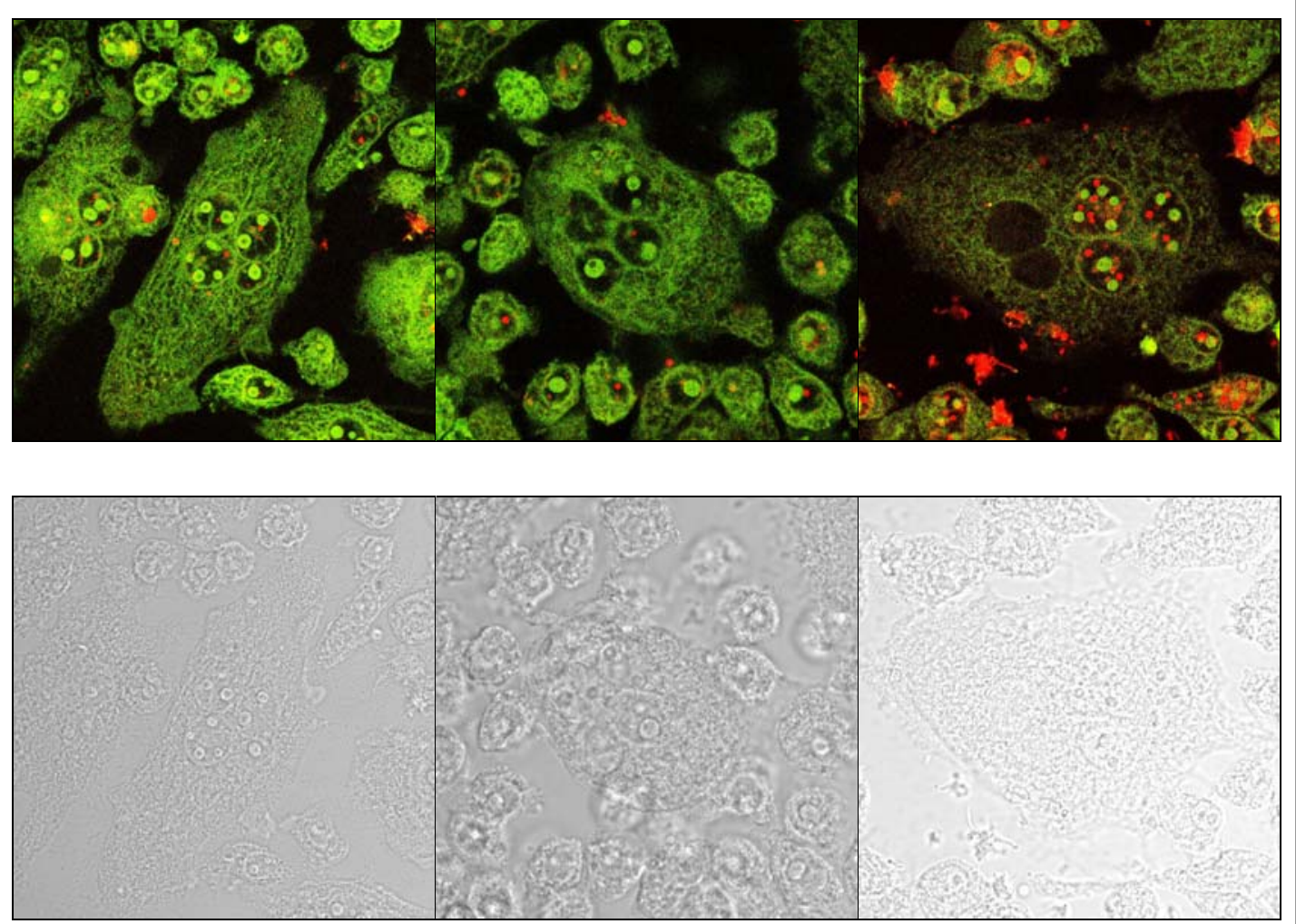

\& $\dot{0} \dot{0} \cdot \frac{0}{0}$

范范方

징 $\sum_{0} \frac{a}{0} \cdot \frac{0}{0}$

过 0

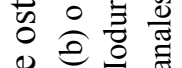

을 $\sum^{2}$

껑

응

ठํㅠ

त)

릉 은

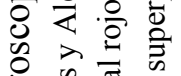

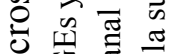

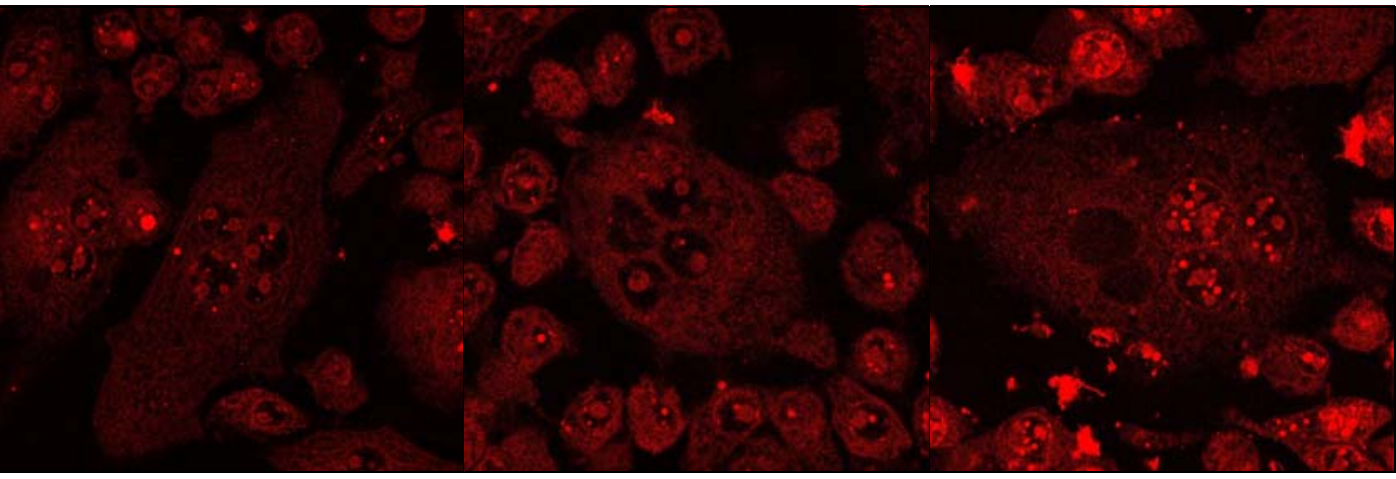

घ《

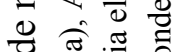

क ष के

击 䓠

D

点

品至

ขับ

$\hat{N} \pi$ 元

ก \%

记

든 을

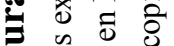

की 0 \%

江 苟
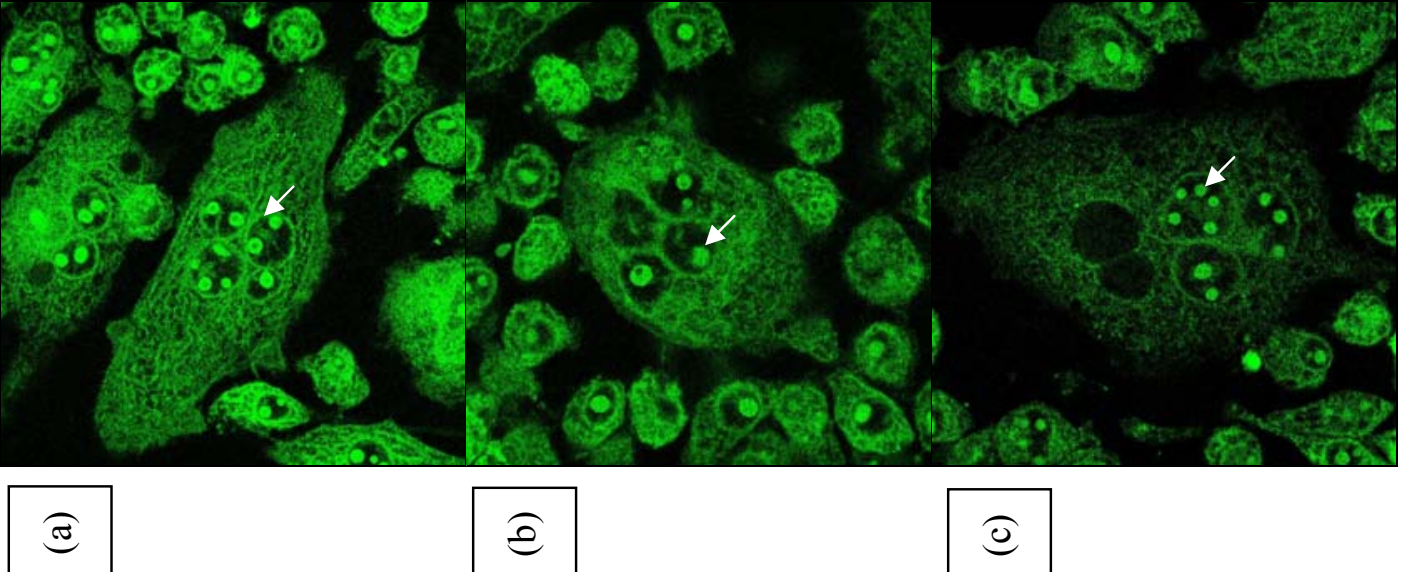

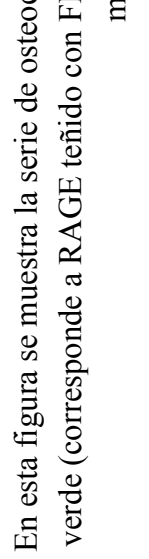




\section{IV \\ DISCUSIÓN}
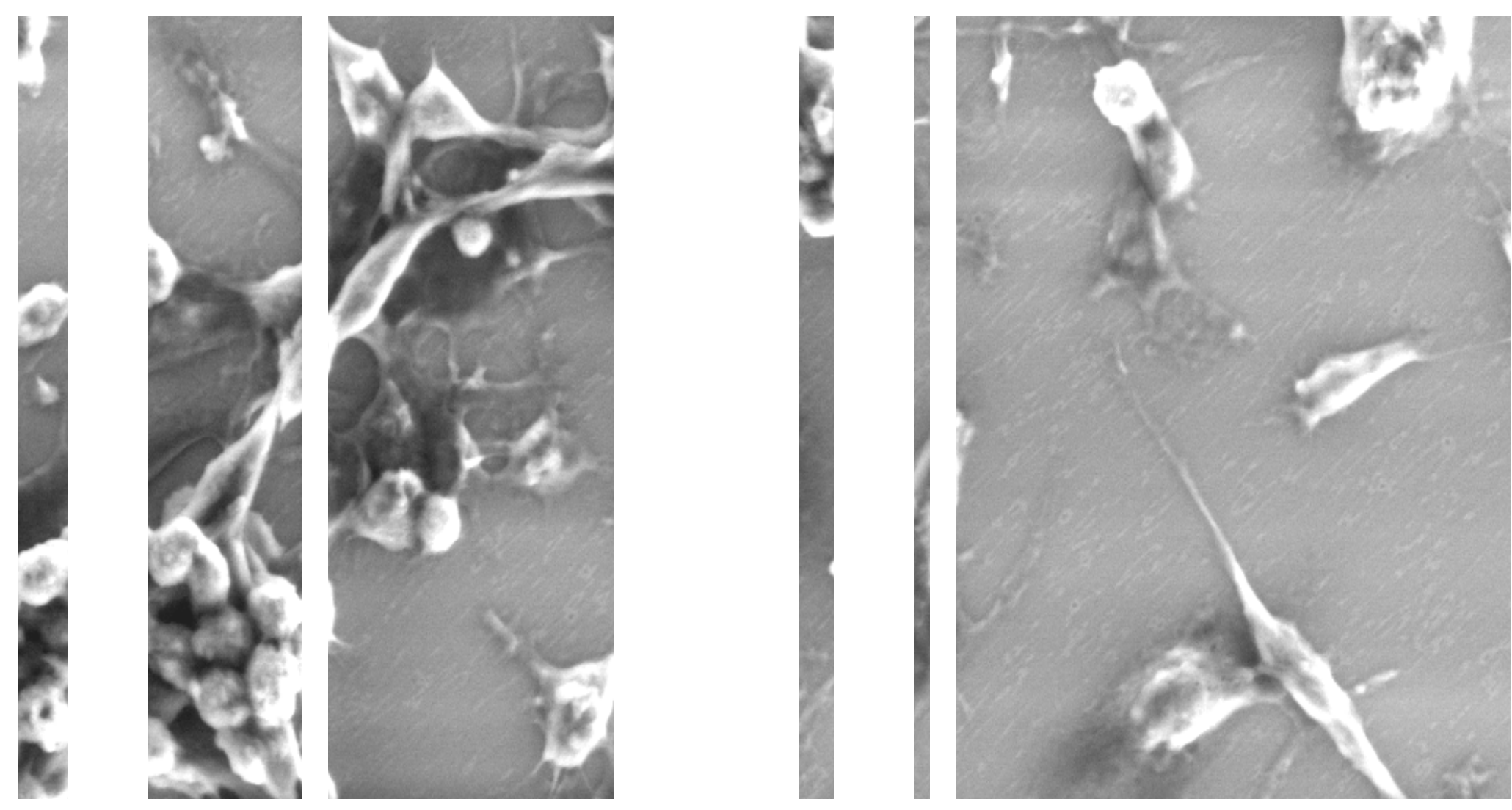
El hueso es un tejido dinámico, que es continuamente remodelado durante toda la vida no sólo para mantener la homeostasis del calcio, sino también para reparar microdaños y mantener así la calidad del hueso. Esta continua remodelación del hueso es consecuencia de la acción de las células que se esfuerzan por lograr una coordinada y equilibrada resorción de hueso viejo, los osteoclastos, y de los osteoblastos, responsables de una adecuada formación de hueso nuevo, de manera local, coordinada y secuencial. Este proceso se denomina acoplamiento y se entiende como la formación de hueso en respuesta a los resultados de la resorción ósea, con una cantidad de hueso formada igual a la eliminada por resorción. El desacoplamiento se produce cuando el equilibrio entre la formación y la resorción se disocia lo cual puede llevar a situaciones que abarcan desde la osteopetrosis hasta la osteoporosis. A pesar de que se ha visto que la formación de hueso está estrechamente unida a la resorción ósea en el recambio normal del hueso adulto, este acoplamiento se puede disociar en circunstancias fisiológicas como durante el crecimiento esquelético (ganancia ósea neta) o la posmenopausia (pérdida neta de hueso), así como en patologías como la Diabetes mellitus [Karsdal et al, 2007; Schwartz, 2003].

Los productos de glicación avanzada (AGEs) son compuestos resultantes de glicaciones no enzimáticas y se acumulan con la edad en diversos tejidos de forma inevitable, pero se ven incrementados en pacientes con diabetes mellitus. Las personas con diabetes tienen concentraciones séricas de AGEs significativamente más altas que los sujetos no diabéticos [Sharp et al, 2003]. También se han encontrado altos niveles séricos de los AGEs (pentosidina y CML) en pacientes con osteoporosis primaria [Hein et al, 2003].

Los AGEs están implicados en el desarrollo y progresión de complicaciones diabéticas crónicas [Ulrich y Cerami, 2001; Brownlee, 2005]. La influencia de los AGEs en las microangiopatías y macroangiopatías diabéticas está bien descripta en la literatura [Barbosa et al, 2008; Goh y Cooper, 2008; Peppa y Vlassara 2005]. Las complicaciones crónicas de la diabetes incluyen también una disminución en la formación y recambio óseo y han sido estudiadas por diversos autores [Bouillon, 1991; Krakauer, 1995; Schwartz, 2003]. En particular, Krakauer et al (1995) en un estudio clínico de 12 años de seguimiento, mostró un deterioro significativo en la producción de matriz extracelular osteoblástica y la mineralización ósea de pacientes con diabetes mellitus tipo 1 y tipo 2 .

La presencia de AGEs puede alterar directamente las propiedades físicas del colágeno óseo y de esa manera alterar el proceso de formación ósea. Los estudios sobre las líneas celulares indican que los AGEs también afectan el metabolismo de las células óseas. 
En particular, nuestro grupo demostró que el colágeno modificado por AGEs es capaz de regular la proliferación y la diferenciación de las células osteoblásticas dependiendo de la etapa de desarrollo [McCarthy et al, 2001; McCarthy et al., 1997]. También hemos visto que la adición de AGE-BSA (proteína soluble) a cultivos de células osteoblásticas, resultó en una reducción significativa de la síntesis de osteocalcina, fosfatasa alcalina y colágeno tipo I. Estos efectos estarían mediados por los receptores de AGE (RAGE) que se han descripto en las células osteoblásticas [Cortizo et al, 2003; McCarthy et al, 1999; Mercer et al, 2007].

Los AGEs pueden ejercer un efecto negativo sobre el hueso interfiriendo en la diferenciación osteoblástica y en la producción de proteínas de matriz como son colágeno y osteocalcina [Alikhani et al, 2007]

En este trabajo de tesis vimos que AGEs-BSA produce una inhibición dependiente de la dosis, de la proliferación de los osteoblastos en cultivo, corroborando resultados obtenidos anteriormente por el grupo. Además la presencia de AGEs en los cultivos produce una disminución en la adhesión al sustrato, y consecuentemente alteraciones en la morfología de estas células lo que llevaría a un detrimento en su función.

Se han descripto resultados similares en células endoteliales donde se ve que los AGES alteran la función de estas células. Por ejemplo, Guo et al, [2009] demostró una disfunción en la barrera de las células endoteliales provocada por AGEs, y que la misma esataba asociada con cambios morfológicos de la F-actina, así como con alteraciones en la vía de las proteínas ERK y MAPK p38.

Otros autores estudiaron los cambios en la estructura del citoesqueleto y el mecanismo de señalización inducido por AGEs en células endoteliales humanas. La estimulación de la vía de RAGE por AGE-BSA indujo la activación de Rho, la formación de gap intercelulares, la presencia de prominentes fibras de estrés de actina y contracción celular. Estos hallazgos sugieren que la activación de RAGE / Rho inducida por los AGEs, participaría en la hiperpermeabilidad encontrada en la diabetes [Hirose et al, 2010].

Los bisfosfonatos son probablemente la familia de drogas antiosteoporóticas más ampliamente utilizada, y aunque su acción primaria tiene por objetivo principal inhibir la función y la supervivencia osteoclástica, también se ha demostrado que puede influir positivamente en el desarrollo osteoblástico y en el potencial de formación ósea [Tsuchimoto et al, 1994; Plotkin et al, 1999; Viereck et al, 2002].

Los bisfosfonatos se utilizan para el tratamiento de pacientes con diabetes mellitus y osteoporosis, aunque con resultados contradictorios [Dagdelen et al, 2007; Yamauchi, 2007]. 
Una vez absorbidos los BPs (suministrados por vía oral), se localizan principalmente en los sitios de remodelación activa del tejido óseo, donde actúan como potentes inhibidores de la actividad osteoclástica [Rogers et al, 2000]. Sin embargo, se ha postulado que los BPs también pueden tener efectos sobre los precursores hematopoyéticos de los osteoclastos y sobre otras células en el microentorno óseo como los osteoblastos y macrófagos [Frith et al, 1997].

En este trabajo de tesis nos propusimos investigar si los bisfosfonatos nitrogenados (N-BPs) podrían revertir en los osteoblastos, los efectos nocivos de los AGEs que hemos descrito anteriormente [McCarthy et al, 1997; McCarthy et al, 2001].

Los resultados obtenidos respaldan esta hipótesis: se observó que los AGEs inducen en las dos líneas osteoblásticas una disminución en la proliferación celular y que ese efecto fue revertido por la coincubación con Alendronato, Pamidronato y Zoledronato en bajas concentraciones $\left(10^{-8} \mathrm{M}-10^{-6} \mathrm{M}\right)$. Yamagishi et al [2006] postularon un efecto similar de los $\mathrm{N}$ BPs sobre los efectos nocivos de los AGEs. Estos autores demostraron que Incadronato y Minodronato eran capaces de revertir los efectos deletéreos de los AGEs, en experimentos con células endoteliales de vena umbilical humana (HUVECs) [Okamoto et al, 2002; Yamagishi et al, 2005]. Los autores adicionalmente demostraron que la acción beneficiosa de estos N-BPs es debida a la supresión de la generación intracelular de ROS por la NADPH oxidasa, probablemente a través de la inhibición de la geranil-geranilación de Rac. La unión del AGEs a su receptor RAGE produce una señalización en las células de la pared vascular que involucra a los ROS y a la proteína pequeña $\mathrm{G}$ Rac, un componente crítico del complejo NADPH oxidasa.

En nuestro trabajo encontramos también que concentraciones altas de BPs $\left(10^{-4} \mathrm{M}\right)$ resultaron tóxicas para los osteoblastos tanto en presencia de BSA como de AGEs. Rogers et al [2000] consideran que la concentración extrapolada in vivo de Alendronato en la laguna de resorción del osteoclasto se encuentra en el rango de $10^{-4} \mathrm{M}$ y $10^{-3} \mathrm{M}$, aunque los osteoblastos no llegarían a estar a concentraciones tan elevadas. Varios autores reportaron resultados similares a los nuestros. Chou et al [2009] rescata el efecto bifásico, estimulatorio a dosis bajas e inhibitorio a dosis altas, del Alendronato sobre los osteoblastos. Entre los efectos que menciona está la inhibición de la apoptosis de osteoblastos a bajas dosis de Alendronato [Plotkin et al, 2006]. Otros autores observaron que bajas dosis de N-BPs estimulan la proliferación y la diferenciación osteoblástica in vitro [Giuliani et al, 1998; von Knoch et al, 
2005; Im et al, 2004]. Altas dosis de N-BPs muestran un efecto no estimulatorio sobre osteoblastos e inhibitorio de la formación ósea.

Im et al [2003] estudió el efecto de Alendronato y Risedronato sobre células osteoblásticas. Este autor encontró que estos BPs aumentaban el número de células, con un pico a $10^{-8} \mathrm{M}$, estimulando marcadores de diferenciación osteoblástica (FAL, colágeno tipo1, osteocalcina y BMP2).

Giuliani et al [1998] reportaron que el Etidronato estimula la formación de nódulos de mineralización en el rango de concentraciones entre $10^{-9} \mathrm{M}$ y $10^{-5} \mathrm{M}$.

Diferentes autores han investigado la modulación directa de los N- BPs sobre la actividad de la fosfatasa alcalina osteoblástica y la expresión del colágeno tipo 1. En general, encontraron que los bisfosfonatos inducen un aumento significativo en ambos parámetros en osteoblastos en cultivo [Fromigué y Body, 2002; Spreafico et al., 2006; Boanini et al., 2008]. Estas observaciones están de acuerdo con nuestros resultados actuales, en los que hemos encontrado que en osteoblastos, el Alendronato induce una reversión total de la inhibición por AGEs de la actividad específica de fosfatasa alcalina, así como de la producción de colágeno tipo 1.

En este trabajo de tesis se vio que los AGEs afectan el potencial de formación ósea osteoblástico, ya que la incubación con AGEs disminuyó la expresión de FAL y colágeno tipo I en las dos líneas celulares MC3T3E1 y UMR106, así como la formación de nódulos de mineral en las células MC3T3E1 diferenciadas 21días en un medio osteogénico. Sin embargo, estas acciones nocivas de los AGEs fueron completamente prevenidas por bajas concentraciones de Alendronato.

La reversión con bisfosfonatos del efecto anti-proliferativo de AGEs, podría ser explicada, al menos en parte, por la acción anti-apoptótica de los bisfosfonatos, como se muestra en el presente trabajo, y que también ha sido reportado por otros autores [Plotkin et al, 1999; Plotkin et al, 2006]. La apoptosis es un proceso de muerte celular programada que está involucrada en varios procesos fisiológicos. En este evento la muerte es iniciada y completada de manera ordenada, a través de la síntesis y/o activación de productos génicos necesarios para la destrucción celular. Recientemente se ha documentado el rol pro-apoptótico de los AGEs y algunos mediadores inflamatorios en distintos tipos celulares [Civera et al 2010; Desta et al, 2010].

La hipótesis más fuerte que involucra el mecanismo de las complicaciones diabéticas es el estrés oxidativo inducido por los AGEs ya que los ROS se encuentran aumentados en 
esta patología y producen disfunción celular en varios tipos celulares. Estudios in vitro demostraron que el estrés oxidativo inhibe la diferenciación osteoblástica e induce daño y apoptosis en los osteoblastos [Hamada et al, 2009]. El CML-colágeno induce apoptosis en cultivos primarios de osteoblastos o en las células MC3T3-E1 in vitro. Este efecto fue mediado a través de la interacción con el receptor RAGE [Alikhani et al, 2007].

Para confirmar la hipótesis de la regulación de la apoptosis por los AGEs y BPs, utilizamos un ensayo específico con anexina V/ioduro de propidio [Varga et al, 1999]. Este estudio permite detectar células en diferentes estadíos del proceso apoptótico. Cambios tempranos en la estructura de la membrana plasmática, tales como la exposición de fosfatidilserina son detectados a través de la tinción con anexina $\mathrm{V}$, mientras que cambios estructurales tardíos como por ejemplo la apertura de poros en la membrana plasmática son detectados con ioduro de propidio, ya que este colorante no difunde en la membrana intacta pero si cuando esta dañada.

Así pudimos observar que los AGEs tienen características pro-apoptóticas mientras que el Alendronato ejerce un efecto anti-apoptótico sobre los osteoblastos, de manera que la inducción de la apoptosis que vemos en presencia de AGEs en las dos líneas celulares, vuelve a los valores basales en presencia de un N-BP a bajas concentraciones. Resultados similares de BPs fueron descriptos previamente por el grupo de Bellido quienes analizaron el efecto anti-apoptótico de los BPs en osteocitos y osteoblastos [Plotkin et al, 1999].

Los resultados de nuestro grupo y los reportados por estos autores sugieren que la capacidad de los BPs para prevenir la apoptosis sería un mecanismo de los BPs para preservar al hueso en distintas situaciones patológicas.

El citoesqueleto de actina juega un papel importante en la determinación de la forma celular, y su propia reorganización está sujeta a modulación por interacciones extracelulares [Small et al, 1999 b].

De los tres polímeros que componen el citoesqueleto, los filamentos de actina que subyacen a la membrana celular son los que contribuyen directamente al mantenimiento de la forma celular [Small et al, 1999c]. Hemos visto que los productos de glicación avanzada provocan un cambio en la morfología celular, así cuando las células osteoblásticas cultivadas en monocapa son expuestas a AGEs-BSA pierden parcialmente la adhesión al sustrato. La actina se dispone en forma de microfilamentos denominadas fibras de estrés, las cuales se estabilizan por interacción con paloidina marcada con fluoresceína, para observarlas más fácilmente [Small et al, 1999a] (en nuestras fotografías se observan con fluorescencia de color 
verde). Las células en presencia de BSA conservan los microfilamentos bien desarrollados, mientras que las células incubadas con AGEs han perdido su patrón normal por la acción nociva del mismo. Los filamentos de estrés permiten a la célula anclarse al sustrato mediante diferenciaciones típicas llamadas contactos o adhesiones focales. Al perderse este patrón normal, las células pierden la adhesión al sustrato y se despegan y poco después mueren, por falta de adhesión, algo vital para células que crecen pegadas al sustrato.

Estudios previos realizados por nuestro grupo demostraron que la acumulación de AGEs sobre una matriz de colágeno de tipo I, inhibe la adhesión de osteoblastos mediada por receptores integrinas [McCarthy et al., 2004]. Adicionalmente, un estudio de Howard et al [1996] sugiere que el entrecruzamiento de las fibrillas de colágeno producido por la glicosilación no enzimática altera las propiedades físicas de la matriz extracelular, dando lugar a cambios intracelulares en la organización del citoesqueleto de actina. Así, ambos mecanismos podrían estar mediando la menor adhesividad osteoblástica a su matriz en presencia de AGEs.

La adhesión de la célula a la matriz extracelular regula la homeostasis celular de múltiples maneras. Esta regulación se efectúa directa o indirectamente a través de conexiones de integrinas al citoesqueleto de actina [Delon y Brown, 2007], de los receptores del factor de crecimiento y cascadas de transducción de señales intracelulares. La interrupción de esta conexión a la matriz extracelular tiene efectos perjudiciales sobre la supervivencia celular. Esto lleva a un tipo específico de apoptosis que se conoce como anoikis en la mayoría de tipos de células no transformadas [Reddig y Juliano, 2005].

Curiosamente, Dobler et al [2006] informaron recientemente que las enfermedades crónicas vasculares en la diabetes están asociadas con la disrupción de las interacciones de células adherentes endoteliales con la matriz extracelular (MEC), poniendo en peligro la supervivencia celular y alterando la estructura vascular. Los autores muestran que el metilglioxal, cuya formación esta aumentada en la hiperglucemia, provoca una fuerte modificación en los sitios de unión de las integrinas en el colágeno IV de la membrana basal vascular, provocando el desprendimiento de las células endoteliales, anoikis, y la inhibición de la angiogénesis. Por lo tanto, el aumento de formación de metilglioxal y la glicación de la MEC en la hiperglucemia afectan la supervivencia de las células endoteliales y la angiogénesis y probablemente contribuyen a una disfunción vascular similar en la diabetes [Chiarugi y Giannoni, 2008]. 
Los elementos del citoesqueleto además de ser críticos para la morfología celular y la transducción de señales, están involucradas en diversos procesos celulares, incluyendo la movilidad, el transporte intracelular y la diferenciación. Algunas proteínas pequeñas de unión a GTP (proteínas G) de la familia Ras, como RhoA, influyen sobre diversos elementos del citoesqueleto. La proteína pequeña RhoA estabiliza el citoesqueleto de actina y promueve la formación de adhesiones focales en las células osteoblásticas. Los N-BPs cuando alcanzan ciertas concentraciones $\left(5 \times 10^{-5} \mathrm{M}\right)$ en los osteoblastos pueden afectar el citoesqueleto de actina y las adhesiones focales a través de acciones sobre grupos geranilgeranil de RhoA y, potencialmente, a través estos efectos pueden influir en la remodelación ósea [Kazmers et al, 2009].

En el presente trabajo hemos visto que tanto el citoesqueleto de actina, como la morfología de las células expuestas a Alendronato $10^{-5} \mathrm{M}$ están afectados, probablemente mediante el mismo mecanismo descripto por Kazmers que involucra a la inhibición de la geranilación de las proteínas pequeñas (RhoA). Aunque no se estudio en este trabajo de Tesis, estos mecanismos de acción del Alendronato podrían ser operativos en los osteoblastos, previniendo la modificación de proteínas Rho y la integridad del citoesqueleto. Varios autores demostraron previamente que el Alendronato es capaz de inhibir enzimas de la vía del mevalonato, previniendo la prenilación de proteínas de unión a GTP pequeñas que son responsables de la integridad del citoesqueleto y de la señalización intracelular en osteclastos [Fisher et al. 1999; van Beek et al. 1999b; Bergstrom et al. 2000]. Recientemente se demostró que el Alendronato es capaz de inhibir la prenilación de proteínas en osteoblastos en cultivo [Idris et al 2008]. Estos autores observaron también que este N-BP inducía apoptosis de los osteoblastos a concentraciones de $10^{-4} \mathrm{M}$, e inhibía la mineralización a concentraciones de $10^{-7} \mathrm{M}$, pero a través de mecanismos independientes de la prenilación de proteínas. Claramente se necesitan más estudios in vitro e in vivo para poder definir completamente el modo de acción de los BP en los osteoblastos.

Por su parte, las células coincubadas con AGEs y alta concentración de Alendronato $\left(10^{-5} \mathrm{M}\right)$ presentan una desorganización aun mayor del citoesqueleto de actina, posiblemente por la acción conjunta de los dos agentes. Por una lado el efecto que describimos recién del N-BP a altas concentraciones y por el otro la acción de AGEs posiblemente a través de la activación RAGE/ RhoA generando gap intercelulares, prominentes fibras de estrés y contracción celular, como se describio para las células endoteliales [Hirose et al, 2010]. 
En la última etapa de este trabajo sobre los osteoblastos, tratamos de dilucidar los mecanismos de señalización que estarían involucrados en la acción de los BP y los AGEs.

Mathov et al [2001] han demostrado que los BPs pueden aumentar directamente la proliferación de los osteoblastos, por la activación de las quinasas reguladas por señales extracelulares (ERK) a través de la entrada de calcio. Estos resultados nos llevaron a investigar si en nuestras condiciones de cultivo, los BPs podrían regular la proliferación osteoblástica a través de alguno de estos mecanismos. Utilizando nifedipina demostramos que, aunque el efecto anti-proliferativo de AGEs es calcio-independiente, la reversión de los mismos con BPs requiere la entrada de $\mathrm{Ca}^{++}$a través canales calcio de tipo-L voltaje sensibles. Los canales de calcio tipo L dependientes de voltaje se encuentran en las células óseas, incluyendo tanto los osteoblastos [Guggino et al, 1989] como a los osteoclastos [Teti et al, 1989]. Varias líneas de evidencia demostraron que cuando los canales de calcio en los osteoblastos se activan, la densidad del hueso se incrementa [Guggino et al, 1989] y la resorción del hueso se reduce [Ritchie et al, 1994]. Hay evidencias que demuestran que el calcio intracelular juega un papel fundamental en las vías mecanotransducción y que el citoesqueleto de actina es un componente crucial para el proceso de transducción de señales. Estos autores sugieren un papel regulador del citoesqueleto de actina en la actividad de los canales de calcio tipo L en las células osteoblásticas [Li et al, 2011]

En otra serie de experimentos se evaluó la producción intracelular de especies reactivas de oxígeno (ROS). Numerosos estudios indican que los AGEs incrementan la producción de radicales libres, generando estrés oxidativo en diferentes tipo celulares: células endoteliales [Zhang et al, 2006; Wautier y Schmidt 2004], en hepatocitos [Guimarães et al, 2010], adipocitos [Unno et al, 2004] y en osteoblastos [McCarthy et al, 2001a]. Estos radicales libres pueden formarse extracelularmente (formados a partir de la reactividad de estructuras AGEs acumuladas sobre proteínas extracelulares de vida media larga como el colágeno) o intracelularmente (generados por AGEs intracelulares, o como vía de transducción de señales del RAGE luego de su interacción con AGEs presentes fuera de la célula) [Negre-Salvayre et al, 2009].

Los radicales libres se pueden definir como moléculas o fragmentos de moléculas que contienen uno o más electrones desapareados en orbitales atómicos o moleculares. Ese electrón desapareado le confiere al radical libre un considerable grado de reactividad [Valko et al, 2007]. El efecto nocivo de los radicales libres, como causantes de daño biológico potencial, se denomina estrés oxidativo y estrés nitrosativo. Esto ocurre en los sistemas 
biológicos cuando hay un exceso de producción de ROS / RNS (especies reactivas de oxigeno y nitrogeno respectivamente) por un lado, y una deficiencia de antioxidantes enzimáticos y no enzimáticos, por el otro. En otras palabras, el estrés oxidativo resulta de las reacciones metabólicas que utilizan oxígeno y representa una alteración en el estado de equilibrio de reacciones prooxidantes/ antioxidantes en los organismos vivos. El exceso de ROS puede dañar a los lípidos, proteínas, o DNA de las células inhibiendo su función normal. Debido a esto, el estrés oxidativo ha sido implicado en una serie de enfermedades humanas, como la diabetes, así como en el proceso de envejecimiento [Valko et al, 2007].

Dentro de las moléculas antioxidantes endógenas, encontramos al glutation y enzimas encargadas de la detoxificación de radicales libres (catalasa, superóxido dismutasa, tiorredoxina, etc). Sin embargo también existen antioxidantes exógenos que agregados al sistema experimental pueden prevenir o revertir el estrés oxidativo inducido por AGEs [Zhang et al, 2006].

Nosotros utilizamos una mezcla de Vitamina C y E como antioxidantes exógenos. La vitamina $\mathrm{E}$ ( $\alpha$-tocoferol) constituye el antioxidante liposoluble más importante en sistemas biológicos. Posee la capacidad de inhibir la peroxidación lipídica, evitando así daños en la membrana y la modificación de las lipoproteínas de baja densidad, al interactuar con los radicales peroxilo mas rápidamente que éstos con los lípidos y proteínas de las membranas plasmáticas [Stahl y Sies, 1997]. El ácido ascórbico se ha demostrado que es un antioxidante muy eficiente en fase acuosa en sistemas vivos. El ácido ascórbico también se ha demostrado que protege las membranas y otros compartimentos hidrofóbicos mediante la regeneración de la vitamina E a la forma antioxidante [Beyer, 1994]. De esta manera el uso combinado de vitaminas $\mathrm{E}$ y $\mathrm{C}$ como antioxidantes se fundamenta en que esta última contribuye al reciclado de la vitamina E incrementando así la acción antioxidante de cada una.

En este trabajo de Tesis se estudió la producción intracelular de ROS en las células MC3T3-E1 y UMR-106, en presencia o ausencia de una mezcla de vitamina E y vitamina C, con el objeto de evaluar la posible intervención de la vía RAGE en el mecanismo de acción de los BPs. Se encontró que la presencia de Alendronato a bajas dosis y/o antioxidantes en el cultivo frena completamente el aumento en la producción de ROS inducido por los AGEs en ambas líneas. Estos resultados están de acuerdo con los encontrados por otros autores, en los que se cultivaron HUVECs con AGEs y BPs [Okamoto et al, 2002; Yamagishi et al, 2005]: en esas condiciones de cultivo, se observó que los BPs son capaces de suprimir la generación de ROS intracelular inducida por los AGEs, a través de la inhibición de geranil-geranilación de 
Rac, un componente importante de la NADPH oxidasa. Aunque no lo hemos probado directamente, es probable que haya operado la misma modulación de los mecanismos de transducción de señales en nuestras condiciones experimentales.

En trabajos previos hemos mostrado que diferentes dosis de BPs pueden inhibir fosfatasas osteoblástica tanto neutras como alcalinas [Vaisman et al, 2005; Molinuevo et al, 2007]. Además, otros investigadores han demostrado que la fosforilación intracelular de proteínas es esencial para el proceso de diferenciación osteoblástica [Xiao et al., 2002]. Así, en el presente trabajo se evaluó la posible modulación de la actividad de las fosfatasas neutras osteoblásticas por los productos finales de glicación avanzada y por bisfosfonatos.

Se demostró que el Alendronato inhibe la actividad de PTP lo que sugiere que podrían ser dianas moleculares de Alendronato cuando se utiliza en el tratamiento de trastornos óseos. Sin embargo, el mecanismo de la inhibición de PTP por Alendronato no se comprende totalmente. Se ha reportado que el mecanismo de inhibición de la PTP por Alendronato ocurre a través de la oxidación de la cisteína del sitio activo, aunque se discute la pertinencia del mecanismo propuesto en un sistema biológico [Skorey et al, 1997].

Se ha postulado que el Alendronato se une al mineral óseo y es internalizado por los osteoclastos que disuelven el mineral óseo. Una vez que el Alendronato alcanza concentraciones críticas en la célula, se inhibe la actividad de los osteoclastos. Las estimaciones indican que en la interfase osteoclasto-hueso, las concentraciones de Alendronato pueden llegar a $100 \mu \mathrm{M}$ o más, que sería suficiente para inhibir las PTP que se expresan en los osteoclastos. El Alendronato y el Etidronato inhiben las PTP con una potencia similar. La diferentes potencias observadas in vivo pueden reflejar diferencias en la farmacocinética en la captación celular o en la PTP objeto de inhibición [Schmidt et al, 1996].

Nuestros resultados actuales son compatibles con la siguiente interpretación: altas dosis de Alendronato $\left(10^{-5}-10^{-4} \mathrm{M}\right)$ podrían inhibir la función de fosfatasas neutras que son dependientes de cationes divalentes. Por otro lado, tanto AGEs y como bajas dosis de Alendronato $\left(10^{-6} \mathrm{M}\right)$ podrían inhibir principalmente fosfatasas neutras independientes de cationes divalentes (como la tirosina fosfatasas). Curiosamente, ya hemos demostrado que la actividad osteoblástica de fosfatasas neutras disminuye en un $45 \%$ en presencia de vanadato (un inhibidor de fosfatasas de tirosina) [Molinuevo et al, 2007], que es un grado de inhibición similar al que hemos encontrado con los AGEs y $10^{-6} \mathrm{M}$ de Alendronato en el presente estudio. 
Con todo, si nuestros resultados pudieran ser extrapolados a la práctica clínica, significarían una vuelta a la normalidad de la maduración de los osteoblastos expuestos simultáneamente a una matriz extracelular enriquecida en AGEs y N-BPs, y que posiblemente lleve a una adecuada capacidad formadora de hueso de los osteoblastos.

En una segunda etapa de este trabajo de Tesis decidimos estudiar los efectos de AGEs y BPs sobre el desarrollo y maduración de los osteoclastos.

Para ello, utilizamos un modelo de cocultivo de Raw 264.7 y UMR-106. Los monocitos/macrófagos Raw 264.7 son células que tienen el potencial de diferenciarse en células similares a osteoclastos in vitro en la presencia de RANK-L. En nuestro caso la fuente de RANK-L fueron los osteoblastos UMR-106. Las células simil osteoclasto presentan tres rasgos característicos de osteoclastos maduros: son células multinucleadas que expresan elevada actividad TRAP (fosfatasa ácida resistente al tartrato) y muestran podosomas de actina in vitro.

Nosotros caracterizamos nuestro sistema y evaluamos la cinética de expresión de actividad TRAP. Vimos que a la semana de iniciado el cocultivo, la actividad TRAP se duplicó con respecto a la condición basal de los macrófagos Raw 264.7. Asimismo, al cuarto día ya se pudo ver un aumento significativo en dicha actividad.

Los osteoclastos son ricos en fosfatasa ácida resistente al tartrato (TRAP) la cual se utiliza como un marcador de este tipo celular. Los niveles séricos de la isoforma específica de los osteoclastos, TRAP5b, se correlaciona con la actividad de resorción y puede ser utilizado como marcador clínico de la actividad de resorción en diversas situaciones clínicas. La TRAP tiene dos actividades enzimáticas diferentes. Funciona como una fosfatasa y también es capaz de generar especies reactivas de oxígeno a través de la reacción de Fenton. La catepsina K, otra enzima que secreta el osteoclasto, activa TRAP por escisión proteolítica. Considerando que se han hallado ambas enzimas (TRAP y catepsina K) junto con productos de degradación de los huesos en las vesículas transcitóticas se estima que esta activación se produce también in vivo. La actividad de generación de ROS de la TRAP facilita la degradación del colágeno y por lo tanto puede tener un papel en la degradación final de los productos de la resorción intracelular [Väänänen y Laitala-Leinonen, 2008].

Como los osteoclastos son blancos de acción de los BPs, sus efectos y mecanismos de acción han sido bien estudiados. Sin embargo el efecto de los AGEs sobre los osteoclastos no está aun completamente dilucidado y las evidencias que se han obtenido son controversiales [Saito y Marumo, 2010]. Solo dos grupos han estudiado el efecto de los AGEs sobre 
osteoclastos, el grupo de Miyata en 1997 y el grupo de Valcourt diez años después. A continuación vamos a discutir brevemente los resultados más importantes.

Miyata et al [1997] encontró un aumento en el número de los pits o lagunas de resorción cuando los osteoclastos eran cultivados sobre cortes delgados de dentina modificada por AGEs. Para estos estudios los autores utilizaron cultivos in vitro de células de médula ósea de ratón no fraccionadas conteniendo osteoclastos. No hubo aumento en el número de osteoclastos formados de novo, indicando un aumento en la actividad de los osteoclastos existentes. El aumento en la resorción ósea inducida por los AGEs, fue apoyada in vivo demostrando que partículas óseas modificadas por AGEs eran resorbidas en mayor extensión que las partículas controles no glicadas, cuando se implantaron subcutáneamente.

En contraste Valcourt et al [2007], muestra un efecto opuesto al que encontró Miyata et al, en un estudio in vitro usando osteoclastos maduros de conejo y de humano. Ellos mostraron que el proceso de resorción era inhibido fuertemente cuando los osteoclastos maduros se plaquearon sobre cortes delgados de marfil conteniendo pentosidina, un AGE bien caracterizado. Esta inhibición de la resorción ósea fue confirmada por una marcada reducción de la liberación de fragmentos de colágeno tipo I generados por las enzimas colagenolíticas secretadas por los osteoclastos en el medio de cultivo de las matrices mineralizadas modificadas por AGEs. Este efecto es probablemente el resultado de una disminución de la solubilidad de las moléculas de colágeno en presencia de AGEs.

Los resultados de Miyata están de acuerdo con evidencia que muestra que la formación de AGEs está aumentada en los huesos de pacientes con osteoporosis postmenopausica y con falla renal crónica [Saito et al, 2006; Urena et al, 1999], situaciones de alto recambio óseo. Por otro lado, los resultados de Valcourt parecen explicar el aumento en la formación de pentosidina en huesos de animales con modelos de Diabetes tipo1 y tipo 2 con bajo recambio óseo [Saito et al, 2006; Silva et al, 2009]

La acumulación de AGEs (como la Pentosidina) esta aumentado en el hueso de patologías con escaso recambio óseo, tales como en la Diabetes [Saito et al 2006; Silva et al 2009], cuando se suprime la resorción ósea con bisfosfonatos [Saito et al 2008; Tang et al 2008], o durante el proceso de envejecimiento. Sin embargo, en estudios in vivo se demostró que un aumento de los AGEs en el hueso se produce tanto en situaciones de bajo como de elevado recambio óseo. Saito y Marumo [2010] han demostrado que el hueso cortical y esponjoso de pacientes con osteoporosis primaria que no tienen diabetes o insuficiencia renal, 
pero con alta tasa de recambio óseo tienen mayor contenido pentosidina tanto en osteonas jóvenes recién formadas, como en osteonas más viejas

En el presente trabajo de Tesis observamos que los AGEs inhibieron en forma dosis dependiente el proceso de diferenciación osteoclástica, encontrando una marcada disminución en la actividad TRAP, así como en el número de células multinucleadas desarrolladas en presencia de AGEs. Estos resultados concuerdan con observaciones similares del grupo de Valcourt et al [2007] en la línea celular monocítica Raw 264.7 y en monocitos humanos primarios pero diferenciadas a osteoclastos en presencia de RANKL recombinante.

Una vez evaluado el efecto de los AGEs, investigamos el posible efecto del agregado de diferentes dosis de Alendronato en coincubación con los AGEs sobre la diferenciación de los osteoclastos. Para ello elegimos la concentración de $100 \mu \mathrm{g} / \mathrm{ml}$ de AGE, la cual inhibe aproximadamente un 13\% la actividad TRAP y un 55\% el número de osteoclastos, respecto al control con BSA. Como resultado de estos experimentos, encontramos que bajas dosis de Alendronato $\left(10^{-8} \mathrm{M}-10^{-6} \mathrm{M}\right)$ indujeron una inhibición significativa, y similar a la inhibición producida por los AGEs, sobre la actividad de TRAP de cocultivos desarrollados en presencia de BSA. Por el contrario, en presencia de AGEs no se observó una inhibición adicional del Alendronato a bajas dosis, respecto de la ya producida por los AGEs. Estos efectos fueron reproducidos por bajas dosis de otros N-BPs como el Zoledronato y Pamidronato (datos no presentados). Por lo tanto podríamos sugerir que los BPs nitrogenados a bajas concentraciones disminuyen la actividad de TRAP en condiciones basales (BSA) pero no afectan posteriormente la acción inhibitoria de los AGEs sobre esta actividad.

Por otro lado, altos niveles de Alendronato $\left(10^{-5} \mathrm{M}-10^{-4} \mathrm{M}\right)$ inhibieron la actividad TRAP en forma significativa, observando un $25 \%$ de inhibición respecto al cultivo con BSA y un $17 \%$ de inhibición respecto al cultivo en presencia de AGEs. Así, parecería haber un pequeño efecto aditivo de los dos agentes sobre la actividad de TRAP observada en presencia de AGE y altas dosis de Alendronato.

Al ensayar la acción del Alendronato sobre el número de osteoclastos vemos que indujo una disminución significativa y dosis dependiente, la cual es más marcada a concentraciones altas $\left(10^{-5} \mathrm{M}\right)$. Por otro lado, mientras que el agregado de bajas dosis de Alendronato en presencia de AGEs, no indujo un efecto adicional sobre la inhibición producida por el AGEs sobre el número de osteoclastos, altas concentraciones de Alendronato $\left(10^{-5} \mathrm{M}\right)$ indujeron una inhibición significativa sobre el número de osteoclastos desarrollados en presencia de AGEs (16\%). 
En resumen, vemos que tanto el número de osteoclastos como la actividad TRAP (marcador de diferenciación osteoclástica), son inhibidos por el Alendronato en una forma dependiente de la dosis. En cambio en presencia de AGEs, el Alendronato en bajas concentraciones $\left(10^{-8} \mathrm{M}\right)$ no afecta la inhibición en la actividad TRAP y el número de osteoclastos, producida por los AGEs solos, mientras que la coincubación con Alendronato $10^{-5} \mathrm{M}$ produce una inhibición significativa respecto a AGEs de estos dos parámetros. Esto sugeriría que la coincubación de AGEs y Alendronato en alta concentración potencia la inhibición de la diferenciación osteoclástica que vemos para cada uno de los agentes.

Extrapolando a la situación in vivo, estas condiciones serían análogas a las que podría encontrar un osteoclasto en la laguna de resorción donde la concentración de BPs alcanza valores cercanos a $10^{-4} \mathrm{M}$ [Rogers et al, 2000] y los AGEs presentes en el colágeno del hueso se liberan.

En un intento por desentrañar en que momento de la diferenciación osteoclástica actúan los agentes estudiados (AGEs y Alendronato), se realizaron una serie de experimentos evaluando la expresión de TRAP en cocultivos de diferentes tiempos de incubación. Como resultado pudimos ver que el Alendronato $10^{-5} \mathrm{M}$ comienza a actuar en la segunda fase del cocultivo (una vez formadas las células multinucleadas), dado que la incubación con Alendronato en el cocultivo corto (4 días) no produce una inhibición significativa en la actividad TRAP. En cambio los AGEs inhiben significativamente la actividad TRAP tanto en los cultivos cortos como en los de 8 días. Así, parecen afectar el primer paso de la osteoclastogénesis, probablemente inhibiendo las células precursoras osteoclásticas y de esta manera su diferenciación a osteoclastos maduros. Estos resultados coinciden con observaciones previas del grupo de Valcourt [2007]. Por último, la coincubación de ambos compuestos induce un efecto aditivo si se agregan en la segunda fase o durante todo el período completo de cultivo.

Aunque los mecanismos siguen siendo desconocidos, se ha sugerido que los AGEs pueden interferir con la diferenciación de los osteoclastos y la actividad resortiva a través de su interacción con receptores específicos de la superficie celular [Valcourt et al, 2007]. Tanto los progenitores de los osteoclastos como los osteoclastos maduros expresan diferentes receptores de AGE, incluyendo al RAGE (receptor de AGE). Adicionalmente la importancia de la interacción de AGEs y su receptor RAGE en la maduración de osteoclastos y su función, ha sido demostrada por Zhou et al. [2006]. Estos autores sugieren que la interacción de los AGEs con el RAGE tendría importantes consecuencias sobre la remodelación ósea. Los 
ratones que carecen de RAGE presentan un aumento en la masa ósea, densidad mineral ósea, así como una disminución de la actividad de resorción ósea in vivo. Los osteoclastos RAGEdeficientes diferenciados in vitro mostraron una disrupción en el anillo de actina y la zona de sellado a la matriz, un deterioro en la maduración, y una reducción de la actividad de resorción ósea.

Basado en estas observaciones, en este trabajo de Tesis investigamos la expresión y localización de RAGE en los osteoclastos murinos por inmunofluorescencia indirecta.

El RAGE fue detectado en bajos niveles en las células multinucleadas generadas bajo condiciones basales (incubadas con BSA). Como ya se ha descripto en otros sistemas, la incubación de osteoclastos maduros en presencia de AGEs-BSA indujo un incremento en la expresión de RAGE (50\% en comparación con BSA no glicado). Las células incubadas con AGEs expresaron una mayor intensidad de fluorescencia asociada al RAGE, tanto en el citoplasma como en el núcleo, y en esta última localización principalmente en los nucleolos y en la membrana nuclear.

Por otro lado, nos preguntamos si bajas dosis de Alendronato, que ejercen un efecto similar al AGE sobre los osteoclastos, podrían afectar la expresión del RAGE. Encontramos que Alendronato $10^{-8} \mathrm{M}$ indujo un incremento significativo en la fluorescencia asociada al RAGE tanto en el citoplasma como en el núcleo de los osteoclastos incubados bajo condiciones basales (con BSA). Por el contrario, altas dosis de Alendronato no modificaron la expresión del RAGE bajo condiciones basales, presentando una intensidad de fluorescencia similar al control con BSA.

Finalmente, la adición de bajas dosis de Alendronato en presencia de AGEs no alteró la "up-regulation" del RAGE inducida por el AGEs manteniendo el patrón de marcación encontrado para AGEs. Sin embargo, cuando los osteoclastos se incubaron con AGEs y Alendronato $10^{-5} \mathrm{M}$, este BP bloqueó el efecto estimulante del AGEs sobre la expresión de su receptor RAGE e indujo una disminución en la fluorescencia asociada al RAGE en el citoplasma pero no así en el núcleo, los nucleolos o la membrana nuclear.

En conjunto los resultados obtenidos en los osteoclastos sugieren que a bajas dosis el efecto inhibidor del Alendronato podría ser mediado por el RAGE bajo condiciones basales. Por otro lado en presencia de AGEs, altas concentraciones de Alendronato ejercen un efecto inhibitorio independiente del receptor RAGE. 


\section{V \\ CONCLUSIONES}
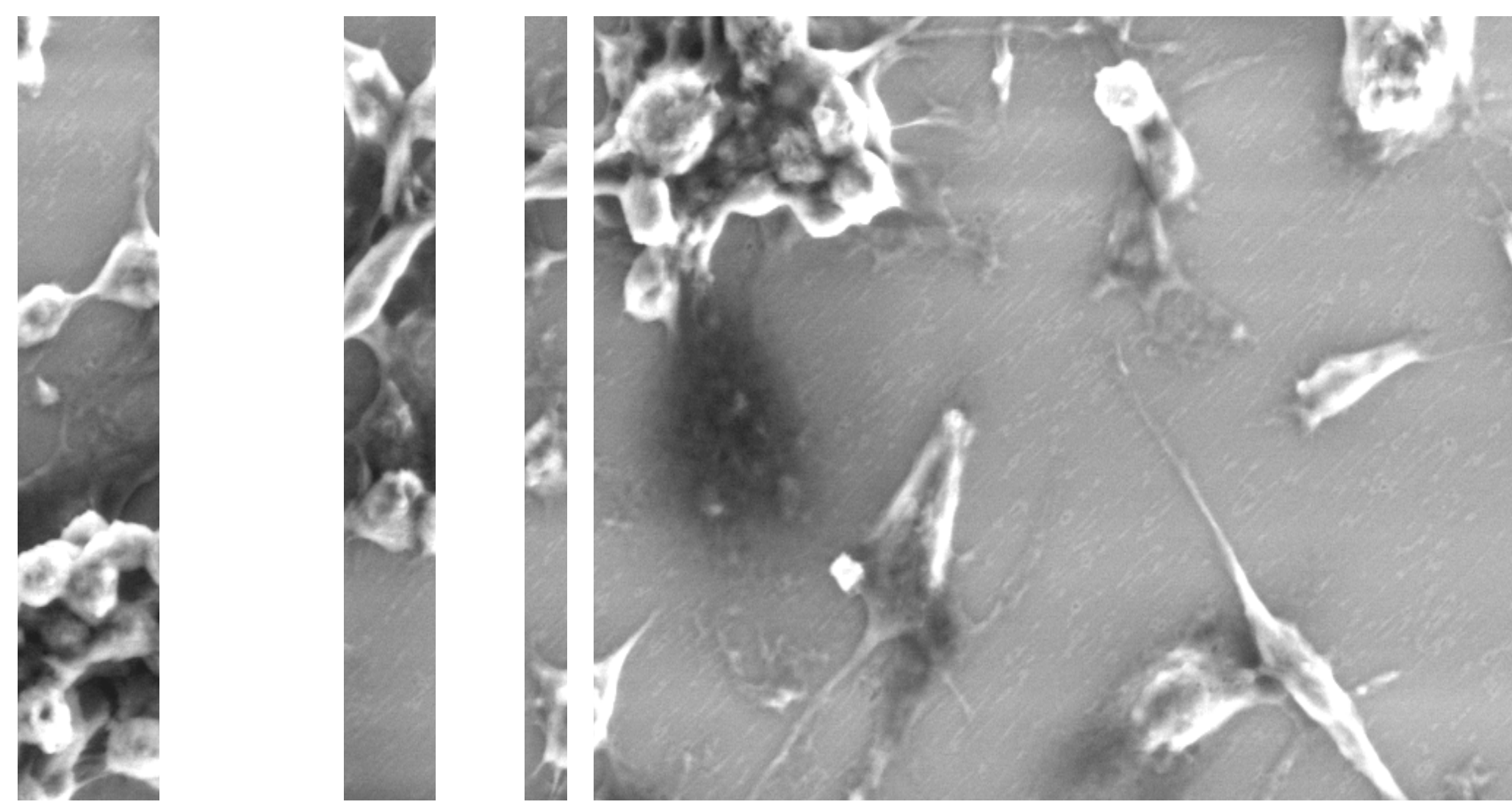
En este trabajo de Tesis se extendieron los estudios previos de nuestro grupo sobre los efectos de los AGEs en células óseas en cultivo, alcanzando las siguientes conclusiones:

$\checkmark$ Los AGEs ejercen efectos deletéreos sobre células óseas en cultivo: inhiben el crecimiento y diferenciación de osteoblastos y osteoclastos y alteran la morfología y ultraestructura del citoesqueleto de los osteoblastos.

$\checkmark$ Los BPs ejercieron un efecto inhibitorio dosis-dependiente sobre los osteoclastos. Por el contrario, en los osteoblastos se observó un efecto bifásico, siendo citotóxicos a dosis superiores a $10^{-5} \mathrm{M}$.

$\checkmark$ Los efectos deletéreos de los AGEs sobre los osteoblastos en cultivo fueron completamente revertidos por bajas dosis de Alendronato $\left(10^{-8}-10^{-7} \mathrm{M}\right)$, a nivel de la proliferación, apoptosis y diferenciación celular, aunque solo parcialmente a nivel de la morfología celular.

$\checkmark$ En los osteoblastos los AGEs generan su acción a través de la interacción con receptores RAGE y Galectina-3 (resultados previos), induciendo estrés oxidativo e inhibición de PTPasas neutras. Aunque no totalmente dilucidado, los BPs actuarían a través de varios mecanismos: la entrada de calcio vía canales de tipo L sensibles al voltaje, como scavengers de ROS y por inhibición de PTPasas neutras.

$\checkmark$ Los efectos inhibitorios de los AGEs sobre los osteoclastos no fueron revertidos por los BPs. Por el contrario, demostramos que altas dosis de Alendronato $\left(>10^{-5} \mathrm{M}\right)$ generan un efecto aditivo sobre el de los AGEs evidenciado a nivel de la actividad TRAP y el número de osteoclastos desarrollado.

$\checkmark$ En los osteoclastos los AGEs actúan incrementando la expresión de RAGE. El efecto inhibitorio de bajas dosis de Alendronato sobre el crecimiento y desarrollo osteoclástico correlaciona con su capacidad para inducir la expresión de RAGE bajo condiciones basales. Por otro lado, altas dosis citotóxicas de Alendronato y sus efectos aditivos al AGEs no se asocian con la regulación positiva del RAGE, sugiriendo un mecanismo de acción de los BPs alternativo. 


\section{VI}

\section{LISTADO DE FIGURAS Y TABLAS}
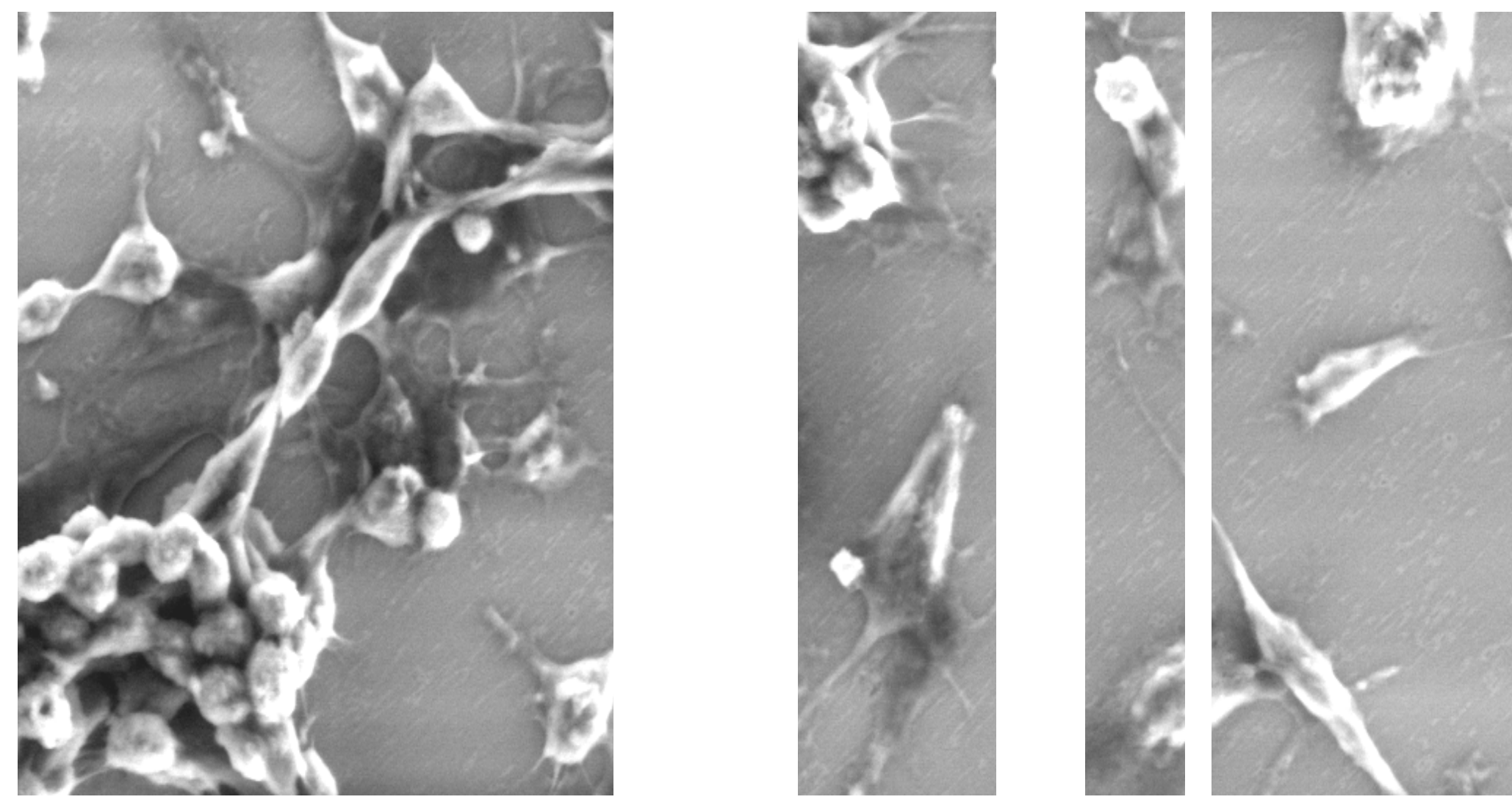


\section{VI.1- FIGURAS}

Figura I.1.2.1.1-Esquema de la estructura de un hueso largo en fase de crecimiento.

Figura I.1.2.1.2- Disposición de los tejidos óseo cortical y óseo trabecular en un hueso largo.

Figura I.1.2.2-Detalle de la de la estructura ósea microscópica de hueso cortical y hueso trabecular.

Figura I.1.3.2.1-Esquema de los distintos linajes en que puede diferenciarce una célula mesenquimal.

Figura I.1.3.2.2- Detalle de la diferenciación de una célula mesenquimal a osteoblasto y los posibles destinos de esta célula.

Figura I.1.3.2.3- Esquema del desarrollo de diferenciación de precursores hematopoyéticos en osteoclastos maduros.

Figura I.1.3.2.4- Mecanismo de diferenciación osteoclástica.

Figura I.1.3.2.5- Mecanismo de resorción ósea del osteoclasto.

Figura I.1.4- Esquema de la formación ósea endocondral.

Figura I.1.5.2.1- Esquema de las fases involucradas en el remodelado óseo.

Figura I.1.5.2.2- Esquema del ciclo de remodelación en un hueso esponjoso y un hueso cortical.

Figura I.1.5.3- Curva de masa ósea en función de la edad.

Figura I.3.1- Estructura química de los principales bisfosfonatos.

Figura I.3.2-Esquema de la vía del mevalonato.

Figura I.4.3.1- Esquema del aumento de flujo a través de la vía de los polioles. [Brownlee, 2001].

Figura I.4.3.2- Esquema del incremento intracelular de precursores AGE y sus consecuencias. [Brownlee, 2001]

Figura I.4.3.3- Consecuencias de la activación de la PKC inducida por la hiperglucemia [Brownlee, 2001].

Figura I.4.3.4- Hiperglicemia incrementa el flujo a través de la vía de la hexosamina. [Brownlee, 2001]

Figura I.4.3.5- Producción de superóxido inducida por hiperglicemia mediante la cadena de transporte electrónico mitocondrial [Brownlee, 2001].

Figura I.4.3.6.1- La producción de superóxido mitocondrial inducida por la hiperglucemia activa las cuatro vías de daño por la inhibición de GAPDH [Brownlee, 2001].

Figura I.4.3.6.2- Mecanismo unificador del daño celular causado por la hiperglicemia. 
Fig. I.5.2.1 Ejemplo de la vía clásica de la glicosilación de proteínas por la glucosa que lleva a la formación de AGE a través de productos de Amadori.

Fig. Fig. I.5.2.2 Estructuras químicas de los tres tipos de AGE:

Fig I.5.4.1. Esquema de señalización de la activación del receptor para los compuestos de glicosilaciónavanzada (RAGE) [Mosquera, 2010].

Fig. II.2.1.1. Espectro de emisión de fluorescencia de AGE-BSA y BSA no glicada.

Fig. II.2.1.2.Espectros de fluorescencia bidimensionales.

Fig.II.2.3.1.a Imágenes de las células MC3T3-E1 en cultivo.

Fig.II.2.3.1.b Imágenes del cultivo de células UMR-106.

Fig.II.2.3.2. Imágenes de E-SEM de los cocultivos de Raw 264.7 y UMR-106.

Fig. II.2.5 1 Esquemas comparativos de un microscocopio de fluorescencia óptico y un microscopio confocal.

Figura III.1.1.1- Efecto de los AGEs sobre la proliferación los osteoblastos.

Figura III.1.1.2- Imágenes de E-SEM del efecto de los AGEs sobre los osteoblastos.

Figura III.1.2-Efecto de los AGEs y BPs sobre la proliferación celular.

Figura III.1.3- Efecto de AGEs y Alendronato sobre la inducción de apoptosis en células osteoblásticas UMR106 o MC3T3E1.

Figura III.1.4.1- Efecto de AGEs y BPs sobre la diferenciación osteoblástica.

Figura III.1.4.2- Efecto de AGEs y BPs sobre la diferenciación osteoblástica.

Figura III.1.5- Efecto del AGEs y Alendronato sobre la morfología de osteoblastos en cultivo: Imágenes de E-SEM.

Figura III.1.6- Efecto del AGEs y Alendronato sobre las fibras de actina.

Figura III.1.7- Estudios de inmunofluorescencia.

Figura III.1.8- Rol del calcio intracelular en el efecto de AGEs y BPs sobre la proliferación osteoblástica

Figura III.1.9- Producción intracelular de ROS: efecto de AGEs y BPs

Figura III.1.10- Efecto de AGEs y BPs sobre la actividad de Fosfatasas Neutras en osteoblastos.

Figura III.2.1-.Cocultivo de ocho días en los que podemos observar células multinucleadas TRAP (+) (flechas). Obj 40x

Figura III.2.2-Cinética de expresión de TRAP.

Figura III.2.3-Efecto de los AGEs sobre la actividad TRAP. 
Figura III.2.4-Efecto de los AGEs y distintas concentraciones de Alendronato sobre la actividad TRAP.

Figura III.2.6- Efecto de los AGEs y Alendronato sobre el número de osteoclastos.

Figura III.2.7.1-Determinación de RAGE en osteoclastos por IFI.

Figura III.2.7.2.1- Imágenes de microscopía confocal de osteoclastos con BSA y Alendronato.

Figura III.2.7.2.2- Imágenes de microscopía confocal de osteoclastos con AGEs y Alendronato.

\section{VI.2-TABLAS}

Tabla I.2.1-Clasificación de la densidad de masa ósea según la OMS (1994)

Tabla I.2.2-Clasificación etiológica de osteoporosis

Tabla I.3.1- Bisfosfonatos y su potencia de acción antirresortiva.

Tabla I.4.2-Clasificación etiológica de la Diabetes Mellitus.

Tabla III.1.10-Efecto de BSA, AGEs y diferentes dosis de Alendronato sobre la actividad de las fosfatasas neutras totales en las células osteoblásticas UMR106.

Tabla III.2.5-Acción de los AGEs y Ale 10 -5 M sobre la actividad TRAP de osteoclastos 


\section{VII}

\section{REFERENCIAS}

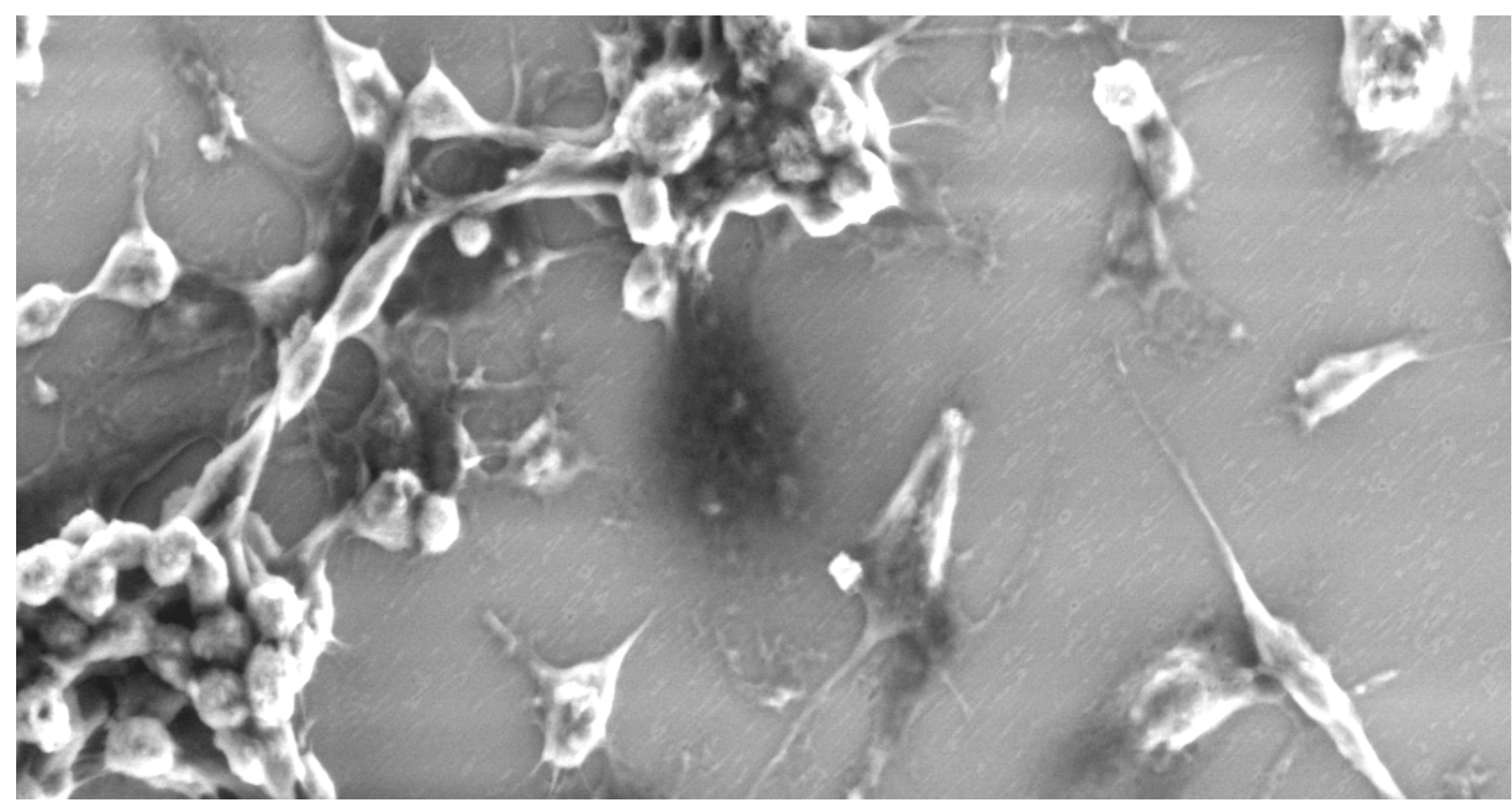


-A-

Aguirre JI, Plotkin LI, Stewart SA, Weinstein RS, Parfitt AM, Manolagas SC, Bellido T. 2006. Osteocyte apoptosis is induced by weightlessness in mice and precedes osteoclast recruitment and bone loss. J Bone Miner Res 21: 605-615

Ahmed N. 2005. Advanced glycation endproducts-role in pathology of diabetic complications. Diabetes Res Clin Pract.67: 3-21

Albright F, Reifenstein EC. 1948. Bone development in diabetic children: a roentgen study. Am J Med Sci 174: 313-319

Alikhani M, Alikhani Z, Boyd C, MacLellan CM, Raptis M, Liu R, Pischon N, Trackman P, Gerstenfeld L, Graves D. 2007. Advanced glycation end products stimulate osteoblast apoptosis via the MAP kinase and cytosolic apoptotic pathways. Bone 40: 345-353

-B-

Barbosa J, Oliveira S, Tojal e Seara L. 2008. O Papel dos Produtos Finais da Glicação Avançada (AGEs) no Desencadeamento das Complicações Vasculares do Diabetes Arq Bras Endocrinol Metab 52: 940-950

Basta G, Schimidt AM, De Caterina R. 2004. Advanced glycation end products and vascular inflammation: implications for accelerated atherosclerosis in diabetes. Cardiovasc Res. 63: 582592

Bellido T, Plotkin L. 2006. Prevention of osteocyte and osteoblast apoptosis by bisphosphonates: a survival pathway mediated by $\mathrm{Cx} 43$ hemichannels and extracellular signal-regulated kinase activation, independently of gene transcription .Actualizaciones en Osteología 2: 131-136

Benford HL, Frith JC, Auriola S, Mönkkönen J, Rogers MJ. 1999. Farnesol and geranylgeraniol prevent activation of caspases by aminobisphosphonates: biochemical evidence for two distinct pharmacological classes of bisphosphonate drugs. Mol Pharmacol 56: 131-140

Bergstrom JD, Bostedor RG, Masarachia PJ, Reszka AA, Rodan G. 2000 Alendronate is a specific, nanomolar inhibitor of farnesyl diphosphate synthase. Arch Biochem Biophys 373: 231-241

Beyer RE. 1994. The role of ascorbate in antioxidant protection of biomembranes: interaction with vitamin E and coenzyme Q. J Bioenerg Biomembr. 26: 349-358

Black DM, Cummings SR, Karpf DB, Cauley JA, Thompson DE, Nevitt MC, Bauer DC, Genant HK, Haskell WL, Marcus R, Ott SM, Torner JC, Quandt SA, Reiss TF, Ensrud KE. 1996. Randomised trial of effect of alendronate on risk of fracture in women with existing vertebral fractures. Fracture Intervention Trial Research Group. Lancet 348: 1535-1541

Black DM, Delmas PD, Eastell R, Reid IR, Boonen S, Cauley JA, Cosman F, Lakatos P, Leung PC, Man Z, Mautalen C, Mesenbrink P, Hu H, Caminis J, Tong K, Rosario-Jansen T, Krasnow J, Hue TF, Sellmeyer D, Eriksen EF, Cummings SR; 2007 HORIZON Pivotal Fracture Trial. Once-yearly zoledronic acid for treatment of postmenopausal osteoporosis. N Engl J Med. 356: 1809- 1822

Bierhaus A, Hofman MA, Ziegler R, Nauroth PP. 1998. AGEs and their interaction with AGEreceptors in vascular disease and diabetes mellitus I. The AGE concept. Cardiovasc Res.37: 586600

Boanini E, Torricelli P, Gazzano M, Giardino R, Bigi A. 2008. Alendronate-hydroxyapatite nanocomposites and their interaction with osteoclasts and osteoblast-like cells. Biomaterials 29: $790-796$ 
Bone HG, Greenspan SL, McKeever, Bell N, Davidson M, Downs RW, Emkey R, Meunier PJ, Miller SS, Mulloy AL, Recker RR, Weiss SR, Heyden N, Musliner T, Suryawanshi S, Yates AJ, Lombardi A. 2000. Alendronate and estrogen effects in postmenopausal women with low bone mineral density. J Clin Endocrinol Metab 85: 720-726

Bone HG, Hosking D, Devogelaer JP, Tucci JR, Emkey RD, Tonino RP, Rodriguez-Portales JA, Downs RW, Gupta J, Santora AC, Liberman UA. 2004. Alendronate Phase III Osteoporosis Treatment Study Group. Ten years'experience with alendronate for osteoporosis in postmenopausal women. N Engl J Med 350: 1189-1199

Bonewald LF. 2007. Osteocytes as dynamic, multifunctional cells. Ann N Y Acad Sci 1116:281-290

Boonen S, Laan RF, Barton IP, Watts NB. 2005. Effect of osteoporosis treatments on risk of nonvertebral fractures: review and metaanalysis of intention-to-treat studies. Osteoporos Int 16: 12911298

Bouillon R. 1991. Diabetic bone disease. Calcif. Tissue Int. 49: 155-160

Boyle WJ, Simonet WS, Lacey DL. 2003. Review Osteoclast differentiation and activation Nature 423: $337-342$

Bradford MM. 1976. A rapid and sensitive method for the quantitation of microgram quantities of protein utilizing the principle of protein-dye binding. Anal Biochem 72: 248-254

Brownlee $M_{-}$2001. Biochemistry and molecular cell biology of diabetic complications. Nature 414: 813-820

Brownlee M. 2005. The pathobiology of diabetic complications: a unifying mechanism. Diabetes 54: $1615-1625$

Brumsen C, Papapoulos SE, Lips, Geelhoed-Duijvestijn PH, Hamdy NA, Landman JO, McCloskey EV, Netelenbos JC, Pauwels EK, Roos JC, Valentijn RM, Zwinderman AH. 2002. Daily oral pamidronate in women and men with osteoporosis: a 3-year randomized placebo-controlled clinical trial with a 2-year open extension. J Bone Miner Res 17: 1057-1064

$-\mathrm{C}-$

Campos Pastor MM, Lopez-Ibarra PJ, Escobar-Jimenez F, Serrano Pardo MD, Garcia-Cervigon AG. 2000. Intensive insulin therapy and bone mineral density in type 1 diabetes mellitus: a prospective study. Osteoporos Int. 11: 455-459

Cauley JA, Robbins J, Chen Z, Cummings SR, Jackson RD, La-Croix AZ, LeBoff M, Lewis CE, McGowan J, Neuner J, Pettinger M, Stefanick ML, Wactawski-Wende J, Watts NB. 2003. Women's Health Initiative Investigators. Effects of estrogen plus progestin on risk of fracture and bone mineral density: the Women's Health Initiative randomized trial. JAMA 290: 1729-1738

Cerami C, Founds H, Nicholl I, Mitsuhashi T, Giordano D, Vanpatten S, Lee A, Al-Abed Y, Vlassara H, Bucala R, Cerami A. 1997. Tobacco smoke is a source of toxic reactive glycation products. Proc Natl Acad Sci U S A. 94: 13915-13920

Chen T, Berenson J, Vescio R, Swift R, Gilchick A, Goodin S, LoRusso P, Ma P, Ravera C, Deckert F, Schran H, Seaman J, Skerjanec A. 2002. Pharmacokinetics and pharmacodynamics of zoledronic acid in cancer patients with bone metastases. J Clin Pharmacol 42: 1228-1236 
Chen AS, Taguchi T, Sugiura M, Wakasugi Y, Kamei A, Wang MW, Miwa I. 2004. Pyridoxalaminoguanidine adduct is more effective than aminoguanidine in preventing neuropathy and cataract in diabetic rats. Horm Metab Res 36: 183-187

Chesnut III CH, Skag A, Christiansen C, Recker R, Stakkestad JA, Hoiseth A, Felsenberg D, Huss H, Gilbride J, Schimmer RC, Delmas PD; 2004 Oral Ibandronate Osteoporosis Vertebral Fracture Trial in North America and Europe (BONE). Effects of oral ibandronate administered daily or intermittently on fracture risk in postmenopausal osteoporosis. J Bone Miner Res 19: 1241-1249

Chiarugi P, Giannoni E. 2008. Anoikis: A necessary death program for anchorage-dependent cells. biochemical pharmacology 76 1352-1364

Civera M, Urios A, Garcia-Torres ML, Ortega J, Martinez-Valls J, Cassinello N, del Olmo JA, Ferrandez A, Rodrigo JM, Montoliu C. 2010. Relationship between insulin resistance, inflammation and liver cell apoptosis in patients with severe obesity. Diabetes Metab Res Rev. 26: $187-192$

Coleman RE. 2005. Bisphosphonates in breast cancer [review].Ann Oncol 16: 687-695

Cortizo AM, Etcheverry SB. 1995. Vanadium derivatives act as growth factor-mimetic compounds upon differentiation and proliferation of osteoblast-like UMR106 cells. Mol. Cell Biochem. 145: 97-102

Cortizo AM, Caporossi M, Lettieri G, Etcheverry SB. 2000. Vanadate-induced nitric oxide production: role in osteoblast growth and differentiation. Eur J Pharmacol. 400: 279-285

Cortizo AM, Kreda S. 2000. Vanadium induced alterations in cytoeskeleton and protein tyrosinephosphorilation in osteoblast cell lines. 6: 714-716. Metal Ions in Biology and Medicine. Eds JA Centeno; PH Collery, G Vernet, RB Finkelman, H Gibb, JC Etienne. John Libbey Eurotext, Paris

Cortizo AM, Bruzzone L, Molinuevo S, Etcheverry SB. 2000. A posible role of oxidative stress in the vanadium-induced cytotoxicity in the MC3T3-E1osteoblast and UMR106 osteosarcoma cell lines. Toxicology 147: 89-99

Cortizo, A.M., Lettieri, M.G., Barrio, D.A., Mercer, N., Etcheverry, S.B., McCarthy, A.D., 2003. Advanced glycation endproducts (AGEs) induce concerted changes in the osteoblastic expression of their receptor RAGE and in the activation of extracellular signal-regulated kinases (ERK). Mol. Cell Biochem. 250, 1-10

Cortizo AM, Sedlinsky C, McCarthy AD, Blanco A, Schurman L. 2006 .Osteogenic actions of the anti-diabetic drug metformin on osteoblasts in culture. Eur J Pharmacol 536: 38-46

Cozen L.1972. Does diabetes delay fracture healing? Clinical Orthopaedics and Related Research 82: $134-140$

Cranney A, Guyatt G, Krolicki N, Welch V, Griffith L, Adachi JD, Shea B, Tugwell P, Wells G. Osteoporosis Research Advisory Group (ORAG). 2001. A meta-analysis of etidronate for the treatment of postmenopausal osteoporosis. Osteoporos Int.12: 140-151

Cummings SR, Bilezikian JP, Christiansen C, Eastell R, Ettinger B, Delmás P. 2007. The effects of tibolone in older women: results of the LIFT trial. 34th European Symposium on Calcified Tissues. 5-9 Mayo, 2007; Copenhague, Dinamarca. 
-D-

Dagdelen S, Sener D, Bayraktar M. 2007. Influence of type 2 diabetes mellitus on bone mineral density response to bisphosphonates in late postmenopausal osteoporosis.Adv. Ther. 24: 13141320 .

Davis L. 1998. Prevention of bone loss with alendronate in postmenopausal women under 60 years of age. J Nurse Midwifery 43: 395-396

Dawson-Hughes B, Heaney RP, Holick MF, Lips P, Meunier PJ, Vieth R. 2005. Estimates of optimal vitamin D status. Osteoporos Int 16: 713-716

Delmas PD. 2003 Clinical use of selective estrogen receptor modulators and other estrogen analogs. En: Favus MJ (ed). Primer on the metabolic bone diseases and disorders of mineral metabolism.Washington D.C.: American Society for Bone and Mineral Research: 331-336

Delon I, Brown N. 2007. Integrins and the actin cytoskeleton. Current Opinion in Cell Biology 19: 4350

Desta T, Li J, Chino T, Graves DT. 2010. Altered fibroblast proliferation and apoptosis in diabetic gingival wounds. J Dent Res.89: 609-614.

Diabetes Control and Complications Trial Research Group 1993: The effect of intensive treatment of diabetes on the development and progression of long-term complications in insulin-dependent diabetes mellitus. N Engl J Med 329: 977-986

Diagnosis and Classification of Diabetes Mellitus. 2008. American Diabetes Association Diabetes Care 31: S55-60

Ding KH, Wang ZZ, Hamrick MW, Deng ZB, Zhou L, Kang B, Yan SL, She JX, Stern DM, Isales CM, Mi QS. 2006. Disordered osteoclast formation in RAGE-deficient mouse establishes an essential role for RAGE in diabetes related bone loss. Biochemical and Biophysical Research Communications 340: 1091-1097

Dobler D, Ahmed N, Song L, Eboigbodin K E, Thornalley PJ. 2006. Increased dicarbonyl metabolism in endothelial cells in hyperglycemia induces anoikis and impairs angiogenesis by RGD and GFOGER motif modification. Diabetes 55: 1961-1969

Dominguez LJ, Muratore M, Quarta E, Zagone G, Barbagallo M. 2004. Osteoporosi e diabete mellito Reumatismo 56: 235-241

Dunford JE, Thompson K, Coxon FP, Luckman SP, Hahn FM, Poulter CD, Ebetino FH, Rogers MJ. 2001. Structure- activity relationships for inhibition of farnesyl diphosphate synthase in vitro and inhibition of bone resorption in vivo by nitrogen-containing bisphosphonates. JPharmacol ExpTher 296: $235-242$

-E-

Ebetino FH, Francis MD, Rogers MJ, Russell RGG. 1998. Mechanisms of action of etidronate and other bisphosphonates. Rev Contemp Pharmacother 9: 233-243

Ettinger B, Black DM, Mitlak BH, Knickerbocker RK, Nickelsen T, Genant HK, Christiansen C, Delmas PD, Zanchetta JR, Stakkestad J, Glüer CC, Krueger K, Cohen FJ, Eckert S, Ensrud KE, Avioli LV, Lips P, Cummings SR. 1999. Reduction of vertebral fracture risk in postmenopausal women with osteoporosis treated with raloxifene: results from a 3-year randomized clinical trial. Multiple Outcomes of Raloxifene Evaluation (MORE) Investigators. JAMA 282: 637-645 
-F-

Fisher JE, Rogers MJ, Luckman SP, Hughes DE, Masarachia PJ, Wesolowski G, Russel RGG, Rodan GA, Reszka AA. 1999. Alendronate mechanism of action: geranygeraniol, an intermediate in the mevalonate pathway, prevents inhibition of osteoclast formation, bone resorption and kinase activation in vitro. Proc Natl Acad Sci USA 96: 133-138

Fleisch H, Russell RGG, Francis MD. 1969. Diphosphonates inhibit hydroxyapatite dissolution in vitro and bone resorption in tissue culture and in vivo. Science 165: 1262-1264

Fleisch H. 2000. Bisphosphonates in bone disease. From the laboratory to the patient, 4th edn. Academic Press, New York

Follet H, Li J, Phipps RJ, Hui S, Condon K, Burr DB. 2007. Risedronate and alendronate suppress osteocyte apoptosis following cyclic fatigue loading. Bone 40: 1172-1177

Forbes JM, Soldatos G, Thomas MC. 2005. Below the radar: advanced glycation end products that detour "around the side". Is HbA1c not an accurate enough predictor of long term progression and glycaemic control in diabetes? Clin Biochem Rev.26: 123-134

Frith JC, Mönkkönen J, Blackburn GM, Russell RG, Rogers MJ. 1997. Clodronate and liposomeencapsulated clodronate are metabolized to a toxic ATP analog, adenosine 5-(beta, gamadichloromethylene) triphosphate, by mammalian cells in vitro. J Bone Miner Res12: 1358 -1367

Frith JC, Mönkkönen J, Auriola S, Mönkkönen H, Rogers MJ. 2001. The molecular mechanism of action of the anti-resorptive and anti-inflammatory drug clodronate: evidence for the formation in vivo of ametabolite that inhibits bone resorption and causes osteoclast and macrophage apoptosis. Arthritis Rheum 44: 2201-2210

Fromigué O, Body JJ. 2002. Bisphosphonates influence the proliferation and the maturation of normal human osteoblasts. J. Endocrinol. Invest. 25: 539-546

-G-

Giuliani N, Pedrazzoni M, Negri G, Passeri G, Impicciatore M, Girasole G. 1998. Bisphosphonates stimulate formation of osteoblast precursors and mineralized nodules in murine and human bone marrow cultures in vitro and promote early osteoblastogenesis in young and aged mice in vivo. Bone 22(5): 455-461

Goh SY, Cooper ME. 2008. The Role of Advanced Glycation End Products in Progression and Complications of Diabetes Clin Endocrinol Metab 93(4): 1143-1152

Goldberg T, Cai W, Peppa M, Dardaine V, Baliga BS, Uribarri J, Vlassara H. 2004. Advanced glycoxidation end products in commonly consumed foods. J Am Diet Assoc.104: 1287-1291

Goldin A, Beckman JA, Schmidt AM, Creager MA. 2006. "Advanced glycation end products: sparking the development of diabetic vascular injury". Circulation 114: 597-605

Green JR, Rogers MJ. 2002. Pharmacologic profile of zoledronic acid: a highly potent inhibitor of bone resorption. Drug Dev Res 55: 210-224

Greenspan SL, Bone HG, Ettinger MP, Hanley DA, Lindsay R, Zanchetta JR, Blosch CM, Mathisen AL, Morris SA, Marriott TB. 2007. Treatment of Osteoporosis with Parathyroid Hormone Study Group. Effect of recombinant human parathyroid hormone (1-84) on vertebral fracture and bone mineral density in postmenopausal women with osteoporosis: a randomized trial. Ann Intern Med. 146: 326-339. 
Guggino SE, Lajeunesse D, Wagner JA, Snyder SH. 1989. Bone remodeling signaled by a dihydropyridine- and phenylalkylamine-sensitive calcium channel. Proc Natl Acad Sci USA 86: 2957-2960

Gugliucci A, Bendayan M. 1996. "Renal fate of circulating advanced glycated end products (AGE): evidence for reabsorption and catabolism of AGE-peptides by renal proximal tubular cells". Diabetology 39: 149-160

Gugliucci A, Mehlhaff K, Kinugasa E, Ogata H, Hermo R, Schulze J, Kimura S. 2007. "Paraoxonase1 concentrations in end-stage renal disease patients increase after hemodialysis: correlation with low molecular AGE adduct clearance". Clin. Chim. Acta 377: 213-220.

Guimarães E, Empsen C, Albert Geerts A, van Grunsven L. 2010. Advanced glycation end products induce production of reactive oxygen species via the activation of NADPH oxidase in murine hepatic stellate cells. Journal of Hepatology 52: 389-397

Gundberg CM, Anderson M, Dickson I, Gallop PM. 1986. "Glycated" osteocalcin in human and bovine bone. The effect of age. J Biol Chem. 261:14557-14561

Guo XH, Huang QB, Chen B, Wang SY, Li Q, Zhu YJ, Hou FF, Fu N, Brunk UT, Zhao M. 2009. Advanced glycation end products induce actin rearrangement and subsequent hyperpermeability of endothelial cells. APMIS. 2006 114: 874-883. Retraction in: APMIS. 2009 117: 549

$-\mathbf{H}-$

Halasy-Nagy JM, Rodan GA, Reszka AA. 2001. Inhibition of bone resorption by alendronate and risedronate does not require osteoclast apoptosis. Bone 29: 553-559

Hamada Y, Fujii H, Fukagawa M. 2009. Role of oxidative stress in diabetic bone disorder Bone 45: S35-S38

Harada S, Rodan GA. 2003. Control of osteoblast function and regulation of bone mass. Nature 423: 349-355

Harris ST, Watts NB, Genant HK, McKeever CD, Hangartner T, Keller M, Chesnut III CH, Brown J, Eriksen EF, Hoseyni MS, Axelrod DW, Miller PD. 1999. Effects of risedronate treatment on vertebral and nonvertebral fractures in women with postmenopausal osteoporosis: a randomized controlled trial. Vertebral Efficacy With Risedronate Therapy (VERT) Study Group. JAMA 282: $1344-1352$

Heaney RP. 2006. Nutrition and osteoporosis Primer on the metabolic bone diseases and disorders of mineral metabolism 6th edition Favus MJ American Society for bone and mineral research Washington DC

Hein G, Wiegand R, Lehmann G, Stein G, Franke S. 2003. Advanced glycation end-products pentosidine and N"-carboxymethyllysine are elevated in serum of patients with osteoporosis. Rheumatology 42: 1242-1246

Hein GE. 2006. Glycation endproducts in osteoporosis--is there a pathophysiologic importance? Clin Chim Acta. 371: 32-36

Hirose A, Tanikawa T, Mori H, Okada Y, Tanaka Y. 2010. Advanced glycation end products increase endothelial permeability through the RAGE/Rho signaling pathway. FEBS Letters 584: 61-66

Hofbauer LC, Brueck CC, Singh SK, Dobnig H. 2007. Osteoporosis in patients with diabetes mellitus. J Bone Miner Res. 22: 1317-1328 
Howard E, Ahern-Moore R, Tomasek J. 1996. Cellular Contraction of Collagen Lattices Is Inhibited by Nonenzymatic Glycation. Experimental Cell Research 228: 132-137

Huebschmann AG, Regensteiner JG, Vlassara H, Reusch JE. 2006. Diabetes and glicoxidation end products. Diabetes Care 29: 1420-1432

$-\mathbf{I}-$

Im GI, Qureshi SA, Kenney J, Rubash HE, Shanbhag AS. 2004. Osteoblast proliferation and maturation by bisphosphonates Biomaterials 25: 4105-4115

Idris AI, Rojas J, Greig IR, Van't Hof RJ, Ralston SH. 2008. Aminobisphosphonates Cause Osteoblast Apoptosis and Inhibit Bone Nodule Formation In Vitro Calcif Tissue Int 82: 191-201

Ivers RQ, Cumming RG, Mitchell P, Peduto AJ. 2001. Diabetes and the risk of fracture: The Blue Mountains Eye Study Diabetes Care 24: 1198-1203

$-\mathbf{J}-$

Jakus V, Rietbrock N. 2004. Advanced glycation end products and the progress of diabetic vascular complications. Physiol Res 53: 131-142

Janghorbani M, Van Dam RM, Willett WC, Hu FB. 2007. Systematic review of type 1 and type 2 diabetes mellitus and risk of fracture. American Journal of Epidemiology 166: 495-505

Jay D, Hitomi H, Griendling KK. 2006. Oxidative stress and diabetic cardiovascular complications. Free Radic Biol Med 40: 183-192

Jude EB, Selby PL, Burgess J, Lilleystone P, Mawer EB, Page SR, Donohoe M, Foster AV, Edmonds ME, Boulton AJ. 2001. Bisphosphonates in the treatment of Charcot neuroarthropathy: a doubleblind randomised controlled trial. Diabetologia 44: 2032-2037.

Jung A, Bisaz S, Fleisch H .1973. The binding of pyrophosphate and two diphosphonates by hydroxyapatite crystals. Calcif Tissue Res 11:269-280

$-\mathbf{K}-$

Kanis JA, Johnell O, Dawson A, De Late C and Jonsson B. 2001. Ten years probabilities of osteoporotic fractures according to BMD and diagnostic thresholds. Osteoporosis Int 12: 989-995

Karsdal M, Martin T, Bollerslev J, Christiansen C, Henriksen K. 2007. Are Nonresorbing Osteoclasts Sources of Bone Anabolic Activity? JOURNAL OF BONE AND MINERAL RESEARCH 22: 487-494

Kazmers N, Ma SA, Yoshida T, Stern P. 2009. Rho GTPase signaling and PTH 3-34, but not PTH 134, maintain the actin cytoskeleton and antagonize bisphosphonate effects in mouse osteoblastic MC3T3-E1 cells. Bone 45: 52-60

Keegan TH, Schwartz AV, Bauer DC, Sellmeyer DE, Kelsey JL. 2004. Effect of alendronate on bone mineral density and biochemical markers of bone turnover in type 2 diabetic women: the fracture intervention trial. Diabetes Care 27: 1547-1553.

Kogianni G, Mann V, Ebetino F, Nuttall M, Nijweide P, Simpson H, Noble B. 2004. Fas/CD95 is associated with glucocorticoid-induced osteocyte apoptosis. Life Sci 75: 2879-2895

Kooy NW, Royall JA, Ischiropoulos H, Beckman JS. 1994. Peroxinitrite-mediated oxidation of dihydrorhodamine 123. Free Radic Biol Med. 16: 149-156 
Koschinsky T, He CJ, Mitsuhashi T, Bucala R, Liu C, Buenting C, Heitmann K, Vlassara H. 1997. "Orally absorbed reactive glycation products (glycotoxins): an environmental risk factor in diabetic nephropathy". Proceedings of the National Academy of Sciences 94 : 6474-6479

Koyama I, Yakushijin M, Gosekic M, Iimura T, Sato T, Sonoda M, Hokari S, Komoda T. 1998. Partial breakdown of glycated alkaline phosphatases mediated by reactive oxygen species Clinica Chimica Acta 275: 27-41

Krakauer JC, McKenna MJ, Buderer NF, Rao DS, Whitehouse FW, Parfitt AM. 1995. Bone loss and bone turnover in diabetes. Diabetes 44: 775-782

$-\mathbf{L}-$

Lapolla A, Fedele D, Traldi P. 2005. Glyco-oxidation in diabetes and related diseases. Clin Chim Acta 357: $236-250$

Laemmli UK. 1970. Cleavage of structural proteins during the asssembly of the head of bacteriophage T4. Nature. 227: 680-685

Lehenkari PP, Kellinsalmi M, Napankangas JP, Ylitalo KV, Mönkkönen J, Rogers MJ, Azhayev A, Väänänen HK, Hassinen IE. 2002. Further insight into mechanism of action of clodronate: inhibition of mitochondrial ADP/ATP translocase by a nonhydrolyzable, adenine-containing metabolite. Mol Pharmacol 61: 1255-1262

Lewiecki EM, Watts NB. 2009. New Guidelines for the Prevention and Treatment of Osteoporosis Southern Medical Journal 102: 175-179

Li F, Wang W, Gu M, Gyoneva S, 'Zhang J, Huang S, 'Traynelis S, Cai H, Guggino S, Zhang X. 2011. L-type calcium channel activity in osteoblast cells is regulated by the actin cytoskeleton independent of protein trafficking. J Bone Miner Metab. Jan 19. [Epub ahead of print]

Liberman UA, Weiss SR, Bröll J, Minne HW, Quan H, Bell NH, Rodriguez-Portales J, Downs RW Jr, Dequeker J. 1995. Favus M. Effect of oral alendronate on bone mineral density and the incidence of fractures in postmenopausal osteoporosis. N Engl J Med 333: 1437-1443

Lin L. 2006. RAGE on the toll road? Cell Mol Immunol. 3: 351-358

-M-

Masarachia P, Weinreb M, Balena R, Rodan GA. 1996. Comparison of the distribution of 3Halendronate and 3H-etidronate in rat and mouse bones. Bone 19: 281-290

Mathov I, Plotkin LI, Sgarlata CL, Leoni J, Bellido T. 2001. Extracellular signal regulated kinases and calcium channels are involved in the proliferative effect of bisphosphonates on osteoblastic cells in vitro. J. Bone Miner. Res. 16: 2050-2056

McCarthy AD, Etcheverry SB, Bruzzone L, Cortizo A.M. 1997. Effects of advanced glycation endproducts on the proliferation and differentiation of osteoblast like cells. Mol. Cell Biochem. 170: $43-51$

McCarthy AD, Etcheverry SB, Cortizo AM. 1999. Advanced glycation endproduct specific receptors in rat and mouse osteoblast-like cells: regulation with stages of differentiation. Acta Diabetol. 36: $45-52$

McCarthy AD, Etcheverry SB, Bruzzone L, Lettieri G, Barrio DA, Cortizo AM. 2001a. Nonenzymatic glycosylation of a type I collagen matrix: effects on osteoblastic development and oxidative stress. B.M.C. Cell Biol. 2:16 
McCarthy AD, Etcheverry SB, Cortizo AM. 2001b. Effect of advanced glycation endproducts on the secretion of insulin-like growth factor-I and its binding proteins: role in osteoblast development. Acta Diabetol 38: 113-122

McCarthy AD, Uemura T, Etcheverry SB, Cortizo AM. 2004. Advanced glycation endproducts interfere with integrin-mediated osteoblastic attachment to a type-I collagen matrix. The International Journal of Biochemistry \& Cell Biology 36: 840-848

McCloskey E, Selby P, Davies M, Robinson J, Francis RM, Adams J, Kayan K, Beneton M, Jalava T, Pylkkänen L, Kenraali J, Aropuu S, Kanis JA. 2004. Clodronate reduces vertebral fracture risk in women with postmenopausal or secondary osteoporosis: results of a double-blind, placebocontrolled 3-year study. J Bone Miner Res 19: 728-736

McCloskey EV, Beneton M, Charlesworth D, Kayan K, deTakats D, Dey A, Orgee J, Ashford R, Forster M, Cliffe J, Kersh L, Brazier J, Nichol J, Aropuu S, Jalava T, Kanis JA. 2007. Clodronate reduces the incidence of fractures in communitydwelling elderly women unselected for osteoporosis: results of a double-blind, placebo-controlled randomized study. J Bone Miner Res 22: $135-141$

McClung MR, Geusens P, Miller PD, Zippel H, Bensen WG, Roux C, Adami S, Fogelman I, Diamond T, Eastell R, Meunier PJ, Reginster JY. 2001. Hip Intervention Program Study Group. Effect of risedronate on the risk of hip fracture in elderly women. Hip Intervention Program Study Group. N Engl J Med. 344: 333-340

McRobert EA, Gallicchio M, Jerums G, Cooper ME, Bach LA 2003. The amino-terminal domains of the ezrin, radixin, and moesin (ERM) proteins bind advanced glycation end products, an interaction that may play a role in the development of diabetic complications. J Biol Chem 278: 25783-25789

Meade SJ, Miller AG, Gerrard JA. 2003. The role of dicarbonyl compounds in non-enzimatic crosslinking: a structure-activity study. Bioorg Med Chem.11: 853-862

Mercer N, Ahmed H, McCarthy AD, Etcheverry SB, Vasta GR, Cortizo AM. 2004. AGE-R3/galectin3 expression in osteoblast-like cells: regulation by AGEs. Mol Cell Biochem. 266:17-24

Mercer N, Ahmed H, Etcheverry SB, Vasta GR, Cortizo AM. 2007. Regulation of advanced glycation end product (AGE) receptors and apoptosis by AGEs in osteoblast-like cells. Mol Cell Biochem. 306: $87-94$

Meunier PJ, Roux C, Seeman E, Ortolani S, Badurski JE, Spector TD, Cannata J, Balogh A, Lemmel EM, Pors-Nielsen S, Rizzoli R, Genant HK, Reginster JY. 2004. The effects of strontium ranelate on the risk of vertebral fracture in women with postmenopausal osteoporosis. N Engl J Med 350: $459-468$

Miyata T, Notoya K, Y oshida K, Horie K, Maeda K, Kurokawa K, Taketomi S. 1997. Advanced glycation end products enhance osteoclast-induced bone resorption in cultured mouse unfractionated bone cells and in rats implanted subcutaneously with devitalized bone particles. J Am Soc Nephrol 8: 260-270

Molinuevo MS, Barrio DA, Cortizo AM, Etcheverry SB. 2004. Antitumoral properties of two new vanadyl(IV) complexes on osteoblasts in culture. Role of apoptosis and oxidative stress. Cancer Chemother. Pharmacol. 53: 163-172

Molinuevo MS, Bruzzone L, Cortizo AM. 2007. Alendronate induces anti-migratory effects and inhibition of neutral phosphatases in UMR106 osteosarcoma cells. Eur. J. Pharmacol. 562: 28-33 
Mönkkönen H, Rogers MJ, Makkonen N, Niva S, Auriola S, Mönkkönen J. 2001. The cellular uptake and metabolism of clodronate in RAW 264 macrophages. Pharm Res 18: 1550-1555

Mönkkönen H, Auriola S, Lehenkari P, Kellinsalmi M, Hassinen IE, Vepsäläinen J, Mönkkönen J. 2006. A newendogenous ATP analog (ApppI) inhibits the mitochondrial adenine nucleotide translocase (ANT) and is responsible for the apoptosis induced by nitrogencontaining bisphosphonates. Br J Pharmacol 147: 437-445

Mosquera JA. 2010. Papel del receptor para compuestos de glicosilación avanzada (RAGE) en la inflamación. Invest Clin 51: 257-268

Murata T, Nagai R, Ishibashi T, Inomuta H, Ikeda K, Horiuchi S. 1997. The relationship between accumulation of advanced glycation end products and expression of vascular endothelial growth factor in human diabetic retinas. Diabetologia 40: 764-769

$-\mathrm{N}-$

Nakamura S, Tobita K, Tachikawa T, Akamatsu S, Ohno Y, Kan A, Katsuragawa M, Yasumura K, Miyazaki S, Sakai S, Morita T, Hirashawa Y, Niwa T. 2003. Immunohistochemical detection of an AGE, a ligand of macrophage receptor, in peritoneum of CAPD pacients. Kidney Int Suppl 84: S152-157

Nancollas GH, Tang R, Phipps RJ, Henneman Z, Gulde S, Wu W, Mangood A, Russell RGG, Ebetino FH. 2006. Novel insights into actions of bisphosphonates on bone: differences in interactions with hydroxyapatite. Bone 38: 617-627

Neer RM, Arnaud CD, Zanchetta JR, Prince R, Gaich GA, Reginster JY, Hodsman AB, Eriksen EF, Ish-Shalom S, Genant HK, Wang O, Mitlak BH. 2001. Effect of parathyroid hormone (1-34) on fractures and bone mineral density in postmenopausal women with osteoporosis. N Engl J Med; 344: 1434-1441

Negre-Salvayre A, Salvayre R, Auge N, Pamplona R, Portero-Otín M. 2009. Hyperglycemia and Glycation in Diabetic Complications. Antioxidants \& Redox signalling 11: 3071-3109

NIH consensus development Panel on Osteoporosis. 2001. Prevention, diagnosis, and Therapy Osteoporosis Prevention, Diagnosis, and Therapy.JAMA 285: 785-795

Nicodemus KC, Folsom AR. 2001. Iowa Women's Health Study: Type 1 and type 2 diabetes and incidence of hip fractures in postmenopausal women. Diabetes Care 24: 1192-1197

Novack D, Teitelbaum S. 2008. The Osteoclast: Friend or Foe? Annu. Rev. Pathol. Mech. Dis. 3: 457484

$-\mathbf{O}-$

Okajima T, Nakamura K, Zhang H, Ling N, Tanabe T, Yasuda T. 1992. Sensitive colorimetric bioassays for insulin-like growth factor (IGF) stimulation of cell proliferation and glucose consumption: use in studies of IGF analogs. Endocrinology 130: 2201-2212

Okamoto T, Yamagishi S, Inagaki Y, Amano S, Takeuchi M, Kikuchi S. 2002. Incadronate disodium inhibits advanced glycation end products-induced angiogenesis in vitro. Biochem. Biophys. Res. Commun. 297: 419-424

Oldfield MD, Bach LA, Forbes JM, Nikolic-Paterson D, McRobert A, Thallas V, Atkins RC, Osicka T, Jerums G, Cooper ME 2001. Advanced glycation end products cause epithelial-myofibroblast transdifferentiation via the rereceptor for advanced glycation end products (RAGE). J Clin Invest 108: $1853-1863$ 
Orimo H. 2010. The Mechanism of Mineralization and the Role of Alkaline Phosphatase in Health and Disease J Nippon Med Sch 77: 4-12

-P-

Parker CC. 2005. The role of bisphosphonates in the treatment of prostate cancer. BJU Int 95: 935-938

Partridge NC, Alcorn D, Michelangeli VP, Ryan G, Martin TJ. 1983. Morphological and biochemical characterization of four clonal osteogenic sarcoma cell lines of rat origin. Cancer Res. 43: 43084315

Peppa M, Uribarri J, Vlassara H. 2003. Glucose, advanced glycation end products, and diabetes complications: what is new and what works. Clin Diabetes.21: 186-187

Peppa M, Vlassara H. 2005. Advanced glycation end products and diabetic complications: A General overview. Hormonaes 4: 28-37

Peyroux J., Sternberg M. 2006. Advanced glycation endproducts (AGEs): pharmacological inhibition in diabetes Pathologie Biologie 54: 405-419

Plotkin LI, Weinstein RS, Parfitt AM, Roberson PK, Manolagas SC, Bellido T. 1999. Prevention of osteocyte and osteoblast apoptosis by bisphosphonates and calcitonin. J. Clin. Invest. 104: 13631374

Plotkin LI, Manolagas SC, Bellido T. 2006. Dissociation of the pro-apoptotic effects of bisphosphonates on osteoclasts from their anti-apoptotic effects on osteoblasts/ osteocytes with novel analogs. Bone 39: 443-452

Plotkin LI, Goellner J, Vyas K, Shelton R, Wynne R, Weinstein RS, Manolagas SC, Bellido T. 2007. A bisphosphonate analog that lacks anti-remodeling activity prevents osteocyte and osteoblast apoptosis in vivo. J Bone Miner Res. 22:S4

Porras AG, Holland SD, Gertz BJ. 1999. Pharmacokinetics of alendronate. Clin Pharmacokinet. 36: $315-328$

Primer in the Metabolic Bone Diseases and Disorders of Mineral Metabolism. Sixth Ed. 2006

$-\mathbf{Q}-$

Quarles LD, Yohay DA, Lever LW, Caton R, Wenstrup RJ. 1992. Distinct proliferative and differentiated stages of murine MC3T3-E1 cells in culture: an in vitro model of osteoblast development. J Bone Miner Res 7: 683-692.

-R-

Rahbar S. 2005. The discovery of glycated hemoglobin: a major event in the study of nonenzymatic chemistry in biological systems. Ann N Y Acad Sci.1043: 9-19

Räkel A, Sheehy O, Rahme E, LeLorier J. 2008. Osteoporosis among patients with type 1 and type 2 diabetes. Diabetes Metab. 34: 193-205

Reddig PJ, Juliano RL. 2005. Clinging to life: cell to matrix adhesion and cell survival. Cancer Metastasis Rev. 24: 425-439

Reginster J, Minne HW, Sorensen OH, Hooper M, Roux C, Brandi ML, Lund B, Ethgen D, Pack S, Roumagnac I, Eastell R. 2000. Randomized trial of the effects of risedronate on vertebral fractures in women with established postmenopausal osteoporosis. Vertebral Efficacy with Risedronate Therapy (VERT) Study Group. Osteoporos Int.11: 83-91 
Reginster JY, Seeman E, De Vernejoul MC, Adami S, Compston J, Phenekos C, Devogelaer JP, Curiel MD, Sawicki A, Goemaere S, Sorensen OH, Felsenberg D, Meunier PJ. 2005. Strontium ranelate reduces the risk of nonvertebral fractures in postmenopausal women with osteoporosis: Treatment of Peripheral Osteoporosis (TROPOS) Study. J Clin Endocrinol Metab. 90: 2816-2822

Report of the Expert Committee on the Diagnosis and Classification of Diabetes Mellitus. 2003. Diabetes Care 26: S5-S20

Reszka AA, Halasy-Nagy JM, Masarachia PJRodan GA. 1999. Bisphosphonates act directly on the osteoclast to induce caspase cleavage of mst1 kinase during apoptosis. A link between inhibition of the mevalonate pathway and regulation of an apoptosispromoting kinase. J Biol Chem; 274: 34967-34973

Retzepi M, Donos N. 2010. The effect of diabetes mellitus on osseous healing. Clin. Oral Impl. Res. 21: $673-681$

Riggs BL, Melton LJ III. 1983. Evidence for two distinct syndromes of involutional osteoporosis. Am J Med, 75: 899-901

Ritchie CK, Maercklein PB, Fitzpatrick LA .1994. Direct effect of calcium channel antagonists on osteoclast function: alterations in bone resorption and intracellular calcium concentrations. Endocrinology 135: 996-1003

Rix M, Andreassen H, Eskildsen P. 1999. Impact of peripheral neuropathy on bone density in patients with type 1 diabetes. Diabetes Care.22: 827-831

Roelofs A, Thompson K, Gordon S, Rogers MJ. 2006. Molecular Mechanisms of Action of Bisphosphonates: Current Status. Clin Cancer Res 12: 6221s-6230s

Rogers MJ. 2003. New insights into the molecular mechanismsof action of bisphosphonates [review]. Curr Pharm Des 9: 2643-2658

Rogers MJ. 2004. From molds and macrophages to mevalonate: a decade of progress in understanding the molecular mode of action of bisphosphonates. Calcif Tissue Int 75: 451-461

Ross JR, Saunders Y, Edmonds PM, Patel S, Wonderling D, Normand C, Broadley K. 2004. A systematic review of the role of bisphosphonates in metastatic disease [review]. Health Technol Assess 8: 1-176

Ross-Pawlina Histología Texto y Atlas color con Biología celular y molecular $5^{\circ}$ edicion

Russell RG, Xia Z, Dunford JE, Oppermann U, Kwaasi A, Hulley PA, Kavanagh KL, Triffitt JT, Lundy MW, Phipps RJ, Barnett BL, Coxon FP, Rogers MJ, Watts NB, Ebetino FH. 2007. Bisphosphonates: an update on mechanisms of action and how these relate to clinical efficacy. Ann N Y Acad Sci.1117: 209-257

Russell RGG, Watts NB, Ebetino FH, Rogers MJ.2008. Mechanisms of action of bisphosphonates: similarities and differences and their potential influence on clinical efficacy. Osteoporos Int 19: 733-759

-S-

Sansom LN, Necciari J, Thiercelin JF. 1995. Human pharmacokinetics of tiludronate. Bone17: 479S$483 \mathrm{~S}$ 
Salerno M, Argenziano A, DiMaio S, Gasparini N, Formicola S, De Filippo G, Tenore A. 1997. Pubertal growth, sexual maturation, and final height in children with IDDM. Effects of age at onset and metabolic control. Diabetes Care 20: 721-724

Sato M, Grasser W, Endo N, Akins R, Simmons H, Thompson DD, Golub E, Rodan GA. 1991. Bisphosphonate action. Alendronate localization in rat bone and effects on osteoclast ultrastructure. J Clin Invest 88: 2095-2105

Saito M, Fujii K, Marumo K . 2006a. Degree of mineralization-related collagen crosslinking in the femoral neck cancellous bone in cases of hip fracture and controls. Calcif Tissue Int 79: 160-168

Saito M, Fujii K, Mori Y, Marumo K. 2006b. Role of collagen enzymatic and glycation induced crosslinks as a determinant of bone quality in spontaneously diabetic WBN/Kob rats. Osteoporos Int 17: $1514-1523$

Saito M, Mori S, Mashiba T Komatsubara S, Marumo K. 2008. Collagen maturity, glycation inducedpentosidine, and mineralization are increased following 3-year treatment with incadronate in dogs. Osteoporos Int 19: 1343-1354

Saito M, Marumo K. 2010. Collagen cross-links as a determinant of bone quality: a possible explanation for bone fragility in aging, osteoporosis, and diabetes mellitus Osteoporos Int 21: 195214

Schmidt A, Rutledge SJ, Endo N, Opas EE, Tanaka H, Wesolowski G, Leu CT, Huang Z, Ramachandaran C, Rodan SB, Rodan GA. 1996. Protein-tyrosine phosphatase activity regulates osteoclast formation and function: Inhibition by alendronate. Pharmacology 93: 3068-3073

Schmidt AM, Yan SD, Wautier JL, Stern D. 1999. Activation of receptor for advanced glycation end products: a mechanism for chronic vascular dysfunction in diabetic vasculopathy and atherosclerosis. Circ Res 84: 489-497

Schwartz AV. 2003. Diabetes mellitus: does it affect bone? Calcif. Tissue Int. 73: 515-519

Sharp PS, Rainbow S, Mukhergee S. 2003. Serum levels of low molecular weight advanced glycation end products in diabetic subjects. Diabet Med.20: 575-579

Silva MJ, Brodt MD, Lynch MA McKenzie JA, Tanouye KM, Nyman JS, Wang X. 2009.Type 1 diabetes in young rats leads to progressive trabecular bone loss, cessation of cortical bone growth and diminished whole-bone strength and fatigue life. J Bone Miner Res 94: 1618-1627

Silverman SL, Chesnut III CH. 2003. Calcitonin therapy for osteoporosis. En: Favus MJ (ed). Primer on the metabolic bone diseases and disorders of mineral metabolism. Washington D.C.: American Society for Bone and Mineral Research: 342-343

Sirohi B, Powles R. 2004. Multiple myeloma [review]. Lancet 363: 875-887

Skorey K, Ly H, Kelly J, Hammond M, Ramachandran C, Huang Z, Gresser MJ, Wang Q. 1997. How Does Alendronate Inhibit Protein-tyrosine Phosphatases? The Journal of Biological Chemistry 272: $22472-22480$

Small JV, Rottner K, Hahne P, Anderson KI. 1999a. Visualising the actin cytoskeleton. Microsc Res Tech. 47: 3-17

Small JV, Rottner K, Kaverina I. 1999 b. Functional design in the actin cytoskeleton. Current Opinion in Cell Biology 11: 54- 60 
Small JV, Kaverina I, Krylyshkina O, Rottner K. 1999 c. Cytoskeleton cross-talk during cell motility. FEBS Letters 452: 96-99

Soulis-Liparota T, Cooper ME, Dunlop M, Jerums G. 1995. The relative roles of advanced glycation, oxidation and aldose reductase inhibition in the development of experimental diabetic nephropathy in the Sprague-Dawley rat. Diabetologia 38: 387-394

Spreafico A, Frediani B, Capperucci C, Gambera D, Ferrata P, Baldi F. 2006. Anabolic effects and inhibition of interleukin 6 production induced by neridronate on human osteoblasts. Reumatismo 58: $288-300$

Stern DM, Yan SD, Yan SF, Schmidt AM. 2002. Receptor for advanced glycation endproducts (RAGE) and the complications of diabetes. Ageing Res Rev 1: 1-15

Stahl W, Sies H. 1997. Antioxidant defense: vitamins E and C and carotenoids. Diabetes.46: S14-18

Stitt AW, Li YM, Gardiner TA, Bucala R, Archer DB, Vlassara H. 1997.Advanced glycation end products (AGEs) co-localize with AGE receptors in the retinal vasculature of diabetic and of AGEinfused rats. Am J Pathol 150: 523-531

Stitt AW, Bhaduri T, McMullen CB, Gardiner TA, Archer DB. 2000. Advanced glycation end products induce blood-retinal barrier dysfunction in normoglycemic rats. Mol Cell Biol Res Commun 3: $380-388$

Stitt AW. 2001. Advanced glycation: an important pathological event in diabetic and age related ocular disease. Br J Ophthalmol 85: 746-753

Storm T, Thamsborg G, Steiniche T, Genant HK, Sørensen OH. 1990. Effect of intermittent cyclical etidronate therapy on bone mass and fracture rate in women with postmenopausal osteoporosis. $\mathrm{N}$ Engl J Med 322:1265-1271

$-\mathbf{T}-$

Tang SY, Allen MR, Phipps R Burr DB, Vashishth D. 2008. Changes in non enzymatic glycation and its association with altered mechanical properties following 1-year treatment with risedronate or alendronate. Osteoporos Int 94: 887-894

Teti A, Grano M, Colucci S, Argentino L, Barattolo R, Miyauchi A, Teitelbaum SL, Hruska KA, Zambonin Zallone A. 1989. Voltage dependent calcium channel expression in isolated osteoclasts. Boll Soc Ital Biol Sper 65: 1115-1118

Thrailkill KM, Lumpkin CK Jr, Bunn RC, Kemp SF, Fowlkes JL. 2005. Is insulin an anabolic agent in bone? Dissecting the diabetic bone for clues. Am J Physiol Endocrinol Metab 289: E735-E745

Tonino RP, Meunier PJ, Emkey R, Rodriguez-Portales JA, Menkes CJ, Wasnich RD, Bone HG, Santora AC, Wu M, Desai R, Ross PD. 2000. Skeletal benefits of alendronate: 7- year treatment of postmenopausal osteoporotic women. J Clin Endocrinol Metab 85: 3109-3115

Tsuchimoto M, Azuma Y, Higuchi O, Sugimoto I, Hirata N, Kiyoki M. 1994. Alendronate modulates osteogenesis of human osteoblastic cells in vitro. Jpn. J. Pharmacol. 66: 25-33

Tullberg-Reinert H, Jundt G. 1999. In situ measurement of collagen synthesis by human bone cells with a sirius red-based colorimetric microassay: effects of transforming growth factor beta2 and ascorbic acid 2-phosphate. Histochem Cell Biol 112: 271-276 
$-\mathbf{U}-$

Ueno A, Kitase Y, Moriyama K, Inoue H. 2001. MC3T3-E1-conditioned medium-induced mineralization by clonal rat dental pulp cells. Matrix Biol 20: 347-355

UK Prospective Diabetes Study (UKPDS) Group. 1998: Intensive blood-glucose control with sulphonylureas or insulin compared with conventional treatment and risk of complications in patients with type 2 diabetes (UKPDS 33). Lancet 352: 837- 853

Ulrich P, Cerami A. 2001. Protein glycation, diabetes, and aging. Recent. Prog. Horm. Res. 56: 1-21

Unno Y, Sakai M, Sakamoto Y, Kuniyasu A, Nakayama H, Nagai R. 2004. Advanced glycation end products-modified proteins and oxidized LDL mediate down-regulation of leptin in mouse adipocytes via CD36. Biochem. Biophys. Res. Commun 325: 151-156

Urena P, De Vernejoul MC. 1999. Circulating biochemical markers of bone remodeling in uremic patients. Kidney Int 55: 2141-2156

$-\mathbf{V}-$

Väänänen H, Laitala-Leinonen T. 2008. Osteoclast lineage and function. Archives of Biochemistry and Biophysics 473:132-138

Vaisman DN, McCarthy AD, Cortizo AM. 2005. Bone-specific alkaline phosphatase activity is inhibited by bisphosphonates: role of divalent cations. Biol. Trace Elem. Res. 104: 131-140

Valcourt U, Merle B, Gineyts E, Viguet-Carrin S, Delmas PD, Garnero P. 2007. Non-enzymatic glycation of bone collagen modifies osteoclastic activity and differentiation. J Biol Chem 282: 5691-5703

Valko M, Leibfritz D, Moncola J, Cronin M, Mazura M, Telser J. 2007. Free radicals and antioxidants in normal physiological functions and human disease. The International Journal of Biochemistry \& Cell Biology. 39: 44-84

van Beek E, Pieterman E, Cohen L, Lowik C, Papapoulos S. 1999a. Farnesyl pyrophosphate synthase is the molecular target of nitrogen-containing bisphosphonates. Biochem Biophys Res Commun 264: $108-111$

van Beek E, Pieterman E, Cohen L, Lowik C, Papapoulos S. 1999b. Nitrogen-containing bisphosphonates inhibit isopentenyl pyrophosphate isomerase/farnesyl pyrophosphate synthase activity with relative potencies corresponding to their antiresorptive potencies in vitro and in vivo. Biochem Biophys Res Commun 263: 754-758

van Beek ER, Cohen LH, Leroy IM, Ebetino FH, Lowik CW, Papapoulos SE. 2003. Differentiating the mechanisms of antiresorptive action of nitrogen containing bisphosphonates. Bone 33: 805-811

Varga F, Luegmayr E, Fratzl- Zelman N, Glantschnig H, Ellinger A, Prinz D, Rumpler M, Klaushofer K. 1999. Tri-iodothyronine inhibits multilayer formation of the osteoblastic cell line, MC3T3-E1, by promoting apoptosis. J. Endocrinol. 160: 57-65

Vestergaard P. 2007. Discrepancies in bonemineral density and fracture risk in patients with type 1and type 2 diabetes - a meta-analysis. Osteoporosis International 18: 427-444

Viereck V, Emons G, Lauck V, Frosch KH, Blaschke S, Grundker C. 2002. Bisphosphonates pamidronate and zoledronic acid stimulate osteoprotegerin production by primary human osteoblasts. Biochem. Biophys. Res. Commun. 291: 680-686 
Vlassara H .1996. Advanced glycation end-products and atherosclerosis. Ann Med 28: 419-426

Vlassara H. 2005. Advanced glycation in health and disease. Role of the modern environment. Ann N Y Acad Sci.1043: 452-460

Vlassara H, Palace MR. 2002. Diabetes and advanced glycation endproducts. J Intern Med. 251: 87101

Vlassara H, Palace MR. 2003. Glycoxidation: the menace of diabetes and aging. Mt Sinai J Med.70: 232-241

von Knoch F, Jaquiery C, Kowalsky M, Schaeren S, Alabre C, Martin I, Rubash H, Shanbhag A. 2005. Effects of bisphosphonates on proliferation and osteoblast differentiation of human bone marrow stromal cells. Biomaterials 26: 6941-6949

$-\mathbf{W}-$

Wang D, Christensen K, Chawla K, Xiao G, Krebsbach PH, Franceschi RT. 1999. Isolation and characterization of MC3T3-E1 preosteoblast subclones with distinct in vitro and in vivo differentiation/mineralization potential. J. Bone Miner Res 14: 893-903

Watts NB, Harris ST, Genant HK, Wasnich RD, Miller PD, Jackson RD, Licata AA, Ross P, Woodson GC III, Yanover MJ, Mysiw WJ, Kohse L, Rao MB, Steiger P, Richmond B, Chesnut CH III. 1990. Intermittent cyclical etidronate treatment of postmenopausal osteoporosis. N Engl J Med 323: $73-79$

Wautier J, Schmidt AM. 2004. Protein Glycation: A Firm Link to Endothelial Cell Dysfunction Circ. Res. 95: 233-238

WHO Study group. 1994. Assessment of fracture risk and its application to screening to postmenopausal osteoporosis. WHO Technical Report Series 843

Whyte MP, 2010. Physiological role of alkaline phosphatase explored in hypophosphatasia Ann. N.Y. Acad. Sci. 1192: 190-200

$-X-$

Xiao G, Gopalakrishnan R, Jiang D, Reith E, Benson MD, Franceschi RT. 2002. Bone morphogenetic proteins, extracellular matrix, and mitogen-activated protein kinase signaling pathways are required for osteoblast-specific gene expression and differentiation in MC3T3-E1 cells. J. Bone Miner. Res. 17: 101-110

$-\mathbf{Y}-$

Yamagishi S, Matsui T, Nakamura K, Takeuchi M. 2005. Minodronate, a nitrogencontaining bisphosphonate, inhibits advanced glycation end product-induced vascular cell adhesion molecule1 expression in endothelial cells by suppressing reactive oxygen species generation. Int. J. Tissue React. 27: 189-195

Yamagishi S, Nakamura K, Matsui T, Takeuchi M. 2006. Minodronate, a nitrogencontaining bisphosphonate, is a promising remedy for treating patients with diabetic retinopathy. Med. Hypothesis 66: 273-275

Yamamoto Y, Kato I, Doi T, Yonekura H, Ohashi S, Takeuchi M, Watanabe T, Yamagishi S, Sakurai S, Takasawa S, Okamoto H, Yamamoto H. 2001a. Development and prevention of diabetic nephropathy in RAGE-overexpressing mice. J Clin Invest. 108(2): 261-268 
Yamamoto T, Ozono K, Miyauchi A, Kasayama S, Kojima Y, Shima M, Okada S. 2001b. Role of advanced glycation end products in adynamic bone disease in patients with diabetic nephropathy. Am J Kidney 38: S161-164

Yamauchi M. 2007. World Health Organization. Absolute risk for fracture and WHO guideline. Treatment of patients with secondary osteoporosis. Clin. Calcium 17: 1106-1113.

Yan SF, Ramasamy R, Bucciarelli LG, Wendt T, Lee LK, Hudson BI, Stern DM, Lalla E, DU Yan S, Rong LL, Naka Y, Schmidt AM. 2004 RAGE and its ligands: a lasting memory in diabetic complications? Diab Vasc Dis Res. 1: 10-20

Yang X, Karsenty G. 2002 Transcription factors in bone: developmental and pathological aspects.Trends mol med. 8: 340-345

Ylitalo P, Holli K, Mönkkönen J, Elo HA, Juhakoski A, Liukko-Sipi L, Ylitalo R. 1999 Comparison of pharmacokinetics of clodronate after single and repeated doses. Int J Clin Pharmacol Ther; 37: 294-300

Yonekura H, Yamamoto Y, Sakurai S, Watanabe T, Yamamoto H. 2005. Roles of the receptor for advanced glycation endproducts in diabetes-induced vascular injury. J Pharmacol Sci. 97(3):305311

$-\mathbf{Z}-$

Zhang J, Slevin M, Duraisamy Y, Gaffney J, Smith C, Ahmed N. 2006. Comparison of protective effects of aspirin, D-penicillamine and vitamin E against high glucose-mediated toxicity in cultured endothelial cells. Biochimica et Biophysica Acta 1762: 551-557

Zhou Z, Immel D, Xi CX, Bierhaus A, Feng X, Mei L, Nawroth P, Stern DM, Xiong WC. 2006. Regulation of osteoclast function and bone mass by RAGE. J Exp Med 203: 1067-1080

Zimmet P, Alberti KG, Shaw J. 2001. Global and societal implications of the diabetes epidemic. Nature 414: 782-787 